\title{
Philosophy for All Children: enhancing knowledge
}

\author{
By \\ AMY MARIE AUSTIN
}

A thesis

submitted to the Victoria University of Wellington

in fulfilment of the requirements for the degree of

Doctor of Philosophy

Victoria University of Wellington

2020 



\section{Abstract}

Building students' critical thinking has been a focus in Education around the world in recent years. The New Zealand Curriculum (2007) is no exception, with an emphasis on critical and creative thinking in its vision statement. However, no advice is offered on how to teach critical thinking. This study uses a qualitative case study approach to explore how teachers teach critical thinking through Philosophy for Children (P4C) and offers some guidance on this for teachers. One of the contributions of this thesis is the claim that the P4C approach enhances social justice by supporting diverse learners children who need support to achieve at school - to develop critical thinking and language capability.

The theoretical framework underpinning my research draws on Bernstein's (2000) 'democratic pedagogic rights' to enhancement, inclusion, and participation, and Wheelahan's (2007), Young's (2009) and Young and Muller's (2013) conceptions of powerful knowledge. While much attention has been given to the theory of powerful knowledge in tertiary and secondary education contexts, to date, very little research has explored what powerful knowledge might look like, in practice, at primary school. Therefore this study makes an original contribution by investigating this unexplored area.

Participants in this research included 104 primary school students aged between 8 and 11 years old and their teachers $(n=4)$ from four diverse primary schools in New Zealand. The research data is drawn from four main sources: audio recordings of classroom discussions, semi-structured focus group interviews with sample students, open-ended interviews with teachers, and student thinking journals. Over a period of 6 months, classes held weekly hour-long P4C dialogues with a focus on both philosophical content and developing critical thinking language and skills. Students were encouraged to evaluate their philosophical and critical thinking both verbally and in written form.

The methodological approach incorporates sociocultural perspectives highlighting the key role of language as a mediator and tool for thinking (Mercer, 2000; Vygotsky, 1962, 
1978). Transcripts of classroom discussions were analysed both inductively and deductively, using Hennessy et al.'s (2016) coding system for analysing classroom dialogue across educational contexts and Daniel et al.'s (2005) matrix outlining the development of the dialogical critical thinking process.

Observation of students' everyday learning in the classroom, together with their and their teachers' reflections, revealed that teachers played a significant role in shaping students' language and critical thinking through modelling, facilitating dialogue, establishing a democratic classroom culture, making thinking visible, and innovating and personalising teaching according to their students' particular needs. Both students and teachers developed a range of capabilities through participating in (or, in the case of the teachers, leading) P4C dialogue: resilience, receptivity, intersubjectivity. This thesis presents one of the first investigations into the practice of teaching powerful knowledge in primary schools and suggests that explicit teaching of disciplinary language enhances students' critical thinking capability and constitutes powerful knowledge. A new conception of powerful knowledge is advanced, termed enhancing knowledge, which emphasises how disciplinary knowledge enhances and is complementary to other knowledges, such as social or cultural knowledge, without devaluing their importance. This term also seeks to avoid the potential dominant connotations of the word 'powerful'. The findings of this study suggest that P4C can offer diverse learners access to enhancing knowledge which has the potential to improve equity in education and enhance social justice.

Keywords: critical thinking, social justice, equity, enhancement, epistemic access, powerful knowledge, Philosophy for Children. 


\section{Acknowledgements}

Just like raising a child, undertaking and completing a doctoral thesis takes a village! I have many people to thank for their support, time, and friendship. Firstly, my gratitude goes to the children, teachers, and schools who welcomed me into their classrooms and shared their insights with me; they brought this project to life. Secondly, this study was funded and made possible by a Ministry of Education Teach NZ Scholarship and a Victoria University of Wellington Doctoral Scholarship. A Victoria University Faculty Research Grant enabled me to travel to Madrid to present at The Learner conference in August 2015. I was grateful to receive a grant from the Philosophy of Education Society of Australasia (PESA) which funded my travel to Melbourne to present at their annual conference in December 2015. I so appreciated P4CNZ's generosity in granting free training to the participant teachers. Thank you to Anna Paris, a professional editor who provided copy-editing and proof-reading services in accordance with the Editorial Advice Policy of Victoria University of Wellington. Huge thanks to my two Island Bay School principals, Perry Rush and Deborah Fenton, for encouraging me to even consider embarking on this journey, for their support and flexibility in releasing me for a day a week for research and writing, and for approving my longer spells of study leave. A big shout out to my research friends, Ann Pairman, Bronwyn Wood, Alison Kitson, Sola Freeman, Michael Harcourt, Helen Walls, Mike Taylor, and Siva Gopal Thaiyalan whose rants, laughter and insight made the long hours at the computer more fun.

My heartfelt thanks go to my wonderful three supervisors, Mark Sheehan, Sondra Bacharach, and Andrea Milligan, for the encouragement to start this malarkey in the first place, and for their constant warmth, enthusiasm, good humour, strategic thinking, constructive critique, and wisdom. Arohanui to the Austin clan, particularly my parents whose love of education rubbed off even when I tried to escape it.

Lastly, an extra special thank you my family: to Simon for his endless patience and constant support in countless ways - particularly in the final leg when we were sleepdeprived new parents into the bargain - and to Violeta, who brought perspective and giggles to that final leg. 

For my grandparents, Phyl \& Des and Nelle \& Peter,

who were curious about people, ideas, language, and the world.

And for Violeta, who was born

just as this thesis was getting ready to leave home (taking its time). 



\section{Contents}

Abstract

Acknowledgements iii

List of figures $\quad$ xiv

List of images $\quad$ xv

Glossary $\quad$ xvi

Introduction 1

Critical thinking and educational inequity 1

Personal motivations for this research $\quad 5$

$\begin{array}{ll}\text { The focus of this research } & 8\end{array}$

$\begin{array}{ll}\text { Structuring the thesis } & 10\end{array}$

Social realist perspectives on educational injustice 13

Social justice: the right to powerful knowledge and enhancement $\quad 14$

$\begin{array}{ll}\text { Powerful knowledge has explanatory power } & 16\end{array}$

$\begin{array}{ll}\text { Powerful knowledge is differentiated knowledge } & 17\end{array}$

Disciplinary knowledge is powerful knowledge $\quad 19$

$\begin{array}{ll}\text { Powerful knowledge is fallible and provisional } & 21\end{array}$

Social constructivism in practice in NZ: relativist in the extreme 23

The influence of critical realism on social realist perspectives $\quad 28$ 
The influence of Bernstein's scholarship: democratic pedagogic rights

Language codes

Horizontal and vertical discourse; hierarchical and horizontal knowledge structures

Powerful knowledge as a means to enhance social justice

Critiques of powerful knowledge

Conclusion

Intersections of $\mathrm{P}_{4} \mathrm{C}$, critical thinking, and social justice: theory and literature

Thinking competency in the New Zealand Curriculum

The everywhere and nowhere nature of thinking

Critical thinking as a contested term

Bringing critical thinking into sharper focus in teaching and learning: $\mathrm{P}_{4} \mathrm{C}$

Which philosophical traditions does $\mathrm{P}_{4} \mathrm{C}$ draw on? How does this shape its implementation?

Four rationales for $\mathrm{P}_{4} \mathrm{C}$

$\mathrm{P}_{4} \mathrm{C}$ builds critical and creative thinking

$\mathrm{P}_{4} \mathrm{C}$ builds collaborative and caring thinking

$\mathrm{P}_{4} \mathrm{C}$ builds philosophical thinking: philosophical progress

$\mathrm{P}_{4} \mathrm{C}$ builds cognitive ability

$\mathrm{P}_{4} \mathrm{C}^{\prime}$ s contribution to social justice in education

$\mathrm{P}_{4} \mathrm{C}$ is a form of democratic education

$\mathrm{P}_{4} \mathrm{C}$ challenges power structures

$\mathrm{P}_{4} \mathrm{C}$ promotes participation and inclusion

$\mathrm{P}_{4} \mathrm{C}$ shifts teacher beliefs and pedagogy for social justice 
Can children do philosophy? $\quad 63$

Is $\mathrm{P}_{4} \mathrm{C}$ philosophy? $\quad 64$

Do the dynamics of a Community of Inquiry always serve the goals of democratic $\begin{array}{ll}\text { education? } & 67\end{array}$

Is $\mathrm{P} 4 \mathrm{C}$ best offered as an extension programme for gifted and talented learners? $\quad 67$

The contribution of this research: $\mathrm{P}_{4} \mathrm{C}$ offers learners epistemic access to powerful knowledge and understandings

\section{Methodology}

Research questions

Researching the socially constructed nature of knowledge

Sociocultural approaches to research

How can we measure critical thinking?

Qualitative research in schools

Research design

A multiple-site case study

Gaining informed consent within schools

Data sources and collection

Classroom dialogues

Thinking journals

Focus group discussions

Teacher interviews

Data analysis

Deductive thematic analysis

Coding challenges and issues 90

Inductive thematic analysis 
Temporal analysis

Case study contexts

School A - Olivia

School B - Emily

School C - Jono

School D - Alana

Structuring the Col

Ethical considerations

Research limitations and credibility 100

\section{Enhancing capability}

Definitions of the themes: resilience, receptivity, intersubjectivity, personalisation

Resilience

The challenges of facilitating $\mathrm{P}_{4} \mathrm{C}$ dialogue require teacher resilience

The challenges of participating in $\mathrm{P}_{4} \mathrm{C}$ dialogue require student resilience

Receptivity

Co-constructive teaching requires receptivity

Supporting students to be receptive

Intersubjectivity

Teacher network builds intersubjectivity

Teachers build intersubjectivity by learning from, and with, their students

Intersubjectivity involves collaborative thinking

Students develop intersubjectivity by understanding the provisionality of knowledge 126 
Developing students' critical thinking skills

Enhancing students' disciplinary philosophical knowledge

Concluding thoughts

\section{Enhancing language}

Links to existing research

Supporting diverse learners

Participation 
$\mathrm{P}_{4} \mathrm{C}$ can enhance learners' perceptions of themselves as critical thinkers

$\mathrm{P}_{4} \mathrm{C}$ can enhance students' knowledge and capital

$\mathrm{P}_{4} \mathrm{C}$ challenges and shifts teachers' preconceptions of learners

Implications for professional practice: teaching $\mathrm{P}_{4} \mathrm{C}$ for social justice

Personalisation

Thinking journals: an alternative form of communication

Explicit structured teaching

Teacher vulnerability 188

Professional learning communities 189

Teacher critical reflection 189

Awareness of the challenges of enacting social justice

\section{Enhancing knowledge: concluding thoughts}

Entitlement to enhancing knowledge

Distinguishing enhancing knowledge from powerful knowledge

\section{References}

\section{Appendix A}


$\begin{array}{ll}\text { Appendix C } & 236\end{array}$

$\mathrm{P}_{4} \mathrm{C}$ for all information letter and consent form - Principals/BOTs $\quad 236$

Appendix D $\quad 239$

$\mathrm{P}_{4} \mathrm{C}$ for all information letter and consent form - Teachers 239

Appendix E $\quad \mathbf{2 4 2}$

$\mathrm{P} 4 \mathrm{C}$ for all information letter and consent form - All parents/caregivers $\quad 242$

$\begin{array}{ll}\text { Appendix F } & \mathbf{2 4 5}\end{array}$

$\mathrm{P}_{4} \mathrm{C}$ for all information letter and consent form - Sample student parents/caregivers 245

$\begin{array}{ll}\text { Appendix G } & 249\end{array}$

$\mathrm{P}_{4} \mathrm{C}$ for all information letter and assent form - All students $\quad 249$

Appendix $\mathrm{H} \quad 252$

$\mathrm{P}_{4} \mathrm{C}$ for all information letter and assent form - Sample students $\quad 252$

Appendix I 255

Temporal Analysis of Coded Student Utterances 255 


\section{List of figures}

$1 \quad$ Knowledge differentiation 17

2 Disciplinary thinking 20

3 Bernstein's Pedagogic Rights, Conditions, and Levels 31

$4 \quad$ Question quadrant $\quad 65$

$5 \quad$ Eight "Big-Tent" Criteria for Excellent Qualitative Research 79

$6 \quad$ Timing of data collection from different sources 82

$7 \quad$ Key coding examples 89

$8 \quad$ Theme-generation and cross-referencing 92

$9 \quad$ Dialogue guidelines 176 


\section{List of images}

$1 \quad$ Thematic analysis diagram 91

2 Boardwork - Performance, skill, and content focuses 131

3 Branches of Philosophy and Col topics sorting activity 134

4 Philosophy Toolbox 145

5 Boardwork - Yes because, no because $\quad 148$

6 Boardwork - Reason, objection, reply 149

$7 \quad$ Reflection lesson exploring the branches of philosophy $\quad 178$ 


\section{Glossary}

BICS

board work

CALP

CoI

dispositions

diverse learners

EAL

ELL

ERO

hui

kaumatua

kaupapa

key competencies

Māori

$\mathrm{P} 4 \mathrm{C}$

Pasifika

tangata whenua

whānau

whānau group basic interpersonal communication skills

written documentation of the learning focuses and student

dialogue during a CoI, usually written by the teacher on a

whiteboard or in a modelling book

cognitive academic language proficiency

community of inquiry

internal motivation to enact skills and knowledge

priority learners, members of under-served groups

English as an additional language

English language learner

Education Review Office - New Zealand's school evaluation

organisation. "ERO evaluates and reports on the education and

care of children and young people in early childhood services

and schools" (Education Review Office, 2016).

meeting

Māori elders

purpose, policy, principle

five competencies for all learners stipulated in the New Zealand

Curriculum: thinking; relating to others; using language,

symbols and texts; managing self; participating and

contributing (Ministry of Education, 2007, p. 12)

indigenous people of New Zealand

philosophy for children

people of Pacific cultures

people of the land; a term that acknowledges Māori as the

indigenous people of New Zealand

family

a group of parents from a school community, usually focussed on supporting biculturalism and te reo (Māori language) and tikanga (culture) in the school 


\section{Introduction}

The government's objective broadly expressed, is that every person, whatever their level of academic ability, whether they be rich or poor, whether they live in town or country, has a right, as a citizen, to a free education of the kind for which they are best fitted, and to the fullest extent of their powers (Beeby, 1938) (pronouns gender neutralised).

Moana: sometimes your thoughts change when you hear someone else's perspective on it - and it changes your opinion

Samuel: sometimes it's not even just changing your opinion, you just ...

Moana: you realise that you agree with them, like, well that's what you were trying to say but in a different light ... I think philosophy well, to sum it up, I think philosophy's pretty fun, kinda like what Johnny said, it's fun critical thinking

School C, post-intervention focus group interview

\section{Critical thinking and educational inequity}

What makes a fair education system that serves all students? Who benefits from the current system? What constitutes meaningful deep learning, and how can we measure its development? These fundamental questions sit behind this study and much educational research. At the heart of this research project is the drive to make our education system more equitable. Many New Zealand educators herald Clarence Beeby, the then New Zealand Director of Education's statement above as an important foundational understanding about a broad and equitable education for all, on which today's education system has been built. For example, the Minister of Education in 2003, Steve Maharey, emphasised the continuing importance of Beeby's message as a goal of "making the education system responsive to the needs of the individual kid" (Maharey, 2003). This lofty ideal of an equitable education system is embedded in the 
New Zealand Curriculum (NZC). My study explores how, and how much, this ideal is actually enacted by teachers in practice.

Like many other nations, New Zealand educational policy emphasises notions of excellence and high expectations for all, as distinct but related aspirations. The Ministry of Education's stated kaupapa is "He mea tārai e mātou te mātauranga kia rangatira ai, kia mana taurite ai ōna huanga. We shape an education system that delivers equitable and excellent outcomes" (Ministry of Education, 2019a). The interlinking concepts of equity, inclusion and social justice are embedded in New Zealand's educational policy. For example, the NZC vision for confident, connected, actively involved, lifelong learners (Ministry of Education, 2007) is underpinned by eight principles that aspire for high expectations and inclusion. In addition, the curriculum lists values "to be encouraged, modelled, and explored" (p.10) including excellence and "equity, through fairness and social justice" (p. 10).

The persistence of educational inequality and its impact on social justice is a problem that researchers have puzzled and theorised about in recent decades. It has been argued that educational inequality weakens democracy and social justice (Bernstein, 2000; Muller, 2004; Young, 2008a, 2008b). Although the NZC's ideals are excellent aspirations for New Zealand students, unfortunately much inequality still exists in the New Zealand school system (Emanuel, 2013; Rashbrooke, 2014; Wylie, 2013), and a key challenge is to better understand how to meet the needs of diverse learners so that they have as many opportunities to achieve excellence as their peers. Notably, New Zealand was ranked $33^{\text {rd }}$ out of 41 wealthy countries evaluated on the equality of their education system by UNICEF's most recent Innocenti Report Card (Chzhen, Rees, Gromada, Cuesta, \& Bruckauf, 2018). This statistic echoes concerns highlighted by New Zealand's Education Review Office (ERO) in their $(2012,2013)$ reports that emphasised the need to promote acceleration for priority learners in order to redress inequality. Further, although one of the stated principles of the NZC is inclusion, recent policy discussion in the primary education sector such as ERO evaluation papers (Education Review Office, 2012, 2013) and the Ministry of Education Inclusion website guidance (Ministry of Education, 2016) about how to achieve the ideal of inclusion tends to focus solely on 
students with special learning needs rather than on priority learners of diverse genders, ethnicities, and socio-economic backgrounds (Ministry of Education, 2012).

This thesis considers the relationship between equity, high expectations for all learners, and social justice in relation to children's critical thinking, therefore it is necessary here to clarify exactly what is meant by these terms. In order to redress inequality, an understanding of equity in education is essential. For the purposes of this thesis I define equity in education as offering tailored support to individuals in order to allow fair access to knowledge. Bourdieu's notion of capital is a useful way to conceive of the knowledge and experience that can advantage or disadvantage children's educational success. Bourdieu (1984) proposes a variety of 'capitals' that individuals can possess: social, cultural, academic, economic and symbolic capitals which contain "concealed intergenerational processes that serve to reproduce socio-economic advantage, disadvantage and privilege" (Holt, 2008, p. 234). I explore how teachers and schools might go about working to develop a more equitable education system that offers enhancement - through the development of critical thinking - to all learners, not just those who arrive at school with high social capital. Muller (2004) emphasises this challenge:

Those most in need of redress will be those whose right to enhancement has been curtailed and who will, by definition, have been deprived of access to 'critical understanding' and, more crucially, to a means for generating 'new possibilities' (p. 2). I argue that when children gain epistemic access to powerful knowledge, this can begin to redress inequity caused by differences in capital.

Just as the notion of redress is inherent to the definition offered above, another key contributor to educational equity is teachers holding high expectations for all learners. A note about the associated terminology employed in this thesis: ERO (2012) define priority learners as students who "have been identified as historically not experiencing success in the New Zealand schooling system ... [which] include many Māori and Pacific learners, those from low socio-economic backgrounds, and students with special education needs" (p. 4). In order to include these learners in my scope, throughout this thesis I use the term diverse learners to denote those students who historically have not experienced success in the New Zealand schooling system. As well as tailoring teaching 
to diverse learners' needs, high expectations for all learners involves teachers explicitly examining any possible prejudices or assumptions they may have about diverse learners, and deliberately shedding these in order to give those learners opportunities to build knowledge to achieve success. The concepts of equity in education and high expectations for all learners are distinct but they contribute to each other; through this thesis I explore how these concepts can illuminate understandings of how to enhance social justice.

There are many ways to conceive of and work towards social justice in education. My conception of social justice in this thesis focuses on distributive justice (Rawls, 1999; Gewirtz \& Cribb, 2002), which seeks to offer equitable access for all to social and cultural capital. This understanding is consistent with the work of Bernstein, Young, Muller, and Wheelahan, whose work I draw on as the theoretical lens for my analysis. As I discuss in Chapter 2, Bernstein (2000) defines a democratic and just society as one that, through education, gives all citizens the democratic pedagogic rights to enhancement, inclusion, and participation. Young (2008a) builds on Bernstein's ideas by proposing a theory of powerful knowledge, and he and Muller (2004) emphasise the importance of all students having epistemic access to powerful knowledge that will enable them to understand and explain the world. Incorporating these scholars' work on powerful knowledge, I define social justice as equitable epistemic access for all to powerful knowledge which builds social and cultural capital. I further discuss this definition of social justice in Chapter 7. I also draw on Fricker's (2007) concept of epistemic injustice in understanding the importance of epistemic access. Fricker (2007) conceives of two kinds of injustice: testimonial and hermeneutic. She argues that testimonial injustice occurs when someone's testimony is questioned or dismissed due to their identity. Hermeneutical injustice occurs when someone's experiences and perspectives are neither understood nor valued by others. These conceptions can help to illuminate how socially just or democratic a CoI might (or might not) be for all students.

In Chapter 8 I build on the concept of powerful knowledge and propose a reworking of this conception, that I have termed enhancing knowledge, to differentiate and emphasise 
the value of academic, conceptual knowledge used in combination with social and cultural knowledge.

This research study explores critical thinking in the context of Philosophy for Children (P4C) in primary schools. Critical thinking is another concept that requires clarification for the purposes of this thesis, particularly because it is a contested term. Furthermore, while the NZC highlights the importance of teaching critical thinking, a clear definition of what critical thinking is, and how to teach it, is not offered. After exploring a range of definitions of critical thinking that have been posited in the literature, Chapter 3 proposes a working definition for critical thinking and, in Chapters 5, 6, and 7, I suggest that an effective way to teach critical thinking is through Philosophy for Children (P4C). P4C is a programme founded by Matthew Lipman and Ann Sharp in America in the 1960s which is now taught around the world. Students as young as five years old take part in philosophical discussions, sparked by their questions that are usually provoked by a picture book. At its core, $\mathrm{P} 4 \mathrm{C}$ encourages critical, caring, creative, and collaborative thinking (Lipman, 1998b), allows students to find their voice in a democratic setting (Burgh \& Davey, 2004; Cam, 2009), and promotes active listening as students learn to understand a range of other perspectives (Burgh \& Yorshansky, 2011; Barrow, 2010).

Bringing together notions of equity, high expectations for all learners, social justice and critical thinking, the primary focus of this research is to investigate how Philosophy for Children can improve student learning and thinking capability for all, and especially diverse, learners. In the following section, I give some contextual background to my personal interest in this research.

\section{Personal motivations for this research}

My interest in this research grew from observing my Year 3 class (made up of seven to eight year olds) in 2012. That year I was learning how to teach P4C and to facilitate a philosophical community of inquiry (CoI) as they learnt how to participate in one. My school had a P4C group that met on Fridays, led by the deputy principal, and made up of children who had been identified by their teachers as 'gifted and talented'. The Friday P4C kids, and their parents, knew that they were special and enjoyed the kudos 
associated with this extension and enrichment activity. I also held whole-class philosophical communities of inquiry that included every child in the class, regardless of their social capital, experience of critical thinking or apparent 'intelligence'. The topics ranged from friendship to bravery to existence. These discussions ran on through the week, in reading group discussions, at lunchtimes, and during inquiry learning, as well as during the set $\mathrm{P} 4 \mathrm{C}$ lesson.

At the outset, there were certain children who I assumed would thrive in a philosophical discussion: those with high social and cultural capital. There were others I presumed would struggle to articulate their thinking, for example, learners who struggled with writing and spelling. While some children could dominate the discussion, and the more experienced philosophers had confidence in their ideas and the presentation of these, I was surprised again and again by the wisdom that came from more unexpected places. Each discussion finished with a final round: an opportunity for each child to say their last idea about the topic for the day. For some children, this might be the only time they had spoken during the hour; however, their contributions could be the most wise or fresh or illuminating. As the year passed, these refreshing contributions from unexpected characters in the class continued. I recognised that my expectations of what learners could accomplish, achieve, and learn at school had shifted. I hadn't thought that I was operating and teaching through pre-conceived expectations of what children might be capable of, but I realised, whenever I was surprised by a child's wisdom and critical thinking, that I had more rigid biases in my expectations of children's potential than I would have liked to think. And these preconceptions were illuminated and challenged by the children's wisdom I saw demonstrated through their philosophical discussion.

I became interested in considering the implicit bias of teachers' expectations of learners' potential, and the ways that these expectations, sometimes even prejudices, can either enable or limit learners' achievement at school. I understood that children come to school to learn what they don't know. Because they don't know what they don't know, it is the teacher's responsibility to teach in ways that support children to discover new knowledge. I wrestled with the conundrum that in order to do this teachers need to 
make judgements about what children are ready to learn next, but that this can lead to teachers making assumptions - however consciously or subconsciously - about what children are capable of. This can result in some students' learning being curtailed or limited due to teachers' low expectations. The challenge of balancing the necessity of making judgements about students' capabilities with empowering them to learn all they are capable of is an ongoing tension for even the most skilled of teachers. I was keenly aware that primary school is a place for exploring and exposing children to as many different ideas, ways of thinking, and experiences as possible, in order to allow them to discover where their passions, strengths and talents might lie (Moir, 2014). I was also aware that research indicates, for example, that children's educational outcomes can be predicted by the educational achievement of their mothers or by the number of books in their home - factors that are beyond the influence or reach of teachers and schools (Hernandez \& Napierala, 2014). I appreciated that if teachers believe that education can make a difference for any learner, then schools need to find ways to redress the inequality that can occur outside the school gates, and to ensure that they are not perpetuating that inequality within school. This prompted me to undertake research in this area.

In my classroom, the insight and critical thinking that I saw was evident, and grew over time, in a range of learners from a range of backgrounds, could be taught not just to those who had already demonstrated capabilities for critical thinking and philosophical discussion, but to all learners. This prompted me to ask the question, if Philosophy for Children can help children to develop critical thinking skills that will deepen their learning and thinking in a range of areas, shouldn't it be offered to all learners, not just those who have been identified as gifted and talented? Taking this a step further, if an equitable education system involves offering all learners the opportunity to succeed, regardless of their backgrounds, shouldn't learners who most need support to achieve at school be the ones who most deserve the chance to take part in a programme like P4C that will deepen their learning and thinking? The experience of discovering the potential of P4C to support the thinking and learning of a wide range of learners, as well as becoming aware of my own unconscious bias towards diverse learners and seeking 
to hold high expectations for all learners, sparked my interest in researching this area further.

\section{The focus of this research}

There is a well-developed body of literature around P4C that explores its value and potential for cultivating critical, caring, creative and collaborative thinking (Barrow, 2010; Cam, 2003; Daniel et al., 2004; Daniel \& Auriac, 2011; Lipman, 1998b; Scholl, 2005; Sharp, 2004; Splitter \& Sharp, 1995; Sprod, 1998), philosophical thinking (Golding, 2009, 2017; Murris, 2000), cognitive ability (Topping \& Trickey, 2007a, 2007b) and dialogic interaction (Barrow, 2010; Daniel \& Gagnon, 2011; Topping \& Trickey, 2014). Other scholars have explored how P4C cultivates democracy (Barrow, 2015; Burgh, 2018; Burgh \& Davey, 2004; Burgh \& Yorshansky, 2011; Cam, 2009; Echeverria \& Hannam, 2013, 2017; Lipman, 1998a; Sharp, 1991) and promotes social cohesion (Garcia-Moriyon et al, 2004; Millett \& Tapper, 2012). Further studies have explored the impact of teaching P4C on teacher pedagogy (Gardner, 1995; Scholl, 2012, 2014; Yeazell, 1981). Critiques of the P4C approach questioning whether children can really do philosophy, cautioning against the instrumentalization of $\mathrm{P} 4 \mathrm{C}$, and exploring the philosophical roots of P4C (Biesta, 2011b; White, 2012; Wilson, 1992) have sparked robust dialogue in the literature (Gregory, 2011; Hand \& Winstanley, 2009; Gardner, 1998) which I discuss further in Chapter 3.

This strong research base notwithstanding, it is notable that very little research has focussed on the impact of P4C on the critical thinking of primary school students of a range of abilities and from diverse ethnic and socio-economic backgrounds (Barrow, 2010; Kennedy, Fisher, \& Ennis, 1990; Scholl, 2012; Trickey \& Topping, 2013). Of the few studies that do exist, Topping and Trickey's (2007a, 2007b) longitudinal analysis of the impact of a regular P4C programme on participants' cognitive ability found that children in the lower quartiles of achievement in the pre-test made the greatest cognitive gains, both in the post-test, after sixteen months' participation in a weekly hour-long P4C programme, and in follow-up testing two years after that. More recently, Colom et al.'s (2014) preliminary results of their 10-year longitudinal study suggest that P4C has had a positive impact on students' general cognitive ability, especially for those 
in the lower tail of achievement, and on students' pro-social behaviour (Colom et al., 2014). My research builds on these studies to explore how diverse learners in New Zealand primary schools can develop critical thinking skills through P4C.

It is also important to note that the bulk of the literature on social justice in education relating to critical thinking and dialogue is focussed on the content of students' discussions (Biesta, 2012; Burgh \& Davey, 2004; Burgh \& Yorshansky, 2011; Cam, 2009; Jackson, 2008; Lipman, 1998a, 1998b; Weber, 2008) and power dynamics (Arnot \& Reay, 2007; Cohen, 1984; Cohen \& Lotan, 1997; Cohen, Lotan, Scarloss, \& Arellano, 1999; De La Garza, 2006) rather than on the implications for social justice of diverse learners gaining access to powerful knowledge by developing critical thinking through dialogue (Barrow, 2010). My research focuses on the latter, that is, how social justice can be enhanced through the procedural features of $\mathrm{P} 4 \mathrm{C}$, rather than through the substantive content of the dialogue. I explore how teachers can work for distributive social justice by offering equitable epistemic access for all to powerful knowledge (Young, 2008; Moore, 2013; Muller, 2009; Wheelahan, 2007) which builds social and cultural capital. Recent work by Scholl (2012) has identified that,

Further research is needed that focuses specifically on the implementation of Philosophy with different socio-cultural groups to provide insights into improving the educational outcomes of disadvantaged groups (p. 234).

A gap exists in the literature in identifying how to develop powerful knowledge for diverse learners at primary school. Therefore this thesis explores further how diverse learners can have epistemic access to powerful knowledge at primary school.

As stated earlier, the primary focus of this research is to investigate how P4C can improve student learning and thinking capability for all, and especially diverse, learners. This involves unpicking and understanding how teachers' conceptions of knowledge and critical thinking shape their teaching, and how this in turn shapes student knowledge, thinking, and learning. My research contributes towards a clearer understanding of the potential of P4C to contribute to social justice. I explore how teachers can work for distributive social justice by offering equitable epistemic access for all to powerful knowledge which builds social and cultural capital. This is important 
for schools and policy-makers to take seriously if they aim to accelerate diverse learners' progress and to keep working towards an equitable education system.

My research questions are:

1. How can Philosophy for Children develop critical thinking capabilities for all, including diverse, learners?

2. How does P4C help us to understand what powerful knowledge might look like in practice in NZ primary schools?

3. How can P4C enlarge our conception of theories of powerful knowledge?

\section{Structuring the thesis}

In the next chapter, I discuss the theoretical resources that have informed the analysis that is presented in this thesis. In addition to the writings of Young and Muller who I have touched on earlier, the next chapter discusses Wheelahan's work because it is also concerned with equity in relation to educational pathways and class. It was Wheelahan who first coined the phrase 'powerful knowledge' in her 2007 paper, How competencybased training locks the working class out of powerful knowledge (Muller \& Young, 2019; Wheelahan, 2007). She examines how working class learners can be deprived of access to opportunities, powerful knowledge and understandings that are open to their middle and upper class counterparts (Wheelahan, 2007, 2009, 2014). While her research has focussed on the tertiary sector, I apply Wheelahan's understandings of powerful knowledge to the primary sector to illuminate how teachers can create a more equitable education system that caters to all learners. The theoretical perspective that Young, Muller, and Wheelahan share - together with other scholars whose work I discuss in Chapter 2 - has become known as social realism. I use this theoretical lens throughout my thesis to emphasise how epistemic access to powerful knowledge offers learners greater academic capital. Chapter 2 reviews the literature centred on social realism and powerful knowledge and elaborates on this conceptual framework and its links to social constructivism.

In Chapter 3, I review the literature in the areas of Philosophy for Children and critical thinking, starting with the New Zealand context, then lifting my focus internationally. I 
explore the contested nature of the term critical thinking and examine the intersection between critical thinking, social justice and P4C literature. I then consider some critiques of P4C: Can children really do philosophy? Is P4C real philosophy? I also examine some cautions and suggestions offered by P4C scholars who advise practitioners (a) not to assume that their students' philosophical dialogue is inherently democratic and (b) to reflect on how to enact democratic processes with their students. Last, I challenge the assumption of some members of the P4C community that $\mathrm{P} 4 \mathrm{C}$ is a programme best suited to gifted and talented learners.

The focus of Chapter 4 is the multimodal temporal case study research design and methods underpinning this study. The chapter begins by laying out the qualitative data gathering approach that was used, which involved observing classroom interactions in their natural contexts. I describe the layers of thematic analysis and sociocultural discourse analysis methods that I used to provide rounded, detailed understandings of participant's language and thinking. I discuss how sociocultural theory and social realism have helped me to analyse how students build knowledge and language and to consider how teachers can ensure that all learners have equitable access to the knowledge and language that will allow them to achieve success. The next section of the chapter details my methodological practices, such as my choice to write about student participants through vignettes in order to capture the complexities of their experience. I also outline the research procedures and ethical considerations of the study.

Chapters 5 to 7 present and discuss the findings of this study. Chapter 5 focuses on the ways in which P4C enhanced teachers' and students' capabilities. I examine the challenges teachers and students faced through facilitating and participating in P4C communities of inquiry, and discuss the impact on participants' resilience, receptivity, intersubjectivity and the value of innovation and personalisation of learning. In Chapter 6, I explore the enhancing potential of philosophical language to develop students' thinking and academic capital. I draw on Bernstein's $(1999,2000)$ and Vygotsky's (Vygotsky, 1962, 1978, 1981) theories of language as well as language learning theory (Cummins, 1979, 1981a; Gibbons, 2002) in my analysis and discussion. The focus of 
Chapter 7 is to discuss the implications of my findings for social justice and inclusion in New Zealand primary education.

Finally, in Chapter 8, I offer an alternative conception of powerful knowledge which I term enhancing knowledge in order to avoid the dominant connotations of the word powerful, and to emphasise how disciplinary 'powerful' knowledge works in conjunction with prior knowledges, for example, cultural knowledge - rather than in opposition to them - to enhance students' understandings of the world. I highlight the contributions of my study to various research communities as well as to primary school educators because it demonstrates that explicit teaching of disciplinary language can enhance students' critical thinking capability and constitutes enhancing knowledge for all, including diverse, learners. I conclude the thesis by describing the limitations of this study and suggesting directions for further research in this area. 


\section{Social realist perspectives on educational injustice}

Just as every theory of education implies a theory of society, educational theories always imply a theory of knowledge (Young, 2008a, p. 198).

Although knowledge can be experienced as oppressive and alienating, this is not a property of knowledge itself. An appropriate pedagogy, which engages the commitment of the learner to a relationship to knowledge, can have the opposite consequences-it can free the learner to have new thoughts and even think the 'yet to be thought' (Young, 2013, $p$. 107).

The progressive education movement that grew from Dewey's (1944) work on democracy and education in the early $20^{\text {th }}$ century has aimed to achieve social justice through tailoring teaching methods to individual learners' needs and, rather than 'telling' children facts, supporting them to gain knowledge through active construction (Freire, 1972). While schools influenced by this movement are potentially emancipatory, despite being driven by these goals many education systems have reproduced and legitimised inequity (Francis, Mills, \& Lupton, 2017; Wheelahan, 2007). This is because, it has been argued, by focussing so much on constructive teaching methods, many progressive educationalists have forgotten about introducing students to the essential knowledge that they need in order to understand, explain, participate in, and critique society and the world. By contrast, Young, Lambert, Roberts and Roberts (2014) define the purpose of schools as:

To enable all students to acquire knowledge that takes them beyond their experience. It is knowledge which many will not have access to at home, among their friends, or in the communities in which they live. As such, access to this knowledge is the 'right' of all pupils as future citizens (p. 10). 
While there are many lenses that can be brought to educational injustice, it is this perspective, an emphasis on the essential power of knowledge to take students beyond their prior experience, which guides this research. Young, Wheelahan, Muller and Moore, building on the thinking of Bernstein, advocate for the need to bring knowledge back into curricula, as a matter of social justice. Furthermore, they argue that without this, social inequities will persist. Specifically, Young argues that the kind of knowledge that all children need access to is powerful knowledge. Together, Young, Wheelahan, Muller and Moore's scholarship has come to be known as social realism. Situated in social realist understandings my research asks why should and how could all students have epistemic access to powerful knowledge?

In this chapter, I outline the theoretical perspectives that have informed my epistemological stance and methodological practices throughout this study. I start by describing the theory of powerful knowledge, and introduce four interconnected and key tenets of this theory. Then I examine the social constructivist theory that currently informs much of New Zealand primary school education and how it plays out in practice. Next I outline key elements of critical realism and of Bernstein's thinking that inform social realist thought, and then describe how powerful knowledge is the lens that informs my understandings of critical thinking, knowledge and social justice in this research. I conclude this chapter with a discussion of critiques that have been made of the concept of powerful knowledge.

\section{Social justice: the right to powerful knowledge and enhancement}

My research is driven by a concern for social justice for all, a belief that all learners are entitled to epistemic access to powerful knowledge and to Bernstein's (2000) notion of enhancement through education. The concept of powerful knowledge offers a useful framework for thinking about social justice and the link between excellence and equity. The social realist argument about powerful knowledge is based on the belief that all students are entitled to knowledge that enables them to learn and to achieve to their greatest potential in life (Moore, 2013). Importantly, this is also a matter of social mobility. As Moore (2013) contends, "the powerful are so not because they can arbitrarily impose their knowledge/culture as 'powerful knowledge/culture', but 
because they enjoy privileged access to the knowledge/culture that is powerful in its own right" (p. 350). Thus,

As a matter of social justice ... the curriculum ought, by moral right, to give access to mobility upwards. To do this, a curriculum ought, as a matter of fairness, [to] include abstract knowledge of the kind that would, if desired, grant the academic conditions for access upwards (Muller, 2009, p. 134).

The term knowledge is used here to describe more than just facts; it also incorporates modes of thinking, procedural knowledge, and frameworks for understanding. These systems of thinking and understanding are built sequentially within a network of disciplinary, conceptual thinking. As I outline in the following section, powerful knowledge has explanatory power, and it is differentiated, disciplinary, and provisional. Thus, I concur with Young (2014) who advocates for the right of all students to have epistemic access to powerful knowledge. This access enables students to evaluate claims, produce knowledge, and join conversations about what society should be like:

Abstract theoretical knowledge enables society to connect the present with the past and the future. It is the means society uses to imagine alternative futures through thinking the unthinkable and the not-yet-thought. It thus provides students with social access to this conversation and this is why access to abstract theoretical knowledge is fundamentally about distributional justice ... Access to disciplinary knowledge provides students with access to criteria they need to judge and critique knowledge claims, and this is essential if they are to participate in debates and controversies in society more broadly and in their field of practice in particular. Access to the methods that the disciplines use to produce knowledge also helps students understand the provisional nature of knowledge as they gain new insights into their objects of study. This will assist students in becoming critics of knowledge and critical producers of knowledge (Wheelahan, 2014, p. 32).

This conception of epistemic access can also redress epistemic injustice because, rather than being disadvantaged due to hermeneutical or testimonial injustice, diverse students gain social access to knowledge and to conversations about alternative futures.

It is important to note that social realist thinkers have built on Bernstein's $(1999,2000)$ conception of enhancement to develop the theory of powerful knowledge (Moore \& Young, 2001; Muller, 2009; Wheelahan, 2010b; Young, 2008a; Young \& Muller, 2010). 
Bernstein (2000) defined the enhancement that all students should be entitled to through education as "not simply the right to be more personally, more intellectually, more socially, more materially, it is the right to critical understandings and to new possibilities" (p. xx). This enhancement can be brought about by epistemic access to powerful knowledge (Moore, 2013). Enhancement is an important concept that I return to throughout this thesis because of its implications for social justice.

\section{Powerful knowledge has explanatory power}

There are at least four interconnected and key features of powerful knowledge; a first aspect being that it has explanatory power. Social realists understand the world through a realist ontology and an interpretive epistemology. This understanding holds that there is a real world that exists independently of our experience of it. Our knowledge of this real world is fallible but there are stronger and weaker ways to interpret our experiences and understanding of this reality. Knowledge creation involves refining our interpretations and understandings of the world to try and provide the best possible account of the world (Wheelahan, 2010a). As Wheelahan (2014) states, "the disciplines don't represent 'the truth', but they do represent our best efforts so far in getting closer to the truth" (p. 135).

Knowledge that illuminates, clarifies, and strengthens one's understanding of the world has explanatory power. Young (2010) describes the explanatory power of powerful knowledge thus:

The key question then becomes not 'who knows?' but 'what is it about certain forms of knowledge that gives power to those who have access to it?' Do they explain? Do they predict? Are they more reliable? Do they enable people to move beyond their experience and locate themselves in a wider context? (p. 11).

This explanatory power allows students to question their experience and understandings, to judge, evaluate, and create knowledge, to make judgements about ideas and to discern how best to interpret their experience in light of new understandings and thinking. Importantly,

One does not need to denigrate the knowledge that people gain from experience, or even to deny that there is an experiential element in all knowledge, however abstract, to 
recognise that experience is often an extremely unreliable basis for deciding whether something is true (Young, 2000, p. 526).

An illustrative example of this is the case of the members of the $17^{\text {th }}$ century Roman Inquisition who found Galileo guilty of heresy, and forced him to recant his knowledge that the earth is round, based on his astronomical observations; they gave more credence to their common-sense experience of a flat earth than to scientific observation.

\title{
Powerful knowledge is differentiated knowledge
}

The discussion in the previous section points to a second trait of powerful knowledge that social realists highlight: knowledge is conceived of as stratified and differentiated. Learning to discern between different kinds of knowledge gives students access to specialist knowledge. Figure 1 below lists just some of the terms that have been used to differentiate between different kinds of knowledge:

Figure 1: Knowledge differentiation

\author{
Everyday knowledge Academic knowledge \\ Soft Hard (Biglan, 1973a, 1973b) \\ Restricted Elaborated (Bernstein, 1962) \\ Profane Sacred (Durkheim, 1977) \\ Horizontal Vertical (Bernstein, 1999) \\ Mundane Esoteric (Bernstein, 2000) \\ Thinkable Unthinkable (Bernstein, 2000) \\ Contextual Conceptual (Muller, 2009) \\ Higher order thinking (Vygotsky, 1981) \\ Concrete Abstract \\ Disciplinary \\ Frees the learner to think the yet to be \\ thought (Bernstein, 2000)
}

For example, Biglan (1973a, 1973b) distinguished between disciplines that were soft and hard, based on a continuum related to the degree to which they operated as a paradigm, "that is, 'the degree of consensus or sharing of beliefs within a scientific field about theory, methodology, techniques and problems' " (Landahl \& Gordon, 1972, p. 
58). Durkheim used the terms profane and sacred, while Young (2008a) differentiates between everyday knowledge and curricular knowledge (p.4), which serve different purposes, one practical and the other theoretical. Rata (2013) defines conceptual knowledge as academic knowledge, arguing that "we go to school to learn a different kind of knowledge from the knowledge of everyday experience" (para. 9), which gives learners new ways of understanding the world.

Social realists particularly draw on Bernstein's differentiation between horizontal and vertical discourses and horizontal and hierarchical knowledges and their accompanying different pedagogies in which knowledge is either segmented (by different contexts) or concepts are sequenced and paced, and recontextualised (Bernstein, 1999; Maton, 2004). Muller's (2009; see also McPhail, 2012, 2016) discussion of contextualised and conceptual knowledge, for example, builds on these notions. He argues that an overemphasis on contextual coherence risks situating learners' knowledge within, and restricting their understanding to, the purview of that particular context, without allowing possibility for application beyond its own context or the development of greater conceptual understanding. Muller calls for an attenuation between conceptual and contextual forms of knowledge; "a new rapprochement between the inner and outer" (pp. 118-119). Wheelahan (2014) also stresses the need for students to gain conceptual knowledge in order to illuminate their contextual understanding:

Access to disciplinary systems of meaning will provide students with better access to the contextual. Unless students have access to knowledge which gives them insight into the causal mechanisms that interact at different levels in constructing the contextual, they will not be able to distinguish between features of the contextual that are necessary and intrinsic to it, and those that are contingent and accidental ... By focussing on the contextual students are denied access to the conditions of knowledge needed to understand the contextual. This is because the complexity contributing to the structuring of the contextual is denied, as is the means to access to the contextual by using the general to understand the particular (p. 134).

Rather than seeing the distinctions between different forms of knowledge as set binaries, placing different kinds of knowledge on a continuum according to their explanatory power may be a more useful way to conceive of knowledge differentiation. 
This argument particularly draws from Bernstein (1999), who sees different knowledge forms as complementary rather than "oppositional" (p. 157) and cautions us against valuing one form over another. Nevertheless, distinguishing different forms of knowledge enables us to better understand the complementarity and differentiation within and between them (Bernstein, 1999). In Chapter 8 I elucidate my proposal that students need access to a range of forms of knowledge, building on Wheelahan's (2014) idea that "knowledge creation in pure and applied disciplines and interdisciplinary work that focuses on particular problems or objects in the world all require institutional forms of support, and each enriches the other" (p. 136). As well as accessing pure and applied disciplines, I argue that social and cultural knowledges are powerful funds of knowledge that students can draw on in combination with academic, disciplinary knowledge. Understanding that there are different forms of knowledge is the basis of an argument that critical thinking allows us to evaluate the explanatory power of different forms of knowledge.

\section{Disciplinary knowledge is powerful knowledge}

The nature of disciplinary knowledge is another key attribute of powerful knowledge. Knowledge has developed and been refined in the disciplines over centuries. Within each discipline, knowledge is ordered, questioned, and understood in different ways according to the logic of that sphere of knowledge. One representation of the logic of the disciplines is proposed by Paul and Elder (2008) (see Figure 2 below). Each discipline has different methods and understandings about how to reason, according to its purpose, essential concepts, and so on. As students learn about the frameworks for understanding, evaluating, and critiquing knowledge through the disciplines, they are inducted into knowledge and thinking frameworks that have been developed by centuries of thinkers. This requires both intellectual humility and hard work, and involves taking students beyond their experience (Young et al., 2014). While knowledge acquisition and production is complex, each discipline improves and develops knowledge as new thinkers build on the work of thinkers who have gone before them. Rata (2013) describes this idea thus:

Academic knowledge enables us to think the unthinkable, to know what we don't and never will experience. It enables us to become more human by being connected to the 
knowledge that has already been created and to the possibilities that lie ahead. None of this comes easily. Sociologist Pierre Bourdieu describes the 20-year-old mathematician who has 20 centuries of mathematics in his mind (para. 11).

Thus, disciplinary knowledge allows learners to - in the words of Isaac Newton (1675) stand on the shoulders of giants. This knowledge is not static, it is constantly being revised. What's more, the conventions and norms for knowledge production that develop within disciplinary communities "are not given truths, but evolve through experience and debate" (Wheelahan, 2014, p. 136).

\section{The Logic of History}

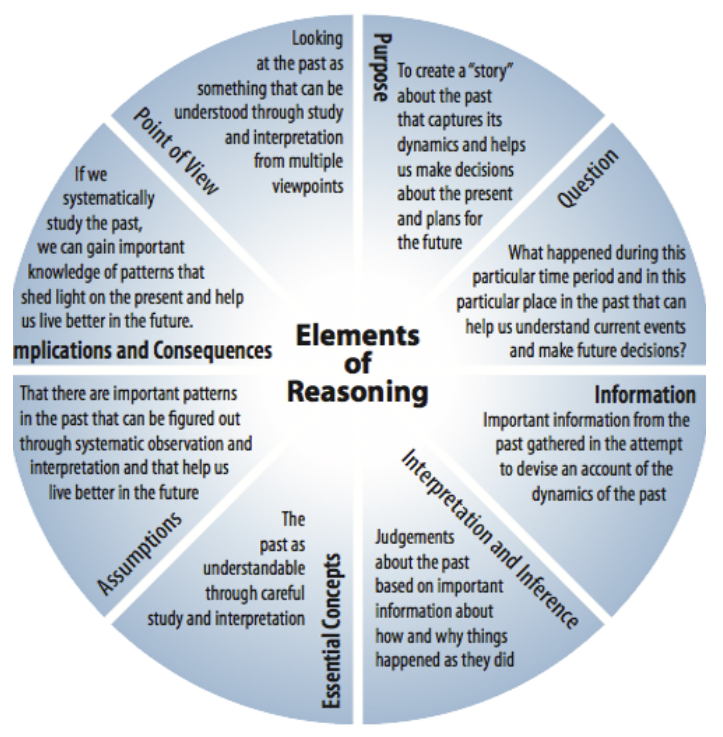

The Logic of Science

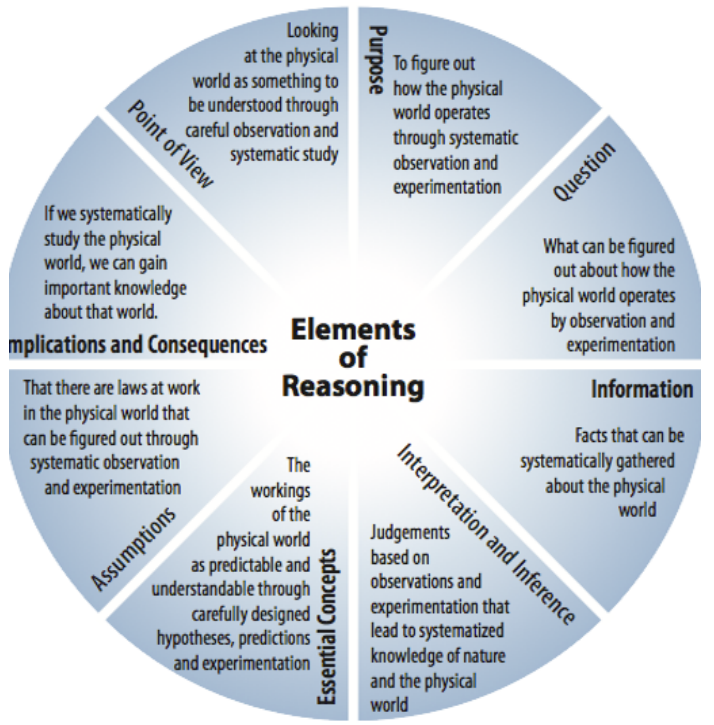

Source: (Paul \& Elder, 2008)

Disciplinary knowledge is taught in different ways across the education sector and has implications for school curricula: "The important point about a knowledge-led school curriculum is that it relies on the 'best' ideas and enquiries of the specialist communities which give priority to discovering, debating, testing and evaluating new knowledge" (Young et al., 2014, p. 31). However, currently there is a gap in the literature in exploring how teachers and learners can build disciplinary knowledge at primary school. How can the foundations for disciplinary knowledge be taught at primary school? What does this mean for primary school teachers, curriculum-creators, 
and primary school students? These are questions that have not yet been addressed in the social realist literature, and which my research explores. I examine what disciplinary knowledge could look like in primary school education, in the context of philosophy.

\section{Powerful knowledge is fallible and provisional}

Disciplinary knowledge constitutes the best understandings we have yet in each discipline. This is not to say that it is objectively true, because new information may refine our knowledge in the future. But it is our best attempt at understanding what is true. Moore (2013) describes this understanding of knowledge as emergentist and also objectivist, "in that it sees such networks as modes of symbolic production realised through collective procedures for the independent evaluation of knowledge claims" (p. 340). This concept of emergent knowledge and its provisionality, fallibility, and defeasibility, is the natural outworking of the social realist understanding of a realist ontology - there is truth out there - and an interpretive epistemology - we are always striving towards better understanding that truth. Integral to an understanding of disciplinary knowledge is the provisional nature of knowledge within the disciplines. As scholars work to further develop and revise knowledge within their disciplines according to their internal rules, they understand that "knowledge is permeable, that its orderings are provisional" (Bernstein, 1972, p. 57). It is for this reason that social realists see curriculum content as open to ongoing debate and the primary importance in curriculum design being "the way in which knowledge is produced and knowledge claims judged ... termed 'procedural objectivity'” (Moore, 2013, p. 348).

Rata (2013) states that "it is the task of those who work in the disciplines to judge knowledge, to retain what has value, to modify and improve, to create new knowledge by adding to the disciplinary canon" (para. 16). Fay (1996) develops this idea by differentiating between the possibility of achieving objectivity as "the outcome of research" and as seeing it as "a property of the process of inquiry itself" (p. 212). He argues that "to fallibilists the method of scientific analysis, not its conclusions, is what is or is not objective" (p. 212). According to this second conception of objectivity, he defines the process as: 
The property of being detached from one's own commitments sufficiently to subject them to examination, of being sufficiently open to the possible merits of other viewpoints. Conceived in this way the objectivity of inquiry consists of its being a social process of ongoing criticism ... According to fallibilism we can never be certain that we are right; all we can hope for is that our beliefs are better than the alternatives ... Fallibilism shows that no method or judgement can be certain ... all methods and judgements can only be provisional. Fallibilism necessitates an attitude of distance towards any conclusion. Thus objectivity requires that investigators be willing to respond to future discoveries, analyses, or criticisms as much as to those in existence at the time of the original investigation (Fay, 1996, p. 213).

The way in which knowledge is created, described above, holds particular importance for the work of this thesis. It imbeds a commitment to what Fay (1996) terms critical intersubjectivity, built on "co-operative conversations bent on collectively exploring the worth of various theories and modes of inquiry from a detached (but not necessarily disinterested) perspective" (p. 213). This could equally be a definition of a P4C CoI, and is the starting point for my exploration of how primary school students might begin to develop powerful knowledge and epistemic frameworks at primary school. As learners learn disciplinary norms, values, standards and systems of critique, they develop the potential to become innovators and knowledge-creators in their own right (Muller, 2009).

An understanding of the relationship between knowledge creation as an emergent process and differentiated knowledge also has implications for social justice outcomes. Bernstein (2000) argues that much esoteric knowledge is potentially powerful knowledge because it constitutes the site of the unthinkable and the yet to be thought ( $\mathrm{p}$. 30). Esoteric knowledge has the potential to challenge the social distribution of power, because of its (not always realised) capacity to transform knowledge and how that knowledge is used. Such knowledge is indirectly related to a material base, and this means that there is a potential for a gap to arise between that knowledge and its material base, which Bernstein refers to as the 'potential discursive gap' (p. 30). Bernstein contends that this gap can "become (not always) a site for alternative possibilities, for alternative realisations between the material and immaterial. The gap 
itself can change the relations between the material and immaterial" (p. 30). Making the link to social justice, Wheelahan (2007) contends that "this is why esoteric knowledge has power and status, and why access to it is always regulated through a division of labour, and through distributive rules that provide access to some, but not others" (pp. 639-640).

\section{Social constructivism in practice in NZ: relativist in the extreme}

To understand social realism is to look at what it positions itself against or attempts to refine. In this section I examine the way that the theory of social constructivism has largely been interpreted in New Zealand primary education, and explore why, despite the best of intentions, this approach has not enhanced social justice outcomes. I draw on the pragmatist view of constructivism to propose an interpretation of constructivism that is consistent with a realist ontology.

The majority of teaching and learning in New Zealand primary schools aligns currently with a social constructivist understanding of knowledge and pedagogy (Ministry of Education, 2007a, 2007b; Young, 2008b, 2010). This theoretical model has helped teachers to build a student-centred approach to teaching and learning that moves away from the transmission-style approach to education that was characteristic of the early $20^{\text {th }}$ century. Many educators have also been influenced by Paulo Freire's (1972) critique of the 'banking' model of education, in which teachers transmit knowledge and facts to their students, who they view as empty vessels. Acknowledging the political nature of education, Freire instead calls for an empowering and liberating pedagogy that uses a problem-posing approach and develops critical thinking:

Education makes sense because women and men learn that through learning they can make and remake themselves, because women and men are able to take responsibility for themselves as beings capable of knowing - of knowing that they know and knowing that they don't (Freire, 2004, p. 15).

This definition of the purpose of education aligns closely with a social constructivist (and social realist) approach to education, incorporating the understanding that learners come to school to build on what they know and to learn what they don't know. In seeking to transform their model of education from Freire's (1972) banking model to 
one which takes into consideration students' prior knowledge and experiences, teachers have moved to constructivist approaches that situate teachers as facilitators, creating learning experiences that scaffold students to construct their knowledge and understandings of the world. By drawing on constructivist and critical pedagogy theoretical frameworks, teachers have been able to examine and deconstruct structures that disempower students by marginalising alternative backgrounds and understandings. There have been many benefits to this approach to education such as more authentic, contextualised teaching and learning, empowerment of student voice, and a valuing of diversity.

However, while teachers need to be aware of the ways in which their own knowledge and understandings may need to grow to incorporate alternative readings of the world, they also have a responsibility to teach students what they don't know. A relativist ontology, that many teachers have conflated with constructivism, means that students whose learning is wholly situated in the realm of their experience miss out on learning new, and potentially powerful ways of understanding the world. Young (2008a) describes the problem with this misinterpretation:

By undermining any claims to objective knowledge or truth about anything, social constructivism, at least in some of the ways it was (and could legitimately be) interpreted, denies the possibility of any better understanding, let alone of any better world (p. 204).

As well as recognising the importance of the experience and prior knowledge that all students bring with them to the classroom, teachers must enable students to discern between stronger and weaker ways to reason and understand the world. This is in order to give students access to educational success, to allow them to have multiple future pathways from which to choose. In other words, powerful knowledge equips students to understand the world, its complexity, and its possibilities.

Two key thinkers have shaped constructivism: Piaget and Vygotsky. Piaget's perspective draws on a concept of subjective interpretation in which individuals take things in to construct personal understandings of the world. He conceived of learning as being shaped by individuals' personal experiences through language, biology, and culture (Peterson, 1996). Piaget's theory elucidates ways that learners learn through 
being presented with new concepts and new knowledge which causes some cognitive dissonance which in turn sets in motion a process of disequilibrium, assimilation, accommodation, and subsequent equilibration (Peterson, 1996).

On the other hand, Vygotsky's social constructivist perspective highlights the social nature of learning and understanding. Vygotsky conceptualises humans as shaped by social interactions which allow the world to construct the individual. For Vygotsky, learning is about incorporating the individual into bodies of understanding; learners develop by rehearsing and mimicking the sophisticated understandings of parents, teachers, and peers around them. They learn as they interiorise the world they observe around them (Davis, 2004). Vygotsky conceived of learning as a process of enculturation: learners grow and develop through activities designed to develop their skills, knowledge and understanding. The individual connects with the collective through practical learning experiences and interaction with more knowledgeable others (peers, teachers, parents). Vygotsky proposed that humans learn best in the ZPD which pushes beyond what an individual can achieve unaided to what they can achieve - or understand - with support. Vygotsky (1978) defined the ZPD as:

The distance between the actual developmental level as determined by independent problem solving and the level and potential development as determined through problem solving under adult guidance or in collaboration with more capable peers ( $\mathrm{p}$. 86).

The support that an individual receives in the ZPD is known as 'scaffolding': the learner is supported to achieve or understand something new, and gradually, as the learner gains competence and understanding, this scaffolding can be carefully withdrawn to allow greater independence. Mercer and Littleton (2007) explain that "effective scaffolding reduces the scope for failure in the task while encouraging efforts to advance" (p. 15). Over time, teachers work to induct learners into disciplinary thinking, allowing them to see how they fit into the bigger puzzle of thought. Through this process, learners are engaged in applying and possibly extending established knowledge within communities of practice (Davis, 2004). In this chapter, I will continue to describe how Vygotsky's approach aligns closely with social realism. 
In theory, Piaget's theory of personal constructivism, involving subjective interpretation, should allow teachers to present learners with new knowledge and frameworks of understanding that expand students' thinking and set the process of equilibration in motion. However, in practice, many New Zealand primary teachers who follow a constructivist approach - that is, largely led by students' questions and contextualised in the learners' experience - often end up with a default position that knowledge is relative (Rata, 2012a, 2013). Through this approach, students come to see their view the world as being as valid as anyone else's. This relativist conceptualisation of knowledge has been criticised by Young (2008a, 2008b, 2010, 2014), Muller (2009), Wheelahan (2007, 2010a, 2014), Moore and Muller (1999), Moore (2013), and Rata (2012a, 2013) because in practice, constructivist approaches to education can inadvertently limit students' learning to the realm of what they already know, without pushing beyond that (Young, 2010). In effect, teachers have emptied out their own role as educators.

Although constructivism has been conflated with relativism in New Zealand primary education, this interpretation is neither suggested nor implied by Piaget or Vygotsky's theories. Theories can often be interpreted, misinterpreted, and applied in various ways. By contrast, Peirce's (1887) pragmatist epistemology is grounded in a realist ontology that incorporates constructivism and fallibilism. Peirce holds that those in the disciplines aim towards truth while recognising that any truth claims are provisional and can never be conclusively justified. Pragmatist thinkers believe knowledge that is refined through the disciplines to be both provisional and tentative on the one hand, and as objective as possible on the other (Seixas, 1993; Gregory, 2002). Thus, "thinking must be subject to a rigorous inquiry to correct and revise theories" (Nichols, Burgh \& Fynes-Clinton, 2016, p. 250). Peirce (1899/1998) argued that "in order to learn you must desire to learn, and in so desiring not be satisfied with what you already incline to think" (p. 48). He believed that new information or interpretations can provoke dissonance and genuine doubt in a learner which is a motivating state that is a necessary part of the learning process (Peirce, 1887). Peirce proposed that genuine doubt drives a learner to inquiry and self-correction. Drawing on Peirce's conception, Gregory (2002) describes this process as "autonomous collective inquiry" that "makes 
possible a kind of objectivity" (pp. 398-399). Peirce's (1887) pragmatist epistemology underpins Lipman's CoI approach.

It is important to note that, while social realist thinkers critique elements of progressive education and the notion of socially constructed knowledge, they also build on these and do not wholly reject the key concerns of these educational theories in relation to social justice. Moore (2013) describes the intention of social realists, not as seeking: To fully displace constructionism, but rather to complete its project by securing a strong epistemological foundation for its claims about the ways in which the construction of knowledge is inevitably entwined with other social forces; relations of inequality and power. The internal contradiction of constructionism is that, by virtue of its lack of a realist ontology, it continually erases the grounds for its own claims (pp. 349-350).

Thus, my use of powerful knowledge is differentiated from the relativist way constructivism tends to be interpreted and enacted in New Zealand classrooms. Social realism and constructivism are therefore not mutually exclusive theoretical perspectives. For example, the disciplinary and provisional knowledge I described earlier are consistent with Vygotsky's conceptions of social learning within disciplinary communities of practice (Davis, 2004; Peterson, 1996; Vygotsky, 1962, 1978).

Furthermore, co-construction, a key concept in constructivist theories of education, is also consistent with a social realist interpretivist epistemology and realist ontology. What Young instead offers us is a new way of thinking about and critiquing the relative ontology generally assumed to be a natural outworking of social constructivism:

Social constructivism was fundamentally wrong in the conclusions that it drew about knowledge and the curriculum. The social character of knowledge is not a reason for doubting its truth and objectivity, or for seeing curricula as no more than politics by other means. Its social character is (even more truthfully) the only reason that knowledge can claim to truth (and objectivity) and therefore for preferring some curriculum principles to others (Young, 2008a, p. 205).

The 'social character' of knowledge, as Young defines it, draws on the history of knowledge in each discipline, built and refined by each generation of thinkers. A relativist constructivist approach can inadvertently privilege students who come to school with knowledge and social capital that will allow them to succeed in the school 
system, and can disadvantage students whose prior knowledge and experience might not equip them for educational success. Wheelahan (2014) highlights a blind spot of ontological relativism: "our knowledge is always mediated by pre-existing concepts and knowledge and by the social conditions of our access" (p. 127). If teachers follow an educational approach that perpetuates social inequality, whether intentionally or not, this is an issue of social justice. Jackson (2008) offers another way to consider the inequitable potential of the constructivist conception of subjective interpretation based on different worldviews and personal experience:

One must walk a fine line in recognising difference while ensuring fair access to ... 'high status knowledge'. We must not respect difference so much as to sift students into different educational tracks, but we cannot ignore diversity and assume relative equality in its place, either (Jackson, p. 144).

This is where many teachers' interpretation of social constructivism falls down: an over-emphasis on relevance and contextualisation risks only cursory attention being given to supporting students to develop powerful, deep, conceptual knowledge. With this critique in mind, I turn to social realism as an approach that endeavours to provide a meaningful lens through which to understand how teaching and learning can give all students access to powerful knowledge that enables them to understand, explain, and critique the world. A social realist lens enables teachers (and policy-makers) to recognise that students from a range of ethnic and socio-economic backgrounds need to be taught through contexts that are relevant to their lives, as well as having clear links drawn from the students' contextual experience to the conceptual knowledge and understanding that will allow them to understand the world and to succeed in the education system. Teachers, schools, and policy-makers aim to create and sustain an education system that offers equitable opportunities for success to all learners; a social realist lens opens up a new space for investigating how to do this by exploring what powerful knowledge is, and how to teach it.

\section{The influence of critical realism on social realist perspectives}

Social realism draws on critical realist thought elucidated by Roy Bhaskar (1998b, 2013) and Andrew Sayer (1992, 2004), so in order to better understand the social 
realist theoretical lens I turn further back, to examine the epistemological and ontological assumptions of critical realist theory. Then I discuss how a social realist theoretical base offers a useful conceptual framework with which to explore how Philosophy for Children can develop critical thinking for all learners in New Zealand primary schools. Underlying my approach is a desire to build a socially just education system and society.

Much of Bhaskar's work addresses ontological and epistemological questions about the nature of reality and our understanding of it. Bhaskar $(1979,1998 \mathrm{~b})$ and Archer, Bhaskar, Collier, Lawson and Norrie (2013) developed concepts about knowledge and society that allowed him to explore how to build theoretical and applied explanations in the social sciences. A key element of his conception of knowledge distinguishes between the 'subjective, epistemological, transitive' and 'objective, ontological, intransitive' sides of knowledge. While there are mechanisms that exist in the world regardless of our perception of them, our understanding of these mechanisms is always interpreted and mediated through our perceptions and understandings. Bhaskar describes transitive objects of knowledge as "the antecedently established facts and theories, paradigms and models, methods and techniques of inquiry available to a particular scientific school or worker" (Bhaskar, 1998a, p. 16) which are contingent on people's interpretations of the world. He defines these transitive elements of knowledge as social products which are shaped by the people who have developed them just as much as cars, furniture and books are. Bhaskar defines objects or processes which do not rely on human production or knowledge in order to exist, such as gravity or the process of electrolysis, as intransitive objects of knowledge. He asks,

If we cannot imagine a science without transitive objects, can we imagine a science without intransitive ones? If the answer to the question is 'no', then a philosophical study of the intransitive objects of science becomes possible. The answer to the transcendental question 'what must the world be like for science to be possible?' deserves the name of ontology ... Any adequate philosophy of science must be capable of sustaining and reconciling both aspects of science; that is, of showing how science which is a transitive process, dependent upon antecedent knowledge and the efficient activity of men [sic], has intransitive objects which depend upon neither. That is, it must be 
capable of sustaining both (1) the social character of science and (2) the independence from science of the objects of scientific thought (Bhaskar, 1998a, p. 18).

Critical realism offers an alternative to both the absolutism of positivism and the potential relativism of constructivism and post-modernism (Moore, 2013). According to Bhaskar, an empiricist view of science is flawed because using the category of experience to define the world conflates epistemology and ontology, giving a particular epistemological concept a general ontological function (Bhaskar, 1998a). His clear differentiation between a realist ontology and an interpretive epistemology is an essential element of critical realist thought which forms the foundation for his understanding of the stratification of knowledge and causal mechanisms, and his models for theoretical and applied explanation. A clear understanding of ontology and epistemology is essential to theories of knowledge in education because these understandings, whether explicit or implicit, shape the ways that schools, teachers, and therefore learners conceive of knowledge and truth, which in turn shapes the curriculum and the way that teaching is devised, planned for, and structured, and the way that learning is experienced, constructed, and absorbed by students. Later in this chapter I clarify how different theories of ontology and epistemology shape different theories of knowledge and result in very different models of education. Now I turn to an explanation of the key elements of Basil Bernstein's theory that shape social realist understandings of knowledge and democracy.

\section{The influence of Bernstein's scholarship: democratic pedagogic rights}

Bernstein's work has influenced the thinking of social realists whose theories and work I am drawing on: Young, Muller, Moore, and Wheelahan. It is therefore useful for me to summarise the key elements of his work that are salient to the theoretical lens that informs the analysis presented in this thesis. Bernstein's theories are grounded in a deep belief in the importance of a democratic equitable education system; this section outlines his description of the essential ingredients of a true democracy, and the concomitant conditions required in a democratic education system (Muller, 2004). I will also discuss Bernstein's theories of elaborated and restricted language codes, vertical 
and horizontal discourses and hierarchical and horizontal knowledges which are foundational to an understanding of the theory of powerful knowledge.

One of Bernstein's key drivers is the persistence of structural educational inequality. He is motivated by "a sense of social justice and outrage at the continuing deformation of life chances by the pedagogic device" (Muller, 2004, p. 1). In seeking to articulate what kind of society he is working for, Bernstein outlines his definition of an effective democracy in the Introduction to Pedagogy, Symbolic, Control and Identity, stating that everyone has the right to enhancement, inclusion, and participation. I draw on these rights in Chapter 7 when I discuss their relationship to student participants' experiences and thinking in my study's Communities of Inquiry. Bernstein describes his conceptions of each of these pedagogic democratic rights thus:

Figure 3: Bernstein's Pedagogic Rights, Conditions, and Levels

\begin{tabular}{|l|l|l|}
\hline Rights & Conditions & Levels \\
\hline $\begin{array}{l}\text { Enhancement: not simply the right to be more personally, more } \\
\text { intellectually, more socially, more materially, it is the right to } \\
\text { the means of critical understanding and to new possibilities. }\end{array}$ & Confidence & Individual \\
\hline $\begin{array}{l}\text { Inclusion: to be included, socially, intellectually, culturally, and } \\
\text { personally ... this right to be included is complex because to be } \\
\text { 'included' does not necessarily mean to be absorbed. Thus the } \\
\text { right to be included may also require a right to be separate, to } \\
\text { be autonomous. }\end{array}$ & Communitas & Social \\
\hline $\begin{array}{l}\text { Participation: not only about discourse, about discussion, it is } \\
\text { about practice, and a practice that must have outcomes ... It is } \\
\text { the right to participate in the construction, maintenance, and } \\
\text { transformation of order. }\end{array}$ & $\begin{array}{l}\text { Civic } \\
\text { discourse }\end{array}$ & Political \\
\hline
\end{tabular}

Source: (Bernstein, 2000, pp. xx-xxi)

Much of Bernstein's work is devoted to finding ways to make educational opportunity as equitable and accessible to all as possible. He argues that "it is certainly possible to create a visible pedagogy that would weaken the relation between social class and educational achievement" (Bernstein, 1996, p. 79). This commitment to social justice, to access for all, and to an excellent education that transcends barriers like ethnicity, class, or gender, is a thread that runs through Bernstein's work and throughout social realist theory, and is a strong guiding principle in my own research. This commitment involves exposing curriculum inequality and working to create equity in curriculum provision. 


\section{Language codes}

One source of inequality stems from different language codes and their use. Language codes are the organising principles behind language and modes of communication used by social groups (Bernstein, 1971a, 1975; Littlejohn, 2002). Bernstein's concept of language codes offers us a new way of thinking about, and theorising, how the language people use in everyday conversation both reflects and shapes the assumptions of a certain social group, and how relationships established within the social group affect the way that group uses language, and the type of speech that is used. Bernstein suggests that the code that a person uses symbolises their social identity (Bernstein, 1971) or, stated differently, "people learn their place in the world by virtue of the language codes they employ" (Littlejohn, 2002, p. 178).

In his early work, Bernstein proposed that there are two kinds of language codes: elaborated and restricted. Restricted language codes are often oral, and used between closely-knit groups, such as families, close social groups, and colleagues, when the subject of conversation is shared, often tangible or concrete, and assumed to be understood by both parties. Restricted code involves slang, 'in jokes', shared language that is context-dependent. This code can strengthen social ties and identifies the speakers as connected members of a certain group. Elaborated code, on the other hand, is used when the subject of communication (spoken or written) requires clear articulation. Often the subject is abstract, conceptual and complex, and specific specialised technical language is needed to clearly describe it. Elaborated language code is the kind of academic language used in school, to clearly describe specific conceptual knowledge. Bernstein (1971) clarifies that:

One code is not better than another; each possesses its own aesthetic, its own possibilities. Society, however, may place different values on the orders of experience elicited, maintained and progressively strengthened through the different coding systems (p. 135).

While everyone has restricted language codes that they use within their own familial and social groupings, not everyone is familiar with elaborated codes that can clearly describe abstract concepts. Bernstein's work always tackles class (more commonly 
termed socio-economic status [SES] in New Zealand), and he proposes that middle-class students are more likely than their working class or low SES counterparts to have exposure to elaborated language codes which will enable them to succeed educationally.

\section{Horizontal and vertical discourse; hierarchical and horizontal knowledge}

\section{structures}

Scholars working with a Bernsteinian lens often use language codes, previously described, as a conceptual tool to analyse and consider how students, particularly those who may not have the cultural capital that would have exposed them to elaborated codes, may benefit from being explicitly taught language structures and codes. This conceptualisation of language codes links closely to Bernstein's differentiation between horizontal and vertical discourses. Horizontal discourse comprises of social, commonplace languages and knowledge, usually oral and local, and highly relevant to the learner's everyday life (Bernstein, 2000). Generally, horizontal discourses are learned from experience and related to specific events; they produce 'restricted' codes, in which meanings are contextualised. The "acquisition of horizontal discourse is a tacit acquisition of a particular view of cultural realities, or rather of a way of realising these realities" (Bernstein, 1999, p. 165).

Bernstein divided vertical discourse into two knowledge structures: hierarchical and horizontal knowledge; he defines the two forms here:

One is a coherent, explicit and systematically principled structure, hierarchically organised; and the second takes the form of a series of specialised languages with specialised modes of interrogation, specialised criteria for the production and circulation of texts (Bernstein, 2000, p. 160).

Hierarchical knowledge, such as the natural sciences, is structured, sequenced, and developed over a long period of time. It follows a coherent, explicit, and systematically principled structure and is hierarchically organised. The specialised languages within different disciplines enable and develop epistemic understanding. To master hierarchical discourse, one requires explicit induction into its modes and knowledge. By contrast, horizontal knowledge is segmentally organised; it doesn't necessarily follow a 
structured sequence. The segmental pedagogies employed to teach horizontal knowledge, for example, social sciences and humanities, often involve gaining competencies "rather than a graded performance" (Bernstein, 2000, p. 161). Horizontal knowledge takes "the form of a series of specialised languages with specialised modes of interrogation and specialised criteria for the production and circulation of texts, as in the social sciences and humanities" (Bernstein, 2000, p. 161).

Bernstein termed the kinds of knowledge accessed through these different forms of discourse esoteric and mundane:

Distributive rules distinguish between two different classes of knowledge that I will argue are necessarily available in all societies... the thinkable class and the unthinkable class... in all societies there are at least two basic classes of knowledge; one class of knowledge that is esoteric and one that is mundane... the control of the unthinkable lies essentially, but not wholly, in the upper reaches of the educational system (2000, pp. 2829).

The implicit point here is that it is the responsibility of the education system to make esoteric, unthinkable knowledge accessible to all learners. It is important that curriculum-makers, schools, and teachers think carefully about the ways they do this. No communication happens in a vacuum; rather, any pedagogic interaction is imbued with power relations and cultural assumptions. School subjects and teaching are always a process of recontextualising the discipline for the learners. What influences this? "The recontextualising principle not only selects the what but also the how of the theory of instruction. Both are elements of regulative discourse" (Bernstein, 2000, p. 35). This can occur differently for hierarchical and horizontal knowledges according to their framing. Hierarchical knowledges are necessarily strongly framed (selected, sequenced, paced and evaluated). This framing can either be explicit, as in traditional transmission-type pedagogy, or 'masked' and hidden, as in progressive pedagogy (Bourne, 2004). Because horizontal knowledges are not as strongly framed as hierarchical knowledges, the humanities are more subject to recontextualisation than sciences. When seeking to contextualise knowledge into a curriculum for learners, teachers must be careful that they are not diluting and weakening the knowledge they teach. 
Essentially, Bernstein's work on knowledge, language and pedagogy explores the distinction between more or less abstract and concrete knowledge, the language to describe that knowledge and the extent to which this distinction is clear and accessible to all learners, regardless of social class (Kitson, 2015). Bernstein posited that, in order to achieve enhancement and inclusion so that they can fully participate in democracy, learners need explicit access to disciplinary knowledge and the language to understand, describe, and create new disciplinary knowledge. Building on this proposition, Young, Muller, Moore, and Wheelahan have continued to theorise on the potential of access for all learners to disciplinary, academic knowledge. I will now turn to the aims of their social realist approach, seeking to give all learners epistemic access to powerful knowledge in order to achieve social justice.

\section{Powerful knowledge as a means to enhance social justice}

Social justice can be conceptualised in many different and intersecting ways. The images, definitions, and metaphors for social justice that each of us holds in our mind may look quite different: for one person, social justice might mean a social state system that provides decent housing for all those who need it; for another, social justice might mean equal pay for women and men. In Chapter 7, I explore how working for equitable opportunities in education can contribute to distributive social justice. It is because enhancing social justice is the driving motivation of social realists that I have chosen this analytical lens for my research. I particularly draw on Young's notion of access for all to powerful knowledge (Young, 2008a, 2008b, 2010, 2013; Young et al., 2014; Young \& Muller, 2010, 2013) and examine the strengths and potential of this theory in helping to clarify what and how teachers can teach in ways that work towards social justice. In short, this thesis examines how an equitable education system, as defined through a social realist lens, might contribute to social justice, in practice.

As I argued in my introduction, all learners come to school to build on their prior experience, what they already know, to learn what they don't know. Prior knowledge such as cultural and social knowledges are powerful in and of themselves; students also deserve to build academic, disciplinary knowledge that will allow them to achieve educational success. The combination of these different knowledges will offer students 
social mobility, allowing them to choose from a range of possible pathways, that which best suits their passions, interests, and strengths, rather than being limited solely to building a future within the realm of their background and prior experience. In thinking about the practical implications for enhancing social justice, in this thesis I ask:

- How can P4C offer all children access to critical modes of thinking and powerful knowledge?

- Can participation in P4C develop critical thinking skills that will improve students' educational outcomes?

- How can teachers teach in a way that makes education equitable for all learners?

- What do teachers need to be aware of, in terms of their own beliefs and practices, and in relation to classroom power structures and dynamics, in order to create more equitable learning opportunities for all learners?

\section{Critiques of powerful knowledge}

The following pages present some of the interpretations and thoughtful critiques of powerful knowledge, and outline some of the defences that have been made in response. Young himself has addressed many of the critiques that have been offered in the last decade since his (2008) book Bringing Knowledge Back In: From social constructivism to social realism in the sociology of education sparked lively debate on the concept of powerful knowledge. Most recently, Muller and Young (2019) have written a paper clarifying their definitions and use of the words power and powerful. I discuss these definitions in relation to my own conclusions in Chapter 8.

Beck (2013) describes the risk that terms like powerful knowledge "can turn into sound-bites, losing precision as they become popularised" (p. 178). The theory of powerful knowledge has, at times, been misinterpreted in the United Kingdom, and hijacked by traditionalists who co-opt his definition, narrowing it to an interpretation that assumes that powerful knowledge is knowledge-as-facts, to be taught using traditional transmission methods (James, Oates, Pollard, \& Wiliam, 2011). For example, Yandell (2014) decries Michael Gove's conservative interpretation of powerful knowledge which influenced the United Kingdom's school curriculum while he was 
Secretary of State for Education, ${ }^{1}$ who suggested that, "To be educated, then, is to possess knowledge - particular forms of knowledge. Such knowledge is unchanging, and the business of schooling is to ensure that these stable bodies of knowledge are transmitted from one generation to the next" (p. 7). Gove's interpretation presumed that the valuable knowledge that should be imparted to students is static and from a particular canon, arguably knowledge of the powerful. By contrast, Yandell (2014) advocates for asking “hard questions like 'Whose knowledge is this?' and even 'Whose knowledge counts?' " (p. 10). There are two threads to unravel here: is powerful knowledge unchanging? and, whose knowledge counts? I will address each of these questions in turn.

Young's definition of powerful knowledge (Young, 2008a, 2010; Young \& Muller, 2010) is a much broader conception of knowledge than that of traditional transmission-style educationalists. It is not solely concrete facts; it includes modes and frameworks for critical thinking and conceptual understanding in different disciplines. Young and Muller's $(2010,2019)$ definition also conceives of knowledge as defeasible, provisional, and revisable: it can always be improved upon and grown. Bernstein (2000) and Wheelahan (2007) describe this as the 'potential discursive gap', mentioned earlier in this chapter; that is, the space where new possibilities and new knowledge can emerge. Knowledge conceived in this way encompasses a wide range of teaching methods, and involves knowledge production through the evaluatory methods and systems of the particular discipline. Social realists conceive of knowledge as a "future-oriented, everexpanding enterprise" (Muller, 2009, p. 116). Wheelahan (2007) describes the ongoing process of knowledge creation and improving on prior understandings thus:

Realist approaches concede that knowledge is a social product and that it is fallible as a consequence, but that an objective reality exists, and that the purpose of knowledge is to understand that objective reality, even if our knowledge is always impartial, socially mediated, and marked by the social conditions under which it was produced, which include power and privilege (p. 641).

\footnotetext{
${ }^{1}$ Michael Gove held the position of Secretary of State for Education in the UK from 2010 - 2014.
} 
Now I turn to the question: whose knowledge counts? While Young and Muller have always been careful to differentiate between knowledge of the powerful (KOTP) and powerful knowledge (PK) (Muller, 2009; Muller \& Young, 2019; Young \& Muller, 2010, 2013), the clarity of this distinction has been questioned. Yandell (2014) and Rudolph et al. (2018) ask, can knowledge can ever really be abstracted from culture and history? Yandell (2014) argues that the forms of knowledge that the privileged gain access to at traditional schools through the power and capital - cultural, social, financial - that they hold, makes it difficult to identify which factors actually contribute to their educational success. It is therefore hard to separate powerful, disciplinary knowledge from its links to KOTP and its concomitant imperialism. This critique argues that powerful knowledge represents only one dominant group's knowledge and is therefore no foundation on which to build an inclusive curriculum for a diverse society. Rudolph, Sriprakash, and Gerrard (2018) suggest that specialised, disciplinary knowledge is both necessary - in its explanatory power - and flawed because of hegemonic relations that exist in the process of specialisation. They recommend examining the history of knowledge production with analyses of colonial tones in disciplinary communities. Arguing that "more just curricula would make visible the politics of knowledge production and the power relations that underpin such politics. It would seek to make students aware of connections between different forms of knowledge" (p. 34), the authors seek to refine, rather than reject, the theory of powerful knowledge by making explicit the "multiplicities and relationality" (p. 35) within and between different forms of knowledge.

Powerful knowledge cannot be completely separated from knowledge of the powerful; Muller \& Young (2019) themselves acknowledge that "no knowledge, including specialised knowledge, when used in the real world of contending interests, can remain innocent of power relations" (p. 13). Even well-meaning professionals can inadvertently sustain broader structures of oppression and social and cultural reproduction (Whitty, 2018). While some educators aiming for social justice ask if powerful knowledge entrenches existing power relations in a way that is detrimental to marginalised communities, Young (2008) argues that "the knowledge issue is both an epistemological issue and a social justice issue" (p. 32) because working class students deserve access to 
powerful knowledge which can provide the basis for generalisable principles and which they may not have access to at home. Young, Lambert, Roberts and Roberts (2014) acknowledge that knowledge can have "elitist and exclusive connotations" (p. 12) but they argue that, "access to knowledge beyond our experience is the only true source of freedom and as such is the 'entitlement of all'” (p. 13). While knowledge can have elitist or dominating connotations, it is how the knowledge is used by knowers, rather than the knowledge itself, that is problematic (Muller \& Young, 2019). I continue to explore the challenge of how to reconcile powerful knowledge with the knowledge of marginalised communities as I turn to how powerful knowledge has been represented in New Zealand.

In New Zealand, the concept of powerful knowledge has been used to discount the value of indigenous knowledge and to critique Māori education and culturally responsive education (Rata, 2005, 2007, 2012a, 2012b). Rata (2012a) argues that powerful knowledge is more useful than cultural or 'social' knowledge because

$[w]$ ith social knowledge the world can only be known subjectively 'from the inside' by the insider and that 'way of knowing' must be authorised by someone of status within the social group. Science (and by this term I include all the disciplines that have the following features) has its own internal authority-the authority of procedures that allow for scrutiny and criticism (p. 105).

She also argues that "the localisation of knowledge has negative consequences for ethnicised groups in the working class in that it limits access to a powerful class resource - that of conceptual knowledge, what Michael Young (2010) calls 'powerful knowledge' " (Rata, 2012a, p.107). While elements of Rata's arguments are compelling, particularly the notion that students deserve to learn what they don't (yet) know at school, rather than just being exposed to knowledge that is consistent with their prior knowledge and experience, she has been critiqued for questioning the value of indigenous knowledge (Pihama, 2019). Rata's term 'ethnicised groups' suggests a radicalisation or politicisation of ethnic identity, and Pihama (2019) argues that this denies Māori identity by labelling Māori educational developments as " 'ethnic fundamentalism', 'secular religion', and 'politicised ethnicity' " (Rata, 2007, p. 13). I return to the difficulties of Rata's interpretation of powerful knowledge in Chapter 8 when I propose an alternate conception of powerful knowledge. 
Another area of debate in relation to powerful knowledge centres on how to make powerful knowledge accessible for students. Beck (2013) suggests that because academic knowledge is often autonomous and self-referential, this:

Constitutes one major impediment to gaining or providing effective epistemic access, especially to those from disadvantaged backgrounds. Disciplinary knowledge is ... intrinsically esoteric. Getting on the inside of disciplinary understanding ... requires prolonged initiation ... therefore, enabling students to make subjectively meaningful connections between these necessarily remote disciplinary worlds and the student's everyday experience may prove to be one of the most challenging and enduring educational problems that face us (p. 187) (italics his).

Although Beck is referring to disciplinary knowledge at the tertiary level, and my research is focussed on the foundations of powerful knowledge at the primary school level, this is still a huge challenge for teachers and one that fuels one of my key research questions: how can teachers teach critical thinking - a form of powerful knowledge - to diverse learners? Rata (2012a) offers a possible method when she acknowledges the value of recognising a student's family and community experiences in order to motivate students and to build relationships between teachers and their students. In an article on conceptual progression, Rata draws on Vygotsky's (1962) contention that conceptual knowledge can be learned when students are able to incorporate it into their everyday knowledge and schemas.

The idea that teachers start with scientific or abstract concepts and then draw on everyday knowledge, which itself is transformed in the process, has profound consequences for teaching. It moves academic knowledge and the knowledgeable teacher to the central position at school, but does not exclude the child's contribution to learning (Rata, 2016, p. 177).

This suggestion, that conceptual powerful knowledge can be connected to students' contextual everyday knowledge, is a way to reconcile constructivism with a realist ontology. Making explicit links between contextual and conceptual knowledge is an essential practical way that teachers can offer epistemic access to all students. Rata does not, however, make the leap to describing the worth of making links between students' cultural knowledge and conceptual powerful knowledge. I develop this idea in Chapter 8 by proposing a new term enhancing knowledge to describe the useful 
connections that can be made between powerful and everyday knowledge, without discounting the value of cultural or social knowledge.

Another critique asks whether the pursuit of powerful knowledge should be the aim of schooling, as Young and Muller (2013) suggest. For example, Brown and White (2012) suggest that other key goals of education should be "developing the imagination, wider sympathies with other people, a love of beauty, personal qualities like confidence" ( $p$. 2). I mention these suggestions here because they raise fundamental considerations such as what is schooling for? and, what does a full education consist of? - that are related to Yandell's (2014) questions about whose knowledge counts. These questions are worthwhile challenges to consider but are beyond the scope and focus of this thesis.

\section{Conclusion}

In this chapter I have considered the key theoretical resources underpinning my research, drawn from social realism, which enable me to examine philosophical dialogue and critical thinking development in primary schools. Social realist understandings of powerful knowledge are built on a realist ontology and an interpretive epistemology that incorporates understandings of disciplinary knowledge frameworks and modes of knowledge critique and production. The process of critique and production requires critical intersubjectivity, built through interaction with other ideas and thinking frameworks. Powerful disciplinary knowledge that has explanatory power, is provisional, and exists in the 'potential discursive gap', enhances learners' understandings of the world and therefore their potential in the world.

Currently, the social realist literature draws on teaching and learning primarily in higher education (Wheelahan, 2007; Moore \& Young, 2001; Muller, 2009), with some discussion of education and curricula at secondary schools (Rata, 2012a; Young, Lambert, Roberts \& Roberts, 2014). However there is no discussion of what constitutes powerful knowledge at the primary school level, and in this thesis I propose that greater attention to how students build and apply critical thinking to their experiences and knowledge contributes to an enriched understanding of powerful knowledge at this level of schooling. My research examining authentic primary school classroom practice 
explores the transformative power of critical thinking developed through Philosophy for Children and offers practical suggestions for primary teachers drawing on concrete examples from the classroom.

In the next chapter, I critically review the literature in the fields of Philosophy for Children, social justice and democratic education, critical thinking and dispositions, and classroom dialogic interaction in order to situate my research and join the academic conversation within these fields. Because there is still very little research that explores what a social realist approach might look like in a primary school classroom - and in order to bridge the gap between this theoretical perspective and the practice of Philosophy for Children - Chapter 4 goes on to explain my use of sociocultural theory to analyse the classroom dialogue in this study. I also draw the links between sociocultural theory, Philosophy for Children, classroom dialogue, and a social realist lens. 


\title{
Intersections of $\mathrm{P}_{4} \mathrm{C}$, critical thinking, and social justice: theory and literature
}

\author{
The history of ideas is important, especially when they are wide open to quite different \\ interpretations. Knowing where ideas came from, and why, helps to determine an \\ appropriate focus and framing for deliberations about them (Hipkins, Bolstad, Boyd, \& \\ McDowall, 2014, p. 6).
}

My project intersects with different fields and research methods in terms of its substantive research focus areas (literature on Philosophy for Children, critical thinking, education in New Zealand, social justice in education), methodological focus (literature on dialogic analysis, researcher positionality, sociocultural theory), and theoretical lenses I use to interpret the data (literature on social realism and constructivism). My central argument is that $\mathrm{P} 4 \mathrm{C}$ is an approach that offers all learners the opportunity to develop critical thinking, which enhances social justice.

Throughout this chapter I will address the themes that I have drawn from the literature relating to my substantive research focus areas: literature on education in New Zealand, critical thinking, Philosophy for Children, and social justice in education. As each theme is discussed, I identify the key ideas and thinkers in relation to my focus, acknowledge the thinkers whose work is connected to (but not directly bearing on) my question, and examine the literature relating to each theme, both internationally and in the New Zealand context. I locate my study in relation to these literatures, explaining the influences on my study. Doing so will enable me to highlight the gaps in the literature within each theme and describe the ways my research might begin to explore those gaps. The following summary and synthesis allows the reader to see where and how I 
situate my research, and to understand the conversations I am joining, as well as those to which I am not contributing.

\section{Thinking competency in the NZC}

In 2007, a new school curriculum was launched in New Zealand following a review and a revision of the prior New Zealand Curriculum Framework (Ministry of Education, 1993) which consisted of sets of achievement objectives for seven essential learning areas alongside essential skills and values to be developed and imparted. The New Zealand Curriculum (NZC) (Ministry of Education, 2007) is an outcomes-based curriculum with two clear sections, known colloquially as the 'front end' and 'back end'. Generally speaking, the front end of the curriculum is procedural, describing how teachers should teach and learners should learn, and the back end is substantive, stipulating what should be taught and learnt. At the front end, the vision, principles, values and key competencies are designed to guide and influence teaching and learning across the curriculum. The 'back end' is a series of outcomes-based achievement objectives grouped within eight subject learning areas: English, the arts, health and physical education, learning languages, mathematics and statistics, science, social sciences, and technology.

At the front end, the NZC's five key competencies are identified as: Thinking; Using languages, symbols, and texts; Managing self; Relating to others; and Participating and contributing (Ministry of Education, 2007, pp. 12-13). The first of the NZC's key competencies is simply thinking, defined as follows:

Thinking is about using creative, critical and metacognitive processes to make sense of information, experiences and ideas. These processes can be applied to purposes such as developing understanding, making decisions, shaping actions, or constructing knowledge. Intellectual curiosity is at the heart of this competency. Students who are competent thinkers and problem-solvers actively seek, use and create knowledge. They reflect on their learning, draw on personal knowledge and intuitions, ask questions, and challenge the basis of assumptions and perceptions (Ministry of Education, 2007, p. 12).

Hipkins and Boyd (2011) argue that the Thinking key competency is the most ubiquitous - they describe it as 'cross-cutting', woven through and integral to all of the 
other competencies, and embedded in all learning. Thinking encompasses a range of modes, including critical thinking. Nevertheless, while critical thinking is clearly valued strongly in the NZC, there is neither a clear definition nor an indication of how teachers might actually build students' critical thinking in their classroom communities. Teachers are left to discern for themselves how best to weave thinking (and the other key competencies) through the content they teach. Research investigating how to grow students' critical thinking in New Zealand primary schools is needed (Benade, 2011).

Alongside the values, which include "innovation, inquiry, and curiosity, by thinking critically, creatively, and reflectively" (Ministry of Education, 2007, p. 10), the key competencies are the closest the NZC gets to mandating teaching critical thinking. The NZC key competencies are based on those defined in the Organisation for Economic Cooperation and Development (OECD) project, The Definition and Selection of Key Competencies (DeSeCo), which grew from the findings of an International commission of education for the twenty-first century report (Delors et al., 1996). The key competencies replaced a set of essential skills set out in the prior (1993) curriculum framework, which did not include critical thinking. Described as "capabilities for living and lifelong learning" (Ministry of Education, 2007, p. 10), the key competencies are presented as capabilities "that are critical to sustained learning and effective participation in society and that underlie the emphasis on lifelong learning" (Sewell, 2007, p. 4). The shift from the language of skills to competencies and capabilities was an intentional change, to highlight the complex, interactive, context-dependent nature of competencies that incorporate knowledge, attitudes, values, and skills (Rutherford, 2005, p. 212).

Since the turn of the $21^{\text {st }}$ century there has been much discussion in education literature about what $21^{\text {st }}$ century learners need and how curricula and education systems might need to change because of our unknown future, with the growing rate of change and technological growth as well as increased geopolitical uncertainty due to climate change, a rise in migration often caused by war, growing terrorism and populist politics (Claxton, 2007; Delors et al., 1996; Gilbert, 2005; Harpaz, 2014; Murdoch, 2015; OECD, 2005, 2018c; Rychen, 2003; Wells \& Claxton, 2002). Internationally, competency (or competence)-based learning has become a common focus for curriculum design, as the 
complexities of using and applying knowledge and knowledge-creation are increasingly recognised and valued. UNESCO's International Bureau of Education, for example, has published a number of reports designed to define and create a framework for competence-based curricula (Marope, Griffin, \& Gallagher, 2017, p. 28). The OECD has also contributed in this space and define competency as:

The ability to successfully meet complex demands in a particular context through the mobilisation of knowledge, cognitive skills but also practical skills, as well as social and behaviour components such as attitudes, emotions, and values and motivations (Rychen, 2003, p. 3).

The inclusion of knowledge in this definition is key: competence can't develop in a vacuum - it requires content to work with. The OECD's (2018c) The future of education and skills education 2030 report emphasises the complexities of developing competences to use and apply knowledge, skills, attitudes and values. This signals a shift from previous focuses for curricula in that the place of disciplinary knowledge is recognised.

Many definitions of competence are complex because they require teachers and learners to weave together a number of elements. Carr (2006) and Hipkins (2013) offer a simple definition for competence: being ready, willing and able to use one's knowledge and skills. While the shift to teaching competencies and capabilities and their emphasis on the importance of teaching students to think - critically, creatively, collaboratively - is grounded in research literature, there are challenges for teachers in understanding how to weave knowledge, skills, attitudes and values together to develop students' competencies in coherent, meaningful ways (Gallagher, Hipkins, \& Zohar, 2012; Hipkins, 2009, 2017; Hipkins, Reid, \& Bull, 2010). I will discuss some of these challenges in the next section. 


\section{The everywhere and nowhere nature of thinking}

There is a wealth of research that indicates that thinking can be taught and that as students develop critical thinking, their learning potential and capability also develops, both within the field of P4C (Burgh, Field, \& Freakley, 2006; Cam, 1995; Daniel \& Auriac, 2011; Fisher, 2003; Kennedy et al., 1990; Lipman, 1984, 1988, 2003; Matthews, 1994; Scholl, 2005; Splitter \& Sharp, 1995; Sprod, 1998; Trickey \& Topping, 2013; Wartenberg, 2009, 2013), and beyond it (Gardner, 2006; Harpaz, 2014; Kuhn, 2005; Noddings, 2006; Perkins \& Grotzer, 1997; Rogoff, 1990). In this section I will discuss the literature on teaching thinking which incorporates, but is also broader than, critical thinking.

Hipkins (2013) discusses the complex task teachers are faced with when teaching the thinking competency: "The characteristics described in the [NZC definition of thinking] have a long history of being everywhere in aspiration (and nowhere in deliberate practice?) in the school curriculum" (p. 233). She argues that thinking is naturally assumed to be an essential element of all learning - thinking is everywhere - however, there are a number of factors that must be considered when teachers plan to teach students to think, which are not clearly articulated in the NZC and are therefore not necessarily explicitly taught - thinking is nowhere. Good teaching for thinking requires teachers to weave content together with relevant contexts, metacognition, disciplinary thinking, and reflection (Hipkins, 2013). Hipkins argues that if teachers do this well, they support students to become investigators, active users of knowledge, and knowledge builders (2013, p. 226). She also acknowledges that many teachers are unlikely to have the time or even the understanding to do this complex 'weaving' well. This complexity can contribute to the 'everywhere and nowhere' nature of thinking if teachers do not have an explicit focus on teaching thinking. While Hipkins has contributed a great deal to the New Zealand literature by articulating and exemplifying pedagogical approaches to teaching thinking, there is room for more work in this area. As I propose later in this chapter, the literature in Philosophy for Children offers both useful definitions and examples of teaching thinking. Before discussing that, I will turn to the discussions and deliberations over various definitions of thinking and critical thinking in the literature. 


\section{Critical thinking as a contested term}

Thinking, particularly critical and creative thinking, is increasingly identified as a central goal of education (Ennis, 1987; Facione, 2015; Fisher, 2003; Harpaz, 2005b; Kuhn, 1992; Lipman, 2003, 2004; Noddings, 2006; Siegel, 2008). Further, thinking plays a central role in all disciplines and in democratic life (Siegel, 2008). However, internationally, there is no single settled definition of critical thinking and a huge range of definitions exist in the literature. Many writers in the field define and advocate for teaching 'thinking' - incorporating critical thinking (Fisher, 2003; Kuhn, 2005; Matthews, 1994) - while others offer more particular definitions related to critical, creative, and reflective thinking (Elder \& Paul, 2013; Goldberg, Kingsbury, \& Bowell, 2013; Splitter \& Sharp, 1995). In the P4C literature, caring and collaborative thinking are added to the list of valued modes of thinking. Harpaz's (2005a) meta-analysis, Approaches to teaching thinking: Toward a conceptual mapping of the field, summarises definitions of thinking in the literature. While this meta-analysis has more elements of 'thinking' than just critical thinking in its scope, Harpaz's classifications can be usefully applied to critical thinking. Harpaz (2005a) proposes that the conceptual diversity of 'thinking' falls into three approaches: skills, dispositions, and understanding. Thinking skills are variously defined as examining and giving reasons for one's thoughts and beliefs, listening to others' ideas, considering others' reasons and arguments, weighing up the reasonability of one's own and others' reasons and arguments (Daniel \& Auriac, 2011; Harpaz, 2014; Lipman, 2003; McPeck, 1991).

Harpaz (2005a) defines a thinking disposition as "a reasoned motivation for a certain thinking pattern" (p. 5). Dispositions relate to internal cognitive traits, such as openmindedness, that are demonstrated through action and behaviour, for example, carefully weighing a range of positions. Costa and Kallick's (2000a, 2000b, 2000c) Habits of the Mind are dispositional because they are internal and attitudinal. Perkins (1995) lists seven thinking dispositions: to be clear, broad, deep, sound, curious, strategic, and aware (pp. 284-285); his language is not about what one does, but how a thinker is. A thinking disposition requires the thinker to be willing to think critically about both abstract, external ideas and the beliefs one holds dearest (Goldberg et al., 
2013; Halpern, 2013). Paul $(1984,1992)$ describes this as 'strong sense critical thinking' - applying the same reasoning and criticality to one's dearest-held beliefs as one applies to abstract, external ideas. This involves constructing one's beliefs by taking into consideration the interests of others and one's own reflections rather than automatically absorbing the beliefs and prejudices around oneself in society (Paul, 1990, 1992). Strong sense critical thinking involves thinkers "questioning and ... developing critical and reflective attitudes toward ideas, behaviours, and life" (Daniel \& Auriac, 2011, p. 419). A thinking disposition is also defined as being willing to change one's thinking if a better argument or reason is offered for an alternative idea or belief (Daniel \& Auriac, 2011; Siegel, 2008; Tishman, Perkins, \& Jay, 1996). This disposition is described by Daniel, Lafortune, Mongeau, Slade, Splitter and de la Garza (2003, 2004, 2005) as intersubjectivity, which I will discuss further in this section.

Many definitions of critical thinking understanding describe disciplinary modes of thinking critically about specific content (Adey \& Shayer, 1993; Broudy, 1977; Harpaz, 2005a; McPeck, 1994; Shaffer, 2006; Sprod, 1998). Harpaz (2014) defines critical thinking understanding as "the ability to locate a concept in a context of other concepts, to implement concepts in new contexts, and to perform thinking processes with knowledge" (p. 52). Understanding involves seeing connections (Dewey, 1910), applying knowledge in a new situation, (Gardner, 1999), and thinking flexibly with one's knowledge (Perkins, 1998). Also described as situated cognition (Brown, Collins, \& Duguid, 1989), or epistemic frames (Shaffer, 2006), critical thinking understanding has to be about something, and the something, or content, influences the type of thinking that may be required (Fisher, 2003; Salomon \& Perkins, 1996). This conception of critical thinking understanding contrasts with the view that critical thinking can be separated from substantive content and taught as a standalone skill (Feuerstein, 1980).

The definition of critical thinking posited by Lipman, who founded Philosophy for Children, encompasses skills, dispositions, and understanding. Lipman (2003) states that "critical thinking is thinking that strives to be impartial, accurate, careful, clear, truthful, abstract, coherent, and practical" (p. 58) (italics his). He also defines a critical thinker as one who produces judgements, is guided by criteria and standards, is 
Intersections of $\mathrm{P}_{4} \mathrm{C}$, critical thinking, and social justice: theory and literature

sensitive to context, and self-corrective $(1984,1988,2003)$. The emphasis on judgements is important, particularly in the New Zealand context in which the majority of teachers conflate constructivism with relativism, as I discussed in Chapter 2. Lipman's statement that critical thinkers must make judgements about ideas requires a realist ontology in order for the strength or weakness of an idea or concept to be judged.

Many thinkers argue that critical thinking looks different according to the context or the discipline; therefore an understanding of disciplinary thinking is crucial to teaching critical thinking (Brown et al., 1989; Elder \& Paul, 2013; Gardner, 2006; Gardner \& Dyson, 1994; Paul \& Elder, 2008; Wheelahan, 2007, 2014). This disciplinary understanding of critical thinking fits within Harpaz's definition of thinking understanding. For example, thinking critically as a scientist involves (among other skills) epistemic thinking, systems thinking, understanding what counts as justification of scientific knowledge, and an awareness of criteria for judging experts (Hipkins, 2013). Thinking critically as an historian, in contrast, requires students to establish historical significance, use primary source evidence, identify continuity and change, analyse cause and consequence, take historical perspectives, and understand the ethical dimension of historical interpretations (Seixas, Morton, Colyer, \& Fornazzari, 2013). As students learn to think critically in one context, they will need to adapt and apply these thinking skills, dispositions, and understandings differently when thinking critically in another context (Brown et al., 1989; Harpaz, 2005a; McPeck, 1990, 1994; Salomon \& Perkins, 1998). Harpaz (2005a) holds that "good thinking depends on substantive understanding and reflective understanding" (p. 8). Teachers who employ methods like split-screen thinking (Claxton, 2007) make explicit for students both what they are learning - the content - and how they are learning - skills, dispositions, and understanding.

In this thesis I draw on and weave together these different conceptions of thinking skills, dispositions, and understanding - as I analyse the data in this study. Of further importance to my definition of critical thinking is Daniel et al.'s $(2003,2004,2005)$ study in Mexican, Australian and Canadian schools that "investigated manifestations of critical thinking in pupils aged 10 to 12 years of age during their group discussions held 
in the context of Philosophy for Children Adapted to Mathematics" (2005, p. 334). Through a grounded theory approach the authors developed a typology that categorised dialogical critical thinking in four modes: logical, creative, responsible, and meta-cognitive $(2004,2005)$. They further identified three epistemological perspectives evident in students' thinking that grew progressively more critical: from egocentric, to relative, to inter-subjective (2004, pp. 298 - 299). Daniel et al. (2007) found that through $\mathrm{P} 4 \mathrm{C}$, children are:

Learning to manage a diversity of opinions for collective enrichment; understanding that uncertainty and ambiguity are a necessary transition toward attaining a significant solution; perceiving the evaluation of acquired knowledge as a fundamental activity; grasping that criticism is a privileged instrument in the evolution of viewpoint and perspectives (p. 352).

As students' thinking transcends egocentrism and relativism, their thinking develops in order to evaluate and understand divergent meanings, and to evaluate and modify perspectives, becoming more intersubjective and therefore more critical. Daniel et al.'s (2005) framework (see Appendix A) offers criteria that can help to distinguish the criticality of students' thinking, and is useful both as a definitional tool for the purposes of this thesis and as a matrix that can be used to chart the development of students' thinking. As is discussed in subsequent chapters, this typology enabled a rich analysis of student dialogue and critical thinking.

\section{Bringing critical thinking into sharper focus in teaching and learning: $\mathrm{P}_{4} \mathrm{C}$}

In this thesis, I focus my examination of critical thinking development specifically within Philosophy for Children (P4C). P4C is an approach developed by Matthew Lipman and Ann Sharp in the USA in the 1970s, centred around a dialogic community of inquiry (CoI) in which children talk, problem-solve and philosophise through discussions usually sparked by a philosophical question raised in a piece of literature (Lipman, 1984, p. 52). Drawing on Dewey's belief that learning comes from reflection on experience (Cam, 2008; Dewey, 1910), Lipman describes how the CoI allows students to bring their own experiences and ideas to the classroom, and to be supported to reflect on and consider these together $(1984,1998 b, 2003)$. Children are encouraged to discuss, explore, play with, and co-construct ideas and positions, based on careful 
listening and clear reasoning. They learn to assess the validity of what they have heard, to develop an argument in support of a position they hold, to take part in rational discussions, and to communicate their views carefully and coherently (Cam, 1995, 2006a; Fisher, 2005; Goering, Shudak, \& Wartenberg, 2013, p. 3). Students are taught to weigh up the reasonability of others' arguments and, if presented with a stronger argument, to be prepared to change their thinking, incorporating the new argument and evidence (Daniel et al., 2005; Fisher, 2005). Regular participation in a P4C CoI gives students frequent exposure to others' points of view and so students "come to view others' perspectives as an invaluable contribution to understanding the complexity of any issue" (Gardner, 1998, p. 1). Lipman (2008) argues that 'educational philosophy' or $\mathrm{P} 4 \mathrm{C}$

[i]s a practical discipline that fosters our thinking in other disciplines. It is philosophy made use of for the purpose of getting students to think effectively in other areas: employing concepts, ideas, judgements and reasoning skills, which have been explicitly borrowed from philosophy in order to facilitate thinking in the subject matter under examination (p. 152).

P4C programmes have been adapted and used around the world, and many countries, including New Zealand, now have P4C organisations that offer resources and support to teachers (Kovach, 2015b; Marples, 2015; Mohr, Lone, \& Wartenberg, 2009).

\section{Which philosophical traditions does $\mathrm{P}_{4} \mathrm{C}$ draw on? How does this shape its implementation?}

$\mathrm{P} 4 \mathrm{C}$ is a form of philosophy that draws on the Socratic method and the philosophical tradition of pragmatism, taking the term 'Community of Inquiry' from Peirce and Dewey (Gregory, 2011; Lipman, 2003; O'Riordan, 2016). The pragmatist tradition involves testing ideas for their consequences and taking up an idea only if it is useful and contributes to social progress (Legg \& Hookaway, 2019). Gregory (2011) describes a conversation with Matthew Lipman in which Lipman defines philosophy as the search for wisdom - a conversation, "going back to Socrates, as a quest to lead qualitatively better lives" (p. 200). Lipman also looked to psychology, to Vygotsky's $(1962,1978)$ social learning theory, which influenced the collaborative nature of the CoI. There has been some critique of the hegemonic nature of the Western knowledge and the 
standpoint of these traditions and the particular conceptions of enquiry that arise from the Western tradition (Biesta, 2011b). This critique has been countered with the claim that the $\mathrm{CoI}$ is a form of social inquiry that seeks diverse perspectives and reinterprets traditions (Gregory, 2011). In addition, many adaptations of the P4C approach have been made in a range of cultures and traditions, using local children's literature (Kohan, 2014; Martens, 1990; Mhlanga \& Shepherd, 2014).

There is a strong body of literature and research evidence underpinning, debating and critiquing Philosophy for Children; many journals have published special issues relating to doing philosophy with children, and in recent years a number of edited books have also been published that chart the development and progression of Philosophy for Children since its inception in the 1970s (Goering et al., 2013; Gregory, Haynes, \& Murris, 2017; Marsal, Dobashi, \& Weber, 2009; Naji \& Rosnani, 2017; Vansieleghem \& Kennedy, 2012). In the sections that follow I explore the debates within the field and begin by outlining four rationales that have been proffered for teaching P4C.

\section{Four rationales for $\mathrm{P}_{4} \mathrm{C}$}

\section{$\mathrm{P}_{4} \mathrm{C}$ builds critical and creative thinking}

Philosophy for Children has been defended as a valuable teaching approach with a range of arguments. The first argument that I explore here concerns the way that P4C builds critical and creative thinking. A strong body of research from countries as diverse as Brazil (Kohan, 2014), England (Williams, 1993), Spain (Colom et al., 2014), Australia (Cam, 1995, 2006a; Fisher, 2005, 2007; Gardner, 1998; Scholl, 2012; Splitter \& Sharp, 1995; Sprod, 1998), Mexico and Canada (Daniel \& Auriac, 2011; Daniel et al., 2005), Hong Kong (Lam, 2013), Scotland (Topping \& Trickey, 2007b, 2014), Iceland (Sigurthorsdottir, 2000), France (UNESCO, 2007), the Philippines (Canuto, 2018), South Africa (Ndofirepi, Wadesango, Machingambi, Maphosa, \& Mutekwe, 2013), New Zealand (Benade, 2011), and the USA (Lipman, 1984, 1988, 1995, 1998b, 2003, 2008), demonstrate that P4C develops critical thinking for students. One of the central arguments across this literature is that because children are themselves philosophising and doing philosophy together through the CoI (rather than being taught about philosophy), they are free to discover, play with, put forward, challenge, and refine their 
own ideas. Fisher (2005) argues that this process enables children to "move from the routine to the reflective, from unconsidered to considered, from everyday thinking to critical thinking" (p. 38). As children learn to question, and through P4C, to refine, deepen, and strengthen their questions, they build critical thinking skills (Scholl, 2005).

A number of studies present compelling evidence that students show improvements in their capacity for perspective-taking after participation in $\mathrm{P} 4 \mathrm{C}$, both for their peers' perspectives and those of members of their broader communities (Burgh et al., 2006; Gardner, 1998). Daniel et al.'s (2003; 2005; 2002, 2004) study saw student thinking develop in four modes: logical, creative, responsible, and meta-cognitive. Over time student thinking became "increasingly complex according to three epistemological perspectives (egocentricity, relativism, and inter-subjectivity oriented toward meaning)" (Daniel et al., 2003, p. 43). Garcia-Moriyon et al.'s (2004) meta-analysis of P4C studies describes a range of studies that indicate that students' critical reasoning skills develop through P4C. Critical and creative thinking are also evidenced through students' metacognitive development (Fisher, 2007).

\section{$\mathrm{P}_{4} \mathrm{C}$ builds collaborative and caring thinking}

A second line of argument in support of P4C is that, because a CoI is driven by dialogue that teases out a range of possibilities relating to a particular topic, students are required to listen to (and take seriously) each other's perspectives and to build on each other's thinking in order to arrive at new understandings, together (Lipman, 2003). Collaborative and caring thinking are therefore intertwined and develop simultaneously through this dialogic process. If students develop caring thinking, this is by nature collaborative because it presupposes an awareness of others and their thoughts, desires and needs; this contrasts with creative and critical thinking, which do not necessarily intrinsically involve collaborative thinking in any essential or necessary way (Cam, 2014a). The development of caring thinking sees students put into practice the ideas that are arrived at through collaborative dialogue - "the capacity to judge, value, and be motivated to act are all of necessity tied to care" (Cam, 2014a, p. 15). Sharp (2004) argues that: 
What we care about is manifest in how we perform, participate, build, contribute and how we relate to others. It is thinking that reveals our ideals as well as what we think is valuable, what we are willing to fight and suffer for (p. 16).

The CoI gives students a context in which to discover and develop the values they care about (Sharp, 2004). More indicators of collaborative and caring thinking are found in the evidence that philosophical inquiry in schools has been found to improve students' social skills and to reduce incidences of playground bullying (Burgh et al., 2006; Millett \& Tapper, 2012; UNESCO, 2007).

The multidimensional nature of critical, creative, collaborative and caring thinking requires reflective thinking, an awareness of the different applications of and contexts that require these different types thinking (Lipman, 2003). Weaving these modes of thinking together is a complex task. In addition, Burgh (2018) argues that:

The capabilities and thinking behaviours acquired from exposure to philosophy are transferrable to other disciplines that inform the learning areas of the curriculum: English, mathematics, science, humanities and social sciences, the arts, technologies, health and physical education, and languages (p. 51).

Because philosophy is the discipline of thinking, sharpening one's thinking skills in philosophy also enhances one's capacity for thinking in other disciplines.

\section{$\mathrm{P}_{4} \mathrm{C}$ builds philosophical thinking: philosophical progress}

P4C has also been defended regarding its value in enabling learners to make philosophical progress (Golding, 2009, 2011b, 2017). Golding (2009) defines philosophical progress as "the movement from philosophical problems to philosophical resolutions" (p. 223). This is not to be misinterpreted as finding simple answers to complex problems. Golding (2009) clarifies that students

know they have made progress not because they have the 'right' answer, but because they have better conceptions that are in greater reflective equilibrium in comparison with the incongruous and inadequate conceptions they started with and in comparison with alternative resolutions (p. 223).

The notion of epistemic philosophical progress has also been described in the literature as self-correcting inquiry (Lipman, 2003), discernible movement and growth (Splitter \& 
Sharp, 1995), seeking truth (Burgh et al., 2006) or making progress towards truth (Gardner, 1995) as the inquiry builds (Burgh et al., 2006).

The process of students listening, considering others' perspectives, refining their ideas and together moving towards a better understanding of the concept they are inquiring into, can also be described as interthinking (Mercer, 2000), much like Vygotsky's (1962; 1978) terms, intermental processes that shape intramental understanding which I discuss further in Chapters 4 and 6. Thinking together through the CoI is a key ingredient in philosophical progress because students can challenge and develop each other's thinking. However, while thinking together is important, it doesn't necessarily result in philosophical progress. The teacher's role as a CoI guide is an important factor, particularly in steering away from a conversation that consists of generic sharing of ideas (Gardner, 1995; Kennedy \& Kennedy, 2011). Golding (2009) uses navigation metaphors like climbing a tree or following a ridge line or river to highlight the importance of following a trajectory together (p. 251). The role of the teacher who enables philosophical progress can be conceived of as an expedition educator (Golding, 2014). Golding (2014) suggests that the expedition educator inquires alongside her students, "enabling students to judge what to do, offering students a choice about the path, advancing the co-created agenda, [asking] 'How can I help my students to make progress in their inquiry, and hence learn to guide themselves?' " (p. 82).

\section{$\mathrm{P}_{4} \mathrm{C}$ builds cognitive ability}

A fourth rationale for $\mathrm{P} 4 \mathrm{C}$ is that it improves cognitive ability. Topping and Trickey's (2007a, 2007b) longitudinal study of the impact of a regular P4C programme on participants' cognitive ability found that children in the lower quartiles of achievement in the pre-test ${ }^{2}$ made the greatest cognitive gains, both in the post-test after 16 months' participation in a weekly hour-long P4C programme, and in follow-up testing two years after that. What's more, the cognitive achievement of those in the control group either was maintained or decreased, both at the end of the 16 month study, and again after two years' gap. This landmark study is cited by many in the P4C literature as a strong

\footnotetext{
${ }^{2}$ All testing used the CAT3, a psychological test of cognitive ability.
} 
defence for the benefits of P4C for all learners. Other studies have affirmed this view. For example, results of a Texan study replicating Topping and Trickey's study reveal a similarly beneficial impact of participation in P4C on students' cognitive achievement (Fair et al., 2015). In another example, Colom et al.'s (2014) preliminary results of their ten year longitudinal study in Madrid suggest that P4C has had a positive impact on students' general cognitive ability, ${ }^{3}$ especially for those in the lower tail of achievement, and on students' pro-social behaviour (p. 55). Similarly, a year-long evaluative study conducted across 48 schools in the United Kingdom found evidence that P4C has a positive impact on student achievement at Key Stage 2 (7-11 year olds), with the greatest impact on the achievement of disadvantaged learners (those eligible for free school meals) (Gorard, Siddiqui, \& Huat See, 2015). However the same study found that analyses of a Cognitive Abilities Test indicated a smaller positive effect, and that "disadvantaged students reaped fewer benefits from P4C than other pupils" (Gorard et al., 2015, p. 33). Explanations for this discrepancy were not found by the evaluators; however, questions about the best ways to measure pupils' progress in P4C were raised. My research builds on these studies to explore further how diverse, priority learners in New Zealand primary schools can develop critical thinking skills.

\section{$\mathrm{P}_{4} \mathrm{C}$ 's contribution to social justice in education}

This thesis is as much concerned with social justice as it is with thinking and in this section I explore four ways in which P4C has been defended in relation to its social justice outcomes.

\section{$\mathrm{P}_{4} \mathrm{C}$ is a form of democratic education}

My conception of social justice in this thesis is that all students deserve epistemic access to powerful knowledge, which can allow students to participate fully in democracy. The $\mathrm{CoI}$ at the heart of P4C is intentionally crafted as a model of education for democracy (Burgh \& Davey, 2004; Cam, 2009; Lipman, 1998a, 2003, 2004): “The community of inquiry is ... an educational tool for the cultivation of democratic character in students

\footnotetext{
${ }^{3}$ This was measured using two standardised cognitive abilities tests: EFAI and IGF.
} 
and the fostering of a sense of community, which are both preconditions for active participation in democratic societies" (Burgh \& Davey, 2004, p. 329).

Philosophy for Children's epistemological heritage owes a great deal to Dewey and his conceptions of democracy. Lipman draws heavily on Dewey's conceptions of learning through inquiry and the intrinsic links between education and democracy (Dewey, 1910, 1916; Lipman, 1998a, 2004; Lipman, Sharp, \& Oscanyan, 1980). Lipman (2003) summarises Dewey's message in his major work in education, Democracy and Education (Dewey, 1916) as "we have got to learn how to teach children to think for themselves if we are to have a democracy worth having. The thinking individual is as important as the inquiring society" (p. 35). A key element of Dewey's (1916) understanding of true democracy was his description of the necessity of mutually interpenetrating interests that are developed and understood through ongoing interaction between as varied and diverse a range of interlocuters as possible. Dewey (1916) describes democracy as "more than a form of government, it is primarily a mode of associated living, of conjoint, communicated experience" (p. 87). Lipman's conceptions relate to education for democracy - creating democratic citizens. Sharp (1991) argues that "the classroom community of inquiry [is] an educational means of furthering the sense of community that is a pre-condition for actively participating in a democratic society ... [by] cultivating skills of dialogue, questioning, reflective inquiry and good judgement" (p. 31). Education for democracy is distinct from democratic education, in which deliberative and participatory democratic structures are essential to the culture and methods of teaching and learning (Burgh et al., 2006; Echeverria \& Hannam, 2013). Burgh \& Yorshansky (2011) clearly describe the difference between these two approaches:

Whereas education for democracy focuses on the acquisition of knowledge and skills as a means to improve the capacity of future citizens to exercise competent autonomy, democratic education recognises the social role of schooling as that of reconstruction and that children and young people have an integral role to play in shaping democracy (p. 439).

Much of the literature on P4C's power for democratic education is focussed on praxis through dialogic participatory education methods, "a process of community formation 
founded on deliberative communications" (Echeverria \& Hannam, 2017, p. 4). When P4C incorporates Dewey's deliberative form of inquiry, which links students' contextual knowledge - their own experience - with the conceptual knowledge under examination, in the context of rigorous communal inquiry that keeps seeking to refine its best explanation of reality until the community no longer holds genuine doubt about the topic under consideration, then it is a form of democratic education (Burgh, 2018). While P4C has been demonstrated to build students' critical thinking, this is by no means its only goal. In fact, to see P4C as solely a thinking skills programme "marginalises the social, ethical, aesthetic, affective and political components that are as integral to the teaching of thinking as the skills themselves" (Splitter \& Sharp, 1995, p. 3). Burgh (2018) proposes instead that "philosophical inquiry is an exemplar of the kind of deliberative inquiry required for informed and active democratic citizenship" (p. 38) and that this is what makes democratic education so important. A study of the impacts of P4C being taught over nine years at Buranda State School in Queensland provides strong evidence of this claim (Burgh et al., 2006). The study describes concrete examples of active citizenship and students effecting change in their own communities in response to needs they have identified. In one example, and as a result of sustained participation in P4C throughout their schooling, students lobbied councillors about dead fish that they had observed in their local creek, resulting in identification of chemical traces in the water and the discovery of possible contamination sites. They presented a petition about this problem to their Member of Parliament and Minister for the Environment, which was then tabled in parliament (Burgh et al., 2006, pp. 202-206). This strong example of active citizenship is one of many linked to the students' improved thinking skills and "willingness to tackle and ability to solve open-ended problems" (Burgh et al., 2006, p. 203).

\section{$\mathrm{P}_{4} \mathrm{C}$ challenges power structures}

Working towards social justice and endeavouring to challenge power structures is not a simple process. Burgh and Yorshansky (2011) suggest that the Col's success is contingent on the teacher's and students' understandings of power and how they "deal with power and the distribution of power as a resource" (p. 450). Equity is related to "access and equitable relations" (Cohen et al., 1999, p. 80) - fair distribution of power as 
a resource - and research has shown that the rate of interaction in the group is a strong indicator of learning gains (Cohen, Lotan, \& Leechor, 1989). Cohen (1984) found that as high-status students interacted more in the group, they learned more from the task; as low-status students interacted less, they in turn learned less. Paradoxically, in cooperative learning designed to promote equity, "unless the teacher intervenes to equalize rates of participation, 'the rich get richer,' and the gap in academic achievement widens." (Cohen et al., 1999, p. 84). Cohen et al.'s (1999) research shows how teachers need to intentionally facilitate discussions and to intervene when necessary in order to ensure fair participation of students. Cohen et al. further emphasise the need for the teacher's active role in order to challenge power structures: Unfortunately, the status order in the classroom is deeply ingrained. While research has shown that a multiple abilities orientation can help to equalize interaction between high- and low-status students ... assigning competence is a public statement that specifically recognizes the intellectual contribution a student has made to the group task. Teachers can assign competence to any student, but it is especially important and effective to focus attention on low-status students (p. 85).

Jackson (2008) describes the need for educators to hold historical and structural perspectives on students' ideas and arguments, arguing that "a structural perspective here enables my appreciating students for who they are in educational settings: humans in need of various sorts of knowledge" (p. 146). Students from different backgrounds bring different "educational advantages and disadvantages" (p. 146) to the classroom; there are many layers of interpretation, power, and inequality present in classrooms and interactions, of which educators and students can be both aware and unaware. She asserts that even setting ground rules for discussions can "benefit the most confident and competent communicators who could say nearly anything they wanted to in any case, but further stifle those who are less flexible and more sensitive to ... the potential negative effects of interpersonal conflict" (p. 146) (or other factors). Jackson's research indicates that it is essential that teachers be aware of the complex factors affecting and influencing power structures in the classroom, to mitigate and dismantle them in order to enact social justice. 


\section{$\mathrm{P}_{4} \mathrm{C}$ promotes participation and inclusion}

The argument that $\mathrm{P} 4 \mathrm{C}$ is a form of democratic education is very closely linked to the proposition that $\mathrm{P} 4 \mathrm{C}$ promotes inclusion and participation which contributes to social justice. Cam (2014b) describes this connection: "Dewey's version of democracy... locates democracy in both the state and society and is concerned with the deliberative process within public communication. Emphasis is not only on participation, but also on the quality of the participation" (p. 29). Studies have demonstrated how P4C helps students to find their voice (Albert, 2018), to recognise the value of their own opinions and experience, and also to be heard and recognised by others - children and adults - as having valuable ideas to contribute (Barrow, 2015; Murris, 2013). A wealth of research indicates that $\mathrm{P} 4 \mathrm{C}$ is a participatory pedagogy that promotes inclusion by students sharing their ideas, and listening to and being heard by others (Anderson et al., 2001; Barrow, 2010; Burgh et al., 2006; Colom et al., 2014; Daniel et al., 2003; Gardner, 1998; Golding, 2009). Because two key elements of the culture of a CoI involve developing caring thinking and not just listening to diverse perspectives, but seeking them out (Burgh \& Davey, 2004), a space is created that is inclusive of epistemic diversity. Anderson (2006) describes the importance of the epistemic diversity of participants in a democracy in order to build meaningful knowledge and understandings: "democratic norms of free discourse, dissent, feedback, and accountability function to ensure collective, experimentally-based learning from the diverse experiences of different knowers" (p. 8).

Fitch and Hulgin's (2008) study, Achieving inclusion through CLAD (Collaborative Learning Assessment through Dialogue), describes the importance of teaching strategies and classroom climates that foster inclusion, using mixed ability groupings that allow students to interact and build on each other's thinking to problem-solve and co-construct their learning: "collaborative learning ... is more commonly aligned with the socio-cultural theories of Vygotsky (1978)... this orientation tends to focus on the co-construction of shared meaning through dialogue and discussion" (p. 425). They emphasise these conditions for meaningful learning:

Learning is social; learning occurs through the course of cognitive conflict; learners are more likely to examine, evaluate, and change their perspectives in the context of 
dialogue that is driven by a group of their peers; and learning is most effective when there is immediate feedback on their work (p. 424).

Feedback can be given by peers in a dialogical setting. Improved outcomes for students related to peer-learning; socio-cognitive conflict was "most likely to occur when children who are working on a problem together are at different cognitive levels" (p. 429). Teachers facilitated "collaborative skills and interaction guidelines for the process ... collaborative skills need to be actively taught and encouraged ... Research shows that the more teachers foster this kind of interaction, the greater the cognitive gains of students" (p. 429). This study adds evidence to the argument that mixed ability groupings support the learning and development of all learners, emphasising the value of inclusion of diverse learners in learning tasks, rather than separating students into ability groupings.

Some studies demonstrate how students learn language structures or "argument strategems" (Anderson et al., 2001) from the teacher and each other through the CoI. Over time, children as young as four years old gain the confidence and capability to use these language structures themselves, thereby strengthening their articulation of their own arguments and perspectives (Daniel \& Gagnon, 2011; Daniel, Pettier, \& AuriacSlusarczyk, 2011). Anderson et al.'s (2001) study observed a snowball effect in students' take up of argument strategems; "once a useful stratagem has been used by a child during a discussion, it tends to spread to other children and occur with increasing frequency" (p. 1). This snowball effect was found to be stronger in open student-led discussions than in "discussions with teacher-controlled participation" (p. 1). These studies reveal the participatory, inclusive benefits of the CoI that enable access for diverse learners to powerful modes of thinking and speaking.

\section{$\mathrm{P}_{4} \mathrm{C}$ shifts teacher beliefs and pedagogy for social justice}

Some research evaluating the impact of $\mathrm{P} 4 \mathrm{C}$ has focussed on the shifts that occur in teachers' beliefs and practice, that is, their pedagogy (Roche, 2011; Scholl, 2012, 2014; Wilkinson et al., 2017; Yeazell, 1981). These studies indicate that teaching P4C develops teachers' knowledge and thinking skills (while this is also happening, in different ways, for the students) and encourages a more critical stance in reflecting on and evaluating 
their teaching. Scholl's (2014) study examined the impact of teaching P4C on pedagogy. The results revealed that teaching $\mathrm{P} 4 \mathrm{C}$

had been instrumental in the transformation of their pedagogy ... to a more

collaborative, democratic and interactive, inter-responsive, inquiry-based approach that found its impetus in student questions (Scholl, 2005); in student (not teacher) voice (p. 93).

Scholl's study provides additional insight into the importance of a collaborative and courageous school culture across teachers and school leaders where pedagogy is shared, as well as the role that:

Students play in pedagogical transformation, the patterns and quality of the interaction between teacher and students, and the importance of reflection to the process of student learning and pedagogical transformation (p. 93).

The pedagogical transformation reported in these studies contributed to social justice because students benefitted as a result of their teachers' improved beliefs and practice.

\section{Critiques of $\mathrm{P}_{4} \mathrm{C}$}

While a considerable body of literature has affirmed the benefits of $\mathrm{P} 4 \mathrm{C}$, the approach has been subject to a number of critiques, largely internally, within the P4C field. Many of these critiques amount to definitional discussions that trouble the edges of P4C. I will discuss these questions and critiques in this section.

\section{Can children do philosophy?}

Piaget (1968) contends, through his influential stage theory of child development, that children are not capable of abstract thought and understanding until they move into the formal operational stage around the age of 11. According to Piaget's theory, it is only once children have reached this stage that they are capable of hypothetical and deductive reasoning. Other educators, such as Kitchener (1990), have subscribed to this theory and argue that children are neither capable of critical and reflective thinking, nor higher order thinking skills. In contrast, this thesis adds to a body of research that demonstrates that children can do philosophy, which involves abstract thought and higher order thinking skills like critical and reflective thinking. There is evidence to show how children are natural philosophers (Singer, 1995). Wartenberg (2009) argues 
that just one conversation with a three year old should convince any doubter of the insatiable curiosity of young children, their love of the question, "why?!" Furthermore, I argue that the kind of critical thinking that children develop through $\mathrm{P} 4 \mathrm{C}$ is an educative right. I have described earlier in this chapter Lipman's argument for children's thinking rights - the right to develop their capacity for thinking in order to reach their potential (2003, p. 204). A UNESCO study of Philosophy for Children (2007) concludes that "the confidence placed in the children's potential for rational thought increases their 'zone of proximal development"' (p. 8). Teachers' high expectations raise students' achievement - this has been demonstrated in many subjects and disciplines (Hattie \& Anderman, 2012; Te Huia, 2015), and growing children's thinking in philosophy is no different.

Nevertheless, White (2012) questions whether young children aged five or six have enough life experience to draw on in philosophical inquiry. He asserts that the simplicity with which children might approach philosophical concepts cannot follow a progression or sequence of complexity towards what he describes as second-order thinking, "i.e. not simply using concepts like pleasure, knowledge, and imagination, but reflecting on interrelations between them and allied ideas, against the background of larger frameworks of ideas" (p. 455). He argues that second-order thinking, as he defines it, emerges from knowledge and experience in other subjects, disciplines, and 'wider frameworks' (p. 455) such as science or religion, which one would only have gained later in life. Murris (2000) counters White's claim by acknowledging that children's thinking and reasoning might not be as complex as adult philosophers' thinking and reasoning, nor would the thinking of novice adult or young adult students of philosophy. However, she argues,

In contrast to non-philosophically trained children and adults, philosophically trained children do have the inclination to think about their own thinking (for example, in metadialogues) in that they think and talk about their ideas and relate them to what other children have said, showing the structure of the dialogue as they speak (pp. 262-263).

Is $\mathrm{P}_{4} \mathrm{C}$ philosophy?

Murris' (2000) contention above suggests that, in just the way that all school subjects are subsets of their respective disciplines (Counsell, 2011; Maton \& Moore, 2010; Young 
\& Muller, 2010), P4C is also an early, embryonic version of Philosophy. This argument leads naturally to another critique of $\mathrm{P} 4 \mathrm{C}$, which can be countered with a very similar argument: is $\mathrm{P} 4 \mathrm{C}$ philosophy?

Figure 4: Question Quadrant

Textual questions

\begin{tabular}{ll|ll} 
Closed & Reading comprehension & Literary speculation & Open \\
questions & Factual knowledge & Philosophical inquiry & questions \\
\multicolumn{2}{c|}{ Intellectual questions }
\end{tabular}

Source: Cam (2006a, p. 34)

A number of scholars in the P4C literature have questioned whether the P in P4C can rightly be recognised as the discipline of philosophy. Wilson (1992) questions whether proponents of $\mathrm{P} 4 \mathrm{C}$ have clear enough definitions of what constitutes philosophical thinking, a philosophical question, and philosophical truth and knowledge. Assuming that these definitions are not clear, he asserts that P4C cannot be regarded as philosophy as a result. This contention notwithstanding, a great deal of work within P4C has focussed on assisting children to understand the nature and purposes of philosophy. Cam's (2003) question quadrant, in Figure 4 above, is one example of a method many teachers of P4C use to differentiate philosophical questions from nonphilosophical ones. While students often see all open questions as philosophical, through the quadrant, Cam differentiates between literary speculation which involves the imagination, and philosophical inquiry which requires reason.

Wilson (1992) further questions whether a CoI, in which students are encouraged to develop philosophical understanding through discovery and co-construction, can actually result in children learning about philosophy. In the same vein, White (2012) contests that because P4C is driven by students' questions, it is not necessarily 
philosophical in nature. Wilson (1992) conjures the risk of "what might be called the romantic or Rousseauesque fantasy: the idea that all or most pupils will, given sufficient encouragement, acquire all the knowledge and abilities they need by the light of nature" (p. 17). This critique is driven by a misunderstanding that a P4C CoI is a free-for-all discussion. Gardner tackles this misconception in her (1995/2015) article, Inquiry is no mere conversation (or discussion or dialogue): Facilitation of inquiry is hard work! in which she discusses the importance of education that is neither solely teacher- nor student-led. She clarifies that a successful CoI "must make progress toward truth" (p. 76) and argues that, while teachers aim to relinquish traditional authority in the CoI, their accompanying responsibilities are "to pounce on a philosophical topic when one emerges ... maintain direction despite frequent digressions (as opposed to letting whatever will be, will be) and ... push for depth in the dialogue" (pp. 81-82). This description of rigour in a philosophical CoI that seeks to make meaningful philosophical progress (Golding, 2009, 2017) is far from the free-ranging, laissez-faire approach that Wilson and White conflate with P4C.

Another criticism outlined by White (2012) asks whether P4C in the Lipman tradition with its concern for developing critical, creative, caring and collaborative thinking - is valuable but not necessarily philosophical. While he agrees with the value of teaching reasoning to students, in a range of subjects, he concludes that "it is various sorts of reasoning rather than philosophising that primary schools should be fostering" (p. 459). Kitchener (1990) also differentiates between thinking critically and thinking philosophically, and questions whether they can be considered to be the same thing (p. 422), suggesting "that critical thinking is necessary but not sufficient for doing philosophy" (p. 423).

Many of these critiques draw out and isolate elements of the P4C approach that have been identified in the literature as benefits of $\mathrm{P} 4 \mathrm{C}$, and describe why each element or collection of elements does not adequately define philosophy. However, when drawn together, the philosophical skills (which include but are not limited to thinking critically, creatively, caringly and collaboratively) combined with the philosophical content of $\mathrm{P} 4 \mathrm{C}$ that are developed through CoIs have been demonstrated to constitute philosophical 
learning for students (Cam, 1995, 2003; Field \& Burgh, 1994; Golding, 2017; Lipman, 2003; Wartenberg, 2009, 2013). Importantly, philosophy can be conceived of as a body of knowledge and as a method of enquiry that involves ongoing questioning (Cam, 2006b, 2018; Kennedy \& Kennedy, 2013; Lipman, 2003; Singer, 1995). Either way, a strong argument can be made for the philosophical nature of P4C whether considering its procedural or substantive content, but the more salient point here is that CoIs involve both dimensions.

\section{Do the dynamics of a Col always serve the goals of democratic education?}

While one of the main espoused aims of Philosophy for Children is to create a form of democratic education, some writers have highlighted that this might not always be the case in practice. Although practitioners optimistically intend to establish a democratic culture that welcomes the viewpoints of diverse students through the CoI, there are always power dynamics at play (Burgh \& Yorshansky, 2011). The creation of a democratic CoI takes effort on the part of the teacher and the students; it is often termed 'deliberative democracy' (Burgh \& Davey, 2004; Burgh et al., 2006). Burgh and Yorshansky (2011) argue that the effectiveness of this deliberative approach is dependent on the awareness of teachers of the "distribution of power among the members of a community of inquiry" (p. 436). Butnor (2012) distinguishes between a culture of intellectual safety - an essential aim of a CoI - and discomfort, which he argues is a key ingredient for intellectual growth of an individual and a community (p. 29). This argument, like the bulk of the critiques addressed in this section, highlights the shades of meaning related to defining and implementing $\mathrm{P} 4 \mathrm{C}$, which are useful for practitioners to be cognisant of as they plan and facilitate P4C.

\section{Is $\mathrm{P}_{4} \mathrm{C}$ best offered as an extension programme for gifted and talented}

\section{learners?}

This chapter has reviewed the literature that indicates that social justice can be promoted through P4C's procedural, substantive skills in building critical thinking for learners. There are also strong claims that teaching critical thinking shows respect to students and builds equity (Lipman, 2003): 
Intersections of $\mathrm{P}_{4} \mathrm{C}$, critical thinking, and social justice: theory and literature

Striving to foster critical thinking in students is essential to treating students with respect as persons... requires that we strive to enable them to think for themselves, competently and well... [and develops] the fundamental ability to determine for themselves... the contours of their own minds and lives (Siegel, 2008, p. 307).

Nevertheless, a prevalent assumption that runs through the $\mathrm{P} 4 \mathrm{C}$ literature is that the approach is best suited to extend the thinking of gifted and talented learners (Betts \& McMaster, 2011; Kovach, 2015a; Millett \& Flanagan, 2007; Winstanley, 2018). This assumption, while not so much a critique of P4C, serves to limit, albeit subtly, the power or potential of a CoI. My research fundamentally questions this assumption by examining how P4C builds critical thinking for all, not just gifted and talented, learners. I develop a hitherto absent critique that recognises the weight of empirical evidence for the power of P4C to develop all students' critical thinking, cognitive achievement, and social and emotional intelligence. I argue that this approach should be offered to all learners because it offers epistemic access to powerful knowledge that benefits all students, arguably especially diverse learners.

This discussion connects to Inclusion, one of the principles of the NZC introduced earlier in this chapter. It is stated that "the curriculum is non-sexist, non-racist, and nondiscriminatory; it ensures that students' identities, languages, abilities, and talents are recognised and affirmed and that their learning needs are addressed" (Ministry of Education, 2007, p. 9). However, discussion in the primary education sector and Ministry of Education guidance about how to achieve inclusion tends to focus solely on students with special learning needs - including gifted and talented students - rather than on diverse learners who experience educational injustices on the basis of gender, ethnicity, and socio-economic backgrounds (Ministry of Education, 2012). Thus, although there is a statement of intention for inclusion, the practicalities of who this extended to, and how it is defined and achieved are unclear. 


\section{The contribution of this research: $\mathrm{P}_{4} \mathrm{C}$ offers learners epistemic access to powerful knowledge and understandings}

Building on the previous discussion about inclusion, my research explores the necessary conditions for supporting diverse learners to develop critical thinking through P4C. Using Hipkins' $(2009,2013,2017)$ work on thinking capabilities and competencies, my research will enable me to refine a definition of critical thinking for New Zealand primary schools, and to offer narratives and observations that further clarify how teachers might go about building critical thinking for all their students. Most centrally, my research explores how priority learners in primary schools can be offered epistemic access to powerful knowledge through P4C. I argue that critical thinking is powerful knowledge: a series of skills, dispositions and understandings that should be taught to all learners, not just to students who arrive at school with the cultural and academic capital that enables them to already demonstrate critical thinking. While the concept of epistemic access is a concern of social realist literature (Wheelahan, 2007, $2009,2014)$, there is a gap in the P4C literature awaiting the articulation of the power of $\mathrm{P} 4 \mathrm{C}$ to offer epistemic access to all learners, and the social justice implications of this. P4C draws together students' contextual knowledge, i.e. their experience, with conceptual knowledge, i.e. philosophical concepts and critical thinking skills. P4C therefore has the potential to offer a practical way to offer epistemic access to diverse learners because they can draw on their own experience, not just contexts that have been predetermined by teachers or a curriculum. Through the CoI, links are made from students' experience to the conceptual knowledge that is under examination. As identified by Scholl (2012), "further research is needed that focuses specifically on the implementation of Philosophy with different socio-cultural groups to provide insights into improving the educational outcomes of disadvantaged groups" (p. 234).

Much of the literature on social justice in education relating to critical thinking and dialogue is focussed more on the content of students' discussions (Biesta, 2012; Burgh \& Davey, 2004; Burgh \& Yorshansky, 2011; Cam, 2009; Jackson, 2008; Lipman, 1998a, 1998b; Weber, 2008) and the power dynamics at play (Arnot \& Reay, 2007; Cohen, 1984; Cohen \& Lotan, 1997; Cohen et al., 1999; De La Garza, 2006) than on outcomes of empowerment, social justice, and equity. In other words, the literature considers social 
justice as a topic and mode of student dialogue, rather than social justice being achieved through students of all abilities and backgrounds gaining access to powerful knowledge (Barrow, 2010). In light of this, my research focuses on how social justice could be enhanced through the procedural dimensions of $\mathrm{P} 4 \mathrm{C}$, rather than through dialogue about social justice issues. Lipman (2003) aptly describes the right that all children have to develop their thinking capability, a right to epistemic access:

Children have a right to the development of their thinking capabilities ... children [should] be seen as having thinking rights ... rights not just to acceptable reading and writing skills, but rights to standards that go beyond mere acceptability: to reasonableness, judiciousness, imaginativeness, and appreciativeness ... children do have a right to perform up to these higher standards, so that they can bring their potentials into closer connection with the requirements of modern communal life ( $p$. 204).

My research explores how, as a matter of social justice, students' thinking rights might be met. 


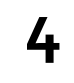

\section{Methodology}

The aim of this research, to explore what happens for diverse learners and their critical thinking skills when they participate in regular P4C communities of inquiry in classrooms, pointed towards a multimodal temporal case study approach that allowed ongoing observation, open-ended perspectives, and “thick descriptions” (Geertz, 1973) to be collected. Rather than using formal, 'moment in time' assessment data, I chose to observe students' dialogue in practice, through classroom dialogues that were part of a six month-long intervention: a weekly P4C CoI. My focus in this chapter is to describe and explain the research strategies I chose to employ in this study.

After reiterating my research questions, I describe the social realist framework which underpins my approach to knowledge production in this research, and how this connects to social constructivist, and sociocultural understandings and approaches. Then I outline the qualitative research design through which I aimed to examine and understand real classroom dialogue, "naturally situated cognition" (Hutchins, 1996) in context, using sociocultural discourse analysis methods (Mercer, 2004, 2010; Mercer \& Howe, 2012) and thematic analysis (Braun \& Clarke, 2012; Guest, MacQueen, \& Namey, 2011) to interpret the data. I explain my decision to report on student participants' experiences through vignettes. Then I give an overview of the four school contexts and participant teachers and classes, and the structure of the P4C programme in each. Because ethical decisions "permeate every phase of the research process" (Denzin \& Lincoln, 2003, p. 30), I describe the measures I have taken to ensure the ethical care of participants and their data. I finish the chapter with some discussion of the credibility and limitations of this research study. 


\section{Research questions}

As stated in my introduction, it is important for schools and policy-makers to take seriously their goal to prioritise priority learners' development and to keep working towards an equitable education system. My research aims to contribute to this by offering:

- an understanding of how P4C can contribute to social justice by developing powerful knowledge for diverse learners;

- a clearer definition of critical thinking in the NZC - what it is, how to measure it, what counts as meaningful evidence of its growth, and an understanding of how qualitative assessment methods can offer rich data to measure this complex process; and

- some strategies for teaching critical thinking to diverse learners through P4C in primary schools.

My key research questions are:

1. How can Philosophy for Children develop critical thinking dispositions and capabilities for all, including diverse, learners?

2. How does P4C help us to understand what powerful knowledge might look like in practice in NZ primary schools?

3. How can P4C expand our conception of theories of powerful knowledge?

One of the key drivers of these questions was my observation that, of the New Zealand schools that teach Philosophy for Children, many saw it as an extension programme suited to gifted and talented learners. However, my experience as a classroom teacher facilitating CoIs with my whole class indicated that P4C is a valuable learning context for all learners, and that learners who needed support to achieve at school thrived in P4C dialogue in ways I had not anticipated. This seemingly counterintuitive hunch that "questions taken-for-granted assumptions, [and] challenges well-accepted ideas" (Tracy, 2010, p. 840) makes the topic of this research worthy in that the research questions are relevant, significant, and interesting (Tracy, 2010). In the next section I will explain why these questions best fit a qualitative research design that seeks to gain 
"access to the nitty-gritty reality of everyday life viewed through a new analytic lens" (Silverman, 2013, p. 235).

\section{Researching the socially constructed nature of knowledge}

In addition to social realism, described in Chapter 2, other intersecting approaches and understandings of knowledge and reality have influenced my research methodology most centrally, theories about the socially constructed nature of knowledge and sociocultural theory. In drawing on a range of theoretical positions and ways to make meaning, I operated as a bricoleur, making use of the tools available to complete the research task (Kincheloe, McLaren, Steinberg, \& Monzó, 2018; Levi-Strauss, 1966).

Drawing on Vygotsky's work, a social constructivist understanding of learning suggests that all higher cognitive functions originate in social interaction, the intermental, and are then internalised to the intramental level. This concept of external interaction becoming absorbed in and shaping internal thought goes back at least as far as Socrates who, in the Theatetus, described thinking as a discourse the mind carries on with itself (Plato, 1961). Knowledge is understood to be actively constructed by learners as they interact with their environment through language and culture (Vygotsky, 1962, 1978; Wertsch, 1985). At its extreme, there are those who take constructivism to mean that the reliability of all knowledge and ethical claims are undermined, but this position therefore undermines its own knowledge and ethical claims (Elder-Vass, 2012). Instead, Elder-Vass (2012) argues for the value and coherence of a realist approach to constructing knowledge. This, I propose, is consistent with a social realist understanding of knowledge in that social realist and social constructivist positions share a number of assumptions about knowledge and reality. As I outlined in Chapter 2, a social realist understanding of knowledge is underpinned by a realist ontology and an interpretive epistemology. An interpretive epistemological stance together with a realist ontology is also consistent with social constructivism. Both theoretical positions recognise that knowledge is social and constructed - rather than fixed - and at the same time both positions strive towards understanding reality. 
I draw on elements of both of these approaches in this research in order to understand how the participants in this research construct meaning and knowledge. Social constructionism and constructivism are used both distinctly and interchangeably in the literature. A social constructionist approach to knowledge holds that our understandings of the world are co-constructed with others' understandings, through shared language, and involve an ongoing reification of these constructs. This process is sometimes described as distributed cognition. The situated and contingent nature of humans' accounts of reality are emphasised and explored. Humans are regarded as complex and messy with identities that shift and grow:

'Identity' is never a fixed entity lying somewhere inside people's heads. We present different aspects of ourselves in different contexts. So, rather than eliminate multiple voices, we need to examine what voices people use, how they use them and with what consequences ... interview participants actively create meaning (Silverman, 2013, p. 240).

By gathering data over time through observation, transcribed classroom discussions, students' thinking journals, and in focus group interviews, I sought to build up a layered understanding of participants, their experiences and their thinking. The data collection methods allowed me insight into participants' action, dialogue, and their subsequent reflections on their thinking during the dialogue. At times these different threads of the narrative clash with each other, as a fuller picture of the participants emerges. As Holstein and Gubrium (1995) propose in relation to research interviews:

Construed as active, the subject behind the respondent not only holds facts and details of experiences, but, in the very process of offering them up for response, constructively adds to, takes away from, and transforms the facts and details. The respondent can hardly 'spoil' what he or she is, in effect, subjectively creating (p. 117).

As a researcher, I share the "critical stance toward taken-for-granted knowledge" (Burr, 2015, p. 2) that is advocated by social constructionists within psychology, and am "eversuspicious of [my] assumptions about how the world appears to be" (p. 3). I recognise that, as a female Pākehā who is an experienced primary school and P4C teacher, I possess professional, cultural and/or gender similarities with the participant teachers and the majority of primary school teachers. This enabled me to form good relationships with the teachers and students in the study but I recognise that this 
familiarity could render certain potentially pertinent observations opaque to me. At the suggestion of one of my supervisors, I aimed to seek out that which was new, surprising, or contradictory in order to challenge my interpretations, biases and assumptions about what I might discover through this research.

\section{Sociocultural approaches to research}

I use sociocultural theory and its language to analyse the interaction, dialogue and thinking among my participants. Many of the constructs of sociocultural theory such as dialogic interaction, exploratory talk, and interthinking (Mercer \& Hodgkinson, 2008; Mercer et al., 2015) aptly describe the processes that occur in Philosophy for Children's CoIs. Sociocultural researchers examine how thinking, communication, and learning are shaped by culture and social interaction. They emphasise the importance of semiotic mediation for mental functioning, and the ways that dialogic interaction develops higher mental functions (Barnes, 2008; Daniels, 2001; Fisher, 2007; Hennessy, Mercer, \& Warwick, 2011; Howe \& Abedin, 2013; Mahn, 1999; Mercer, 2004; Mercer \& Hodgkinson, 2008; Mercer et al., 2015; Rogoff, Baker-Sennett, Lacasa, \& Goldsmith, 1995; Wells \& Claxton, 2002). Scholars who use sociocultural theory consider the connections between language and thought and between the social and psychological or as Vygotsky described it, the intermental and the intramental - processes that influence learning and thinking (Vygotsky, 1978). I draw on this Vygotskian understanding of how language acquisition and use and its internalisation transforms children's thinking (Mercer \& Howe, 2012) and builds children's social development and concept formation (Mahn, 1999; Wells, 1999) in my data analysis.

Sociocultural theoretical perspectives have developed from both Bernstein's and Vygotsky's work, and align closely with a social realist framework which has a similar theoretical genealogy. In addition, social constructivist and sociocultural approaches are very closely linked. Sociocultural theorists hold that the context influences both what is learned and how it is learned. From this perspective, researchers view knowledge as "not just an individual possession but also the creation and shared property of members of communities, who use 'cultural tools' (including spoken and written language), relationships and institutions (such as schools) for that purpose" (Mercer \& Howe, 
2012, p. 12). As well as exploring individuals' talk, and what it might indicate about their thinking, a sociocultural analysis examines dialogic thinking amongst groups of people, and how thinking together (Mercer et al., 2015) can develop students' learning, thinking, and understanding. Researchers explore questions like "how does dialogue promote learning and the development of understanding? What types of talk are associated with the best learning outcomes? Does collaborative activity help children to learn, or assist their conceptual development?" (Mercer, 2010, p. 2). This understanding of collaborative talk and thinking informed my research design both in terms of data gathering methods (recordings of classroom discussions, focus group interviews with sample students, and individual thinking journals) and the levels of data analysis, namely examining individual students' speech and communicative events in which multiple speakers think together (Hennessy \& Rojas-Drummond, 2015; Hennessy et al., 2016b). Mercer (2010) neatly summarises the focuses of sociocultural researchers, stating that they:

Typically emphasize that knowledge and understanding are jointly created, that talk allows reciprocity and mutuality to be developed through the continuing negotiation of meaning, and that education depends upon the creation and maintenance of intersubjectivity or 'common knowledge'. An implication often drawn is that teachers need to guide and scaffold learning, balancing the control of dialogue between teachers and students (pp. 2-3).

\section{How can we measure critical thinking?}

As a form of interaction, dialogue and thinking, and as was discussed in the previous chapter, critical thinking involves complex and internal processes. People think critically in different ways in different contexts. People's thinking can be contradictory and provisional, particularly in relation to understanding and describing their own capacity for critical thinking (Goldberg et al., 2013). This means that it is difficult to quantify and to measure critical thinking using standardised tests (Facione, 1990; Kennedy et al., 1990; Sternberg, 1986). While quantitative tests of critical thinking can offer some insight into people's critical thinking in some contexts, the results can be limited and do not have strong consequential validity or reliability (Ennis, 2013; Goldberg, 2011; Goldberg et al., 2013; Harpaz, 2005a, 2014) - outcomes that are usually argued to be a strength of quantitative research. Qualitative approaches that 
incorporate conversations, interviews, and transcript analysis by nature deal with smaller samples, which can restrict the generalisability, consequential validity or reliability of the findings. However, they can offer richer, more specific insights into how critical thinking develops than quantitative measures (Creswell, 2003, 2014; Denzin \& Lincoln, 2009; Goldberg et al., 2013). The multi-layered nature of critical thinking requires this depth of analysis in order to do justice to understanding how it can develop in primary school students.

There is a strong justification in the literature for the value of performances of understanding - opportunities for students to demonstrate their understanding in practice, often by applying understanding in new contexts - in measuring students' thinking (Harpaz, 2005a, 2014; Perkins, 1998; Wiggins \& McTighe, 2005; Wiske, 1998; Wiske, Sick, \& Wirsig, 2001). Examples include a mock trial, documentary film, exhibition, debate, dramatic performance, and presentation (Harpaz, 2014). Perkins, Tishman, Ritchhart, Donis, and Andrade (2000) describe performances of understanding as 'intelligence in the wild' - students having the opportunity to demonstrate a series of complex skills, dispositions and understandings in a real life context rather than in artificial contexts such as test conditions. Through a performance of understanding, students can express knowledge, analyse, synthesise and apply knowledge, and criticise and create knowledge. Teachers' (and researchers') assessment of student thinking involves observation and identifying student action that demonstrates critical thinking, and weaving this together with understandings of the demands of the task - complex assessment for a complex internal process (Boud, 2000; Harpaz, 2014). In this study I conceived of children's classroom interactions and dialogue as performances that demonstrated elements of their critical thinking dispositions and understanding in action in the classroom. My study builds on and contributes to conceptions of performances of understanding and their value as a form of complex, sustainable assessment (Boud, 2000). Classroom dialogue in the form of a philosophical CoI was an ideal natural context in which the participant teachers and I could observe and analyse students' performances of understanding in order to observe, measure and assess the development of students' thinking, in the wild. 


\section{Qualitative research in schools}

Qualitative research involves the researcher finding "the extraordinary features of ordinary life" (Silverman, 2013, p. 7). My interest in exploring classroom interactions, in context, meant that a qualitative approach to gathering and analysing the data was the best fit for my questions because I sought to understand the characteristics of teaching and learning that develop critical thinking for diverse learners. I chose to work with naturally occurring data (classroom discussions) that allowed me to form thick descriptions (Marsh, O'Toole, \& Jones, 2007; Rubin \& Rubin, 1995) of the teaching and learning processes at play. As I described in Chapter 2, naturally occurring classroom dialogue is an open system of the kind that critical realists value in order to understand the world. Because of my interest in "the authenticity of human experience" (Silverman, 2013, p. 6), I sought to use sustainable assessment methods (Boud, 2000) that allowed me to observe learning and cognition in the wild (Hutchins, 1996; Perkins et al., 2000).

The trustworthiness of qualitative research is demonstrated through the dependability or consistency of the results obtained from the data (Lincoln \& Guba, 1985).

Understandings of qualitative rigour and trustworthiness have grown in the literature over the years, building on Lincoln and Guba's (1985) techniques for establishing trustworthiness (Morse, 2018). I found Tracy's (2010) criteria for excellent qualitative research very useful in evaluating the quality of my research practices and methods: worthy topic, rich rigour, sincerity, credibility, resonance, significant contribution, and ethical and meaningful coherence (p. 840) (see Figure 5 below). I refer to these criteria throughout this chapter as I describe the methods I chose to use in order to offer trustworthy interpretations of, and conclusions from, the data. 


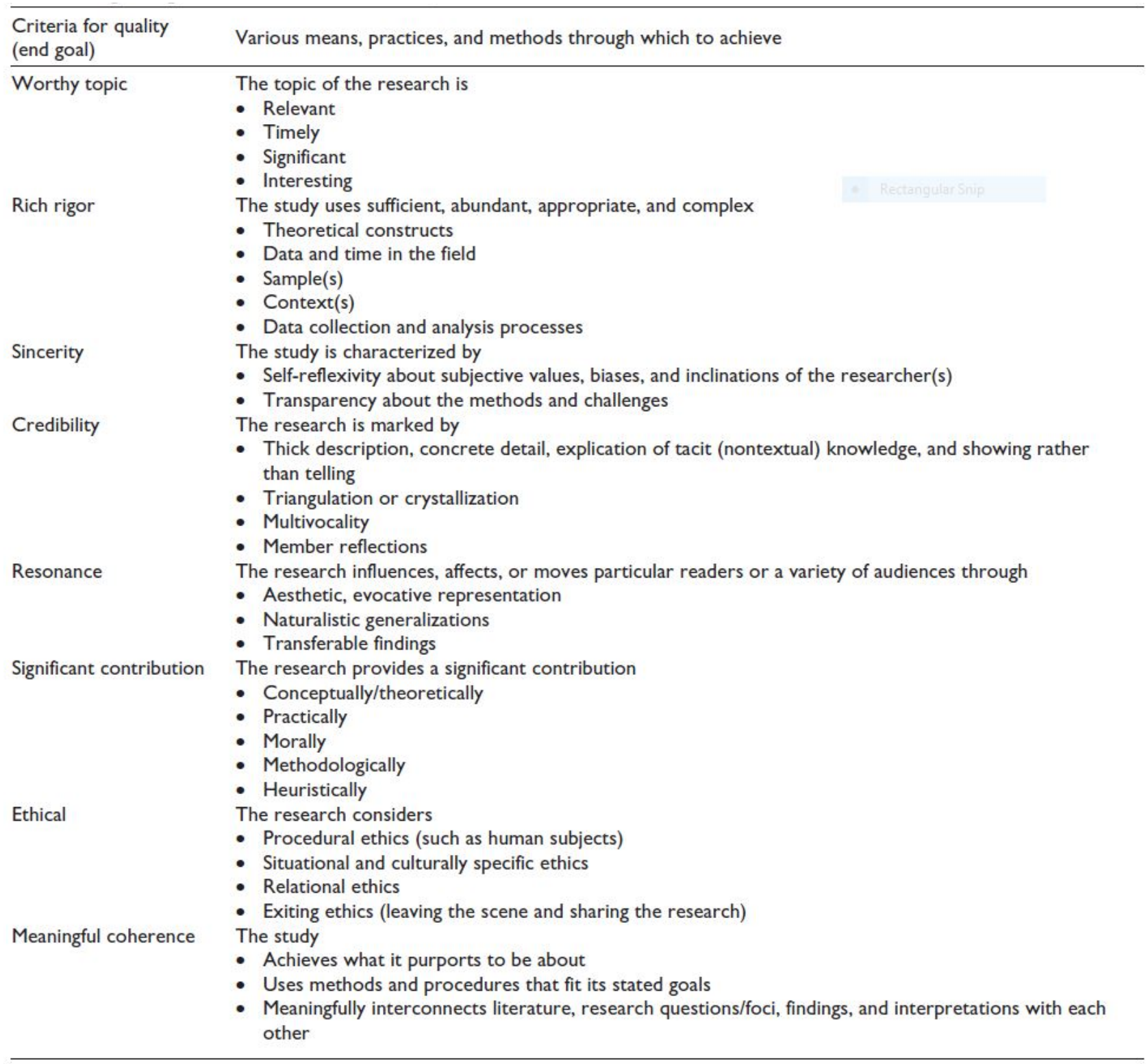

Source: (Tracy, 2010, p. 840)

\section{Research design}

A multiple-site case study

A multiple-site case study allows the researcher to identify both unique and common features within and across sites (Wood, 2011; Yazan, 2015). By comparing and contrasting the experiences of teachers and students at different schools, I could 
explore the ways that conceptions of, and potential for, teaching and learning could vary across contexts (McLeod \& Yates, 2006).

I set out to achieve an understanding of a range of teachers' and children's teaching and learning processes in classrooms through purposive sampling. I sought schools from diverse socio-economic backgrounds, using the Ministry of Education's decile rating system as an indicator of socio-economic status. Schools are given a rating from 1 for a low socio-economic community to 10 for a high socio-economic community. This rating is calculated using census data about household income, parental occupation and qualifications, income support and household crowding. I drew my sample from four schools, of a range of deciles, in the Wellington region. Within each school my aim was to ensure diversity within my focus groups of sample students across three variables: student gender, ethnicity, and ability. Teachers chose five to six sample students in each class to represent a range of those variables. Pseudonyms have been used for all participants and schools.

\section{Gaining informed consent within schools}

After having received ethics approval for this research from the Victoria University of Wellington Ethics Committee (approval number: 22057), I embarked on finding participants. Because Philosophy for Children is only taught in a small number of schools in New Zealand, I drew on both the P4CNZ network and teaching networks in order to approach teachers who either had experience in teaching P4C or were interested in training to teach $\mathrm{P} 4 \mathrm{C}$ so they could participate in the project. In order to create a sample from a range of deciles, I also approached two principals from lower decile schools and asked them if any teachers in their school might be interested in participating. I wanted to work with students who were of a similar age (8-10) so this further narrowed the scope of possible teachers who might be interested in participating. While both of the principals were interested in the study, the teachers of that age group chose not to participate. Four of the six teachers I approached were interested in taking part in the research. I sent letters to these teachers (see Appendix D) providing information about the project and seeking consent to participate. I also met with the principal of each participating school to discuss the research and to seek 
their permission to conduct research in their schools (see Appendix C). When meeting with the principal I offered to run an information session for parents interested in finding out more about the research. Also, to honour the tangata whenua ${ }^{4}$ status of Māori and in order to consider contextual and culturally-specific ethical considerations (Tracy, 2010), I asked principals if their school had a Whānau Group with whom I could consult. School D invited me to their Whānau Group hui which I visited to discuss my research and to gain their perspectives on my research design. They expressed interest in the research and did not have any suggestions for changes to my research design. None of the principals saw the need for me to run an information session for parents in addition to the information I provided in the parent information letters, which I describe next.

The next step involved sending letters (see Appendix E) to all of the parents in the participant classes seeking consent for their children to participate in the research. Parents of focus group students received a different letter (see Appendix F) that detailed the part focus group students would play in the research. The parent information letters emphasised that their children could withdraw from the research any at stage prior to the completion of the data analysis. Finally, the students themselves were asked for their assent to participate in the research. Because the ethical guidelines of Victoria University of Wellington stipulate that participants under the age of 16 require parental consent to take part in any research, children cannot give consent; however I wanted to respect their right to make choices about their participation so I sought their assent through a student letter (see Appendix G) which explained the research and encouraged the students to discuss the research project with their parents and teacher before deciding whether or not they would like to participate. Focus group students received a different letter (see Appendix $H$ ) that detailed the part they would play in the research. The class teachers collected the parent consent and student assent forms in a box I provided; every child who was invited to participate gained parental consent and gave their assent to take part in the research.

\footnotetext{
${ }^{4}$ Indigenous - directly translated as people of the land.
} 
Parents were offered the opportunity to provide their email address if they would like to receive a summary of the findings and any other publications from the research in the future but none of the parents took up this option.

I present a summary of selected schools and participants later in this chapter in the case study contexts section.

\section{Data sources and collection}

The data I drew on for this study was multi-modal and came from four main sources: recordings of classroom dialogues, interviews with teachers, focus group interviews, and focus group students' thinking journals. In order to undertake a temporal analysis (Mercer, 2008) of the development of student thinking, I gathered data from the different sources at different stages through the project, as outlined in Figure 6. Data collection in schools occurred between August and December in 2015.

Figure 6: Timing of data collection from different sources

\begin{tabular}{|l|l|l|l|}
\hline \multirow{2}{*}{ Data source } & \multicolumn{2}{|l|}{ Timing of data collection } \\
\cline { 2 - 4 } & $\begin{array}{l}\text { Beginning of } \\
\text { study }\end{array}$ & Middle of study & End of study \\
\hline Classroom dialogues & $1^{\text {st }}$ recordings & $2^{\text {nd }}$ recordings & $3^{\text {rd }}$ recordings \\
\hline Teacher interviews & $1^{\text {st }}$ recordings & & $2^{\text {nd }}$ recordings \\
\hline Focus group interviews & $1^{\text {st }}$ recordings & & $2^{\text {nd }}$ recordings \\
\hline $\begin{array}{l}\text { Focus group students' } \\
\text { thinking journals }\end{array}$ & Students wrote/drew their ideas & $\begin{array}{l}\text { Researcher made } \\
\text { copies of these }\end{array}$ \\
\hline
\end{tabular}

\section{Classroom dialogues}

As discussed earlier in this section, the whole-class CoI dialogues constituted performances of understanding (Harpaz, 2014; Wiggins \& McTighe, 2005; Wiske et al., 2001) that I recorded, transcribed, and analysed in order to examine the development of student thinking through the study. This data source offered a window into everyday classroom interactions, cognition in the wild (Perkins et al., 2000), that allowed me to 
examine what happens in practice in primary school students' philosophical dialogic interaction.

\section{Thinking journals}

Any research with children involves a power imbalance in the research encounter. While I aimed to gather classroom dialogue that was as naturally occurring as possible, this doesn't entirely remove the adult-centred power that exists in research (Barker \& Smith, 2001) and in schools. As well as acknowledging this power positionality, I utilised student thinking journals as a form of participatory research practice, seeking to actively involve "research participants in the construction of data" (Gallagher, 2009, p. 138).

Understanding is an internal process, therefore any attempt to research and evaluate student understanding involves a degree of intuition. I wanted to draw on a range of data sources in order to illuminate as much as possible the guesswork involved in my understanding of student thinking and understanding. Carr's (2001) and Lee and Carr's (2012) research on narrative assessment and learning stories influenced my decision to incorporate student thinking journals as another data source in this study. The thinking journals served a number of purposes. Teachers used them during classroom dialogues as a way to encourage children to document their thinking. Often teachers would encourage students to draw a Venn diagram or a table in order to brainstorm lists of categories in order to draw distinctions when defining concepts pertinent to the discussion. Teachers encouraged students to reflect on both the content and the process of the dialogue at the end of a CoI. Also, students were encouraged to draw or jot down their thoughts both during and after philosophical discussions. Carr (2008) contends that "stories can be a valuable unit of analysis for the understanding of learning, especially when the definition of learning includes dispositions" (p. 10). The students used thinking journals to document their thinking through the project, and I read and analysed the thinking journals of the focus group student participants. The thinking journals offered another window into student thinking that allowed me to add further layers of understanding to the learning stories or vignettes (which I discuss later in this chapter) that I created about sample students. 


\section{Focus group discussions}

In order to gain further insight into students' internal thought processes, I recorded focus group discussions in the form of semi-structured interviews with the sample students in each school. I asked reflective questions about their speaking and thinking processes. The reflective metacognitive talk about talk that these discussions provoked was an invaluable data source that deepened my understandings of the development of student thinking. Although I prepared some questions for these discussions, I also invited the students to ask questions of themselves and each other about P4C and their experience of it. These discussions gave the students the opportunity to offer their own analysis of the impact of P4C on their thinking. I sought to hear the students' voices and to share the power of analysis and evaluation of the study with them (Barker \& Smith, 2001). This was a deliberate attempt to use code talk (Arnot \& Reay, 2007) which gives students the opportunity to discuss the rules that govern their learning and the degree of enhancement, inclusion and participation (Bernstein, 2000) they experienced. In the student focus group interviews my position of power - as both an adult researcher and a teacher - is a factor that I took into consideration in my analysis of the students' responses. I questioned how much students were giving me the answers they thought I wanted to hear, or that would be sanctioned in their school context, rather than truly honest responses.

\section{Teacher interviews}

The aim of the teacher interviews was very similar to that of the focus group discussions: I hoped to gain further insight into the teachers' thinking, pedagogical frameworks and decision-making as well as to hear their thoughts and analysis of their students' development through and experience of P4C. In trying to avoid directive or closed questions or interpretations I adopted "a stance of 'talking back' to the interviewee" (Griffin, 1990; Taylor \& Ussher, 2001, p. 296); our interviews were conversational. The reflective nature of the post-intervention teacher interviews gave me useful insight into teachers' thinking, dispositions, and beliefs. Many of the teachers also offered suggestions and ideas they were hoping to try in future. 


\section{Limitations}

The nature of real world classroom research means that various factors can affect the data collection and thus its reliability. One such challenge was presented by the third CoI recording at School C. The teacher, Jono, had planned a reflection lesson that encouraged students to create skits to demonstrate the skills they had learned and developed through P4C. The affordance of this lesson was that it allowed me to observe teacher innovation and personalisation in action, and I discuss the value of this student reflection in Chapter 5. However because this lesson didn't take the form of a standard CoI, it didn't generate the same kind of philosophical language as the first two recordings I had made at School $\mathrm{C}$ which skewed the data I generated from coding and analysing student utterances. I therefore drew on another data source, the teacher and student reflections in their post-intervention interviews, in order to understand the kinds of language growth that had occurred for this group of students across the study. The post-intervention interviews were very useful in allowing me to more broadly understand the development of student critical dialogue and thinking through the reports of students and teachers since a lot of that growth occurred during CoIs that I hadn't recorded. Ideally I would have been able to record and analyse every single CoI throughout the project however that would have resulted in a mountain of data too great for the scope of a $\mathrm{PhD}$ research study.

As well as building a layered and complex picture of participants' experiences, the range of data sources I drew on in this study allowed me to triangulate the patterns and themes I drew from the data. This contributed to the rigour and credibility of my research because, as Bloor (2001) states, "findings may be judged valid when different and contrasting methods of data collection yield identical findings on the same research subjects; a case of replication within the same setting" (p. 384).

\section{Data analysis}

I used two analytic approaches, deductive and inductive thematic analysis, for different data sources and in order to establish trustworthiness and credibility so that I could generalise from my analysis (Guba \& Lincoln, 1994; Morse, 2018; Silverman, 2013). Through familiarisation with the data; coding; generating, reviewing, defining and 
naming themes, thematic analysis enables the researcher to identify patterns of meaning in the data in order to find answers to one's research questions (Braun \& Clarke, 2019). In this section I describe how and why I utilised these forms of analysis.

\section{Deductive thematic analysis}

After transcribing the recordings of classroom dialogues, I used one main deductive analysis system to code and analyse the classroom dialogue data: Hennessy and RojasDrummond's (2015) and Hennessy et al.'s (2016b) Scheme for Educational Dialogue Analysis. I wanted to draw on and learn from the knowledge and expertise that more experienced researchers had developed and to apply this to my own data in order to make my analysis as robust as possible. In addition, Daniel et al.'s (2005) matrix of the Development of the Dialogical Critical Thinking Process-Content and Form (see Appendix A) informed my analysis of the types of thought and epistemological perspectives the students demonstrated.

Hennessy and Rojas-Drummond's (2015) and Hennessy et al.'s (2016b) Scheme for Educational Dialogue Analysis (SEDA) is a coding scheme and analytic framework for systematically analysing classroom dialogue for application across a range of educational settings. The framework attempts to make sense of the form and function of "peer and pupil-teacher dialogic interactions in the classroom" (Hennessy et al., 2016b, p. 17). The scheme was developed through a deductive-inductive process undertaken by "multiple, experienced academics in the field with different cultural and research backgrounds [which was] brought into inter-relation, and... woven into an integrated framework" (p. 20). In refining the scheme, the team of researchers tested the SEDA using recordings from classroom settings in the United Kingdom and Mexico across various age ranges and in different dialogic contexts such as whole class, small groups or pairs. Drawing on sociocultural theory and citing Dewey as an influence, Hennessy et al.'s (2016a) emphases are consistent with the processes and aims of the P4C CoI; they focus on:

The forms of educational dialogue that seem to be productive for learning ... attunement to others' perspectives and continuous co-construction of knowledge through sharing, critiquing and gradually reconciling contrasting ideas ... these forms of dialogue are 
cumulative over time ... Furthermore, productive dialogue is intelligible both as a pedagogical tool for constructing subject knowledge, and as a valued process in itself linked to increasingly prevalent purposes concerned with critical thinking, making relevant links between and within subject disciplines, active and democratic citizenship and living peacefully (pp. 1-2).

Hennessy et al. (2011) analyse dialogic teaching and learning from a sociocultural theoretical perspective, which emphasises "the intrinsically social and communicative nature of human life" (p. 3). A sociocultural perspective highlights the key role that language plays as "a tool for thinking” (Hennessy et al., 2011, p. 17; Mercer, 2000; Vygotsky, 1962, 1978) and "posits that education and cognitive development are cultural processes enacted through interactions with others" (Hennessy et al., 2016b, p. 17; Howe \& Abedin, 2013) that allow learners to co-construct knowledge and meanings and develop intersubjectivity. This approach is very consistent with the goals of both $\mathrm{P} 4 \mathrm{C}$ and the social realist theoretical perspective I am using in this research, so it was a useful tool to use to support my analysis.

The SEDA is made up of 33 codes that have been clustered into 8 groups:

I Invite elaboration or reasoning

E Express or invite ideas

$\mathrm{R} \quad$ Make reasoning explicit

B Build on ideas

P Positioning and coordinating

C Connect

RD Reflect on dialogue or activity

G Guide direction of dialogue or activity

The full scheme can be found in Appendix B. I coded all of the classroom dialogue transcriptions using the SEDA scheme. At times multiple codes were assigned to statements when a number of purposes were served by the one statement. Coding the transcripts using the SEDA helped me to identify the kinds of statements that indicated critical thinking. Alongside this framework, I used Daniel et al.'s (2005) framework for the Dialogical Critical Thinking Process (see Appendix A) to guide my analysis of the critical thinking that different kinds of statements could indicate. As denoted in their 
dialogical critical thinking framework, Daniel et al. (2005) contend that cognitively, dialogical critical thinking involves four thinking modes: logical, creative, responsible and metacognitive, and that epistemologically, "dialogical critical thinking is only manifested in a context where egocentricity of perspective and relativism of beliefs are transcended" (p. 334). They identify this critical thinking epistemological stance as inter-subjectivity. I used this matrix to support my analysis of the language I observed students using in dialogue and the kinds of thinking the language indicated.

As I became more familiar with the SEDA codes and my data I recognised that a number of the code categories indicate inter-subjectivity: Positioning and coordinating codes such as Synthesise ideas, Compare/Evaluate alternative views, Acknowledge shift in position; and Make reasoning explicit codes such as Explain or justify own contribution, Speculate or predict on the basis of another's contribution, and Speculate and Predict. Others are suggestive of relativism or the beginnings of inter-subjectivity: Build on ideas codes such as Build on/ explain/ clarify others' contributions and Clarify/ elaborate own contribution; and Invite elaboration or reasoning codes such as Ask for explanation or justification, Invite possibility thinking or prediction, and Ask for elaboration or clarification. Without being aware of this list of codes, students recognised and identified, in their reflections and post-intervention focus group interviews, that statements of these kinds indicate philosophical thought. Once I had coded all of the transcripts I was able to identify patterns within and across the different participant classes, which I discuss in Chapter 6. Figure 7 below gives examples of the kinds of statements that were coded for these codes that indicated critical, philosophical thought. 
Figure 7: Key coding examples

\begin{tabular}{|c|c|c|}
\hline Code & Student examples & School \\
\hline $\begin{array}{l}\text { B1 Build on/ explain/ } \\
\text { clarify others' } \\
\text { contributions }\end{array}$ & $\begin{array}{l}\text { Um, like Jason said, the plant is a living thing but ah a pen isn't but the } \\
\text { pen can be made of living things like the rubber from a rubber tree on } \\
\text { a pen }\end{array}$ & $\begin{array}{l}\text { C, } \\
\text { CoI } 1\end{array}$ \\
\hline $\begin{array}{l}\text { B2 Clarify/ elaborate } \\
\text { own contribution }\end{array}$ & $\begin{array}{l}\text { telling the truth is brave because for example, when I was } 5 \text { I wasn't } \\
\text { brave because um I I dropped a bowl of pasta and I hid under the table } \\
\text { cos I was scared that I would get told off and that was an example that } \\
\text { I wasn't brave but telling the truth is brave }\end{array}$ & $\begin{array}{l}\text { D, } \\
\text { CoI } 1\end{array}$ \\
\hline $\begin{array}{l}\text { I3 Invite possibility } \\
\text { thinking or prediction }\end{array}$ & Are you always free in the outdoors? & $\begin{array}{l}\text { A, } \\
\text { CoI } 3\end{array}$ \\
\hline $\begin{array}{l}\text { I4 Ask for explanation } \\
\text { or justification }\end{array}$ & What are your reasons for thinking that? & $\begin{array}{l}\text { D, } \\
\text { CoI } 3\end{array}$ \\
\hline $\begin{array}{l}\text { I6 Ask for elaboration } \\
\text { or clarification }\end{array}$ & What do you mean by, it's free? & $\begin{array}{l}\text { B, } \\
\text { CoI } 2\end{array}$ \\
\hline P1 Synthesise ideas & $\begin{array}{l}\text { Philosophical questions are questions that you can't just use your } \\
\text { common sense for. A question like, let's say, if you're thirsty, should } \\
\text { you take a drink? Yes! You're just using your common sense to answer } \\
\text { that question but with philosophical questions, the sort of questions } \\
\text { that we do there, they're you you really have to think about it to get an } \\
\text { answer that's really good and really right and really close and also I } \\
\text { think that if you've come up with an idea or a classification you've } \\
\text { never really finished it. }\end{array}$ & $\begin{array}{l}\mathrm{B}, \\
\mathrm{CoI} 2\end{array}$ \\
\hline $\begin{array}{l}\text { P2 Compare/ evaluate } \\
\text { alternative views }\end{array}$ & $\begin{array}{l}\text { It really depends - I think it's brave because you're climbing down a } \\
\text { dangerous cliff but if I was the person that was doing that I wouldn't } \\
\text { do it for a pencil case cos you can always buy a new one }\end{array}$ & $\begin{array}{l}\text { D, } \\
\text { CoI } 1\end{array}$ \\
\hline $\begin{array}{l}\text { P4 Acknowledge shift } \\
\text { in position }\end{array}$ & $\begin{array}{l}\text { Also my new idea is that mood is just a definition for a good or bad } \\
\text { feeling or good or bad feelings - that's just another idea }\end{array}$ & $\begin{array}{l}\text { B, } \\
\text { CoI } 3\end{array}$ \\
\hline $\begin{array}{l}\text { R2 Explain or justify } \\
\text { own contribution }\end{array}$ & $\begin{array}{l}\text { Just because you never play with someone, doesn't mean you're not } \\
\text { friends, like, me and Katie, we're friends, but she lives far away so we } \\
\text { never play }\end{array}$ & $\begin{array}{l}\text { C, } \\
\text { CoI } 1\end{array}$ \\
\hline $\begin{array}{l}\text { R3 Speculate or predict } \\
\text { on the basis of } \\
\text { another's prediction }\end{array}$ & $\begin{array}{l}\text { I think what Noam said explains Troy's idea quite well because but if it } \\
\text { was just about a rocket flying it might make sense but then again it } \\
\text { might not because the higher up a rocket goes, the more it falls apart ... } \\
\text { but then again as a plant gets older its leaves fall off, unless it's a } \\
\text { conifer, and its flowers fall off, and occasionally its fruit falls off, so } \\
\text { Troy's theory could make sense but then again it couldn't }\end{array}$ & $\begin{array}{l}\mathrm{C}, \\
\mathrm{CoI} 2\end{array}$ \\
\hline $\begin{array}{l}\text { R4 Speculate and } \\
\text { predict }\end{array}$ & $\begin{array}{l}\text { He might've blown down the house as a reason because the pigs were } \\
\text { being mean }\end{array}$ & $\begin{array}{l}\text { A, } \\
\text { CoI } 2\end{array}$ \\
\hline
\end{tabular}




\section{Coding challenges and issues}

Coding can pose many challenges and involve many decisions for the researcher. At each step the researcher is making meaning and interpreting the meaning(s) of the speaker. One challenge is "to be explicitly mindful of the purposes of your study and of the conceptual lenses you are training on it-while allowing yourself to be open to and re-educated by things you didn't know about or expect to find" (Miles \& Huberman, 1994, p. 56). Another challenge is to make decisions about the degree of fine-grained analysis one chooses to focus on, while remaining cognisant of the big picture. One might choose to code a fragment, a whole statement, or a paragraph of speech from the transcript; each choice shapes the analysis. I assigned a code to each statement of roughly sentence length in the transcriptions. I used NVivo 11 and subsequently NVivo 12 to code the classroom dialogue transcripts. After coding all of the classroom dialogue transcripts I examined the incidence over time through the study of certain kinds of statements that indicated critical thinking and intersubjectivity. I describe this temporal analysis (Mercer, 2008) in Chapter 6. The long process of transcribing and coding the classroom dialogues allowed me to get close to the data, to mull over and consider the language and thought processes that were evident in the dialogic interactions. This led to my second, inductive, round of analysis.

\section{Inductive thematic analysis}

In order to recognise themes in the data, both those that had been hypothesised and those that were surprising and unexpected, I employed an inductive approach to analysing the student thinking journals, focus group interviews, and teacher interviews. Inductive analysis involves moving from the particular to the general and is used to identify regularities or patterns (Miles, Huberman, \& Saldana, 2014; Punch, 2014). Using thematic analysis I sought "both to reflect reality and to unpick or unravel the surface of 'reality'” (Braun \& Clarke, 2006, p. 81). I identified patterns and themes, and selected those which are of interest in order to analyse and report on them (Braun \& Clarke, 2006). One method I used to do this was by creating diagrams in order to sort my observations into themes and to draw the links between these (see Image 1 below). By nature, this selection is subjective, influenced by my own stance, my interpretation of the data and what it could mean, because "data are not coded in an epistemological 
vacuum" (Braun \& Clarke, 2006, p. 84). Identification of inductive themes required considered judgement on my part.

\section{Image 1: Thematic analysis diagram}

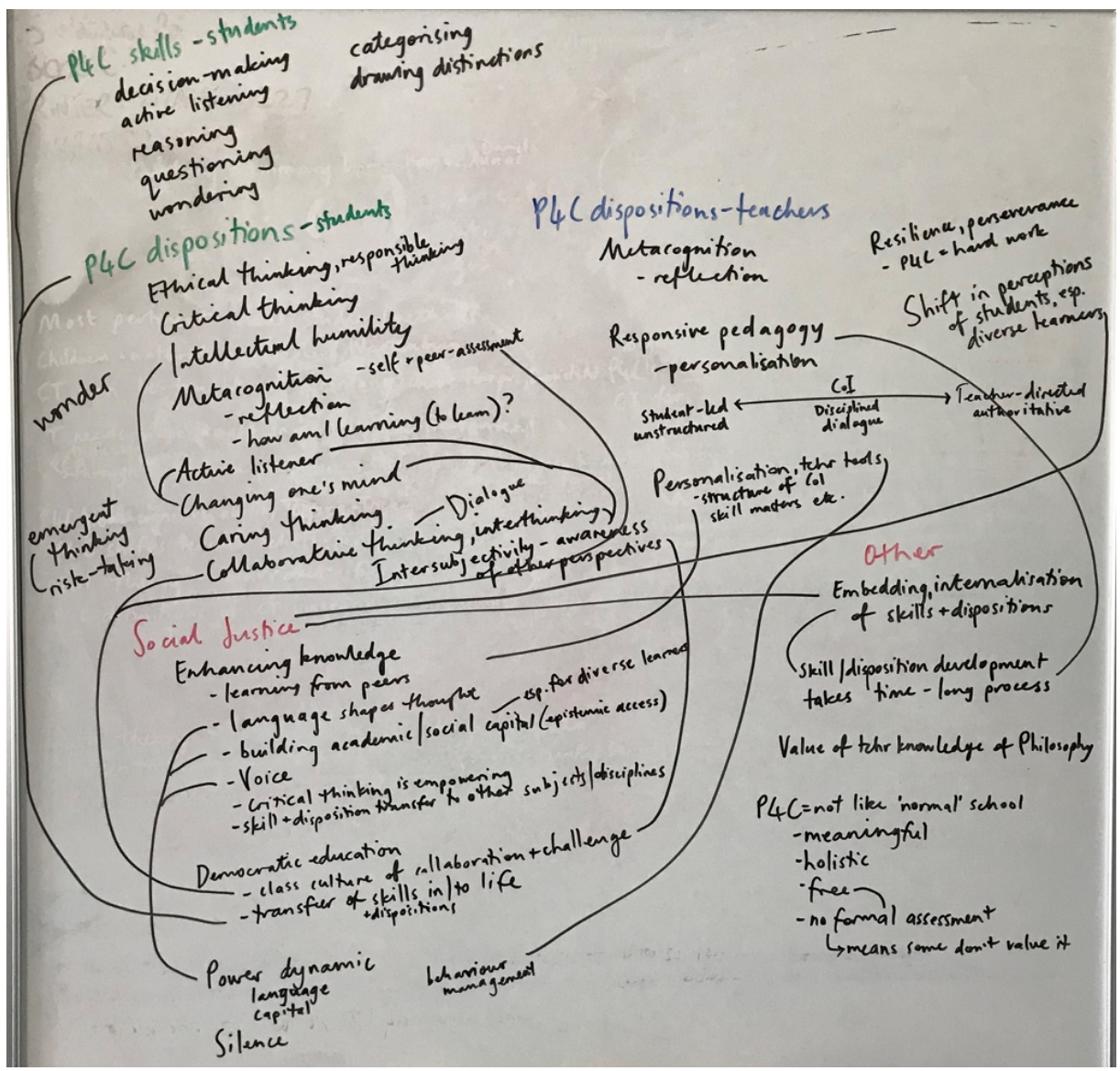

Concepts and statements drawn from teacher and student post-intervention interviews

One method I used to strengthen the credibility and trustworthiness of my analysis was to identify where themes intersected across different participant responses, and my own observations, using a table with these categories: Student observations (about themselves), Teacher observations (about their practice), Teacher observations about students, Researcher observations about students, Researcher observations about teachers. An example of some of the early themes I identified is shown in Figure 8, below. By cross-referencing themes across these different categories, I sought to recognise patterns and deepen my understanding by determining which observations or themes were identified by all participants and which were limited to certain groups. An observation only made by one group, for example, teacher observations about students, was not necessarily discounted because the other groups had not made the 
same observation. I asked myself questions as I considered, grouped, and refined the themes, such as:

'What does this theme mean?' 'What are the assumptions underpinning it?' 'What are the implications of this theme?' 'What conditions are likely to have given rise to it?' 'Why do people talk about this thing in this particular way (as opposed to other ways)?' and 'What is the overall story the different themes reveal about the topic?' (Braun \& Clarke, 2006, p. 94).

Figure 8: Theme generation and cross-referencing

\begin{tabular}{|c|c|c|c|c|c|c|}
\hline Themes & Sub-themes/codes & $\begin{array}{l}\text { Student } \\
\text { observa- } \\
\text { tions (about } \\
\text { themselves) }\end{array}$ & $\begin{array}{l}\text { Teacher } \\
\text { observa- } \\
\text { tions (about } \\
\text { themselves) }\end{array}$ & $\begin{array}{l}\text { Teacher } \\
\text { observa- } \\
\text { tions about } \\
\text { students }\end{array}$ & $\begin{array}{l}\text { Researcher } \\
\text { observa- } \\
\text { tions about } \\
\text { students }\end{array}$ & $\begin{array}{l}\text { Researcher } \\
\text { observa- } \\
\text { tions about } \\
\text { teachers }\end{array}$ \\
\hline 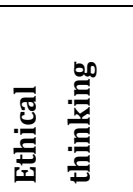 & $\begin{array}{l}\text { CoI develops } \\
\text { decision-making, } \\
\text { responsible thinking }\end{array}$ & / & & / & / & \\
\hline \multirow{3}{*}{ 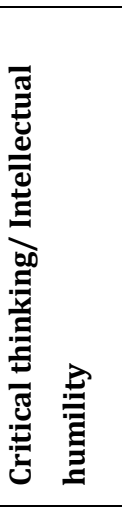 } & $\begin{array}{l}\text { Good philosophers } \\
\text { give (good) reasons }\end{array}$ & I & & / & / & / \\
\hline & $\begin{array}{l}\text { Good philosophers } \\
\text { change their mind } \\
\text { when presented with } \\
\text { stronger reasoning } \\
\text { for an alternative } \\
\text { view }\end{array}$ & / & & / & / & / \\
\hline & \multirow{2}{*}{$\begin{array}{l}\text { CoI develops } \\
\text { collaborative } \\
\text { thinking, } \\
\text { interthinking }\end{array}$} & \multirow[t]{2}{*}{ / } & \multirow[t]{2}{*}{ / } & \multirow[t]{2}{*}{ / } & \multirow[t]{2}{*}{ / } & \multirow[t]{2}{*}{ I } \\
\hline $\bar{\S}$ & & & & & & \\
\hline 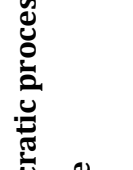 & $\begin{array}{l}\text { P4C teaches the } \\
\text { importance of active } \\
\text { listening }\end{array}$ & I & & $/$ & / & \\
\hline 这 & $\begin{array}{l}\text { Col builds positive } \\
\text { class culture }\end{array}$ & & & / & / & \\
\hline 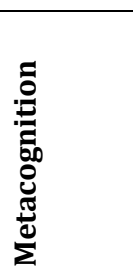 & $\begin{array}{l}\text { P4C develops peer } \\
\text { assessment, } \\
\text { identification of use } \\
\text { of skills and } \\
\text { language }\end{array}$ & & & / & / & \\
\hline
\end{tabular}


Themes were identified at two different levels, either at the semantic, explicit level, or at the underlying latent, interpretative level (Boyatzis, 1998). The overarching themes that I report and discuss in Chapters 5, 6, and 7 are largely latent themes that are interpretative in nature. In order to exemplify and present the latent themes I identified inductively in the data, I wrote vignettes about sample students. I describe the process of writing vignettes in the next section.

\section{Developing character narratives}

Children naturally change and evolve as they grow. Drawing on Holstein and Gubrium's $(1995,2000)$ notion of respondents' shifts in roles and subject positions, I sought to notice and identify when participants disrupted the understandings I had developed of their modes of thinking demonstrated through dialogue. Humans are complex and contradictory; I made a conscious effort not to smooth the edges of these contradictions in my research analyses, but rather, to engage with the complexity of everyday life (Dwyer \& Limb, 2001). For this reason, I chose to report my findings through vignettes, to allow for and to honour this complexity.

Vignettes can be composite portraits that represent participants' experiences and summarise and encapsulate findings (Ely, Vinz, Downing, \& Anzul, 1997; Spalding \& Phillips, 2007). They are used to construct an interpretive account of the participants' experiences in order to develop an analysis of the situation. I used vignettes as a method of reporting the data because they are a form of narrative that includes thick descriptions and rich detail that offer the reader a flavour of the participants' experiences. The narratives show, rather than tell, the participants' experiences, and allow for multivocality, which contributes to the credibility of the research (Tracy, 2010). The other reason I chose to use vignettes was because composite narratives in the form of vignettes can protect participants' identities by combining a range of examples and excerpts from different participants that illustrate a case or a theme without singling out one particular participant (Spalding \& Phillips, 2007, p. 960). This can strengthen the trustworthiness of the data analysis by utilising and combining true accounts while preserving participant anonymity. Some of the vignettes are based on one participant; others are created as a composite of a number of students from 
different schools with similar experiences. Because of this the composite vignettes are not given a caption identifying which school they came from.

\section{Temporal analysis}

Because teaching and learning is a long term process that is cumulative and iterative, a temporal analysis (Mercer, 2008) is a valuable approach in order to take this into account. Barnes (1992) argues that "most learning does not happen suddenly: we do not one moment fail to understand something and the next moment grasp it entirely" (p. 123). The reason I chose to gather data in the form of recordings of classroom dialogue at the beginning, middle, and end of the research project was in order to gain a sense of the progression of student thinking and dialogue over time. The recordings are merely snapshots of student dialogue and thinking. While they offer glimpses of student learning in normal classroom contexts, many other factors influence how conducive each $\mathrm{CoI}$ and its context was to demonstrations of growing dialogic critical thinking. Learning is messy (Rush, 2014): it does not follow a clean straight trajectory, and it takes time to explore and practise new knowledge, concepts and skills. Some discussion topics generated more collaboration or evaluation of alternative views and the opportunity to acknowledge a shift in one's position than others. This means that some CoIs provoked less of certain kinds of intersubjective critical thinking than others. Teacher and student reflections at the end of the intervention were therefore very useful in illuminating the kinds of shifts that occurred across the whole project. I discuss teacher and student reflections and the patterns I observed in the fine-grained dialogue analysis I undertook of each school's CoIs in Chapter 6.

\section{Case study contexts}

Four teachers in four schools ran P4C communities of inquiry in their Years 4/5 classes for an hour a week over six months. Each school was in a different part of a metropolitan city, with different socio-economic and cultural contexts and decile ratings ${ }^{5}$. However the school's decile rating does not in itself give a rich picture about

\footnotetext{
${ }^{5}$ New Zealand schools are given a rating from 1 to 10 that denotes "the socio-economic position of a school's student community relative to other schools throughout the country. For example, decile 1 schools are the $10 \%$ of schools with the highest proportion of students from low socio-economic communities, whereas decile
} 
the demographics of a school or a class within that school. The demographic census data that is used to ascertain a school's decile comes from everyone who lives in its local community regardless of whether or not they have children who attend the school (Bridgeman, 2012). Therefore, expensive inner-city apartments can often inflate the decile ratings of inner-city schools. Next I give a brief overview of each school, teacher, and class to provide a context to the research participants and the data.

\section{School A - Olivia}

School A was a decile 3 state full primary school (Years 1-8) in a suburban area of one of four cities that make up a metropolitan area. At the time of the research, the school's population was made up of 53\% Māori, 15\% Pasifika, 13\% Asian and 13\% NZ European / Pākehā students. ${ }^{6}$ The multicultural nature of the school was celebrated throughout the school's charter, vision, and values. The decile 3 rating accurately captured the socio-economic circumstances of the local and school community. Olivia's class reflected the school's ethnic makeup of a majority of Māori students and more Pasifika students than the smaller ethnic populations of Asian and Pākehā students.

Olivia was Māori, as were the majority of her students. She was an experienced teacher, having taught for 20 years. She was new to teaching P4C - she had taken part in a twoday training course in the month prior to the beginning of the research project. Olivia's behaviour management style was firm, with clear expectations and consequences for those who didn't uphold the class' agreed participation guidelines. Olivia's class was used to deferring to adults to enforce expectations of conduct and behaviour. The classroom culture here was more teacher-led than the other participant classes. Respect for adults was strong.

10 schools are the $10 \%$ of schools with the lowest proportion of these students. A school's decile does not indicate the overall socio-economic mix of the school or reflect the quality of education the school provides. Deciles are used to provide funding to... schools to enable them to overcome the barriers to learning faced by students from lower socio-economic communities. The lower the school's decile, the more funding they receive" (Ministry of Education, 2019b).

${ }^{6}$ I have used the Ministry of Education's ethnicity codes as reported on the Education Counts website: www.educationcounts.govt.nz for the participant schools at the time of the research project (data was accessed in December 2015). 


\section{School B - Emily}

School B was a decile 8 state full primary school (Years 1-8) in a central urban area of a metropolitan city. At the time of the research, the school's population was made up of 35 different cultural groups: 12\% Māori, 9\% Pasifika, 13\% Indian, 9\% Chinese, 12\% Other Asian, 7\% African, and 28\% NZ European / Pākehā students. The diverse range of ethnicities at the school were made up of indigenous, immigrant, and refugee populations. Although School B was a decile 8 school, its inner-city location drove up its decile rating. Emily's class was the most ethnically diverse of all the participating classes and reflected a lower socio-economic income bracket than the school's decile would suggest.

Emily was Pākehā. She was then a provisionally registered teacher, in the second year of her teaching career. Like Olivia, she was new to teaching P4C and had taken part in a two-day training course in the month prior to the beginning of the research project. Emily's behaviour management approach drew on strong relationships with the students and was flexible according to different students' needs. The class had a diverse range of learning and behaviour needs and was the largest in number of all participant classes.

\section{School C - Jono}

School C was a decile 6 state contributing primary school (Years 1-6) with a special character unit attached to the school, in a suburban area of a metropolitan city. At the time of the research, the school's population was made up of 11\% Māori, 3\% Pasifika, 18\% Asian, 9\% African, 11\% European, 4\% Middle Eastern and 44\% NZ European / Pākehā students. Like School B, the diverse range of ethnicities at School C were made up of indigenous, immigrant, and refugee populations. While School C was a decile 6 school, the particular class that participated in the study was drawn from a special character fee-paying part of the school which meant that the students' families were more likely to be from a higher socio-economic income bracket than the majority of families at that school. The majority of students in Jono's class were also Pākehā. 
Jono was Pākehā. He had 6 years of teaching experience and had some experience of teaching P4C 3 years prior to the project. He also took part in the two-day training course in the month prior to the beginning of the research project. Jono's approach to behaviour management style involved using his voice effectively to gain students' attention; he would tackle unwanted behaviour quickly with clear boundaries and consequences. Jono's class already had a system for whole-class discussion and decision-making through their weekly class hui. This meant that the students were already used to listening to each other, having the opportunity to raise issues and concerns, problem-solve, and make decisions together.

\section{School D - Alana}

School D was a decile 10 state contributing primary school (Years 1-6) in a suburban area of a metropolitan city. At the time of the research, the school's population was made up of 14\% Māori, 2\% Pasifika, 3\% Indian and 74\% NZ European / Pākehā students, meaning that School D was the least multicultural school of the participant schools in the study (consisting of a majority of Pākehā students). A number of the students in Alana's class had participated in P4C CoIs in previous years at school, either in class or in a special P4C group led by the Deputy Principal at that school.

Alana was Pākehā. She had been teaching for 4 years, and had been teaching P4C all that time. Because she had already been trained in teaching P4C to an intermediate level, she did not need to take part in training prior to the research project. Alana's behaviour management style was calm; she empowered students by questioning them and encouraging them to make good choices about their engagement and behaviour. Alana's class had quite a number of students who were used to having a voice, articulating it clearly, and it being heard. They were empowered to make decisions about how they learned, and what they learned (to a degree).

\section{Structuring the Col}

Each teacher planned their P4C lessons following this general outline:

1. Discuss/reiterate shared discussion guidelines agreement

2. Game, often related to a particular skill focus for the day 
3. Sharing a stimulus (usually a picture book) to spark inquiry

4. Student questioning, formulating and agreeing on a philosophical question to begin the CoI

5. Whole class dialogue, facilitated and documented - on a whiteboard or modelling book - by the teacher. At times the teacher would encourage the class to break into small groups or pairs for more dialogue; then they would return to the whole class dialogue

6. 'Final round': going around the circle, giving each student the opportunity to make a final point about the topic of discussion, and to reflect on the quality of the dialogue and philosophical thinking that day

7. Reflections written or drawn in students' thinking journals (sometimes done later in the week)

Any given lesson might vary from this structure. Sometimes the concept game formed the main focus of the dialogue; other times a dialogue from the previous week would flow on and students would delve further into the concept under consideration.

In order to facilitate student-led dialogue, teachers used a talking object such as a soft ball or dice to denote who the speaker was at any given time. This system allowed students to choose the next person to speak in the dialogue by passing them the talking object. Because the classes were made up of between 24 and 36 students, it was a challenge to ensure that all students had a chance to contribute. Teachers managed this in different ways, either by limiting the number of contributions each student could make, or by pausing the whole-class dialogue regularly to allow students to share their thinking with a dialogue partner or small group.

At a meeting at the outset of the research project, the participant teachers decided that it would be best for each teacher to plan their own CoIs individually, rather than planning together and teaching the same content, because this gave them the flexibility to tailor the P4C dialogue content and skills to the needs and interests of their particular students. The materials teachers had received at the P4C training course gave them resources to support their planning. The researcher also sourced picture books that 
were philosophical in nature for teachers to use as stimulus material. Three of the participant teachers, Alana, Jono, and Emily, shared planning and teaching ideas and stimulus material throughout the project, which they modified according to the needs, strengths and interests of the students in their respective classes.

\section{Ethical considerations}

In addition to the procedural ethics that were met through the process of gaining ethics approval from the Ethics Committee at Victoria University of Wellington, there were other ethical factors that I considered through this research project.

As I stated earlier in this chapter, research with children involves a power imbalance in the research encounter between them and the adult researcher. From the outset I sought to mitigate this imbalance by finding ways to show respect to the students, to uphold relational ethics (Tracy, 2010). I did this by seeking the students' assent to participate in the research as well as gaining parental consent, and by working to build rapport with the students whenever I visited their classrooms by actively listening to their questions and ideas. Often, at the end of a CoI, there were students who still had much more that they wanted to say about the dialogue that day; I would take time to listen to their ideas, to support their enthusiasm and to show that I valued their voices. In the focus group interviews I asked the students to ask questions of themselves and each other as well as my prepared questions so that our discussion could benefit from their insight and perspectives. Despite this, I recognised that I still held a position of power that influenced our interactions; this is an ongoing tension in research with children.

Teacher workload was another factor that I considered throughout the project. I sought to minimise the amount of extra work and effort required by the teachers in any way possible, whether that was by offering support with planning and resourcing the $\mathrm{P} 4 \mathrm{C}$ lessons, or by setting up easy systems for tasks like the collection of parent consent forms. The three teachers who had not already been trained in teaching $\mathrm{P} 4 \mathrm{C}$ gave up two days of their school holidays to attend a P4C training course. I was grateful to P4CNZ, New Zealand's P4C organisation, who waived the fee of the training because it 
was for the benefit of research, and hoped that the provision of free professional development went some way towards making up for the time they had given.

The confidentiality of participants and schools was maintained by the use of pseudonyms throughout the reporting of the research.

\section{Research limitations and credibility}

Because this study is a small-scale qualitative project, I have sought to offer thick descriptions that allow for the complexity of students' and teachers' experiences in schools. This methodology has certain affordances and other limitations that I outline here. As stated earlier, I chose this approach because I wanted to examine, in practice, the nuances and complexity of how critical thinking can develop through P4C for students in primary schools.

One limitation of such a small scale project is that the results are specific and related to the four particular case study contexts that were examined. Further research with a bigger sample size would be needed to allow greater generalisation of the findings.

Another limitation of this project stems from the inability to report with any depth on the influences of ethnicity and family background upon students' critical thinking dispositions. While the literature indicates that cultural understandings and socialisation impact on students' language and thinking skills and dispositions (Gibbons, 1998, 2002; Mercer \& Howe, 2012; Perkins et al., 2000; Tishman \& Perkins, 1997), the school-based context of this study as well as issues of access and privacy meant that I didn't collect this data, thus reducing my ability to draw conclusions related to ethnicity and family influences.

Although the shared quality of a whole class CoI can benefit the class culture and can build shared understandings, the nature of a whole class dialogue also means that most students spend most of their time listening rather than speaking. This meant that a further limitation of this project was that a number of students' voices were not heard in the whole-class dialogues. An alternative approach to data collection for future 
research would be to use more recording devices to capture small group discussion. This would allow more voices to be represented which would give further insight into the critical thinking dispositions and language of a broader range of students.

One of my techniques to build credibility was through seeking multivocality (Tracy, 2010). I achieved multivocality by listening to a range of students' and teachers' voices, both through classroom dialogic interaction in practice, and in the metacognitive, reflective settings of the focus group and teacher interviews, which allowed participants to describe and illuminate their thought processes; this was a form of participant collaboration in the interpretive, meaning-making phase of the research. The use of multiple data sources enabled me to use different lenses to actively look for confirming or contradictory patterns and to assess commonality and contrasts across the data (Pairman, 2018). I have described other methodological practices through which I sought to achieve credibility in this research: thick descriptions, in the form of vignettes and excerpts of teachers' voices that show, not tell; gathering data through a range of sources in order to triangulate the patterns and themes I drew from the data; and participatory methods such as thinking journals and semi-structured interviews that seek the participants' descriptions and interpretations of the impact of P4C on their language and thinking processes.

In striving for sincerity in this research, I sought to be transparent about the research process with the participants (Tracy, 2010). Throughout the research process I was aware of my biases, values, and elements of my personal and professional background that are likely to have influenced my interpretations of the data (Lincoln, Lynham, \& Guba, 2018). I kept seeking the unexpected and contradictory, in an attempt to observe with my eyes wide open to interpretations my biases could mask from me. It is likely that some blind spots and limitations remain, however, my conscious aim for honesty and sincerity, together with the complex and layered data collection and analysis processes contribute to the rigour and trustworthiness of my research (Tracy, 2010). The challenge of balancing one's own bias while offering an honest interpretation and as accurate a representation as possible of the participants' experiences and understandings is an ongoing tension in qualitative research with children. 
Methodology 


\section{5}

\section{Enhancing capability}

This chapter explores the ways in which the dialogic, democratic pedagogy of P4C impacts on teacher theory and pedagogy, and enhances teaching capability, and how this in turn enhances student critical thinking and learning capability. It contributes to a small but growing research interest within the field of literature on Philosophy for Children about teacher beliefs and practice, and their intersection (Golding, 2010; Scholl, 2012). As described in Chapter 2, the social nature of knowledge means that it is constructed and emergent. My research suggests that the process of teaching and learning and constructing knowledge through P4C builds both teacher and student capability. Four interconnected themes related to capability were identified through my analysis: teachers' and learners' resilience, receptivity, intersubjectivity, and personalisation of learning. These are first defined and then addressed in turn. I describe my observations of teachers' practice alongside their own reflections, and identify the links between teacher theory and pedagogy and student experiences. The themes are illustrated by vignettes (Spalding \& Phillips, 2007; Wilson \& While, 1998) that exemplify key insights drawn from the data. This research suggests that $\mathrm{P} 4 \mathrm{C}$ has the potential to enhance students' capability regardless of their background and capital, enabling them to construct and refine new knowledge and understandings.

\section{Definitions of the themes: resilience, receptivity, intersubjectivity, personalisation}

My conception of teacher and student capability is shaped by the definitions of competencies and capabilities (Carr, 2006; Hipkins, 2013; OECD, 2018c; Rychen \& Salganik, 2003), and Harpaz's (2005a) descriptions of thinking dispositions and understanding discussed in Chapter 3. Capabilities are complex and overlapping, they require application and transfer of knowledge and skills in meaningful contexts, and 
grow through internal motivation and understanding. I examine four such capabilities in this chapter.

Resilience is "the capacity to recover quickly from difficulties" (Oxford University Press, 2018, para. 1). For both teachers and learners, the emergent nature of philosophical dialogue requires vulnerability; as teachers and students explore and propose different possible ideas and directions for the dialogue, these may prove to be fruitful or they may not. A student's willingness to put themselves on the line in front of others by offering their emergent ideas for others to evaluate involves vulnerability because the idea may or may not help the shared inquiry to progress. If an idea isn't taken up by the group or it doesn't stand up to critique by one's peers, the student needs resilience in order to continue listening and contributing to the dialogue. Similarly, a teacher's attempts to support and facilitate student thinking during an unexpected turn in the CoI may or may not be successful. If a teacher's facilitation of the dialogue proves to be unsuccessful, they can feel vulnerable and require resilience in order to persevere with firstly the dialogue in the moment, and secondly the approach of P4C itself.

A separate but connected concept to resilience is receptivity. A receptive learner or teacher is "willing to consider or accept new suggestions and ideas" (Oxford University Press, 2018, para. 1). Open dialogue does not follow a prescribed path. While teachers could plan for possible directions a dialogue may take, they could not be certain what course the dialogue would follow; I outline the ways in which they were receptive to the student thinking that emerged through the dialogue. I describe how students recognised the value of others' suggestions and ideas in improving their own understanding and thinking capability.

The constructed knowledge observed in the communities of inquiry in this study involves intersubjectivity within and across different groups of participants: between teachers, between individual teachers and their students, and between students. Intersubjectivity has been explored and defined in a number of ways in different disciplines. In Education, intersubjectivity denotes the shared, social nature of knowledge and mutual understanding. In this thesis I draw on Daniel et al.'s (2003) 
definition which describes intersubjectivity as an epistemological perspective that values knowledge co-constructed from a series of diverse viewpoints that are open to evaluation and criticism. This is consistent with Dewey's (1916) definition of community - "a mode of associated living, of conjoint communicated experience" (p. 87) - which he believed to be at the heart of democracy. Dewey proposed that communal life was achieved through interaction between as many diverse groups of people as possible, in order that individuals might be able to take into consideration "mutually interpenetrating" (p.87) interests when making decisions about how to live and to act. Daniel et al. (2003) conclude that in children, "critical evaluation has its limits, since it arises more from pupils' experience and reasoning than from theoretical knowledge, which is limited at this age" (p. 48), thus an intersubjective perspective for children is likely to be oriented towards personal understanding and meaning. According to Daniel et al.'s (2005) definition, intersubjective thought involves conceptualisation, transformation, categorisation, and correction - changes of perspective, as well as "spontaneous and elaborated justification ... evaluation of meanings ... manifestations of doubt ... [and] evaluation/modification of perspectives" (p. 344).

Personalisation of learning is the opposite of standardisation. Rather than following a one-size-fits-all model, personalised teaching and learning involves teachers modifying their teaching approaches according to the needs of the learners with whom they work. As much as was possible, teachers personalised their pedagogy in a number of ways in this study in order to best meet the needs of their learners; complete personalisation is an almost impossible feat in the context of a CoI. Some of the innovations teachers made in their own classes inspired other teachers to trial each other's methods; I outline one of these such innovations as an example.

\section{Resilience}

A compelling latent theme that I identified in both the teachers' and students' data was the need to develop the disposition of resilience in order to persevere through the challenges in developing one's capability in P4C. However, this need was manifested for teachers and students in different terms. While the teachers were enthusiastic about the programme, all of them described how challenging a task they found facilitation of CoIs 
to be. The challenges were particularly related to the complexity of the many threads they held together during a CoI, and the uncertainty of where an open student-led dialogue may lead. For the students, resilience was required when their emergent thinking shifted and changed mid-stream while speaking, or during the course of a CoI. This theme was one that each of the teachers identified in relation to their own teaching and the need for resilience that they observed in their students.

\section{The challenges of facilitating $\mathrm{P}_{4} \mathrm{C}$ dialogue require teacher resilience}

My study affirms previous research that has found that facilitating a $\mathrm{CoI}$ is complex, challenging and multi-layered (Gardner, 1995; Golding, 2011b, 2017; Scholl, 2014). The many roles that teachers juggled when leading a CoI in this study were:

- as co-inquirer alongside their students;

- engaging learners in the philosophical content;

- listening to student questions;

- helping students to discern which questions will lead to a fruitful philosophical discussion;

- listening to student contributions and documenting these (usually on a whiteboard or in a modelling book - described as 'boardwork') in a way that helps students to see the structure of their collaborative dialogue;

- questioning;

- modelling critical language structures and intellectual humility;

- challenging and encouraging learners to share their thinking;

- judging when to pause the whole-class discussion to give students a chance to think-pair-share or to write in their thinking journals;

- recognising when clarification is needed, perhaps of a distinction or a category they haven't realised they are describing;

- ensuring that students who want to speak are being given the opportunity to;

- managing student behaviour;

- following the thread of the dialogue;

- encouraging students to respond to and build on each other's thinking;

- $\quad$ supporting philosophical progress; 
- noticing when to highlight a student's use of a philosophical skill (e.g. giving a counterexample);

- timekeeping; and

- knowing when to stop the dialogue to allow enough time for the final 'round' when each student can say a final comment and reflect on the quality of the day's dialogue.

Each teacher found that managing these diverse roles meant that they had to draw on and cultivate their own teaching dispositions (Perkins et al., 2000) of perseverance, risk-taking, and reflection. Further, the teachers found that developing what Shulman (2005) calls signature pedagogies - in this context, skilled and responsive teaching skills particular to the dialogic approach of $\mathrm{P} 4 \mathrm{C}$ - took time to refine. The process involved playing, exploring, adapting, taking risks and making mistakes. And in addition, perseverance. Inevitably, there were times when teachers were not as successful as they'd like to have been in managing the discussion or in reigning it in from a divergent tangent. Rather than allowing themselves to become demoralised by the unsuccessful features of classroom dialogues, teachers described the importance of reflecting on less successful dialogues in order to consider how they might plan, lead, or respond differently next time. They each found this challenging:

I mean it is quite challenging, it is quite challenging, I found my role within it quite challenging - you're trying to keep track of where the conversation's going and behaviour management and pull some more ideas or push them a bit further and it's like aarghh and so I suspect that's just experience - it comes with experience. - Emily, School B, post-intervention interview

Emily's repetition of the adjective challenging indicates quite how hard it was for teachers to find themselves in the vulnerable position of teacher-as-learner. As discussed in Chapter 3, other studies have indicated that teaching P4C can develop teachers' pedagogy as well as encouraging a more critical stance in evaluating their teaching practice (Roche, 2011; Scholl, 2012, 2014; Wilkinson et al., 2017; Yeazell, 1981). In order to remain buoyant, Emily also described the importance of celebrating the successful elements of classroom dialogues: 
All the time you think of ways you could've done things better ... I think I'm getting a little bit better... at noticing the things that went well, not just the things that were like diabolical - and there's been a lot of diabolical moments I've had to just cling on to the goodies this year. I think that's quite important actually. - Emily, School B, post-intervention interview

Alana also described how it took her a long time to become confident in managing all the different elements required to facilitate a CoI well:

As you grow in confidence you can take it where you want it to... It took me a long time to get the hang of writing [the students' thinking] down [on the board] and I think you just have to practise it ... it doesn't bother me now if it doesn't go how I was expecting it to go. - Alana, School D, post-intervention interview

Alana's acceptance of the fact that a CoI can be unpredictable was an example of the teachers' resilience. My observations of the four participant teachers indicate that it is likely that teacher resilience is reliant on both an acceptance of failure and a positivity that begets perseverance and ultimately, enhancement. Bernstein's (2000) definition of enhancement includes discipline; it involves working through challenges. Bernstein states that he sees '"enhancement' as a condition for experiencing boundaries, be they social, intellectual or personal, not as prisons, or stereotypes, but as tension points condensing the past and opening possible futures" (p. x). According to Bernstein's theory, the many challenges I have outlined that teachers face in facilitating P4C can be seen as tension points that open possibilities for enhancement. I further discuss teachers' ongoing professional development in and through P4C later in this chapter.

\section{The challenges of participating in $\mathrm{P}_{4} \mathrm{C}$ dialogue require student resilience}

Having discussed the teachers' need for resilience in facilitating P4C, now I turn to focus on the students' experience of challenges through P4C dialogue and explore the ways that they developed resilience, both individually and with the support of their peers and teachers. As well as the challenges for teachers, P4C can pose challenges for students. While the students were positive and enthusiastic about the benefits of $\mathrm{P} 4 \mathrm{C}$ for themselves and their peers, they faced a number of challenges as their thinking, speaking and listening skills developed. 


\section{Vignette: Freddy}

Freddy was a highly intelligent and articulate student at School B who did not appear to enjoy school much of the time. For example, in the focus group interview at the start of the project, when asked what he liked about school, he responded: "I like at the end of school when I get to go home."

Sometimes he required a great deal of encouragement from his teacher to participate in learning activities and he could become quickly frustrated or upset at times. His teacher chose him as a focus group student because she had a hunch that $\mathrm{P} 4 \mathrm{C}$ might be a part of school that he would both enjoy and find stimulating.

At the beginning of the project, there were a number of instances when Freddy would be in the middle of describing his idea when he would stop and begin to cry or show frustration because he had realised that the idea didn't make sense and he was changing his mind as he was speaking. His teacher Emily recognised that Freddy's awareness of his changing thinking was a sign of metacognition and intersubjectivity and sought to clarify this for Freddy, emphasising that changing one's mind is a natural and valuable part of philosophical inquiry and a sign that one is in the process of refining one's thinking. As the project went by, Emily explicitly modelled the process of articulating emergent thinking - talking about half-formed or newlyformed thoughts - in order to demonstrate to the students the fact that philosophical dialogue can often generate new ideas that negate or refine one's previous ideas. In the following example, which occurred towards the end of the research project, Emily gave Freddy positive feedback when he expressed the fact that he was making up contrasting ideas for everyone to think about in the dialogue:

Ella: with Freddy saying that a feeling is basically a mood,

Freddy: that's my other opinion, uh tha- I just made up two things that people could think about

Emily: that's great

Interviewer: so you're playing around with the idea

Freddy: yeah 
Emily: two go - two ideas on the go

School B, $3^{\text {rd }}$ recorded CoI

Emily is emphasising that trying on different ideas for size is valuable in philosophy. By the end of the project, Freddy was able to change his idea mid-stream and continue to refine and articulate his thoughts without expressing frustration with himself:

Freddy: um - I agree but it's not always like that because sometimes let's say I thought of an idea and Tony had his own idea and he says that oh this is wrong - this would make a better idea, but he still has his own idea. So you can still have your own individual thoughts but there can still be loads of big combined thoughts ... um I do wanna say just supporting that, you know how the queen is basically our queen, we're basically, oh na- na that's not a good example. Like, we're allies with a bunch of different countries but we're still our own country, you know what I mean?

School B, post-intervention focus group interview

By this time Freddy had become much more comfortable with changing what he was saying while speaking. In the focus group interview at the end of the project, Freddy offered this definition of philosophy:

Freddy: Philosophical questions are questions that you can't just use your common sense for, like let's say - if you're thirsty, should you take a drink? Yes, that's obvious, you can just use your common sense to figure that out. But with philosophical questions you really have to think about it to get an answer that's really good and really right and really close. Also I think that if you've come up with an idea or a classification or a definition, you've never really finished it - there's always room for improvement, cos like some famous philosophers spent years on the same questions.

School B, post-intervention focus group interview

By the end of the project Freddy had clearly understood that the ongoing process of changing and improving ideas and understandings over long periods of time was a key element of philosophy.

Freddy is an indicative example of a small number of participants ( 4 or 5 in each class) who found elements of the collaborative dialogue and the many ways that one's 
thinking could be challenged through philosophical inquiry, difficult at first. For other students, their discomfort was sometimes due to being confronted with alternative perspectives that they had not encountered or considered before. Peirce (1887) identified this discomfort as genuine doubt in one's own and others' beliefs, knowledge and interpretations that can induce students into behaviours that support resolution if they are exposed to problem-solving experiences as in a COI. Through the course of the project, students began to develop an understanding of the value of the difficulties they faced as their thinking was challenged by their peers and their teacher. As they became more comfortable with the disequilibrium generated by an awareness of their emergent thinking or challenges to their prior thinking, the students developed greater resilience by accepting the feelings of discomfort that could arise through this process. Bernstein (1996) describes emergent thinking as the 'yet-to-be voiced'. Dialogue creates the conditions for new ideas to emerge, form, and develop.

\section{Changing one's mind is part of resilience}

All of the focus group students identified changing one's mind as a key element of philosophical thinking. I describe this theme in greater detail later in the chapter in relation to intersubjectivity. However, I touch on it here because it is also relevant to the theme of resilience. Intellectual resilience, that is, a willingness to allow rigorous debate and reasoning to shape one's ideas was understood by the students to be part of the process of deepening understanding and thinking critically. The following excerpt reveals the focus group students' conclusion that changing one's mind, when presented with better reasoning than one's own, is a key part of philosophical thinking:

Interviewer: what did you used to think about philosophy and what do you think about philosophy now?

Theo: I thought it was just sharing your ideas with other people

Interviewer: and what do you think it is now?

Theo: um it's also changing your mind and following other people's ideas

Interviewer: so when, when do you change your mind?

Theo: when um somebody has a better reason than you

School D, post-intervention focus group interview 
Later in this focus group interview the students further clarified what they thought constitutes a better reason:

Interviewer: are there some ideas or reasons that are better than others? Or not?

Lola: ahh

Theo: yes if you explain it better and give more depth to it

Interviewer: uh huh okay

Lola: some ideas can be really stupid

Interviewer: what, what would make an idea really stupid?

Lola: like saying oh I like this idea because it's really cool and I like the word it has in it, stupid

Interviewer: okay so are you saying

Billy: like an example Sione used, last time we were doing a warm up game

Interviewer: what was the example, Sione?

Sione: $\mathrm{mm}$

Billy: um Dan said something and he said, um we're wh- because and, I can't remember what Dan said - Dan said something I can't remember and his reply was, because I'm awesome

Interviewer: oh yeah, and why was that not like a really strong reason?

Billy: because it didn't really connect to what Dan said

Interviewer: so strong reasons need to connect, is that what you're saying?

Billy: yeah, connections are really big in philosophy

School D, post-intervention focus group interview

This example illustrates an understanding that is central to the notion of powerful knowledge: our knowledge is always provisional, fallible, it can always be improved and refined by newer discoveries and further thinking (Wheelahan, 2007). Burgh, Field, and Freakley (2006), while not drawing on the notion of powerful knowledge, describe the importance of an understanding of fallibilism to a CoI: "Genuine inquiry commits to an understanding that knowledge claims are invariably vulnerable, and that attaining an absolute, final or definitive truth is not in principle within the inquirer's grasp" (p. 82). 
A fallibilist approach recognises that "a consensus reached in a community... is not a final truth, but merely the most reliable knowledge the community can produce by applying its best methods to available evidence" (Gregory, 2002, p. 399). For students to recognise openness to other understandings as a valuable intellectual stance and not to perceive changing one's mind as an indication of a failure of thinking embodies both resilience and intellectual humility.

In this section I have described ways in which $\mathrm{P} 4 \mathrm{C}$ both requires and develops the disposition of resilience for both teachers and students. Resilience was required in order for both teachers and students to build capabilities to, respectively, facilitate and participate in P4C.

\section{Receptivity}

The theme of receptivity stood out in both the teachers' post-intervention interviews and the students' post-intervention focus group interviews. Two sub-themes I found to be evident in relation to receptivity are that each of the teachers (i) was learning to coconstruct knowledge with their students, and (ii) had a key role in supporting students to be receptive to others' ideas, perspectives, and reasoning. For teachers, receptivity involved listening and responding while navigating discussions and scaffolding student dialogue by supporting students to be receptive to each other's contributions and ideas. For students across all four schools, receptivity to others' ideas was a key feature in their definition of a good philosopher.

\section{Co-constructive teaching requires receptivity}

All of the participant teachers emphasised that collaborative philosophical dialogue demanded students' receptivity to others' thinking and flexibility in their own thinking. One signature pedagogy that was evident in three of the teachers' $\mathrm{P} 4 \mathrm{C}$ practice was receptive co-constructive teaching. This means that teachers needed to be (or to learn to be) responsive and to think quickly to guide the dialogue to a more productive pathway. Because a student-led CoI sparked from student questions requires a great deal of openness from the teacher - they cannot always predict where the dialogue might lead - teachers found that their planning did not always prepare them for the 
direction of the dialogue. A thread of dialogue could either be very productive or it could run dry.

The verbs that teachers used to describe their teaching in the P4C context: 'facilitating', 'guiding', 'co-constructing', indicated the shared nature of the project they found themselves in together with their students. The learner constructs their knowledge alongside their peers, in a conducive environment, guided or 'scaffolded' in the process by their teacher(s) (Vygotsky, 1962). While many teachers stated that they aim to coconstruct learning across the curriculum with their students, they reported that this is a challenging task because there are not many models for teachers of how to do this well. In addition, the responsibility to teach curriculum knowledge can inhibit teachers' willingness to explore co-constructive models. However, the democratic, dialogic approach of the CoI requires teachers to share their power in directing the dialogue with the students more than they would in other teaching, meaning that the approach promotes co-construction:

The thing I liked about philosophy is that we always talk about co-constructing the learning and student agency and that was always something that I didn't really know how to do - I talked the talk but didn't know how to actually enact that and in philosophy, it just came very easily. - Alana, School D, postintervention interview

Alana found that after having had many discussions in staff meetings about the theory of co-construction and student agency, but not having understood how to enact it with her students, the structure of the CoI and its emphasis on student inquiry and dialogue taught her, practically, how to co-construct student understanding and learning. This co-construction was inquiry in action; students refined their understanding of philosophical concepts by listening to and evaluating each other's perspectives and reasoning, modifying their prior knowledge, together making progress towards deeper, more nuanced understandings. While teachers described ways that they saw students using philosophical skills and dispositions in other learning contexts, they did not explicitly identify the impact of this teaching method on their teaching and coconstruction in other curriculum areas and contexts. However, all the teachers described the positive impact of the $\mathrm{P} 4 \mathrm{C}$ approach on the class culture, making it more 
democratic and respectful. This finding appears to support a small number of research studies that have explored the impact of teaching P4C on teacher pedagogy (Roche, 2011; Scholl, 2012, 2014; Yeazell, 1981) and indicate that teachers experience improvements in teaching knowledge, and in teachers' own thinking skills (as well as their students). However, further research conducted over a longer period of time could give greater insights into the impact of teaching $\mathrm{P} 4 \mathrm{C}$ on receptivity in teaching across the curriculum.

\section{Supporting students to be receptive}

A key challenge for the teachers in facilitating a democratic student-led open dialogue was discerning when they needed to step in in order to support student thinking and interaction, and when to let the dialogue flow and allow the students to moderate their interactions. At times teachers interrupted the flow in order to clarify a point or to highlight a thinking skill a student had demonstrated, for example, to emphasise a distinction a student had made. Most of the teachers agreed that one of the most challenging elements to navigate was discerning when to intervene if a student seemed to be dominating the discussion too much, or others were not having the opportunity to contribute their thoughts to the dialogue.

\section{Vignette: Billy}

Billy was a confident student at School D with high cultural capital. He had taken part in a special P4C group for children identified as gifted and talented for two years prior to this research study. This meant that he saw himself as an expert and was both assured in his understanding of what philosophy was and experienced in presenting his ideas to his peers, as demonstrated in this excerpt of dialogue:

Ataahua: um, I used to think that Philosophy was when you um just like, think of like a topic or something and like sometimes kind of like debate about it and ask questions about it, yeah

Interviewer: do you still think that?

Ataahua: um, yeah, kind of 
Billy: that's quite an accurate first thought... I've done philosophy for three years in a row with a professional... and that's what he was telling us philosophy is

Interviewer: what'd he say?

Billy: it's all about connections, thinking, debating

School D, post-intervention focus group interview

While Billy often offered useful and insightful contributions that drove the dialogue forward, sometimes he could dominate the discussion without listening or giving space for others' perspectives. His peers recognised that he had a quick logical mind and would defer to his argument at times. Billy often challenged his peers' reasons and offered them examples of more valid reasons when he judged that their reasoning wasn't clear or strong enough. Many of his comments during the discussion were of a metacognitive nature, evaluating the strength of his and others' claims, questioning and reasoning, or assessing the trajectory of the dialogue, for example, when the discussion was taking a tangential turn, saying "I know a way to pull it back." He would also often offer counter-examples to refine the shared understanding or definition of an idea or concept.

There were a number of instances during the $2^{\text {nd }}$ recorded CoI when Billy ignored the agreed turn-taking convention of waiting to be handed the talking object and interrupted his peers to make his point heard. Alana gently reminded Billy to wait for his turn and to write his thoughts in his thinking journal if he wanted to. After multiple further interruptions from Billy, Alana reinforced the expectations and warned him that he would need to take some time out from the dialogue if he interrupted again, and then followed through on this by sending him out the next time he interrupted another speaker. This gave space for others to speak and emphasised to Billy that the dialogue rules applied to him as well as to everyone else. While he would often interrupt or comment out of turn, he would quickly chastise others if they did so. 
His teacher, Alana, commented in her post-intervention interview that Billy disliked P4C in class because “he probably doesn't like having to listen to people for that long. So it would've been difficult for him... [P4C is] great for kids like him to learn how to listen. It's more listening than talking - that's what they don't realise." She suspected that part of the challenge of P4C for Billy was the democratic nature of it. In class Billy was used to being one of an elite few who had a strong voice that everyone would listen to but in P4C everyone could have a say, and all students were developing the skills to voice their perspectives.

In the post-intervention focus group interview, Billy said that he was bored of P4C and didn't enjoy it much anymore however he also described elements of $\mathrm{P} 4 \mathrm{C}$ that he enjoyed:

\author{
Billy: I like working with new people \\ Interviewer: why? \\ Billy: because you get to understand different ways different people learn, \\ how they choose to answer questions, their strategies... also everybody is \\ the teacher \\ Interviewer: how come? \\ Billy: cos everybody's explaining their ideas \\ School D, post-intervention focus group interview
}

This description is at odds with his teacher's analysis however perhaps both analyses are true. While in theory Billy recognised the value of working with and listening to others, in practice this was more challenging for him.

Each class in Schools B, C and D had a group of 3-5 boys who were similarly confident and outspoken. Many of them found it very difficult to wait for their turn to speak in the dialogue. There were contrasting outcomes from these students' contributions. On the one hand, their dominance could result in silencing others' voices and privileging their own perspectives. On the other hand, the thinking skills and language demonstrated by these students could help their peers to learn how to reason, disagree, question, and counter others' claims. Students like Billy could, from a Vygotskyan perspective, take 
the role of a more-expert learner by helping a less-expert learner to scaffold their learning (Vygotsky, 1978). Other students could observe, practise and internalise the new skills and knowledge they saw modelled by more articulate speakers. The dominant speakers could also learn from their more considerate peers who followed the agreed dialogue guidelines. In her post-intervention interview, Alana described how she had observed that, over time, students who had previously been quieter had become more vocal and more prepared to challenge their peers who interrupted, staking their claim for airspace. The democratic structure of the CoI served to shift classroom power dynamics and empowered quieter students, offering them ways to present their own perspectives to their peers. This shift that Alana observed is an example of epistemic access for diverse learners as they developed confidence to participate in the dialogue of the CoI.

The question of when teachers should step in and mediate the dialogue in order to support students to be more receptive to each other's ideas was one that the teachers tackled together. At an early participant teacher meeting, the teachers discussed this issue:

Emily: the last afternoon was like... [laughter] argh, I want to be quite grumpy, can I be grumpy? Is it okay to send people out of philosophy? It's supposed to be... it just felt wrong

Jono: I've done that, I've sent people out

Alana: of course you can

Emily: oh really? I just wasn't sure...

Interviewer: same thing goes

Emily: same same

Alana: because well it's the rules for a discussion; if you can't take part in the discussion you shouldn't be there

Teacher meeting one month into the project

The democratic, co-constructed nature of the CoI caused Emily to question her role as enforcer, able to give consequences to reinforce the boundaries, of dialogue rules. Over time she recognised how essential the teacher's role was in supporting student co- 
construction; in her post-intervention interview Emily said, "you need that structure in order to have that flexibility of thinking." The structure of the CoI and the dialogue guidelines gave healthy boundaries within which a robust dialogue could occur. Another strategy teachers used when students were not following the P4C rules (which all participant classes had created and agreed on together at the outset of the project) was to stop the dialogue and ask the students how they could solve the problem and how they would like to proceed. This handed the power to have a successful dialogue back to the students and emphasised their responsibility to be receptive to each other's contributions. It also empowered students by giving them a space to describe how they felt when others dominated the discussion.

\section{Intersubjectivity}

The previously described receptivity that $\mathrm{P} 4 \mathrm{C}$ requires of both teachers and students builds an openness to each other's ideas and perspectives, which is an essential precursor to intersubjectivity. In this section, I present four sub-themes: two relate to the participant teachers, who (a) built intersubjectivity by sharing their insights and professional learning with each other and learning from each other, and (b) learnt from, and alongside, their students. Then I describe two elements of intersubjectivity evident in student interactions, firstly in relation to collaborative thinking and then in relation to fallibility.

\section{Teacher network builds intersubjectivity}

There were common threads across teachers' descriptions of the professional learning they gained through teaching P4C. All four began to develop their P4C teaching practice and theory by taking part in an initial training course facilitated by P4CNZ (New Zealand's national Philosophy for Children organisation). Three of the four participant teachers took this training together (one teacher had already undertaken this training). Teachers benefit from support systems to help them to reflect together and learn from each other (Butler, 1996); the network of the four participant teachers was a forum that offered this support. Three of the teachers whose schools were geographically close stayed in touch with each other throughout the project and shared planning and teaching ideas, and occasionally visited each other's classrooms to observe each other's 
practice. Teachers described the value of this in recognising possibilities for personalisation of the programme (which I elaborate on later in the chapter), picking up tips from each other in terms of structuring the CoI and ways to introduce philosophical skills and concepts, and having time to reflect on their own pedagogy in light of a colleague's practice. They developed a shared intersubjective understanding about what made a good CoI and how to create the best conditions for students to develop critical language and thinking.

\title{
Teachers build intersubjectivity by learning from, and with, their students
}

The key factor that teachers identified as shifting their teaching theory and pedagogy was the actual practice of philosophising with children. This section describes how their observations of student learning and thinking influenced their teaching practice, and how much their own thinking developed and was challenged through the P4C discussions. They were learning from, and alongside, their students, as these two teachers enthused:

\begin{abstract}
And your own thinking, there were a few times when I thought, oh, I don't know what I think about that. But that's kind of the beauty of it at the same time, on the flip side, it's like, well, I'm not sure, so I'll let them go and we'll see where we end up. It's actually quite nice. - Emily, School B, post-intervention interview

We're all in this big conversation together and I love it because I can see how the children's thinking is developing, I think. But also it's really engaging for me. I'm really intrigued by the questions they're developing and it's highly thought stimulating for me as a teacher as well. There's so much going on that it's an incredible experience. Every week for this whole hour, you're immersed in this incredible conversation. - Jono, School C, post-intervention interview
\end{abstract}

In this instance, the teachers' intersubjectivity grew through their interactions, not with teaching peers, but with their students. Their thinking and pedagogy were influenced and at times transformed by both the nature and the content of the student dialogue. Through teaching philosophy, teachers (as well as their students) came to see knowledge as "the product of a continuing process of examination, comparison, evaluation, and judgment of different, sometimes competing, explanations and perspectives" (Kuhn, 1991, p. 202). As teachers observed the development of their students' thinking and argumentation skills, they came to recognise the value of their 
explicit teaching of certain philosophical skills and the impact of this on student capability. Later in the chapter, in the Personalisation section, I elaborate on the kinds of explicit teaching that teachers grew to value through facilitating philosophical dialogue.

\section{Intersubjectivity involves collaborative thinking}

For students, a key element of intersubjectivity related to collaborative thinking. Students highlighted the ways that building on others' thinking improved their own thinking and the shared understanding of the group. As well as indicating receptivity, as I described earlier in the chapter, the students' preparedness to build on each other's ideas contributed to their developing intersubjectivity. In this section I develop the points raised in the receptivity section about building on other's thinking, in relation to intersubjectivity. Students also emphasised the importance of evaluating each other's reasoning and being prepared to change one's mind if presented with stronger reasoning for an alternative understanding.

A clear theme that emerged from all of the focus groups was the value the students placed on thinking together. There is a robust literature exploring the value of collaborative thinking, also known as interthinking (Mercer \& Littleton, 2013), social shared cognition (Resnick, 1991), cognitive elaboration (Webb, 2009), or socially mediated learning (Salomon \& Perkins, 1998) that builds on Vygotsky's concept of the ZPD, whereby external social processes support individuals' internal cognitive development beyond what individuals could have achieved alone (Vygotsky, 1978). Each focus group described the value they saw in collaboratively building, refining, and deepening an idea or an understanding of a concept, together: the idea that together we are capable of more than we would be able to accomplish on our own. In this section I outline the students' observations and perceptions of the power of collaborative thinking.

For the students, collaborative thinking had a number of components and was beneficial to them in a number of ways. Firstly, collaborative thinking allowed them to refine their thinking, their ideas: 
Caitlyn: if I had like a bad idea, and if I actually share it, you never know if it's good - you can get it better by letting other people choosing what it actually means

Sophia: so like building on, is that what she means?

Interviewer: ok - is is that what you mean?

Sophia: wait - building on each other's ideas

Greta: [whispers] like a house

Interviewer: how does that help you to figure it out?

Caitlyn: I think it's by how you talk it

School A, post-intervention interview

Here Caitlyn describes some of the aspects of interthinking that many of the students highlighted in each of the focus group interviews: the opportunity to talk about halfformed ideas, and then to assess the ideas oneself, while speaking. Speaking in front of others could enable one to self-correct: to evaluate one's ideas, through the perceived lens of others, without even necessarily needing to hear their feedback. As new ideas emerged, the speaker could evaluate how robust they are, both independently and by hearing others' evaluations and judgements of the idea(s). An affordance of dialogue and collaborative thinking is the opportunity to have one's ideas and reasoning evaluated by one's peers. Trust in one's peers' interpretation and judgement grew over time, by using agreed standards to evaluate the validity of others' reasoning.

\section{Vignette: Samuel - thinking together helps you to go further}

Samuel was a student at School C who was well-respected by his peers. He had high social and academic capital and was an independent learner who often ran learning workshops for his fellow students. Samuel had experienced a version of philosophy a few years prior to the research project which he had not enjoyed because it was too prescriptive. He said that he preferred the way the $\mathrm{CoI}$ in this research project was open yet focussed, and more cooperative - you could help each other's thinking to develop. 
In his post-intervention focus group interview, he gave an example to illustrate why he thought thinking together is so valuable:

Samuel: if you've got five different people working on the same problem and you're all meant to work together but you're doing it independently - then none of you might get to it cos it's just one person on their own but if they're thinking together while working on it and someone finds something out that someone else is stuck on and that person helps the second person, then the second person can go to the next thing which perhaps the first person was stuck on. So by helping each other you go further because one person might not know how to do something and another person might not know how to do something else so if they work together it's kind of like one person knowing how to do both things. If they work together properly, that is.

School C, post-intervention interview

The following discussion that unfolded during the post-intervention focus group interview at School C shows the students' shared understanding and valuing of collaborative thinking and its accompanying elements: holding ideas lightly and being prepared to change one's mind when presented with stronger reasoning than one's own:

Moana: like sometimes when someone says something and then you get the dice and then, you're set on what you're saying, but then you're just thinking about what they've just said, sometimes,

Samuel: yeah

Moana: and then it changes your mind

Samuel: that's kind of the problem with active listening

Moana: and you kind of counter example against yourself almost... it's not a bad thing but...

Interviewer: it can be confusing

Moana: yeah

Samuel: yeah and if they like

Johnny: in the middle of speaking when you've been waiting for ages

Samuel: if they've got a completely different um idea and you're the first person on the other side, of your little, like, go... um you might and they've said something on the no, and you were going to say something on the yes, ah but then, you're active listening, to the people on the no and then you're like, wait, what was I saying again? Oh yeah that guy just said that so let me just rephrase that or something. So you end up going on to the no as well 
Interviewer: right, so they can they might actually convince you

Samuel: mmm, either that or you're just too actively listening and you lose track of what your idea was and then you end up not, yeah

Johnny: and then sometimes they're like, you're thinking of an idea and then they give a really good counter example and you're like, oh it actually makes sense, something like that

Samuel: yeah

Johnny: and they persuade you

Samuel: and also if you've got a really good idea and then they say something which is like, oohh, then instead of having your big rant, um you might be just like, well I agree with that guy's idea

Moana: sometimes your thoughts change when you hear someone else's perspective on it - and it changes your opinion

Samuel: sometimes it's not even just changing your opinion, you just

Moana: you realise that you agree with them, like, well that's what you were trying to say but in a different light

School C, post-intervention interview

These students are interthinking while they're discussing the power of interthinking! Here the students identify the power of active listening: they suggest that in true dialogic interaction, you should devote yourself to listening to others when they speak, rather than rehearsing the point that you think you want to make next because often the point you think you want to make will be influenced by the current speaker's idea. Active listening involves allowing your thinking to be shaped by others. They recognise that either your interlocutor will change your perspective on the topic under discussion, or perhaps you may even realise that your perspective isn't as different from theirs as you might previously have thought. Another's alternative phrasing and description may help the listener to clarify one's own understanding or the listener may discover that the speaker has articulated the same idea better than the listener could have.

Samuel describes the 'yeses and nos'- two sides of an issue, and then shifts, as he and another participant speak, in this meta-discussion, towards describing an aligning of oppositions. This awareness of the blurred and hypothetical nature of oppositions and binaries (Biesta, 2014; Daniel et al., 2004, 2005; Golding, 2011b; Lipman, 1995, 2003) 
re-appears in many forms throughout my analysis. As students shift away from a mode or perspective of egocentricity, through relativism, towards inter-subjectivity, they move away from dualistic thinking towards thinking that values uncertainty, and recognises complexity and the value of flexibility (Bleazby, 2011; Cam, 2008; Daniel et al., 2005; Dewey, 1910, 1925, 1944; Golding, 2011b). Interthinking, democratic dialogue, is not black and white. It is grey, it recognises and celebrates the shades of grey in the world and in our ever-fragile provisional thinking.

All of the participants in the study appeared to express excitement in the breadth and depth of scope available to them when they were thinking together and engaging in critical dialogue in a CoI:

Leo: what I like about philosophy is we're in a group of people to have great ideas and ... we can like share our ideas around to make, like, if we say one idea and then someone else can add to that idea and it ca- and they can keep adding and adding and adding, to make it more interesting

School A, post-intervention focus group interview

To return to sociocultural theory, as I described in Chapter 4, Mercer and Howe (2012) neatly summarise Vygotsky's claim about the tools and purposes of language:

'Intermental' (social, interactional) activity forges some of the most important 'intramental' (individual, cognitive) capabilities, with children's involvement in joint activities generating new understandings and ways of thinking - not only for them, but also sometimes for those with whom they are interacting (p. 13).

I restate this definition of intermental activity here because seems to be precisely what the students saw happening when they were thinking together, building on each other's ideas. As students collaboratively build knowledge, this process of co-construction requires students to justify their thinking, acknowledge and clarify each other's ideas, and elaborate on others' claims (Barron, 2003; Webb, 2009). 


\section{Students develop intersubjectivity by understanding the fallibility of knowledge}

Samuel: I was going to say, I agree with myself, but

Interviewer: why do you agree with yourself?

Samuel: because I always agree with my idea!

Interviewer: do you ever change your mind?

Samuel: yes

Interviewer: so then you agree with the new idea?

Samuel: yes but then that becomes my idea

Interviewer: I understand

Samuel: you gave it to me!

School C, post-intervention interview

Samuel clearly describes the way his thinking changes here. His first statements: "I agree with myself... I always agree with my idea!" could be interpreted (at first) to indicate a certain rigidity of thinking however he quickly dispels this interpretation. Samuel's ideas are not fixed. Likewise, his identity as a thinker is not fixed. He holds ideas lightly, playing with them, trying them on for size, and then discarding them if they don't fit. He is open to being persuaded by those with whom he is in dialogue. Samuel's response epitomises that of all of the focus group students, who described changing one's mind as a key ingredient in their definition of a good philosopher.

Integral to a social realist understanding of knowledge is the provisional nature of knowledge (Bernstein, 2000; Wheelahan, 2007, 2010a, 2014), which is inextricably linked to the social character of knowledge. An acknowledgement of the social character of knowledge doesn't need to take away from its veracity. In fact this social character of knowledge can strengthen it, because of the refining nature of ongoing examination, questioning and challenging:

The objectivity of knowledge is in part located in the social networks, institutions and codes of practice built up by knowledge producers over time. It is these networks of 
social relations that, in crucial ways, guarantee truth claims and give the knowledge that is produced its emergent powers (Moore \& Young, 2001, p. 456).

Although Moore and Young are describing the process of knowledge building in the disciplines amongst experts, not children learning to philosophise, in fact the network of a CoI that teaches children to listen, evaluate, question and challenge each other's claims is a very similar structure to that of a disciplinary community of researchers and experts (Seixas, 1993). Through P4C, students learn to reconstruct and co-construct truth claims in dialogue with others within agreed codes and values - processes essential to disciplinary thinking (Collins, 1998; Gregory, 2002: Moore \& Young, 2001, p. 458; Peirce, 1887). They develop an understanding of the provisional nature of knowledge, and learn to strive to get as close as possible to 'the truth' (Wheelahan, 2014). Samuel's comments, which indicate a fallibilist form of inquiry, are indicative of many of the students' understanding of philosophical thinking by the end of the project.

Integral to the process of refining and improving knowledge is the ability to evaluate reasoning and the validity of claims. Most students recognised the importance of judging and evaluating each other's reasoning in order to decide whether or not they were convinced sufficiently to change their mind. The importance of evaluating reasoning is highlighted through the next composite student vignette which demonstrates many students' thinking about the importance of strong reasoning.

\section{Vignette: Greta - Evaluating reasoning ${ }^{7}$}

Greta was an inquiring student who always had many questions and ideas to offer to the CoI. In the post-intervention focus group meeting, Greta suggested that the CoI could have been improved by having more recording devices so that whenever anyone had an idea that they wanted to explain, they wouldn't have to wait for a turn in the group discussion, they could just tell it to a recording device. Clearly she had a lot of thoughts she wanted to convey, and wanted to be heard. At the same time she saw the value of listening to and building on each other's ideas in order to develop both one's own ideas and the group's shared understanding of a concept. She often

\footnotetext{
${ }^{7}$ Greta is a composite sample student so her quotes are not attributed to a particular school.
} 
asked thoughtful questions about the nature of philosophy: "do you think this is a philosophical book?" about a book she'd brought from home, and "what kinds of jobs would philosophy help you with in the future?" In her post-intervention focus group interview, she emphasised the importance of good reasoning.

Greta: if you aren't in agreement with it, it can still be a good idea if they say it clearly, and they give lots of reasons why, then it can still be good

Interviewer: so if you don't agree, it can still be good if they give lots of reasons

Greta: no it can still be a good idea... if they're good reasons, cos it's like, they're easy, like if you're trying to explain why you think something and then you just said like, 'because it can,' or 'because it is,' that wouldn't be a good reason

Here Greta is tackling questions that the students in each participant school wondered about: what distinguishes good reasoning from weak reasoning? How can we evaluate the strength of reasoning presented to us? She emphasises the importance of good reasoning; she also clarifies what she means by good reasoning (or rather what isn't good reasoning): if someone gives lots of reasons for their position but they're not good reasons, this is not persuasive (quantity doesn't equal quality). Greta also states that 'reasons' that are not actually a reason, e.g. "because it can" or "because it is" are not good enough.

When Greta's group were discussing how they might use the skills they've developed in $\mathrm{P} 4 \mathrm{C}$ in real life, she suggested that:

Greta: just in general life, like if you're doing something or someone else is saying something, or doing something, you can kind of see what they're thinking with our guidelines and our thinking skills like, you could tell if someone was making an assumption, and it's just, a handy thing to know.

Here Greta identified how an explicit metacognitive understanding of the skills and process of philosophical discussion (such as listening, asking questions, giving reasons, thinking about other's points of view, helping each other, disagreeing respectfully, thinking together) could help her to understand others' thinking. Her statement: "it's just a handy thing to know" appears to indicate that she recognised 
how this knowledge could afford her deeper understanding when debating a concept, 'in general life.'

Over the course of the project, the students developed a stronger idea of what good reasoning is, and held each other to account according to the strength of each other's reasoning. In the final set of recordings across the four schools, there were many instances of students asking for reasoning from their peers if a justification was not initially offered, and evaluating the strength of each other's reasoning. All of the focus group students recognised the value of the skill of being able to evaluate others' (and one's own) reasoning, not just in $\mathrm{P} 4 \mathrm{C}$, or just in school, but in life.

In this section I have described the professional development that occurred for teachers through teaching P4C. As well as the formal training they took part in and the intersubjectivity they built through their professional network of fellow participant teachers, the teachers emphasised the importance of the professional learning they gained through the practice of philosophising with children. I have also examined how student intersubjectivity grew as they philosophised together, through collaborative thinking, which involves active listening, building on each other's ideas, evaluating others' thinking and reasoning, and being prepared to change one's mind if presented with stronger reasoning for an alternative perspective.

\section{Personalisation and innovation}

This section describes the innovations that teachers made that were new, responsive and adapted to the needs of the students in their classes. All the teachers described a process of trial and error that they went through in adapting the $\mathrm{P} 4 \mathrm{C}$ programme in order to scaffold the development of their students' critical thinking. To be successful, teachers found that they needed to be responsive and adaptive in their teaching decisions and actions in P4C. The P4C training course had furnished the teachers with resources, some practice and experience, and an understanding of the fundamentals of a P4C programme. Teachers new to P4C took time to identify which elements were essential to a CoI and which elements could be tweaked and adapted according to a class' needs and the teacher's style. Some of the teachers realised upon reflection that 
they had started out with somewhat rigid expectations about the structure and form of a CoI. However they realised, over time, that the structure of the programme could be quite flexible. Each teacher found that they needed to personalise their P4C programme according to the experience, needs, strengths, and interests of their students. This personalisation required reflection and responsiveness on the part of the teacher. Furthermore, by adjusting their pedagogy in order to meet their learners' needs, the teachers worked to redress epistemic injustice and to offer epistemic access to diverse learners.

The section reviews three key ways that teachers personalised their P4C programmes for their students: through explicit teaching of critical thinking skills and the language of argument, by building disciplinary understandings, and by carefully structuring the P4C programme according to the needs of the students. As I discuss, some of the decisions and actions the teachers took in adapting their P4C programmes were similar, and influenced by each other; other adaptations were different according to the needs of their different classes.

\section{Developing students' critical thinking skills}

A first innovation on the part of the teachers related to developing students' critical thinking skills. Many of the teachers' conceptions of critical thinking were discussed in relation to the development of thinking skills which were perceived to denote a certain type of flexible, problem-solving, intersubjective thinker. For example, teachers described how as a result of participation in P4C, students could develop new skills and capabilities in group work, for example, listening, understanding other perspectives, or decision-making. Teachers identified that $\mathrm{P} 4 \mathrm{C}$ could have meaningful educational and personal outcomes for students and could promote deeper thinking and understanding.

Teachers saw a lot of value in teaching the students thinking skills as well as the philosophical content of the discussions. As I described earlier in the chapter, the participant teachers formed a teaching as inquiry network through their participation in the research study. They shared ideas with each other, trialing and tweaking each 
other's innovations. Alana, who was the most experienced in teaching P4C, tried different ways to make the different learning foci visible to her students.

Image 2: Boardwork-Performance, skill, and content foci

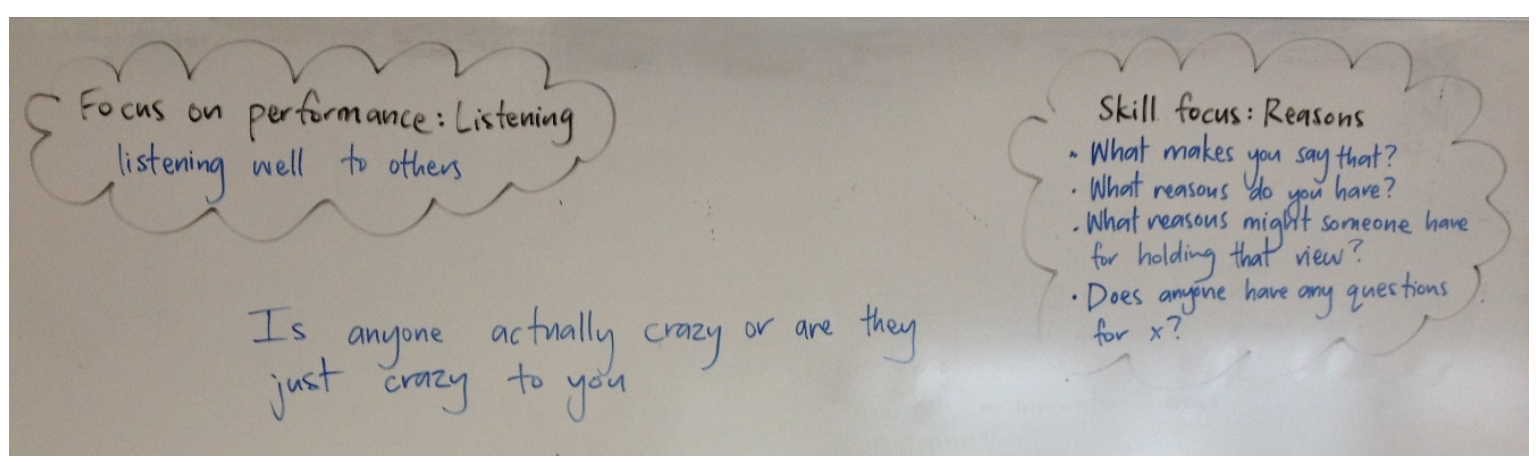

School D, Col mid-project

This example of Alana's boardwork demonstrates the different foci she highlighted for her students in a CoI:

Performance focus: Listening

Skill focus: Reasons, with a list of suggested questions to encourage students to challenge each other to give reasons for their claims

Content focus: Is anyone actually crazy or are they just crazy to you?

The content focus of the lesson grew from a question one of the students had posed in the previous CoI, which the students had decided to save for the following week when they could devote a whole dialogue to that question. The skill focus questions were drawn from a list of 'Procedural or Content-neutral Questions' in the training material from the P4CNZ training course (Kovach, 2014), which built on Golding's (2011a) thought-encouraging questions for critical thinking. Kovach's (2014) list includes questions to encourage focus, clarification, evaluating, explanation, evidence, implications, connections, distinctions, definitions, assumptions, consistency, examples, counter-examples, alternatives, summarising, questions, and participation. As well as writing examples of the questions students could use to foster the skill focus of the day on the whiteboard, Alana created skill master cards with the questions - drawn from Kovach's (2014) list - written on them, which she gave to selected students who could act as skill masters during that CoI. Their role was both to participate normally in the dialogue, and also to listen to their peers' claims and, if need be, to challenge them to 
give reasons by asking one of the questions. Other children were also welcome to ask each other the reason-encouraging questions but it was the particular job of the skill masters. Teachers varied the skill master questions according to the skill focus of the day.

Two of the other participant teachers, Emily at School B and Jono at School C, were inspired by Alana's idea and started using skill master cards in their Cols as well. The teachers identified a number of benefits of this innovation:

Skill masters [are] good for you as a teacher to know what you've covered. I was thinking about that in relation to creating a curriculum for philosophy, like how do we keep track of what we've done, what skills they're learning? Alana, School D, post-intervention interview

One thing that really empowered Will [a diverse learner] was that he became the Example Master one day so his role was to say, can you give me an example of that? And at first he had to be prompted every time, often Moana or someone would go, "hey Will ask that question," and he would say, "oh ah can, can I get an example?" and forget the question and things and then eventually started using it himself. - Jono, School C, post-intervention interview

By identifying particular skills that students needed to develop next, and introducing these to the class through the skill master role, teachers explicitly made thinking processes visible for the students (Ritchhart, Church, \& Morrison, 2011). In their planning they could track which skills they had taught. During the dialogue, the skill masters' responsibility to ask the thought-encouraging questions meant that teachers could focus on the other roles they were juggling while facilitating the CoI. It was another way to share power with the students; not only were the students thinking about the content of the discussion and the skills they themselves were using, they were also assessing each other's speaking and listening and supporting each other to deepen their thinking and questioning. This explicit teaching of critical thinking capabilities meant that, rather than thinking being 'everywhere and nowhere' (Hipkins, 2013) - a problem I discussed in Chapter 3 - teachers ensured that students understood how and when to use critical thinking and language in meaningful contexts. 


\section{Vignette: Tony - finding a voice}

Tony was a focus group student at School B who was an English language learner (ELL). While he appeared to be comfortable speaking in the small group situation of the focus group interviews (making 42 contributions across 2 focus group interviews), he did not make many contributions to the whole class dialogue during the 3 recorded CoIs ( 4 in total). His teacher Emily noted this reticence and intentionally chose him as a skill master, hoping that this role might support him to participate in the discussion.

Emily: so are you saying doing something dangerous is brave, if it's dangerous?

Child 1: if it's dangerous

Emily: okay

Child 2: It depends how big the cliff is

Emily: bec- oh mm

Tony: what reasons do you have? What reasons do you have?

Child 2: it depends how big the cliff is because - if it was really little, you could jump jump jump you could you could go down you could go down if you fell it wouldn't be as bad a landing and you and it wouldn't be as bad

School B, 2nd recorded CoI

Tony was clearly following the dialogue closely and accurately recognised the need to challenge Child 2 to extend her claim by giving a reason at just the right time. In a later discussion when Tony hadn't explicitly been given a skill master role, he still took the role of peer-questioner, asking a peer, "what do you mean by, it's free?" to clarify her statement.

The skill master questions that teachers introduced to the students became more widely used by the students over the course of the research project. Children - not just the skill masters - encouraged each other to deepen their thinking, speaking and reasoning by questioning each other. For ELL students, the structure of the skill master questions was a useful scaffold to help them to participate in the dialogue. More than 
aiding participation, these questions helped students to build cognitive academic language proficiency (CALP) which all language learners need to develop in order to be able to think and reason in another language (Gibbons, 2002). Two of the participant teachers described intentionally choosing ELLs as skill masters in order to support their oral language development.

\section{Enhancing students' disciplinary philosophical knowledge}

A key element of P4C is that students learn to be philosophers rather than learning about philosophy. Philosophy is the discipline of good thinking; it tackles the conceptual and epistemic foundations of all of the other disciplines (Splitter \& Sharp, 1995, p. 89). A CoI is a dialogic practice which supports children to form and collaboratively refine their own hypotheses about philosophical concepts. Jono, the teacher from School C, made a second innovation to support students' philosophical knowledge development. Once the students had had the opportunity to explore and co-construct their own ideas about these concepts, he wanted to help them to see how their inquiries had links to essential philosophical concepts.

\section{Image 3: Branches of Philosophy and Col topics sorting activity}

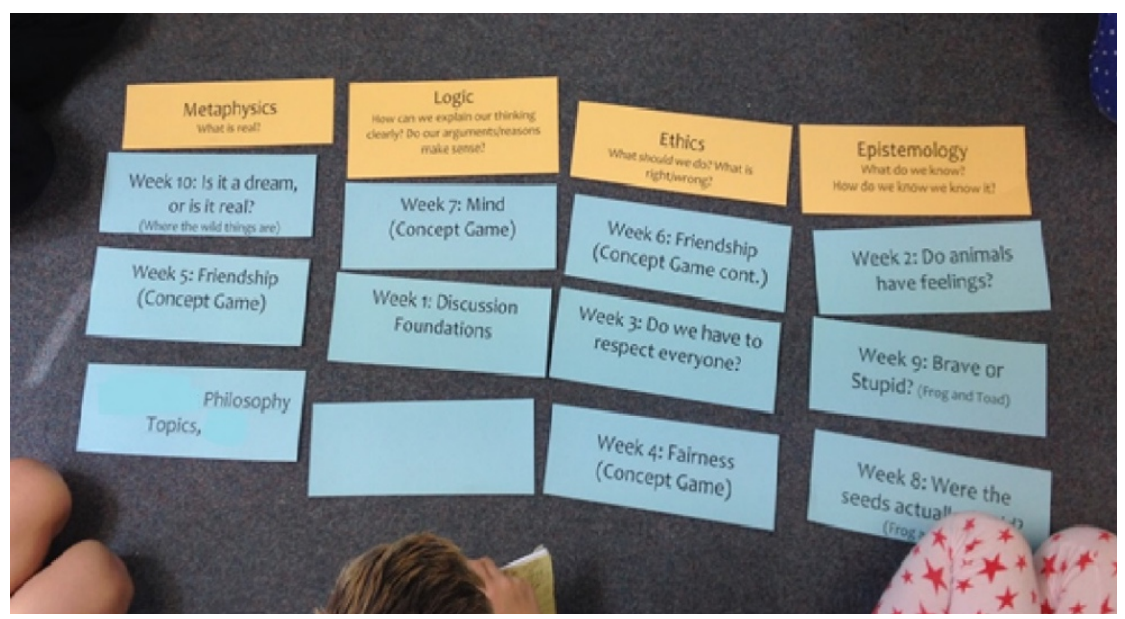

School C, Col mid-project

After Jono's class had been doing P4C for a term, he ran a reflective lesson with the students in which he introduced the branches of philosophy with a simple explanation for each, and then invited the students, in groups, to sort the topics they had tackled that term into their respective branches of philosophy. 
The learning activity was a form of backward-mapping, allowing the students to make connections between understandings they had constructed together and broader philosophical concepts. This gave the students the opportunity to identify how their discussions connected to conversations philosophers have been having for centuries. Jono identified that, in order to keep the philosophical learning exploratory for the students, it was important that the branches of philosophy were only introduced to the students retrospectively, once they had spent time inquiring into these concepts based on their own thoughts and experiences. Had he started the project by introducing the branches to philosophy to his students, the students would not have had a tangible context in which to situate their understanding, and the teaching would have been didactic rather than collaboratively co-constructed. This approach was consistent with Lipman and Sharp's (1986) conception of democratic education, that formulates its educative mandate in terms of thinking rather than in terms of instruction, treats children as active and creative subjects rather than as passive listeners, and respects their inclination to research and to question instead of considering curiosity as an instinct to tame (pp. i-ii). This lesson built powerful knowledge for the students both because of its reflective metacognitive nature and because it connected their learning and thinking to disciplinary knowledge.

\section{A structured approach to facilitating the Col}

A third innovation I observed in the teachers' approaches was a distinctive feature of Olivia's approach to teaching P4C at School A: her structured approach to leading the CoI. This structure took two forms: a more teacher-directed discussion, and a clear focus on language and thinking tools. Olivia had very clear behaviour expectations for her students; there was a calm respectful tone in the class both amongst the students and between the students and the teacher.

Olivia questioned, clarified and rephrased students' statements often in order to ensure that she - and the other students - understood the logic of their claim. She also regularly modelled the key language that students needed to use: 
Olivia: right remember our two words that we were using yesterday...?

"Because" or "my reason..."

School A, $1^{\text {st }}$ recorded CoI

In addition to that, Olivia often made explicit references to students' language and challenged them to use specific language to convey their thinking:

Child 1: 'cos it was yours on the first of all? So you're just taking it back kind of?

Olivia: okay can we think of a word, when you take back something that belongs to you?

Child 1: um - taking it back!

Olivia: it's not stealing, you're saying, it's, does anyone have a word?

Child 1: taking it back

Child 2: retrieve?

Olivia: retrieve, that's a great word, re- re- anything else? Re-...?

Child 3: return?

School A, $1^{\text {st }}$ recorded CoI

Olivia often decided who would speak next in order to ensure that a range of students had the opportunity to speak, or would step in and introduce a 'round' to give everyone an opportunity to contribute to a particular idea, for example:

Olivia: so what I'm going to do is I'm gonna send the dice around and if you would like to make a comment about that, if you have an idea about unfair and fair and where that Maria scenario should go you can speak about it okay? We'll go this way this time. If you don't want to um share your thinking that's absolutely fine just pass the dice on, right? Okay.

School A, $1^{\text {st }}$ recorded CoI

At the end of the project, while Olivia still questioned and guided student thinking and dialogue closely, she also encouraged them to choose who would speak next, as demonstrated in this dialogue about being free:

Sophia: it's like um like you said if you're like in jail

Olivia: sorry, Ben was talking - you ready, Ben? Okay, try again. 
Sophia: and um when you're in jail and then you get out of prison um you're free but like in school, like in a classroom we're not really free

Olivia: keep going, keep going, keep going, I wanna hear more of that

Sophia: it's like, it's like the movie Tangled, she got stuck in a tower and when she got out, she was like, free.

Olivia: where were you going with the classroom idea? Keep going with that one

Sophia: like you, if you're inside you're not really free but when you're out with fresh air and stuff then you're free

Olivia: okay so you're saying like a physical, you're confined inside of a room or a place, that's not being free right, that's what you're saying? That's not being free? Okay, cool, pass the dice to someone else that hasn't had a turn

School A, $3^{\text {rd }}$ recorded CoI

Here Olivia pushes Sophia to elaborate on her claim that they are not really free in a classroom to explain why she thinks that.

At the beginning of the project there were fewer students at School A who already used the kind of thinking language required in philosophical dialogue, therefore Olivia needed to model this for her students. In the other schools the teachers could let the dialogue flow in a more student-directed way because there were more students who could model the language of dialogue for their peers.

Olivia described her planning for student learning in P4C as intuitive and responsive, according to the students' needs at the time. School A was the lowest decile school of the participant schools, with the highest proportion of Māori and Pasifika students. Olivia saw the value of $\mathrm{P} 4 \mathrm{C}$ in empowering her students because, through $\mathrm{P} 4 \mathrm{C}$, they could develop "life tools, all this kind of stuff that children need for their decision making... to give them some control, power, judgement... if they can think really clearly then it makes everything else easier" (School A, post-intervention interview). Olivia concluded that P4C helped the students to probe deeper in their learning and to develop "skills for life". P4C offered access, for a range of diverse learners, to powerful knowledge and skills that were valuable for their future learning and in life. 


\section{Concluding thoughts}

In this chapter I have described a number of ways that teachers' teaching capabilities and students' thinking and learning capabilities grew through P4C. I identified four overarching and interconnected patterns in the data in relation to the development of capabilities: resilience, receptivity, intersubjectivity, and innovation and personalisation.

The data in this research corroborated many findings already widely reported in the research literature about the impact of $\mathrm{P} 4 \mathrm{C}$ on student thinking: that $\mathrm{P} 4 \mathrm{C}$ promotes a range of skills (asking questions, categorising, drawing distinctions, reasoning, active listening, judgement and decision-making) and that it develops intellectual humility that recognises the value of changing one's mind if presented with stronger reasoning for an alternative perspective (Burgh et al., 2006; Cam, 2003, 2006a; Haynes, 2014; Lipman, 1998b; Millett \& Tapper, 2012; Sprod, 1998). Similarly, many aspects of the teachers' developing P4C pedagogies in this study resonated with themes highlighted in the literature: that teaching P4C involves discernment on the part of the teacher, it is a form of democratic pedagogy (Burgh, 2018; Cam, 2009), teachers can scaffold and support students to structure their thinking and understanding through board work (Kovach, 2014), the CoI is relevant and valuable when sparked by student questions (Splitter \& Sharp, 1995; Topping \& Trickey, 2014), and that student thinking and metacognition is supported by teachers encouraging student reflection (Fisher, 2007).

A substantive new finding from this research indicates that a collection of teacher dispositions and capabilities (the list generated here is by no means exhaustive) enhance P4C teaching skills: resilience, receptivity, intersubjectivity, innovation and personalisation of teaching to meet students' particular needs. The CoI model is a dialogic, democratic approach that each participant teacher described as different from most standard primary school pedagogical approaches; it explicitly builds emergent, constructed knowledge. Therefore, teaching $\mathrm{P} 4 \mathrm{C}$ requires a different set of teaching skills and dispositions than much other teaching. Dialogic teaching is an approach in which students both take part in collaborative construction of meaning through interpretive discussion (Meadows, 2013) and share control over classroom discourse 
(Alexander, 2005; Hennessy et al., 2011; Mercer \& Littleton, 2007; Reznitskaya \& Gregory, 2013; Wegerif, Mercer, Littleton, Rowe, \& Dawes, 2004). Through dialogic teaching, teachers come to view students as "active meaning makers who learn through constructing and negotiating new understandings in interaction-rich communities of practice" (Reznitskaya \& Gregory, 2013, p. 116). The process of supporting and scaffolding students to construct and negotiate new understandings together calls on teachers to be open to student inquiry and discussion, and to let this develop and progress without shaping its course too much. This was challenging for teachers when the inquiry went off into uncharted territory, which had the potential either to lead somewhere fruitful or possibly to reach a dead end, and the teachers had to relinquish control over the direction of the dialogue.

The many challenges that the teachers in this study faced in facilitating P4C can be seen as tension points that open possibilities for enhancement (Bernstein, 2000), as discussed earlier in this chapter. For example, the teachers stressed the value of both co-construction with students and explicit teaching of thinking skills; this was another interesting and novel finding. These two pedagogical methods are counterpoints, ensuring that teaching is neither too prescriptive nor too laissez faire. Receptive teaching enabled teachers to model, identify and highlight the cognitive moves that children were capable of when thinking together, which then became internalised by individuals. As the teachers modelled and scaffolded the dialogue, they enacted Vygotsky's ZPD (Sprod, 1998). As Vygotsky says, “What the child can do in cooperation today, he [sic] can do alone tomorrow" (1962, p. 104). While a co-constructed dialogue is a democratic mode of education that empowers students, the teachers still had a very important role in structuring and guiding their students' learning. As teachers new to P4C developed their skill in facilitating the CoI, they learnt to balance their role with the student-led nature of classroom dialogue. This process involved a great deal of trial and error which meant that teachers felt vulnerable at times when dialogues didn't flow as they had planned. Teachers found themselves in the role of learner; this called for resilience at times, which enhanced teachers' capability. 
One of the key aspects of P4C that the participant students valued was intersubjectivity. This confirms Daniel et al.'s (2002, 2003, 2005) findings about the development of dialogic critical thinking. In the students' words, this meant active listening, thinking together, building on each other's ideas, considering each other's reasoning, and changing one's mind. As Amelie put it,

Philosophers listen to other people's conversations, talk about what they have to say. You also say their ideas if they've got a better reason - a good philosopher would change their mind and agree with them because their idea is better. If they have a really good set of reasons, you should change - and say, I don't see why I should disagree with you.

School C, first focus group interview

In developing an awareness of the importance of refining one's ideas by pitting them against others', students in this study were forming the foundation for disciplinary thinking and establishing an understanding of "the social conditions under which knowledge is produced" (Wheelahan, 2007, p. 638). Bernstein (2000) proposes that rigorous abstract, conceptual knowledge is the means by which societies build knowledge by thinking 'the unthinkable' and the 'yet to be thought' (p. 30). P4C's democratic approach has the potential to redress the advantage afforded to those students with high social capital. Through P4C, diverse learners are given access to the knowledge, thinking skills, and language that can enhance their capability by enabling them to form, present, evaluate, and refine their knowledge and understandings in the light of the knowledge and understandings of their peers and teacher, to think the yet to be thought. 


\section{6}

\section{Enhancing language}

What comes first, a word or a thought? (Tishman \& Perkins, 1997, p. 368).

Thought is not merely expressed in words; it comes into existence through them (Vygotsky, 1962, p. 126).

\section{Language shapes thought}

There is a long-held fascination within linguistics and education with the power of language to shape thought (Halliday, 1993; Vygotsky, 1962; Wells, 1999). Vygotsky $(1962,1978)$, for example, argued that language allows, shapes, and sharpens thought; language mediates thought; one cannot think beyond the limits and boundaries of one's language capability. This chapter explores the various ways in which the language of philosophy enhanced students' academic language, thinking, confidence and ultimately, capital. My analysis draws on Bernstein's (1999; 2000) theories of elaborated and restricted language codes and horizontal and vertical discourses, Vygotsky's (1962, 1978) theory of how language shapes thought, as well as Cummins' $(1979,1981 b)$ language learning theory relating to the development of basic interpersonal communication skills (BICS) and cognitive academic language proficiency (CALP). My central claims, based on my findings, are that explicit teaching of philosophical academic language enhances students' articulation of their thinking, and in turn, their capacity for thinking critically. The enhancement of the students' language capability was so important that it warranted a chapter of its own. Philosophical language structures constitute elaborated language code (Bernstein, 2000) that gives students epistemic access to deeper modes of thinking and understanding. Teachers who explicitly teach learners language structures for deep thinking scaffold learners and hold high expectations for all learners which can set them up for success. In Chapter 7, I 
link this analysis to the social realist theoretical lens I am using to understand what this means for diverse learners' epistemic access to enhancing knowledge.

This chapter discusses two main themes that, like Chapter 5, are exemplified by vignettes of teacher observations and student experiences. Firstly I describe how teachers used critical talk moves and other innovative thinking routines to scaffold language and thinking and to make these visible. Then I present a temporal analysis (Mercer, 2008) of how student language and thinking patterns developed during the project. The data indicates that the complexity of student language and thinking varied for different groups of students across and within schools; I describe how some of this can be explained through the relationship between language and class. Further, not all students consistently engaged in dialogue. Next I outline the varying levels of student involvement in classroom dialogue, ranging from silence at one extreme to dominance at the other. I explore how students' language capability influenced their levels of involvement and examine a range of reasons for student silence in dialogue. I conclude by discussing how some of these findings about the relationship between language and thought affirm existing research. I also offer some new questions that the findings pose about student involvement and silence.

\section{Critical talk moves}

In this section I explore how students were exposed to elaborated language codes - the language of thinking - both through their teacher's modelling, and by listening to and absorbing the discourse of their peers. Over time, students had the opportunity to trial and refine their use of new language structures within the collaborative philosophical dialogue (Anderson et al., 2001). Gradually their social intermental processes of dialogue were absorbed and internalised and became natural intramental processes that enabled higher mental functioning (Vygotsky, 1997).

All the teachers in my study recognised and strongly valued the power of academic language to scaffold student learning and thinking; they conceived of the language structures they were teaching as thinking tools. Jono's description of his understanding 
of the power of language to influence thought explicates the tools metaphor that all of the teachers used:

Words can influence thought essentially, into deeper than that: words as like technological tools - once you learn how to swing a hammer you can build things, in the same way once you can conceptualise something with a word, you can then swing off into a whole new world of thought that didn't exist to you before ... Once you can name it, and you have [an] understanding of what that name means, then it's so much easier to talk about it and understand it. Jono, post intervention teacher interview

Jono's description indicates how teachers saw the power of language structures to enhance not only students' understandings of the world but also their thinking and speaking capabilities. The use of skill masters, described in Chapter 5, is one way that teachers scaffolded students' language learning and thinking development. Another important mechanism was that, as children learnt to philosophise and to take part in a CoI, they gradually built up a collection of 'critical talk moves' (Michaels \& O'Connor, 2015; Wegerif \& Mercer, 1997) with the explicit guidance of their teachers (O'Connor \& Michaels, 2017). The use of talk moves is well documented in the literature (Reznitskaya et al., 2008; Reznitskaya \& Gregory, 2013; Wilkinson et al., 2017). Talk moves are also described as thinking routines (Ritchhart et al., 2011), language structures or sentence frames (Tretter, Ardasheva, \& Bookstrom, 2014), exploratory talk (Mercer \& Littleton, 2007), or talk frames (Godinho \& Shrimpton, 2003). I use these terms interchangeably in this chapter. These talk frames were as simple as "I think ... because ..." or "I disagree with X's idea because ..." or "Can you clarify that statement please?" or "I've changed my mind because ..." Despite the apparent simplicity of the phrases, they both provoked and indicated complex thinking: making reasoning explicit, inviting elaboration or reasoning from others, connecting to and building on ideas, evaluating thinking, positioning and coordinating ideas and perspectives, and reflecting on the dialogue and the learning process, purpose, and value (Hennessy \& RojasDrummond, 2015; Hennessy et al., 2016b). Tishman \& Perkins (1997) contend that: Using the language of thinking in the classroom helps develop learners' sensitivity to occasions for engaging in high-level thinking. Terms like claim, option, opinion, guess, and doubt alert learners to opportunities to do such things as probe an assumption, seek evidence, identify reasons, or look at a problem from a new point of view (p. 372). 
This language is an integral part of the subject-specific register (Gibbons, 2002, p. 10) of philosophy which is the discipline of thinking.

As teachers observed the positive impact of these simple language structures on student dialogue and thinking, they grew to recognise the importance of teaching critical talk moves and the critical thinking skills and dispositions they engendered. The need to explicitly teach critical language structures was identified by all four teachers as an essential element of teaching $\mathrm{P} 4 \mathrm{C}$. The teachers highlighted the importance of teaching elaborated language codes, the language of argumentation and critical thinking in order to support students - particularly diverse learners - to express conceptual knowledge clearly. They recognized the dispositional impact of the talk moves, supporting learners to challenge and to question themselves and each other, eventually without prompting from the teacher. Teachers perceived how "the language of argumentation ... draws learners into the values and commitments of critical analysis" (Tishman \& Perkins, 1997, p. 372). Furthermore, the teachers described the positive impact of their awareness of these critical language frames and thinking skills and dispositions on their teaching in other curriculum areas. They noticed that they more consciously identified and explicitly taught disciplinary critical thinking skills and language across the curriculum as a result of seeing their benefits in P4C CoIs.

\section{Talk moves: teacher innovation and personalisation}

This next section presents innovative approaches that teachers devised to teach language structures - or talk moves - to help students to structure their thinking. The teachers introduced talk moves in different ways, often focusing on one talk move for a series of lessons, before introducing another. For example, Olivia (School A) scaffolded her students' development of philosophical language structures through the metaphor of a 'Philosophy Toolbox'. At the back of their Thinking Journals, Olivia encouraged her students to create a list of the new philosophical language structures, vocabulary, and thinking skills that they were learning, and to add to this whenever a new talk frame was introduced. During some lessons, Olivia would introduce a new word or phrase at the beginning of the lesson, encouraging the students to try using it in the dialogue. In other lessons language structures would emerge organically during the lesson, and in 
the reflection time at the end of the CoI, she would ask students to identify any new language they had noticed themselves or others using during their dialogue and encourage them to add the new phrase to their Toolbox. Thus, she made their language learning explicit and transparent, supporting students to integrate argument structures into their vocabulary. Furthermore, she drew on the affordances of dialogic learning, encouraging peer learning by explicitly encouraging students to identify philosophical language or the language of argumentation that they noticed their peers using, then to note this down and to try using the new language themselves in future dialogues. The following vignette indicates the impact of Olivia's toolbox approach on her students.

\section{Vignette: Groucho}

Groucho was a quiet, thoughtful student at School A who listened to his peers a lot during CoIs and didn't often contribute to whole class dialogues. However, he contributed more to the smaller focus group dialogues. His teacher noted that, at the end of a CoI, he often reminded the other students to add any new language they'd learnt to their Philosophy Toolbox list at the back of their thinking journals. Groucho recognised the value of the toolbox as a personal resource he was creating for himself. Image 4: Philosophy Toolbox

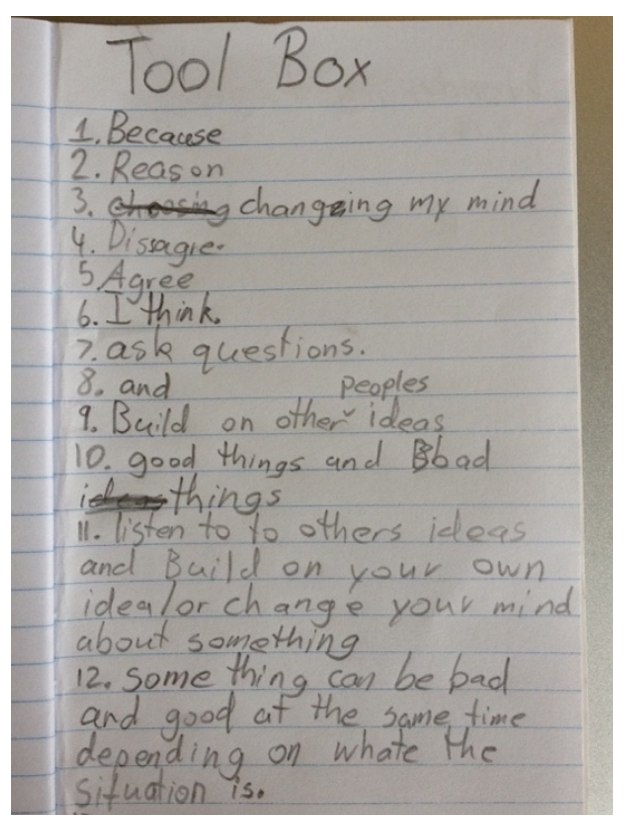

Groucho's Thinking Journal, School A 
In the post-intervention focus group interview, Groucho said that while at the outset he had thought that P4C was a group discussion, he now understood that there is more to it, that people could disagree and agree and you could add on to other people's ideas. He added that he liked philosophy because "it really gets you thinking and you could just keep thinking till the next day, you could be thinking about it on and on." He said that philosophy helped him to develop his creative writing, that when he thought about his ideas in a philosophical way, "it made my idea grow, instead of being so small."

Groucho's development seemed to be largely internal through this project. He was absorbing the language that his teacher modelled and that his peers used. He clearly recognised the power and value of the talk moves that he identified and noted in his journal. Groucho didn't often offer his opinions in the focus group; his contributions were normally of a reflective and procedural nature, discussing how a CoI worked, or what sort of language was philosophical, or philosophy's application in other areas of learning and life. Groucho appeared to be in a marinating phase, letting the language and the processes of the CoI season his thoughts, taking time to see what flavour he could add to the collaborative dialogue.

Each class in the study had a group of 5-15 students who, like Groucho, were clearly engaged in the content and process of the philosophical dialogue but who didn't often contribute to the whole class dialogue. Often they were more comfortable sharing their thinking through writing or drawing in their thinking journals or by talking with a partner or in a small group. Some of the teachers reported that they were surprised to hear from some the parents of these students about the lively and sustained conversations the philosophy topic had provoked around their dinner tables. Many of these students indicated to their teachers that they really enjoyed P4C and that, like Groucho, they thought about and weighed up the ideas sparked from the discussion for a long time after the dialogue. Another way to conceive of these students' marinating phase is to consider that they were operating in the early section of Vygotsky's ZPD, benefitting from the assistance of their teacher and peers, not quite ready to participate in philosophical dialogue unaided, while engaging in and rehearsing philosophical 
dialogue at home. They were taking time to integrate language structures that would build critical thinking routines. Research in language acquisition indicates that students learning an additional language need more time than native speakers to absorb, formulate, and articulate ideas (Cummins, 1981a, 1981b; Gibbons, 1998, 2002). In the same way, I observed that some students learning the academic language of a new discipline, in this case philosophy, needed more time to absorb, formulate and articulate their thinking, as well as to learn and become comfortable operating within the norms and modes of philosophical dialogue.

Like Bernstein's categories of restricted and elaborated language codes, language learning theorists use the terms 'context-embedded' and 'context-reduced' language (Cummins, 1981b) to distinguish between everyday language and academic registers. The parallels between the processes of learning a second language and learning academic language are very useful in understanding academic language acquisition. Cummins $(1979,1981 b)$ describes the use of everyday social language as basic interpersonal communication skills (BICS) and the mastery of the academic language of thinking as cognitive academic language proficiency (CALP). When students are learning a new language, they can usually master BICS in one year but it takes seven years to achieve CALP in a second language (Gibbons, 2002). Students' CALP is hugely improved through explicit teaching of disciplinary language structures (Gibbons, 2002). The data indicated that similarly, students who have mostly been exposed to, and communicated in, context-embedded restricted language codes and have had little exposure to context-reduced elaborated language codes, benefit from explicit teaching of academic language structures. We cannot assume that a child who comes from an English-speaking background into an English-speaking classroom has necessarily been exposed to academic vocabulary and linguistic forms or language structures that allow them to think as a scientist or an historian or a philosopher. In just the same way that teachers need to build the CALP (Cummins, 2008) of second language learners, the language demands of disciplinary thinking also require CALP. These students also take time to listen to how academic language is used in context, and time to incorporate this language into their own grammar and vocabulary. With practice, these language 
structures became thinking routines (Ritchhart et al., 2011) that shaped deeper modes of thinking and analysis.

Vignette: Alana - language structures as thinking routines

Partway through the study, Alana recognised that while her students were starting to use philosophical language to give reasons to develop their claims, the dialogue was often made up of a string of separate ideas and arguments but the students weren't responding to or building on each other's ideas. She described the CoI as a 'splattergun dialogue', whereas she wanted to teach her students to develop an idea together in order to build a new shared understanding of a concept. Alana wanted to challenge her students to think more intersubjectively (Daniel et al., 2005). Alana used structured boardwork to teach her students to use philosophical language appropriately so that they could see the arguments they were building together growing as they added reasons to the dialogue.

Image 5: Boardwork - Yes because, no because

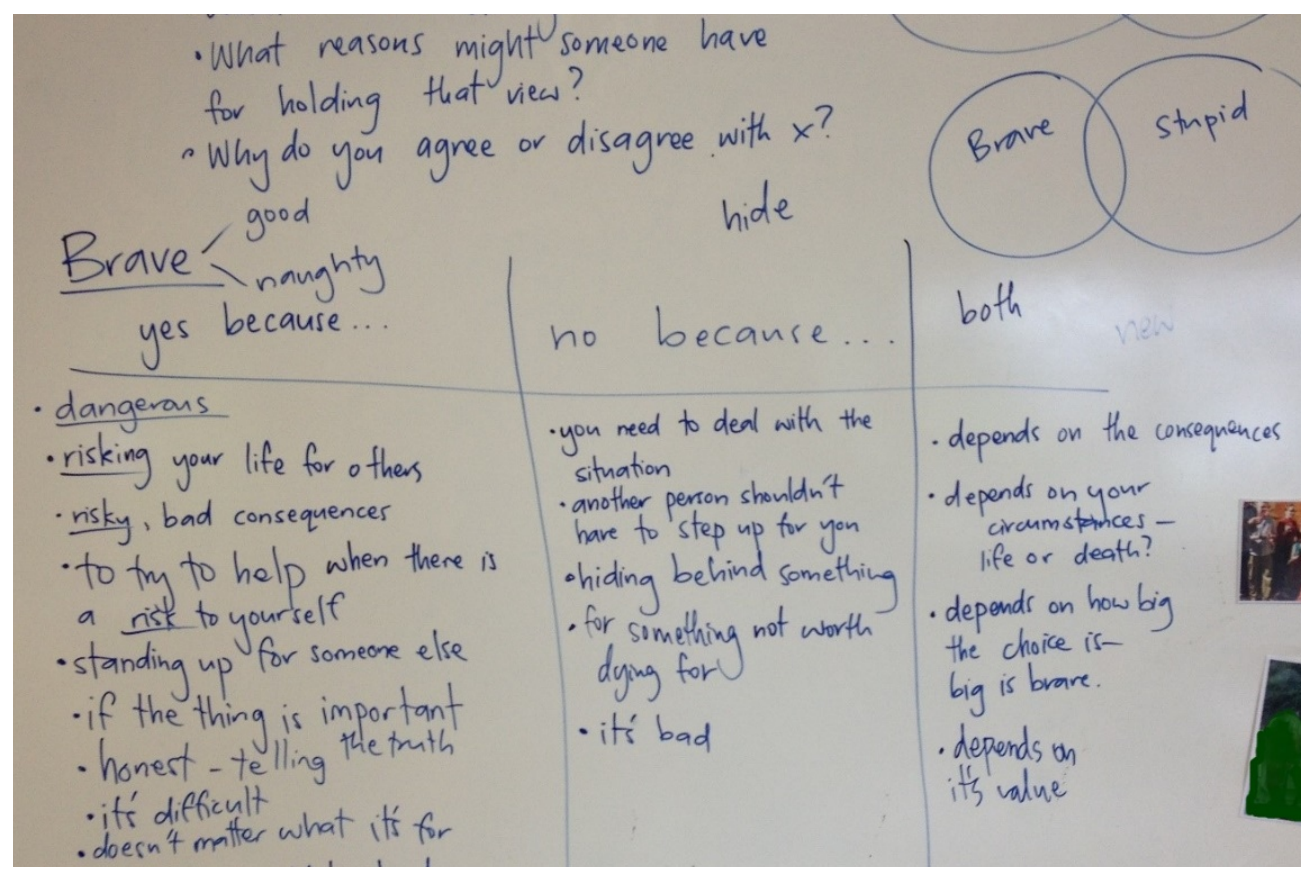

School D 


\begin{abstract}
By setting out different positions that students could take about the situation they were discussing, and eliciting student reasoning and documenting it, she helped students to see how their ideas were taking shape. Later in the study, Alana developed the boardwork structure further to support students to listen to each other's claims and to respond with another example or an objection, and then to encourage a subsequent reply to the objection with an alternative reason or counterexample:

Image 6: Boardwork - Reason, objection, reply
\end{abstract}

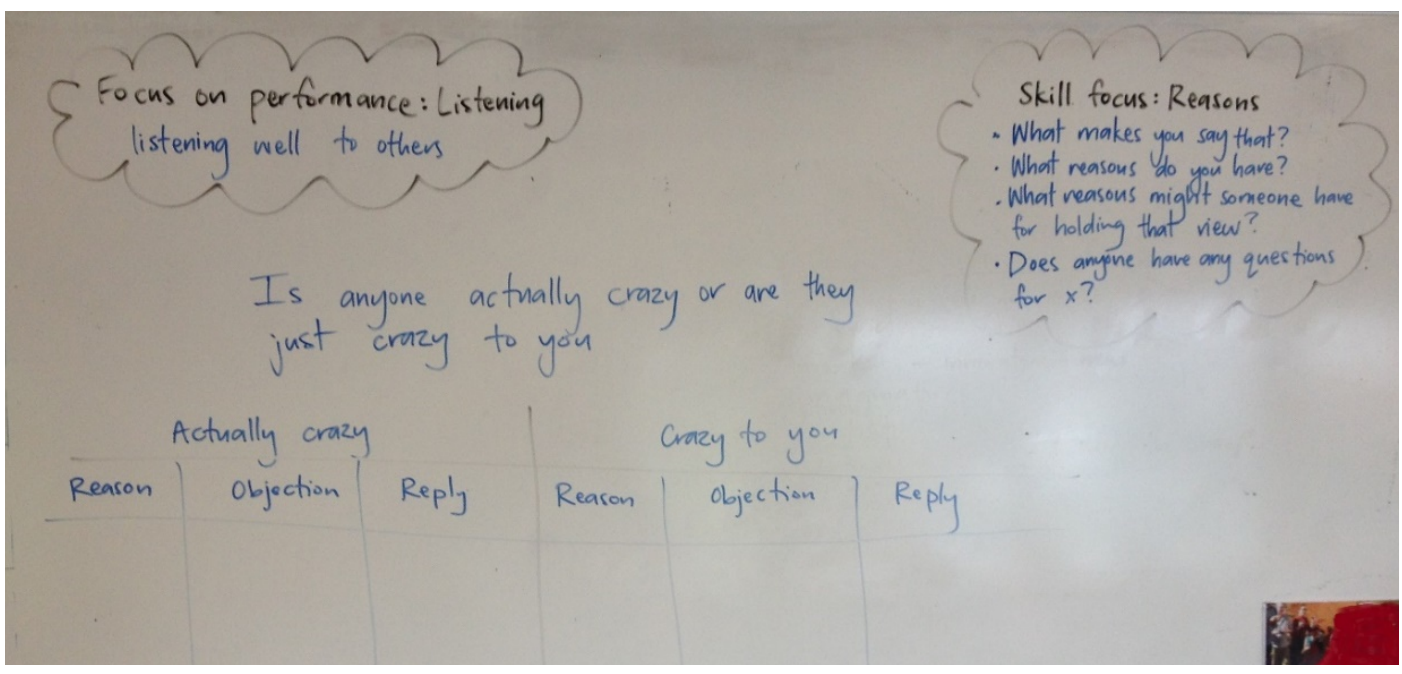

School D

Alana reported that the use of this structure resulted in more coherent dialogue in which students considered and responded to each other's thinking and reasons more carefully.

Alana shared this approach with two of the other participant teachers and they explored scaffolding student language and thinking using boardwork structures to help students to visualise, follow, and contribute to the development of the argument. All three teachers who had experimented with using this approach to boardwork in the latter part of the study said that they intended to keep using this structure with subsequent classes and CoIs because they could clearly see its value in scaffolding a more intersubjective dialogue. 
Vignette: Emily - scaffolding language and concepts

In her post-intervention teacher interview, Emily talked about how much she had learnt about teaching P4C through the study and how much she was looking forward to applying that knowledge to her planning and teaching with her new class the following year. A key teaching practice that she identified that supported students' linguistic and conceptual development was interleaving literature-sparked dialogues with 'concept games' that developed a particular talk frame and philosophical concept. For example, when teaching students about drawing distinctions, they spent one P4C session discussing similarities and differences between certain places, objects, or concepts, starting with the similarities and differences between a fort and a prison:

Ella: um one for instance, one thing is that like, well one similarity is that they're both to stop people doing something like, a prison is to stop you getting out of it, because you've done something wrong, and a fort is to stop you getting in it because there's something special so they're both, to like, stop you and also um I agree with what Julie was saying about oh what was it, oh about the the um ... about the the fort being a safer place ... because they would they might put someone in there to keep them safe, so that people couldn't get in there, like so let's say everyone was attacking the king because they were really grumpy with the king so well they might put the king ... oh this is

Emily: no, you're giving an example, thank you

Ella: they might put the king in the fort to keep him safe from, from whoever is trying to attack him whereas prison, is like to stop those people, the people who want to attack him

School B, 2nd recorded CoI

Later in the dialogue some students were identifying the similarities and differences between a mother and a father:

Ella: and the similarities were that they're both human and they're both parents, the same as them and our differences were, the first one was their personality and the second one is ah the mother gives birth to the child.

Emily: ahh excellent; can we just pass on to Freddy, I think he's going to say the thing that I was thinking 


\section{obvious \\ Emily: he just wants to make a little, a distinction \\ Freddy: parents don't have to be human \\ School B, 2nd recorded CoI}

Freddy: yeah definitely, I mean I don't mean to be mean to them but it's

In each excerpt Emily helps students to identify what philosophical skill or thinking move they are using by naming it for them, whether that be giving an example or making a distinction. Then she would encourage students to apply that language and skill in subsequent CoIs. In the post-intervention teacher interview Emily said, "weaving in the different concept activities - that took quite a long time to get going and turned out to be quite crucial."

Like the prior vignette, a key teaching focus in these examples was making thinking visible by identifying and naming the thinking move that the students were using, in order to support students - both those using the thinking move and those observing to recognise the value of certain cognitive moves in building a logical argument. A number of the teachers mentioned that they noticed their role in modelling and guiding student language development changing over time as students developed their familiarity with, and use of, philosophical language. As the language frames became routine for students, there was less of a need for teachers to spend time explicitly modelling and labelling them. The intermental processes - talking frames - had become internalised; now they were intramental habits. In Chapter 7 I further discuss how the process of internalisation of language structures and thinking routines contributed to students' understanding of how and when to make certain cognitive moves, which in turn built students' capital.

\section{Temporal analysis of student dialogue and thinking}

In order to gain an overview of patterns of intersubjective thinking that grew over time, I analysed the incidence of statements in dialogue that indicated critical thinking. The detail of this analysis is presented in Appendix I. The nature of the language I was able to observe in the recorded CoIs was affected by the teaching focus for the particular 
lesson, which impacted on the conclusions I was able to draw from this data source. Two CoI recordings in particular didn't generate as much intersubjective language: CoI 2 at School D and CoI 3 at School C. The lesson focus of School D's 2nd CoI was on sorting questions into categories using a question quadrant which helped students to understand what makes a question philosophical but didn't produce much language of critical thinking. As discussed in Chapter 4, School C's 3rd CoI was a reflection performance lesson which also didn't generate many instances of intersubjective language. Therefore in order to understand how the students' language had developed for both School C and D, I drew on my other data sources: the students' and teachers' observations in their post-intervention interviews. In their post-intervention interviews, the students at Schools $C$ and D emphasised the importance of strong reasoning and being open to changing one's mind when presented with stronger reasoning (described in more detail in Chapter 5); this indicated the development of their critical language and thinking. Jono observed that his students:

have taken on the skills that we've explored like giving reasons for their thinking or giving examples of their reasons. Giving counterexamples is starting to come on as well. It started with just learning the terminology for those thinking skills, just developed into kids being able to notice it when they themselves use them and it's developing into kids being able to notice thinking skills that each other are using.

School C, post-intervention interview

Jono discovered that explicit teaching of language and thinking skills built the students' awareness, identification, and use of philosophical language and thinking. In her postintervention interview, Alana described how her students had started using more language of critical thinking in other curriculum areas: "I did start to see it filter through," particularly in their literacy circles - book groups which the students ran themselves, questioning each other and discussing ideas and themes in texts they had read.

In each school, there was a growth in language that indicated student reasoning: making reasoning explicit, explaining or justifying their thinking. Students at Schools C and D already demonstrated the language of reasoning at the outset of the study, and this grew over time at School D. Students at Schools A and B steadily developed this 
language over the project. Student elaboration and clarification of their own contributions grew in particular during the project in Schools A and B, from very few instances of this at the outset to a tenfold increase in both schools by the end of the project. However students in Schools C and D demonstrated this language a little from the outset, and this didn't grow during the project.

At School D, students compared and evaluated alternative views and speculated and predicted from the outset; the incidence of this language stayed the same across the project. On the other hand, at Schools A and B, there were very few instances of comparison and evaluation of alternative views or speculation and prediction at the beginning of the project, but this language grew during the project so that it was occurring at a similar rate to School D by the end. Students at School C demonstrated very little language of comparison and evaluation of alternative views or speculation and prediction across the project.

While in Schools A, B and C there were very few instances of students explaining or justifying another's contribution at any point throughout the project, in School D the number of instances of students explaining or justifying another's contribution increased by more than double from the first to the third recording. There was also a higher incidence of student language that built on, explained, or clarified others' contributions at School D than the other three schools; this kind of language grew slowly over time at Schools A and B.

Language that challenged another's viewpoint was rare at Schools A, B and C but at School D, the language of challenging another's viewpoint increased over the duration of the study. Students at School D learned to use the sentence starter, I disagree with X'S idea because ... and talked about the value of disagreement in refining their reasoning and understanding in their reflections.

In the next section I discuss the patterns in the data in relation to class and explore some of the inferences one can draw from these findings. 


\section{Language and class: opportunity}

New Zealanders generally like to think of New Zealand society as equitable and classless. However, as discussed in Chapter 1, growing research indicates that inequality in New Zealand is increasing (Emanuel, 2013; Rashbrooke, 2014, 2013; Wylie, 2013). Some inferences can be drawn from my data about the links between socio-economic status and usage of elaborated language code (Bernstein, 1971b) or cognitive academic language proficiency (CALP) (Cummins, 1979). To appreciate this, we need to return to the notion of capital introduced in Chapter 1.

Children who come to school with the capital that allows them to succeed in the New Zealand education system have an advantage over those whose capital has offered them different understandings. Put another way, students with capital - due to inequality, usually students at higher decile schools - have more access to powerful knowledge. This advantage can be reproduced if teachers interpret constructivism as involving a relativist approach to knowledge: if students are left to choose what they want to learn, or are taught different skills and content based on teachers' assumptions about what is relevant to particular students then, despite good intentions to make learning engaging and relevant to students, this sets students on different pathways according to their prior knowledge and experience. Because students don't know what they don't know, they cannot choose to learn about something, however important, that they haven't encountered before. Those who have been exposed to powerful knowledge through their cultural capital will have an advantage and the others risk missing out on this powerful knowledge. Jackson (2008) argues:

One must walk a fine line in recognizing difference while ensuring fair access to ... 'high status knowledge' ... We must not respect difference so much as to sift students into different educational tracks, but we cannot ignore diversity and assume relative equality in its place, either (p. 144).

This research is grounded in a belief that all students deserve access to 'high status' powerful knowledge.

The data indicated that P4C offers a way to build capital and offer powerful knowledge to diverse learners, who are generally more highly represented in lower decile schools. The complexities of the decile rating system and the particular nature of each class 
described on pages 105-108 in Chapter 4 must be borne in mind when considering the implications of the patterns that were revealed in the data in this study. The comparisons were clearest in the differences between School D's patterns and the patterns of Schools A and B. School C's data did not fall into a clear pattern.

The patterns of student language demonstrated at School D were noticeably different to those I observed in the other three schools. From the outset, School D students were more versed in the language of reasoning and justification, comparison, evaluation of alternative views, speculation and prediction. They appeared to be more comfortable with, and were able to develop, language that challenged another's viewpoint. Lastly, and most indicative of intersubjectivity, the dialogue between students at School D showed more collaboration related to thinking: building on, clarifying, explaining and justifying others' language and ideas.

The data for Schools A and B followed similar patterns to each other. The strongest shift that occurred over the project, in both schools, was the increase in explanation, justification, elaboration, and clarification of students' own contributions. Teachers reported that the talking frame, "I think ... because ..." as well as skill master questions such as, "What reasons do you have?" were instrumental in eliciting this kind of language and thinking from students. By the end of the study, students at Schools A and $B$ were explaining or justifying their contributions as much as the students at School D did at the beginning of the study. The other clear shift that occurred at Schools A and B was the increase in the language of comparison, evaluation of alternative views, speculation and prediction. There was very little of this language demonstrated at Schools A and B at the beginning of the project, but by the end the language of comparison, evaluation of alternative views, speculation and prediction occurred at a similar rate to School D. This epistemological stance was clearly identified by the sample students in their post-intervention focus group interviews. They all agreed that a good philosopher listens to other perspectives, weighs them up, and if the reasoning is convincing, a good philosopher would incorporate these perspectives into a new understanding of a concept. 
The language of philosophy is a vertical discourse; it "takes the form of a coherent, explicit and systematically principled structure ... [and] a series of specialised languages with specialised modes of interrogation" (Bernstein, 2000, p. 157). While the students at School D were familiar with and could use this kind of language, which indicated they had had exposure to it either because of prior experience of $\mathrm{P} 4 \mathrm{C}$ or their social capital, the students at Schools A and B seemed to possess very little of this language at the beginning of the study. The teachers' explicit teaching of talk frames and philosophical language structures enabled students to understand, practise, and eventually incorporate this language into their repertoires. This enabled students to enter a philosophical debate with the linguistic and cognitive moves that their philosophical toolbox offered them in order to formulate and articulate their own thinking and to evaluate others' thinking.

These findings echo Topping and Trickey's (2007a, 2007b, 2007c) results that indicated that sustained participation in P4C CoIs resulted in the greatest cognitive gains for children who were in the lower quartiles of achievement at the outset of their study.

\section{Student involvement in dialogue}

While language has the power to enhance students' capacity for thinking, it can also be problematic due to a number of factors. The power dynamics and social dynamics within a classroom can influence and shape student language; student language and dialogue can also be an indicator of the power and social dynamics at play in a classroom (Bernstein, 1999, 2000). In Chapter 5 I described in a vignette an example of one of the students, Billy, whose cultural capital gave him the confidence to speak up and convey his ideas often, at times at the cost of other students having an opportunity to speak. In this section I describe different levels of student involvement in classroom dialogue and what these levels of involvement could indicate about epistemic injustice, student capital, confidence, social motivation and understanding.

There was a range of levels of student involvement in classroom dialogue. There were students who were dominant, some who were empowered to speak, those who were gathering confidence to speak and to use philosophical language, others who were more 
comfortable talking in small groups, and some who remained silent. Some students displayed a range of levels of involvement, depending on the topic or the dynamics of a given day. Some of these patterns differed across schools; I discuss my observations and some possible inferences about the influence of various factors on patterns of classroom dialogue. The following three vignettes explore and exemplify the different levels of student involvement in dialogue that I observed in the data.

Vignette: Lola-empowered to speak

Lola was a student at School D who, at the outset, was quiet and didn't contribute to the dialogue much; she said to her teacher at the beginning of the project that she didn't like P4C. However, over the course of the project she became more involved in the dialogue and reported to her teacher that she really enjoyed it. In the postintervention teacher interview, Alana described Lola's development over the project: "she's so softly spoken and she became so much more vocal." In the following example, halfway through the project, Alana encouraged Lola to wait for her peers to listen properly before speaking, so that she could convey her message:

Alana: Can you please tell us your reasons? Why is it fair?

Lola: the reason I think it's fair is like ...

[some chatter from other students]

Alana: sorry, Lola, just do what we talked about earlier which is where we wait to see that people are listening, before we start. So, if you are not listening, what do you need to do to show to Lola that you're listening?

Lola: [waits] ... um I think it's fair because if you were um if you're having a vote and people with the least votes win, that's quite unfair but if the people with the most votes win, like if you were playing a game of octopus or something, um and you were deciding who would be captain, you'd have a vote and see who wants to play in that vote and then you could split up into two groups

School D, $2^{\text {nd }}$ recorded CoI

By the end of the project, Lola stood her ground independently when other children interrupted her turn. She would wait until there was a gap in the dialogue, and then she would make her point, as this example shows: 
Interviewer: can you do this kind of [philosophical] thinking on your own?

Lola: well you could, but it's harder

Interviewer: it's harder - why is it harder?

Lola: the reason why philosophy is since, since if you wanna do philosophy, you wouldn't be able to - it would just be thinking about a book

Interviewer: okay

Lola: wouldn't exactly be philosophy

Billy: yeah

Interviewer: mhmm, so what's the difference, with philosophy?

Lola: you have, if you have people with you then it makes it much easier

Alana: more ideas

Lola: more ideas

Interviewer: oh more ideas

Billy: and also you use their work with more than one person

Lola: people help you

Interviewer: people helping you, you work with more than one person ...

Theo: and the more people the more ideas you get so the more, um you can change your mind

Lola: but --

Billy: and it connects and the more you think, you're being forced to think by your partner, more inclusive ideas

Interviewer: got it

Lola: since, if you were on your own, you might've made a really bad decision on something and then, like,

Billy: they just help you

Lola: yeah

Billy: they don't say

Lola: it's a bad decision

Billy: oh that's a terrible, th-

Lola: and then

Billy: they actually help you and say oh that's a bit off 
Interviewer: what about this?

Billy: why don't we, why don't we connect?

Lola: um

Billy: this and try

Lola: like

Billy: find a new idea

Lola: and something else good about philosophy, um, good about being a philosopher is- you always have to give a good example

Interviewer: why?

Billy: also, it doesn't have to turn out amazing

Lola: an example is like, it helps, even if they're real or even made up

Interviewer: why do examples help?

Lola: so people can picture it

School D, post-intervention focus group interview

Despite other students wanting to state their opinion, Lola grew in confidence to calmly make her case. One factor in this change is the encouragement of her teacher, empowering Lola to let her peers know that she's waiting for their attention before speaking. The democratic nature of the CoI, supported by the ground rules that were created collaboratively and the talking object that students used to choose who will speak next and to clearly denote who had speaking rights, all helped to build a culture of listening and respect that grew over time. These conditions built hermeneutical justice by enabling students like Lola to find their voice and develop the confidence to share their ideas despite interruptions from students around them, like Billy, who were so keen to claim the airspace in order to share their own ideas. Perhaps the growing awareness of the value of a range of perspectives emboldened Lola, helping her to recognise the importance of sharing her own perspective so that others could learn from her. 
Vignette: Sione - gaining confidence to use philosophical language

Sione was a student at School D. His teacher observed that he often made quiet comments to himself or to a few students near him rather than making a contribution to the whole group. These comments were usually both astute and apt, and indicated that he was engaged in the dialogue and following his peers' contributions closely. He did not always readily share his thinking with the whole group. At times he would rather agree with another student's idea than add a new idea of his own, as demonstrated in this example:

Interviewer: mhmm, so we're describing how our thinking has changed about philosophy - Sione, how about you?

Sione: umm I thought philosophy was like the same as Theo Interviewer: which was ...

Sione: ah,

Theo: just sharing your ideas

Sione: yeah, sharing your ideas

Interviewer: and how would you describe it now?

Sione: ah - like, going into a big group and sharing your ideas with um other people and um um making them into a right answer

School D, post-intervention focus group interview

Perhaps Sione did not want to lose face in front of his peers by making a contribution that wasn't 'the right answer'. The potential show of vulnerability involved in presenting one's ideas in front of one's peers at times caused students to be reluctant to share their own thinking.

One possible interpretation of Sione's asides - the quiet responses he made to his peers that only a few children near him could hear - is that they were rehearsals for contributions to the wider group. Sione had ideas and evaluations of others' ideas which he was slowly gaining confidence to offer up for a wider audience. 
Vignette: Amelie - silence

Amelie was a Pākehā student from School D. Her teacher Alana chose her to be a focus group student because she had thought that philosophy would both challenge and interest her. However Amelie did not contribute to the class dialogue at all. In the post-intervention interview, Alana described her observations of Amelie through the $\mathrm{P} 4 \mathrm{C}$ intervention:

Academically she's very strong but she's not a critical thinker - she's very reserved with her opinions. Very cautious. She pretty much spoke through Lucy. When she was in the small group she would talk but even so, not very strong in her opinions ... when she's working with people she knows, she gets her point across in a very subtle way and they know what she means, she's no pushover.

School D, post-intervention teacher interview

Alana was puzzled and intrigued that Amelie hadn't participated more fully in the CoI, especially because she was an able student. In the post-intervention focus group interview, when the students went round the circle to say what they liked or didn't like about philosophy, Amelie was the only student who didn't say anything at all.

Why did some students remain silent during the dialogue? Not speaking is subject to multiple interpretations. For some, it could just have been that there wasn't an opportunity for them to contribute their ideas. The nature of a whole-class dialogue in classes of 28-32 students is that each student will inevitably have to spend more time listening than speaking. Olivia, the teacher at School A, mediated the classroom discussions more than the other teachers which at times resulted in more opportunities for a range of students to speak in the whole-class dialogue because Olivia stepped in to direct the talking object to a student who hadn't had a turn for a while. The teachers at Schools B-D sought to share the power and control over the direction of dialogue with the students. One of the challenges and necessities of the democratic, more student-led discussions that the teachers at Schools B-D encountered was the need to negotiate with the students about how to ensure that a range of students got the opportunity to share their thinking. They found that the teacher has a very important role in facilitating democratic discussions - often this involved structuring the discussion by encouraging 
students to break into pairs or small groups to discuss interesting concepts that emerged during the discussion so that all students had the opportunity to discuss their thinking. In this way, teachers seeking to facilitate a student-led democratic dialogue ensured that more students were afforded the opportunity to articulate their thinking and be heard.

Even if they were silent in the whole-class dialogue, all students were able to discuss their ideas with a partner; teachers' use of the think-pair-share thinking routine was a useful way to generate dialogue. Some students contributed their ideas to the discussion via their partner without having to identify themselves as the source of the idea - this method worked for students like Groucho who were still building their confidence in order to make the vulnerable step of contributing newly formed or uncertain ideas to the wider group.

Other students didn't know what they thought - either the concept under discussion was so big or new that they were still formulating their own understanding of the idea, or they just didn't have the words to describe what they were wondering about. Some students in the focus groups found it challenging to describe what philosophy was or what they had learned through philosophy. In these cases, the students' silence seemed to be due to an emergent conceptual understanding.

Alana's intuitive interpretation of Amelie's silence was that she did not feel comfortable with the open, provisional nature of philosophical dialogue. Jono had a similar theory about an able student in his class at School C who did not contribute to the CoI anywhere near as much as Jono had anticipated he would. Perhaps for some students who are used to knowing the answers at school and to quickly understanding new concepts, the emergent nature of philosophical dialogue was not clear enough for their liking. Furthermore, the definition of an 'able' student is often in reference to a student's achievement in the core curriculum areas of Reading, Writing and Maths which, it could be argued, follow a series of steps and formulae in order to master, particularly at primary school level. Philosophy, on the other hand, involves creativity, thinking 
'outside the box', challenging boundaries, and finding connections between seemingly disparate concepts.

I can only propose these explanations as hunches and possibilities because students' motivations are internal and therefore difficult to interpret. Future research exploring the motivations and thinking of students who remain silent or who contribute little to philosophical dialogue would help to illuminate our understandings of these students' cognitive and philosophical progress.

\section{Links to existing research}

In this section I draw links from my findings to those of existing research, highlighting how my study affirms observations already presented in the literature.

\section{Language, critical thinking and critical talk moves}

My findings about the power of enhancing language to develop critical thinking through explicitly taught language structures echo Anderson et al.'s (2001) and Reznitskaya et al.'s $(2002 ; 2008 ; 2013)$ findings that have shaped their development of Argument Schema Theory (AST). More than just learning the language frameworks and thinking skills required in a philosophical dialogue, the findings of this study indicated that students were able to make the most productive collaborative philosophical progress when teachers explicitly taught them how and when to make the cognitive moves that would challenge and build on each other's thinking in order to develop conceptual understanding together. This process builds what Reznitskaya (2008) and Anderson et al. (2001) describe as an argument schema for students. Reznitskaya (2008) contends that,

Argument schemas are developed through socialization into argumentative discourse in dialogic collective settings ... practices present in a dialogic discussion, such as generating and challenging each other's reasons, or questioning assumptions, are "psychological tools" (Vygotsky, 1981) that mediate the development of an individual argument schema (p. 2).

Anderson et al. (2001) describe as argument stratagems the strategies I have termed language structures and critical talk moves, for example, “(a) managing the 
participation of classmates, (b) position in relation to a classmate's argument, (c) acknowledging uncertainty, (d) extending the story world, (e) making arguments explicit, and (f) supporting arguments with evidence" (p. 4). I observed students using similar strategies in this study as they developed philosophical language, thinking processes, and the dispositions to understand how and when best to use and apply these in order to build an argument. The result of the teachers' explicit teaching of these strategies built students' metacognitive awareness of how and when to use these critical talk moves.

\section{Supporting diverse learners}

Topping \& Trickey's (2007a, 2007b) study presented compelling findings about the power of P4C to support the cognitive development of diverse learners. As I described in Chapter 2, their research found that children in the lower quartiles of achievement in the pre-test made the greatest cognitive gains, both in the post-test after sixteen months' participation in a weekly hour-long P4C programme, and in follow-up testing two years after that. While my study used a different methodology - it is qualitative and therefore interpretive in nature - my findings suggest that the language structures and thinking routines that students learn through P4C can enhance diverse learners' language and thinking capability. The talk frames that teachers introduced to students helped to expand students' vocabulary, schemas, and thinking processes. Students at the schools with more diverse learners made the greatest gains in developing the language of elaboration and clarification. Students at all schools developed the language of reasoning over time. Students at the lowest decile school developed the language of comparison, evaluation of alternative views, speculation, and prediction so that by the end of the project it was occurring at a similar rate to the highest decile school. This language development indicated that diverse learners who, at the outset of the project, were not using this kind of language in their dialogues, were exposed to and able to use the language of philosophy through taking part in P4C over time. The P4C programme offered diverse learners epistemic access to the language of thinking. This could be described as an instance of distributive justice in action (Gewirtz \& Cribb, 2002), increasing diverse learners' social and academic capital. 


\section{Equity, participation, and reflective pedagogy}

Barrow's (2015) research study explores how P4C can operate as a dialogic

participatory pedagogy. Similar to the concerns of my study, she examines in her (2010) paper how P4C can strengthen student voice, the transformative potential of dialogue, and "the problems caused by inequality between dialogic partners" (p. 61). She concludes that when teachers can accommodate "the potential perplexity and discomfort of genuinely open dialogue" (p. 68), then the communities of inquiry can be truly dialogic. My findings about the importance of teacher and student resilience and receptivity (and the vulnerability involved in achieving these qualities) in achieving intersubjectivity also point to the perplexity and discomfort that are a natural part of genuine and open dialogue.

While it took longer for some diverse learners to offer an opinion or to contribute, teachers noticed that for many of these students, their willingness to participate developed over time - some students needed time to observe and absorb the language and culture of philosophical inquiry before they felt ready to take part. Some of the teachers hypothesized that some of this confidence was developed through the language structures that they taught the students through P4C. Some of the teachers recognised that the democratic nature of $\mathrm{P} 4 \mathrm{C}$ is not wholly unproblematic and cannot be assumed to be a natural feature of any CoI:

The very nature of [P4C] is democratic ... It's hard because just speaking isn't necessarily democratic because if you haven't had the same exposure to whatever then that's not democratic but I think that the language that is specifically taught within it does give kids the opportunity to be able to express themselves more. - Alana, post-intervention teacher interview

In recognising that students' social capital shaped their spoken language capability, Alana emphasises that the democratic nature of a CoI cannot be assumed but needs to be built intentionally through systematic planning and explicit teaching. Alana highlighted the importance of teachers specifically teaching philosophical language in order to support learners who may not have the capital or prior experience that would provide them with this language. The teachers' growing awareness of both their prior assumptions and therefore their responsibility to mitigate the inequities caused by 
students' differing social capital and access to powerful knowledge had the potential to drive them to work harder to consciously hold high expectations for all learners.

Barrow (2010) holds that the equal participation of a range of students in a CoI is complex and problematic, citing Jackson's (2008) contention that "ground rules for classroom talk privilege one sort of discourse over others, as those children most confident in privileged forms of discourse are more able to subtly subvert the rules" (p. 68). This is an ongoing tension that teachers cannot expect to resolve easily, but need to continually reflect on and work to mitigate the power that privilege brings.

\section{Conclusion}

The dialogic nature of a CoI allows teachers to model argument structures, to draw students' attention to their peers' language capabilities, such as effective usage of language structures, and to scaffold students in integrating this enhancing language into their own dialogue. The simplicity of these words and phrases belies their power to promote more cognitively complex thinking for students. My findings contribute to growing empirical evidence that indicates that dialogic teaching - "a pedagogical approach that involves students in the collaborative construction of meaning and is characterized by shared control over the key aspects of classroom discourse" (Reznitskaya \& Gregory, 2013, p. 114) - has the potential to help students to develop elaborated language codes, higher order thinking, epistemological understanding and greater disciplinary knowledge (Alexander, 2005; Hennessy et al., 2011; Mercer et al., 2015; Wegerif, 2011). As students' language and thinking is refined, both by challenges from peers or their teacher such as "Can you clarify that statement?" and by listening to and integrating the language structures modelled through dialogue, interpersonal learning is internalised to intrapersonal understanding (Wertsch, 1985). Philosophical dialogue offers "students a kind of apprenticeship, during which the principles of disciplined inquiry, first practiced among peers (i.e. social, intermental plane), become part of one's cognitive functioning (i.e. individual intramental plane)" (Reznitskaya \& Gregory, 2013, p. 118). 
For some students in this study, the language and thinking of philosophical dialogue was so new that they took time to listen and to observe how their teacher and their peers used this language to interact, share, evaluate, and build on each other's ideas. Students who did not contribute to the dialogue but who told their teachers that they continued to think about the philosophical dialogue long after the discussion had ended were clearly learning from the CoI but this development was largely internal, as much deep learning is. Further research is needed that explores both how student thinking marinates, grows and changes over time, and the range of ways that students might engage to demonstrate their thinking development.

The explicit teaching of elaborated language code in the form of philosophical language structures (and a greater teacher awareness of their impact on student cognition) could go some way towards redressing some of the educational inequalities caused by social deprivation in New Zealand. These language structures and cognitive moves offer diverse students epistemic access to the wider conversation that others with greater social capital are already part of about how we should live, what we should do, and how we can better understand the world. I explore this theme in much greater detail next, in Chapter 7. 



\section{Enhancing social justice}

The goal of social justice education is full and equal participation of all groups in a society that is mutually shaped to meet their needs (Bell, 1997, p. 3).

In Chapter 2 I described how powerful knowledge is a concept that has emerged in the sociology of education in the last twenty years; the proponents of which have come to be known as social realists. Much of the literature in this field is largely theoretical in nature, and all of the examples of powerful knowledge are drawn from secondary and tertiary educational contexts. This chapter revisits the previous two, pedagogically focussed, chapters to explore and illustrate the impact that P4C's democratic dialogic approach can have on social justice. After clarifying my definition of social justice, I propose that $\mathrm{P} 4 \mathrm{C}$ is a learning context in which primary teachers can support all learners to develop powerful knowledge - and that this contributes to social justice. To develop this argument, the chapter draws together my findings with Bernstein's (2000) theory of democratic pedagogic rights. Then I report on some of the ways teachers were working towards social justice that are not directly accounted for through notions of democratic rights and powerful knowledge. These largely had to do with shifts in perceptions and power relations among the students and teachers. In the last section, I identify key findings of the study that appeared to be most effective in redressing educational inequities, as practical suggestions for teachers aiming to improve social justice through their teaching.

\section{Social justice in education}

Much educational research is driven by goals of social justice. This recognises that an education system is shaped and constrained by the social, economic and political 
contexts in which it exists; schools can contribute to mechanisms of social reproduction and injustice (Gewirtz \& Cribb, 2002). Sensoy and DiAngelo (2014), for example, propose that social justice involves acknowledging that:

- all people are individuals, but we are also members of socially constructed groups;

- $\quad$ society is stratified, and social groups are valued unequally;

- social groups that are valued more highly have greater access to resources and this access is structured into the institutions and cultural norms;

- social injustice is real and exists today;

- relations of unequal power are constantly being enacted at both the micro (individual) and macro (structural) levels;

- we are all socialized to be complicit in these relations;

- those who claim to be for social justice must strategically act from that claim in ways that challenge social injustice; and

- this action requires a commitment to an ongoing and lifelong process (p. 2).

Many different conceptions of social justice exist in the literature. While it is broad and multi-faceted, in this chapter I examine social justice in relation to notions of equitable, democratic education. To establish a framework for understanding how social justice is conceived in education, I begin with a brief discussion of some of the key voices that shape the literature in this sphere. One of these voices is Rawls' (1999) conception of distributive justice. Distributive (or distributional - these terms are used interchangeably) justice is concerned both with economic conditions and the distribution of cultural and social resources or capital (Gewirtz \& Cribb, 2002) such as self-respect, access to employment, educational and decision-making opportunities, and the freedom to pursue one's conception of the good (Brighouse, 2004; North, 2006). Speaking from a lens of distributive social justice, Ho et al. (2011) contend that social justice involves equal access to opportunities and rights (such as education), the state or system taking "responsibility to build [each] individual's ability to take up opportunities and exercise rights, for example ensuring a minimum level of literacy and numeracy, computer and other skills" (p. 12), and support and protection of people who are vulnerable or disadvantaged. Those seeking to enact distributive justice aim to rework political structures to achieve more equitable outcomes. Reich (2002), for example, contends that such principles should create an education system in which all 
children are "provided an education that fosters their autonomy, which in turn contributes to their participation as equal citizens in the public sphere and facilitates a capacity to form, revise, and pursue a conception of the good" (p. 8).

Another conception of social justice considers conditions and entitlements that are indivisible in society. Recognition justice - popularised as identity politics - for example, is enacted when group differences are valued rather than being used as reasons for oppression or domination (North, 2006; Young, 1990). Lynch and Baker (2005) propose that in education, issues of misrecognition can be addressed through creating regular opportunities for teachers and students to experience diverse perspectives and to speak critically about difference, human rights, and social justice. In the context of education and curriculum, recognition justice involves valuing students' cultural, geopolitical and historical backgrounds as well as making connections from these contexts to conceptual knowledge. Students' "culture will not be forgotten in order for them to learn 'high status' culture" (Gandin \& Apple, 2002, p. 268) and knowledge. I return to the notion of recognition justice when I propose an alternative conception of powerful knowledge in Chapter 8. Associational injustice, another conception, occurs when patterns of association between individuals and groups prevent some people from participating in decisions that affect how they live and act (Gewirtz \& Cribb, 2002; Power \& Gewirtz, 2001). Therefore, working for social justice through the lenses of recognition and association involves awareness of power relations and active redress of such injustices, in addition to attending to the redistribution of goods and resources in society.

Closely linked to the notions of recognition and associational injustice is Fricker's (2007) conception of epistemic injustice and its concomitant definitions of testimonial and hermeneutic injustice. Epistemic injustice occurs when "someone is wronged specifically in their capacity as a knower" (Murris, 2013, p. 245). Fricker (2007) argues that this kind of injustice can be caused by prejudice related to someone's identity testimonial injustice - or prejudice related to interpretations of someone's experience and perspective - hermeneutical injustice. Hermeneutical injustice can occur for diverse learners when their experience isn't understood or valued in their classroom. Fricker 
(2007) defines it as “the injustice of having some significant area of one's social experience obscured from collective understanding owing to a structural identity prejudice in the collective hermeneutical resource" (p. 155). Later in this chapter, I use the notion of hermeneutical injustice in order to understand the teachers' preconceptions of diverse learners.

There are tensions in how social justice is enacted in education in relation to "differential emphases on equality as difference and equality as sameness" (North, 2006, p. 508). Work to challenge essentialism and to identify and celebrate students' diverse funds of knowledge can help teachers to understand the complexity of notions of equality, difference and sameness. North further argues that "just educational communities need to be both inclusive and capable of addressing historically based, systemic inequality between sociocultural groups" (p. 519). This means that working towards social justice also involves balancing attention to both macro-level processes like educational policy making and micro-level processes like daily social interactions in classrooms, and recognising the relations between macro- and micro-level processes (Lynch \& Baker, 2005; North, 2006). With such tensions in mind, I define social justice in education in this thesis as the opportunity for all learners (including diverse learners) to have epistemic access to powerful knowledge that will allow them to build academic capital and experience enhancement, to be wholly included and able to fully participate in society and in society's conversations about how we should live together. Actions for social justice require teachers and researchers to be aware of their/our own positionality in the classroom, and facilitate participative and democratic processes. This goal aims to enact distributive justice for all learners. Teachers, schools, policymakers and governments have a responsibility to create the conditions to make this possible for all learners, regardless of their background.

\section{$\mathrm{P}_{4} \mathrm{C}$ and democratic pedagogic rights}

As I described in Chapter 3, a key element of Dewey's understanding of true democracy was his description of the necessity of "mutually interpenetrating interests" (Dewey, 1916) that are developed and understood through ongoing interaction between as varied and diverse a range of interactors as possible. Dewey (1916) emphasises that 
democracy doesn't just relate to systems of government but to the ways we interact in society: “... more than a form of government, [democracy] is primarily a mode of associated living, of conjoint, communicated experience" (p. 37). Consistent with this conception is Bernstein's (2000) description of all students' pedagogic democratic rights, outlined in Chapter 2: enhancement, inclusion, and participation. Ensuring all learners have these rights is a key element of my definition of social justice in education.

In this section, I pose some questions related to Bernstein's (2000) pedagogic democratic rights and explore how the teachers in this study created the conditions for inclusion, participation, and enhancement. I make this connection between Bernstein's work and P4C because it has been argued that the methods of teaching and learning that accompany a philosophical CoI can create the conditions for collaborative problemsolving, peer-learning, and learning through socio-cognitive conflict. Democratic inquiry in the classroom, using methods that build participation, citizenship and connections across difference, can be a means to democracy in society (Burgh \& Yorshansky, 2011).

\section{Inclusion}

There are many questions for teachers of P4C to consider in relation to inclusion. How can we know if all students feel, and indeed are, included in a classroom environment and culture? If a child sits in a discussion circle but doesn't speak during the discussion, are they included? If a child contributes ideas that are not their own to a discussion (for example, echoing a friend's opinion in order to demonstrate social solidarity), are they included? If a child doesn't talk about the topic of conversation until they are in the playground with their friends or sitting at the dinner table that night with their whānau, are they included? During the discussion, who is being heard, who is being silenced? Who is choosing silence, and if so, why?

Bernstein (2000) describes inclusion thus: the right "to be included, socially, intellectually, culturally, and personally ... this right to be included is complex because to be 'included' does not necessarily mean to be absorbed. Thus the right to be included may also require a right to be separate, to be autonomous" (p. xx). Inclusion may involve students being empowered to choose their level of contribution to a discussion; 
if they don't want to speak, they don't have to, however if they want to, there should be an opportunity for them to be able to contribute. Another way for students to be autonomous is to recognise when their own thinking and reasoning is rigorous and clearer than that of other reasoning presented during a discussion. Alternatively, they may recognise that multiple understandings can be held concurrently, or that at times "different contexts require different applications of rules and principles" (Daniel et al., 2004 , p. 296). The teachers, and indeed some of the students, recognised that including autonomous thinkers therefore doesn't necessarily require consensus.

The teachers held differing understandings of inclusion. Some believed that their role as inclusive facilitator included a degree of enforcing the agreed classroom discussion guidelines, while others believed that as a facilitator of a student-led dialogue they should not intervene too much. Over the course of the study, teachers recognised more explicitly that they had a key role in creating the conditions for inclusion. In some cases, teachers encouraged children who were dominating the discussion to listen without interrupting, to create space for diverse voices in the highly contested space of dialogue. Some teachers enforced the class' agreed discussion guidelines more stringently than others. I interpreted this as differing responses and actions driven by similar motivations: wanting to allow students to discuss and to share their ideas, and wanting to support students to learn about how to self-manage within an inclusive, collaborative CoI.

The explicit focus on teaching language structures and argument schemas was another method teachers used to ensure inclusion. These tools were practical ways that teachers offered epistemic access to diverse learners. Student inclusion could be compromised by the constraints of a whole class discussion made up of 26-34 students. Children would have to wait for their turn and, at times, the dialogue may have progressed beyond the point they were planning to make by the time they got a turn to speak. Although teachers tried to mitigate this through the use of the thinking journals to jot down ideas, and by regularly pausing the whole-class discussion to allow students to discuss ideas with a partner or a small group, the nature of a large group discussion resulted in limited contributions from many of the participants. However, inclusion can 
be conceived of in many ways. For example, a number of students described how they would go on thinking for days after a CoI; the thinking that was provoked by the discussion could be considered to be a form of inclusion.

\section{Participation}

Bernstein (2000) states: "Participation is not only about discourse, about discussion, it is about practice, and a practice that must have outcomes ... It is the right to participate in the construction, maintenance, and transformation of order" (pp. xx-xxi). In the context of a CoI, Bernstein's discourse relates to the content of the philosophical discussions, and his practice encompasses both the process of communicating: how students listen to others' and present their ideas; and the reflective, meta-cognitive element of the CoI: students evaluating how well they are listening to others' and presenting their ideas and considering how to improve their individual and collaborative practice. This process of action and reflection has deep, democratic implications (Biesta, 2011a, 2012, 2014; Dewey, 1925, 1944; Norton, 2014). This is because, as Dewey (1925) proposed, we do not learn from experience; we learn from reflecting on experience. As I described in Chapter 4, one element of the design of my study was student reflection. This supported students' democratic pedagogic right to participation because the metacognition involved in reflecting on the learning process, purpose and value made their thinking visible (Ritchhart, Church, \& Morrison, 2011) and deepened students' philosophical knowledge and understanding, which allowed them to more fully participate in and contribute to the CoI. Teachers drew out student reflection in a number of ways. One form of reflection that teachers employed was to conclude the CoI with a 'final round': an opportunity for each student to state their 'last ideas' related to the content or discourse, and to evaluate the process or practice of the discussion that day. Children would state the burning point they hadn't yet had an opportunity to express, make a judgement about how well they or others had listened and contributed, and share where the discussion had taken their shared thinking. Also, many students who hadn't contributed to the dialogue would take this opportunity to speak. This feedback gave teachers an opportunity to encourage the class to re/consider their approach to and methods of dialogue, and to renegotiate their dialogue guidelines agreement, if need be. 
Students' thinking journals were another vehicle for participation and reflection. Teachers often finished a CoI or even followed up the next day by inviting students to write an evaluation or reflection in their thinking journal. Sometimes this involved identifying new language structures or phrases that had been introduced or had emerged through the discussion, which facilitated philosophical thinking and dialogue. Other times this involved formulating (or reformulating) their opinion on the topic of discussion that day (explication of discourse). Thinking journal reflections also took the form of an evaluation of their own performance in the CoI, either generally, or in relation to an agreed skill focus, such as expressing agreement or disagreement with a reason or identifying misconceptions and addressing them with a counter-example, or building on others' thinking. These frameworks for reflection supported student metacognition which builds student agency: participation in and ownership of their own learning process.

\section{Figure 9: Dialogue guidelines}

P4C Guidelines

- Agree/disagree respectfully

- Change your opinion if you want to

- Listen to others' ideas

- 3 second think time

- Last person to speak chooses the next speaker

- Be sensible

School D

Alana supported student participation "in the construction, maintenance, and transformation of order" (Bernstein, 2000, pp. xx-xxi) by regularly starting the CoI by asking her students to evaluate their agreed guidelines (shown in Figure 9, above) for discussion. She would ask the students to analyse how well they had upheld their agreement in recent weeks, and to identify whether any elements of the agreement needed reiteration, clarification or adjustment. This made their guidelines a working document that students continued constructing in order to maintain and transform 
order within their CoI. This process made it clear that students could give each other feedback and make decisions together about how they wanted their CoI to operate together. This democratic process emphasised the value of each student's voice in constructing and maintaining shared agreements about the form and structure of their dialogue.

A number of the philosophical skills and dispositions and language structures that teachers introduced to students through P4C helped to build a culture of participation, for example:

- "I dis/agree with X's idea because ..."

- "I'm building on X's idea ..."

- "A different perspective could be ..."

- "I've changed my mind because ...", and

- as Groucho aptly put it: "something can be bad and good at the same time depending on what the situation is."

Student participation was enabled by these language structures because they implicitly created a culture of interthinking (Barnes, 2008; Mercer \& Littleton, 2007, 2013; Mercer et al., 2015; Pantaleo, 2007) and intersubjectivity (Biesta, 1998, 1999, 2014; Daniel \& Auriac, 2011; Daniel et al., 2004) that was political in nature. This is partly because when students used these phrases in dialogue, their beliefs, knowledge and values were lifted from the sphere of the subconscious to the conscious. Members of the CoI were forced to examine their thinking and to consider what their reasons were for holding to their beliefs, values, and knowledge. A culture developed over time that allowed students to question both each other's and their own understandings, and to be challenged by alternative reasoning, thinking, and perspectives. This process allowed many of the students to refine their understanding, knowledge, beliefs, and attitudes.

Student reflection was a form of student participation in understanding and analysing both their own learning processes, and those of the collective group. Jono supported student reflection through whole-class or group activities. As discussed in Chapter 5, at the end of the first term of P4C, he taught his students about the key branches of philosophy and their areas of exploration. Then he asked the students, in groups, to 
recall the topics of philosophical discussion they had covered that term, and to identify which branches of philosophy they related to.

This meta-analysis and reflection took a whole lesson, and involved much discussion within and between the groups of students. The students recognised that a number of their discussions had spanned and touched on a number of branches of Philosophy (see Image 7, below). Through their teasing out of this categorising, they gained a greater understanding of the intricacies of the definitions of each branch of Philosophy, as well as of the ways their own thinking had echoed the thinking of philosophers over centuries.

\section{Image 7: Reflection lesson exploring the branches of philosophy}

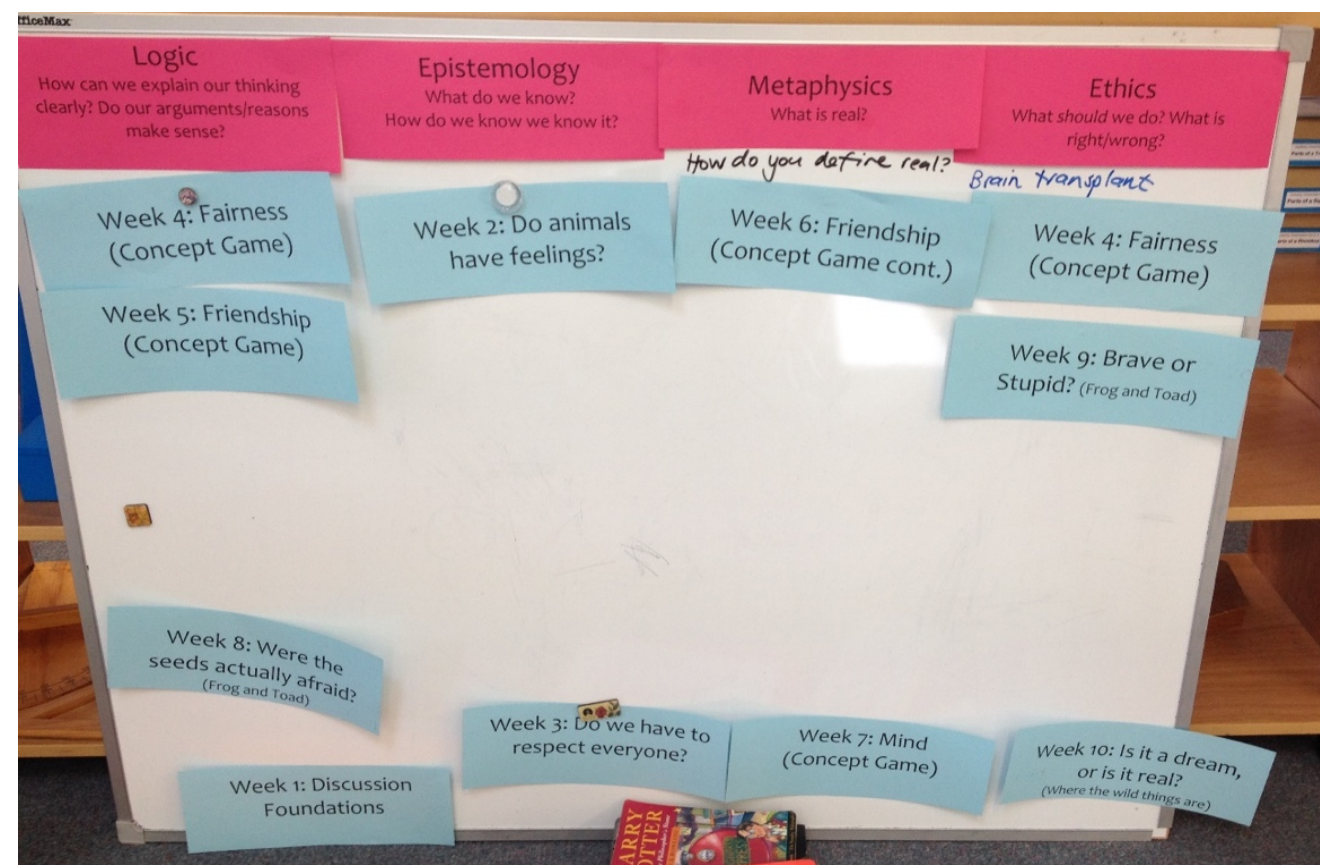

School C

Jono emphasised that he would only introduce this disciplinary philosophical knowledge after students had tackled these areas through exploratory dialogue. By making explicit links between students' contextual understandings and conceptual knowledge, Jono offered his students epistemic access to powerful knowledge by building students' knowledge of the discipline of philosophy in an accessible way. This reflection allowed the students to recognise their place in a history of philosophical thought, while allowing them to retain their exploratory approach to being 
philosophers rather than learning about philosophy. Another form of group reflection that Jono employed after two terms of P4C was to task the students with creating a creative demonstration of a philosophical skill. They were encouraged to first identify the range of philosophical thinking skills and language structures that they had developed through participation in $\mathrm{P} 4 \mathrm{C}$, and then to find a creative way to communicate this to an audience. Groups were encouraged to choose their performance medium, create their performance, perform this to their peers, and then to evaluate each other's performances by identifying the philosophical skills they had demonstrated through their performance. This was a performance of understanding (Harpaz, 2014; Wiggins \& McTighe, 2005; Wiske, 1998) that was form of meta-reflection because students were required to consider what they had learnt, to convey this learning by applying it to a new context, and then to analyse their peers' performances in order to identify the thinking skills and language structures they were demonstrating.

\section{Enhancement}

Enhancement is not simply the right to be more personally, more intellectually, more socially, more materially, it is the right to the means of critical understanding and to new possibilities (Bernstein, 2000, p. xx).

Bernstein's concept of enhancement has been amply discussed in Chapters 5 and 6. I have argued that P4C can build powerful knowledge that enhances the academic capital of those with low social capital; this can redress educational inequities caused by the varied degrees of social capital held by different students.

Diverse learners' capability and language were enhanced through P4C in a number of ways. For example, the language Groucho collected in his Philosophy Toolbox enhanced his critical understanding of both his own thinking and the thinking of others, as well as the philosophical ideas that sparked their philosophical discussions each week. Groucho recognised these language structures as powerful, and in gathering them together he was able to access the power and critical understandings that they afforded him. Troy's enhancement occurred through the recognition that he could present his ideas coherently through discussion, without the constraints of written language. The 
language structures and argument schemas that he learnt through CoIs gave him an eloquence that he had struggled to find in written language. His teacher observed that he was also more engaged and able to concentrate for longer on a particular topic, because the spoken nature of the dialogue removed barriers he encountered in other learning areas through written language. For Freddy, the new recognition that the vulnerability one might feel when presenting provisional ideas and understandings and shifting one's thinking (possibly many times) during a dialogue is indicative of intellectual humility and flexible thinking enhanced his resilience and capacity for deep learning. Tony's experience as an English Language Learner (ELL) was representative of other ELLs in the study: once equipped with philosophical language structures, he was able to participate in the CoI with greater confidence. Each of these students' experiences are examples of ways that P4C enabled a redressing of inequities caused by differences in social, emotional, linguistic, and educational opportunities or understanding. This redressing of inequity contributed to greater social justice for each of these students.

An alternative conception of enhancement, for students with high cultural capital, is the opportunity to learn to listen to others' perspectives. For students like Billy, whose experience I described in Chapter 5, P4C helped them to learn that others who are quieter or less confident in class than them may well have interesting ideas worth asking about, and to learn the value of exchanging ideas, thinking together and being part of a larger community. Another of the vignettes in Chapter 5 explored Samuel's experiences and descriptions of the layers of understanding that others' thinking can add to one's own conceptions. In these cases, their thinking and understanding was enhanced through the new possibilities that others' diverse perspectives brought them.

\section{Enhancing social justice through shifting perceptions and power relations}

In this next section I draw out new examples from the data and key themes related to social justice. I propose that the structures of P4C can redistribute power by shifting learners' perceptions of themselves and of knowledge and learning processes, and shifting teachers' perceptions, attitudes, beliefs and practices. 


\section{$\mathrm{P}_{4} \mathrm{C}$ can enhance learners' perceptions of themselves as critical thinkers}

Many of the focus group students described how they kept on thinking about the ideas they had explored in the CoI for a long time afterwards. To them, philosophy was all about thinking deeply, and many of them described how their inner thought life was enriched by the philosophical dialogue. Some focus group students described how the P4C dialogues felt more meaningful and connected to real life than other school learning. The fact that the structure of a P4C dialogue places value on students' thoughts and ideas gave diverse learners both the opportunity and the confidence to consider and share their perspectives. Ella's description of her understanding of philosophy exemplifies the way many of the focus group students talked about the impact of philosophy on their thinking:

Ella: I think [philosophy is] about thinking about questions that no one has a definite answer to and that you can't just go like, oh so I looked this up, this is the right ... you know, just sort of you, you have to think in your head, really hard and you have to listen to other people's ideas to help with your ideas

Interviewer: why does listening to others help?

Ella: it helps me to think what I actually think, like, when they say their idea, I think oh yeah, that's a really good idea - yeah, that's right, yeah and also it helps me to build my ideas

Interviewer: do you change your mind?

Ella: yes, in lots of the discussions I've changed my mind from what other people have said and I've told you I get confused cos I've got many ideas cos of other people's ideas, like, oh but that might be right, yeah, so when I listen to the other people's ideas um yeah

Interviewer: and do you disagree with others?

Ella: yes, that still helps because if I disagree it helps me to think what I think like those circles with the ideas and the similarities sometimes other people's ideas come into my circle of ideas and sometimes they stay on their side and sometimes they come into the middle but it helps me and I think it's right or not right for me.

Interviewer: is it ok for people to have a different opinion?

Ella: yeah you're allowed to have your own ideas and everyone's allowed to have different ideas because it's their thinking and their mind so they can have different ideas. Sometimes their idea might not be a very good idea but they can still think that like: you should never ever listen to your parents, so in my opinion it's not a great idea - they can think what they think and if it's not a great idea they can find it out for themselves.

Interviewer: can you try to convince someone? 
Ella: yes it is a good idea to do that. They can still think what they think but if they want to jump off a cliff then you might, you should try and convince them that. Sometimes you shouldn't always listen to your parents because they might tell you something dumb.

Interviewer: can you clarify that?

Ella: ...in philosophy if we all had ideas and we didn't try to convince other people of [our] ideas then you're not going to have a very good discussion so you have to explain it.

School B, post-intervention focus group interview

Ella's comments and those of many of the focus group students conveyed how their perceptions of themselves grew through P4C; they found their voice and recognised the value of their and their peers' ideas. I further discuss the development of student voice and teachers' recognition of this later in this chapter. In addition, Ella's comments indicate the focus group students' growing intersubjectivity and understanding of the value of evaluating their own and others' ideas. While she recognised that others have their own ideas, "because it's their thinking and their mind," she moved beyond a purely relativist approach to ideas. Ella emphasised the value of dialogue to convince others (or to be convinced) of a stronger line of reasoning. This required an openness to changing one's mind - a key element of intersubjectivity - which Ella recognised as the basis for good dialogue.

\section{$\mathrm{P}_{4} \mathrm{C}$ can enhance students' knowledge and capital}

The data from this study indicates that, for students who don't have high social capital that would afford them an advantage in the education system, $\mathrm{P} 4 \mathrm{C}$ has the potential to offer an alternative pathway to educational success by building academic capital. Students can be taught language structures and critical thinking routines that can enable them to understand and contribute confidently to the conversations that children with capital already have access to. Through P4C, the teachers in this study systematically scaffolded students' learning and knowledge development by not only teaching their students the language structures that would enable them to think and dialogue philosophically, but also by teaching them how and when best to use them. Explicit teaching of the cognitive moves required in dialogic interaction taught learners what to do with the language structures and critical thinking they were developing. The 
vignettes about student involvement in dialogue in Chapter 6 gave examples of this critical thinking development. The collaborative, dialogic nature of a CoI supported students who don't have high social capital to learn from the language and cognitive moves of those who do.

As diverse learners' voices were strengthened, students with high social capital were exposed to other perspectives and learnt to listen to others' reasoning, as described in the section in Chapter 5 about supporting students to be receptive. This reflected the way that marginality can open up the potential discursive gap: "the experience of the excluded is the basis for thinking that which has not been thought before" (De La Garza, 2006, p. 13). Furthermore, including epistemically diverse knowers enhanced the success of the CoI (Anderson, 2006) because it allowed students to interact with and consider a range of perspectives, and could help to mitigate against stereotypes and prejudices that the students may have held towards others and other understandings. This process has the potential to challenge privilege and to build students' capital, enabling social justice - an internal shift that is hard to measure but that appeared to occur for a number of students in the study.

\section{$\mathrm{P}_{4} \mathrm{C}$ challenges and shifts teachers' preconceptions of learners}

When we talk about education, citizenship and democracy, we must remember that not all persons living in our societies are real citizens. While they remain in conditions of ignorance, exploitation and poverty, many of our children are very far from experiencing democratic citizenship (De La Garza, 2006, p. 17).

My findings suggest that teachers have a vital role in consciously building epistemic justice and academic capital for diverse learners in order to redress inequities caused by differences in social capital and socio-economic background. One of the greatest contributions to social justice that I observed in this study was the way that teachers' preconceptions of diverse learners were challenged through the dialogue they observed in P4C CoIs. By listening to the thinking that diverse learners were able to convey through philosophical dialogue, teachers recognised potential and capacity in the diverse learners in their classes that they hadn't previously thought was possible. This 
raised their expectations, both of what these students were capable of, and of their own responsibility to explicitly teach diverse learners to think, critically. In turn, this went some way towards redressing epistemic injustice for diverse learners.

Teaching P4C can reveal teachers' unconscious bias. It is sometimes the case that students with high social capital can be held in greater esteem in relation to their thinking than other students who might have less social capital, as Kotzee (2017) proposes:

Teachers may give more epistemic credit to the views of students from epistemically privileged groups. On the testimonial level, they may believe or praise such students more often due to their identity as a member of an epistemically privileged group. On the hermeneutic level, teachers, but more so, the school's culture, language and ethos may give more credence to such students' perspectives, engage more naturally with these perspectives and fail to comprehend the perspectives of less privileged students (p. 327).

This can result in epistemic injustice, particularly hermeneutical injustice (Burroughs \& Tollefsen, 2016; Fricker, 2007), for students whose social capital, socio-economic background, or perceived capability may shape teachers' assumptions about what that student can offer or learn.

All four teachers expressed surprise at the way the student dialogue through $\mathrm{P} 4 \mathrm{C}$ gave them new insights into particular students' capacity for critical thinking. Each teacher described how P4C provides opportunities for different learners to shine (and for the teachers to notice students' strengths that they hadn't recognised before). By listening to students' thinking, teachers' preconceptions and unconscious bias towards some diverse learners were revealed to them. All of the teachers in the study talked about students who surprised them by demonstrating a greater depth of thinking, logic, or argument skills and dispositions than the teachers had expected they would be capable of. Alana's surprise at the logic demonstrated by one of her students exemplifies the surprise each teacher expressed about certain diverse learners in their classes:

It definitely gave me an insight into kids I wouldn't have predicted like Priya she was definitely the standout for me ... She's just - she does have the ability to think logically about things [surprised tone]. When she was talking about it she was grasping the topic. She wasn't always able to unpack her thinking but 
that's what she was beginning to do because mostly when you see her in other curriculum areas, she's just not engaged at all, for example, writing, maths, all over the place. [But] when we do inquiry, she's outspoken. - Alana, postintervention teacher interview

This revelation gave teachers greater insight into students' potential and challenged teachers to consider the impact of their prior judgements of particular diverse learners and their capacity to learn and think on those students' learning and opportunities at school. The teachers recognised the value of P4C for students from a range of backgrounds. This new awareness served for the teachers as a critical juncture (Capoccia, 2016; Scholl, 2014) which can unsettle teachers, causing them to reflect on their own practice, in a very similar way to the learning process in which cognitive dissonance and disequilibrium leads to integration of new understandings. Only a handful of studies have explored the impact of teaching philosophy for children on teacher pedagogy (Cherednichenko, Harvey, \& Roberts, 2003; Golding, 2009; Scholl, 2012, 2014; Splitter \& Sharp, 1995). Of those that have, while teachers have been found to express surprise at "the experience, knowledge, understanding and wisdom of their students" (Scholl, 2014, p. 100), this surprise and shift in teacher understanding has not been related specifically to the potential and capacity of diverse learners in the way that it was evident in this study.

Teachers identified that the core, common, contestable nature of philosophical questions means that everyone has some experience and ideas to bring to the dialogue. This contributes to epistemic justice for all learners, making the CoI open and accessible to all learners, regardless of their background or capital, as Olivia described:

For some of my special needs kids I think it has been good - it's like a leveller in terms of you know, everyone comes with something, you know, some experience that they can bring to the big question that's on the table at the moment, you know, whatever their experience is, is valid, so in that respect, for them they've been able to achieve success in being able to express their opinions ... You might change your thought, but that's valid too, you know, it's like a win-win, there's no losers or failures in philosophy. Everybody's just growing you know so that's been really good. - Olivia, post-intervention teacher interview

Students who were often quiet in other curriculum areas found a voice through philosophy and spoke up much more than they would in other contexts at school - this 
also opened teachers' eyes to children's different capacities in different contexts. Teachers identified that many students who needed support to achieve in core curriculum areas at school found P4C to be a forum where they could contribute more confidently. Jono gave the example of a particular student in his class who was, as Jono put it,

Well below in all [core curriculum] areas and often he is, he gets muddled in his questions and reading and in saying anything out loud but in Philosophy he's been so keen to express his opinion and contribute and he gets challenged but he does start to give reasons for his thinking. - Jono, post-intervention teacher interview

The language and culture of a P4C CoI gave this student (and others) a space in which to express his thinking and to learn how to articulate his thinking so that others could understand his thought processes.

The teachers observed that P4C's open dialogue, meaningful subject matter and the collaborative culture of thinking that grew in the CoIs gave teachers the opportunity to hear and appreciate the thinking and potential of a range of diverse learners: those with less social capital, those who were often quiet in class, and those who needed support to achieve academically. This shifted teachers' conscious and unconscious bias and preconceptions, and allowed teachers to recognise that diverse learners' potential and capacity to learn was greater than they had previously expected. This realization brought with it a responsibility to ensure that their teaching offered all of their students access to powerful knowledge.

\section{Implications for professional practice: teaching $\mathrm{P}_{4} \mathrm{C}$ for social justice}

In this section, I identify key findings of the study that appeared to be most effective in redressing educational inequities, as practical suggestions for teachers aiming to improve social justice through their teaching.

\section{Personalisation}

There are a myriad of factors that interact with each other in different ways to influence the academic achievement of diverse learners. Rather than viewing diverse learners as one homogenous group, the participant teachers spent time getting to know each 
student, through observation, assessment, discussion and consultation with the student and their whānau. As the teachers built a picture of each student's strengths, areas of need, interests, motivation, cultural backgrounds and social and emotional needs, they were more able to personalise their teaching in order to meet the student's particular learning needs, according to the student's background. Cummins (1984) proposes that, in seeking to understand the "complex set of interacting variables" that affect diverse learners' academic progress, "there is unlikely to be one over-riding determinant" (p. 95). The complex pictures that the teachers formed of their students shaped their teaching; the teachers' receptivity and responsiveness to student needs allowed them to personalise and structure their teaching in order to meet diverse students' learning needs. In practice, this personalisation manifested in teaching decisions such as teachers intentionally giving Skill Master roles to students who were learners of English with phrases that they could use to participate in the discussion, or noticing if certain students weren't getting the opportunity to speak and stopping the whole class discussion to allow students to discuss their thinking with a partner. Each deliberate teaching decision that teachers made in order to personalise and scaffold the learning for diverse learners was a step towards social justice.

\section{Thinking journals: an alternative form of communication}

Integral to the research design was the use of thinking journals to give students another way to convey their thinking. If they didn't get the opportunity to speak when they wanted to during the dialogue, they could write or draw their thoughts in their thinking journals and share this with peers or their teacher later on. This was an intentional different pathway for diverse learners so that, as well as spoken language, they could use written language or drawings to communicate their thinking. Some students preferred using the thinking journals to speaking in the whole class dialogue. Teachers recognised that the thinking journals offered an alternative way for some students to share their thinking:

For those children who probably don't have so much visible success in the traditional curriculum areas, it has allowed them to have a voice. When I look at their journals, the things that they have written, it's quite mind-blowing really, the quiet ones, the ones that don't often speak and share. Through their journals, they've had a voice. - Olivia, post-intervention teacher interview 
The thinking journals offered teachers a window into student thinking to which they otherwise wouldn't have had access. The journals could also serve as a method for students to be heard and to engage in dialogue with their teacher, or other peers. Alana came up with a suggestion in her post-intervention interview that she was going to try with her next class:

I always say to them with their philosophy notebook, if you're bursting at the
seams and you really want to say something, write it down and then at least
you've got it there and you can look at it later. Maybe I could even offer for
them to hand it in if they want me to respond - if they just want the knowledge
that they had this idea and they really want to share it. Because it's not a nice
feeling to be at a discussion and never get your voice heard, no matter how
much you got done, it's unsatisfying. - Alana, post-intervention teacher
interview

The thinking journals constituted an alternative channel of communication between students and their teacher, which enhanced social justice by making the learning process more inclusive for children with different strengths.

\section{Explicit structured teaching}

Rather than assuming that their students would pick up the language of philosophy by osmosis, the teachers explicitly and methodically taught philosophical language structures, giving their students time to practise and assimilate the new language structures before introducing new ones. As well, teachers encouraged students to notice each other's language and to make note, in their thinking journals, of new language structures or thinking routines they had noticed their peers using. This process made the philosophical thinking and language visible so that the powerful knowledge was shared with all learners, which enhanced social justice.

\section{Teacher vulnerability}

Despite the challenges that teaching P4C posed to the teachers, they were willing to risk making mistakes by trialling new teaching methods that were not always successful on the first attempt. The vulnerability and openness that the teachers demonstrated which were elements of the resilience I observed in the teachers, as discussed in Chapter 5 - allowed them to grow and develop their teaching practice rather than 
sticking to known methods they were comfortable with and had already tried which may not have met the needs of diverse learners.

\section{Professional learning communities}

During the study three of the participant teachers formed an informal professional learning community. By sharing planning and ideas and observing each other's practice they were able to learn from each other and improve each other's teaching practice and personalisation for students. The ongoing challenge the teachers offered each other refined their teaching practice. Teachers described the value of seeing certain teaching approaches in practice when they observed each other teaching, and how this allowed them to recognise how they could tailor those approaches, of which they sometimes hadn't fully appreciated the importance, for their own students, in order to cater to diverse needs.

\section{Teacher critical reflection}

Closely linked to the value of teacher vulnerability and professional learning communities is the value of teacher critical reflection. Each participant teacher in this study was a reflective practitioner who spent time thinking about each CoI after it had unfolded and considering how to improve their teaching for the next CoI. Reflective teachers of P4C ask themselves questions like:

- How inclusive is the dialogue?

- How do my actions develop the students' knowledge and learning?

- How much agency and influence do I afford to and expect of children?

- When should I intervene to encourage greater participation from a wider range of students?

- Whose beliefs, knowledge and values are received unquestioningly and whose are challenged?

- During the discussion, who is being heard, who is being silenced?

- How are different systems of ethics implicitly condoned or denied?

- How can I support diverse learners to participate in the dialogue? 
Critical reflection involves teachers intentionally "identifying and checking the accuracy and validity of our teaching assumptions" (Brookfield, 2017, p. 3) and, when needed, developing alternative ways of teaching. Critical reflection leads teachers to learn from experience (Dewey, 1910, 1929), to interpret and create new knowledge, and to act and teach deliberately and intentionally as a result (Shandomo, 2010). An example of one of Alana's reflections after an early CoI during the project indicates her ongoing thinking:

I need to give them time to write in their journal tomorrow, as they did not get time today. It would be good to ask them to reflect on their use of reasons in the session: What reasons did we give? Did we think of different reasons? Were they good reasons? - Alana, teacher reflections early in the project

Alana's reflection sparked planning about what she wanted to focus on next in order to enhance the students' learning in relation to the skill focus of giving reasons. Alana's reflection emphasised the need to encourage the students to reflect in order to make their thinking visible, which is a form of cognitive apprenticeship (Collins, Seely Brown, \& Holum, 1991) that supports diverse learners. The changes teachers made as a result of their critical reflection enhanced social justice because their teaching improved and better catered to the needs of diverse learners.

\section{Awareness of the challenges of enacting social justice}

Sensoy and DiAngelo (2014) problematise the assumption that discussions with social justice content are improved by guidelines that support the sharing of opinions, personal feelings and connections. They propose that, in fact, such guidelines can:

Actually increase unequal power relations in the classroom ... through an embedded assumption that it is possible to create a space that is experienced by all students as respectful, validating, and protective, regardless of their social locations ... [because] the interests and needs of dominant groups usually drive the common guidelines (p. 2). Instead they propose that teachers who seek to enact social justice ought to restrict dominant narratives and make space for marginalised voices and perspectives in order to equalise the imbalance that exists, daily, in society. "Everyone's perspective is not equally valid when some are uninformed, unexamined, or uphold existing power inequities" (p. 4). What makes knowledge powerful is understanding how it is produced (Young \& Muller, 2010; Wheelahan, 2010b, 2014). The fact that students could challenge each other's points in a P4C CoI - this was welcomed - gave students an 
opportunity to critically analyse problematic dominant perspectives. This indicates that CoIs could challenge the power inequities Sensoy and DiAngelo (2014) highlight, because students were encouraged to examine their thinking in light of other perspectives and strong reasoning. While the teachers were conscious of finding ways to empower diverse learners, they acknowledged that it was not an easy task to redress this imbalance in the classroom, and while they attempted to create an open, democratic space for all students, they recognised that this is an ongoing challenge that requires conscious reflection. In his post-intervention interview, Jono said that P4C "has encouraged a more democratic culture," but modified this later, saying, "it's not democratic enough." He then suggested ways he hoped to make further changes to his P4C pedagogy the following year, by breaking into smaller groups more often in order to allow diverse learners more of an opportunity to contribute. All four of the teachers, in their post-intervention interviews, described ways they planned to change their teaching during $\mathrm{P} 4 \mathrm{C}$ in order to make it more accessible and democratic for diverse learners. They recognised that the lofty goal of social justice in the classroom requires constant attention and intention.

\section{Concluding thoughts}

This chapter has explored the ways in which P4C can make a contribution to social justice in education. Using Bernstein's (2000) notion of democratic pedagogic rights, I have highlighted findings that demonstrate how $\mathrm{P} 4 \mathrm{C}$ can promote inclusion, participation and enhancement. Explicit structured teaching of philosophical language structures, critical thinking moves, and argument schemas not only supported learners to develop language and critical thinking capabilities for philosophical dialogue, but enhanced their metacognitive awareness of how and when to use language and thinking structures for best effect. One of ERO's key goals for New Zealand schools is acceleration for diverse learners (Education Review Office, 2013, 2016). This explicit teaching was a method that could support acceleration and contribute to distributive social justice for all learners by enabling diverse learners to participate more fully in philosophical discussion with their peers. I described strategies that teachers used such as Skill Master roles, partner discussion, and thinking journals that appeared most effective in enhancing social justice. In addition, the teachers' resilience, reflection, and professional 
learning through their teacher network, enhanced their capability to teach diverse learners. This chapter has also discussed the broadening of teachers' perceptions of diverse learners' potential and capability to learn. This shift, which was identified by all of the teachers in the study, enhanced recognition social justice for those learners. I discuss this finding further in Chapter 8. 


\title{
8
}

\section{Enhancing knowledge: concluding thoughts}

\author{
Philosophical questions are questions that you can't just use your common \\ sense for, like let's say - if you're thirsty, should you take a drink? Yes, that's \\ obvious, you can just use your common sense to figure that out. But with \\ philosophical questions you really have to think about it to get an answer that's \\ really good and really right and really close. Also I think that if you've come up \\ with an idea or a classification or a definition, you've never really finished it - \\ there's always room for improvement, cos like some famous philosophers \\ spent years on the same questions ... \\ - Freddy, School B, post-intervention interview
}

After having spent years on the same questions that this research explores, I agree with Freddy: there's always room for improvement! The aim of this research was to explore how P4C could improve student thinking and learning capability for all, and especially diverse, learners. I have argued that because P4C builds critical thinking, it is a form of powerful, enhancing knowledge that improves student learning and thinking capability. New Zealand's education system is not equitable (Chzhen et al., 2018); diverse learners need support to achieve at school and many are not currently receiving the support that they need to achieve social mobility. Of the New Zealand primary schools that offer P4C, many of them do not offer P4C for all, and particularly diverse, learners. Rather, it is often seen as an extension programme for gifted and talented learners. This research study challenges that assumption and evaluates how P4C can build critical thinking, particularly for diverse learners, so that teachers can have a clearer idea of how to build students' critical thinking capability through P4C in order to support diverse learners to achieve educational success.

The state of inequality in the New Zealand education system reflects international trends in relation to inequity in education (OECD, 2018a); the OECD Director for Education and Skills, Andreas Schleicher, has stated, "more investment is needed to help 
disadvantaged students do better, including recognition of the critical role that teachers have to play" (OECD, 2018b, p. 1). This research was driven by the challenge of finding ways to improve the equality of the education system. The findings of this research point to the importance of teacher expectations and explicit teaching of knowledge, language, and skills to support diverse learners. The results of this thesis indicate that P4C has the potential to build equity by developing academic capital for students who arrive at school with less social capital than their peers.

In this final chapter I begin by describing the contribution that this research makes to knowledge of $\mathrm{P} 4 \mathrm{C}$, and the ways that $\mathrm{P} 4 \mathrm{C}$ can build powerful knowledge for primary school students. Then I offer a contribution to theory by proposing a new conception of powerful knowledge: enhancing knowledge, which values both contextual and conceptual knowledge and addresses the negative connotations of the word powerful. The chapter concludes with suggestions for future research.

\section{Significant findings that contribute new knowledge within the field of $\mathrm{P}_{4} \mathrm{C}$}

My research sheds light on a number of key findings and themes that I drew out from the data in this study, which were discussed in detail in Chapters 5 and 6. It is worth summarising these now, to appreciate their role in my larger defence of P4C for all learners.

As I have described in Chapters 5 and 6, there were a number of key findings and themes that I drew out from the data in this study which I summarise here.

The first question I set out to answer was, "How can Philosophy for Children develop critical thinking dispositions and capabilities for all, including diverse, learners?" I identified certain teacher and student dispositions that contributed to student critical thinking. I observed that open dialogic interaction in a philosophical CoI required vulnerability from both students and teachers, which built resilience. Ongoing P4C dialogue taught students to be receptive to diverse ideas and perspectives and required receptive teaching approaches from teachers. The data demonstrated that $\mathrm{P} 4 \mathrm{C}$ could facilitate intersubjectivity - between students, between students and teachers, and 
between teachers. I described in Chapter 5 the ways that students' dispositions of resilience and receptivity allowed their critical thinking to grow. I also explored the qualities of the intersubjectivity the students developed and demonstrated through the research project: collaborative thinking, evaluating reasoning, changing perspectives, and developing an understanding of the provisionality of knowledge.

Many factors contributed to the students developing qualities of intersubjective critical thinking, both emerging from the dynamics of the intersubjective culture that grew in the CoI, and due to intentional actions on the part of the teachers. In Chapter 6 I described the ways that teachers developed dispositions of resilience and receptivity (like their students) in their teaching, in order to cultivate the conditions for critical thinking in their classrooms. For example, teachers needed resilience to persevere with the challenges of facilitating a P4C CoI. Good P4C teaching required innovation, personalisation and explicit teaching approaches, according to the particular needs and strengths of the students. Because student thinking development is complex, philosophical language and a democratic thinking culture took time to grow and develop. Teachers observed and reflected on their students' contributions (or lack of contributions) to the dialogue and innovated and personalised the knowledge and skill focuses of their teaching accordingly to support students' particular learning needs. One example of this was giving students who were English language learners (as well as other learners) the role of skill master, with a card of phrases and questions to contribute to the dialogue that would help to draw out their peers' thinking. This teaching action served multiple purposes in that it made the language of thinking visible for all learners, made the skill focus explicit for all learners, offered students who might need support to contribute a useful role in the dialogue, and lifted the quality of other students' dialogue through the questioning of the skill masters. Another factor that supported the teachers to build students' critical thinking was the collaboration between teachers. By discussing the challenges they were facing, observing each other facilitating communities of philosophical inquiry and sharing resources and teaching strategies that had been successful, they helped each other to improve and to personalise their teaching for a range of learners. 
Across Chapters 5, 6, and 7, I explored the particular ways that P4C can build critical thinking for diverse learners. In Chapter 6 I discussed the ways that P4C can support learners to develop language structures, thinking routines, and argument moves or argument schemas (Reznitskaya \& Anderson, 2002). The data suggested that academic language proficiency can be shaped by socio-economic factors but can also be taught. The results affirmed that philosophical language structures support critical thinking. Over time, students developed greater language capability in order to explain, justify, elaborate, and clarify their, and others', thinking. Students also learnt to understand concepts, such as a misconception, and that one way to highlight a misconception is to offer a counterexample that helps to illuminate an alternative understanding or perspective. Once students had the language for these concepts, they could understand them and work with them in a dialogue, as argument moves. Gradually these language structures and argument moves became thinking routines that were internalised and helped to clarify thinking (Anderson et al., 2001; Mercer et al., 2015; Reznitskaya \& Anderson, 2002; Ritchhart et al., 2011). Students from lower socio-economic backgrounds developed greater language capability in the language of comparison, evaluation of alternative views, speculation and prediction. Students learnt language and thinking strategies from peers as well as their teachers. These critical language structures and the critical thinking that students developed built powerful knowledge. In addition, the resilience, receptivity and intersubjectivity that students built through P4C also constitute powerful knowledge.

\section{$\mathrm{P}_{4} \mathrm{C}$ as a route to powerful knowledge}

My second research question asks, "How does P4C help us to understand what powerful knowledge might look like in practice in New Zealand primary schools?" As I outlined in Chapter 2, social realist theorists differentiate between knowledge of the powerful and powerful knowledge (Moore, 2013; Young, 2013). In offering learners access to disciplinary knowledge that is powerful, social realists seek to redress power and social justice imbalances caused by different degrees of cultural, social and academic capital. By highlighting the power of different kinds of knowledge to illuminate students' understanding of the world, Young and Muller (2010) aim to equip all learners with the powerful knowledge that broadens students' understanding and their future potential. 
The implication is that when powerful knowledge is taught to all learners, social justice can be achieved in education through epistemic access for all learners to knowledge that enables people to explain and understand the world more deeply and fully.

P4C can build early disciplinary knowledge. At primary and secondary school, the curriculum is organised into discrete subjects that can be mapped onto disciplines. Primary school subjects are generally seen as a simplified version of the academic discipline (Stengel, 1997). Young (2013) argues that subjects:

are recontextualized from disciplines which are a society's primary source of new knowledge. The link between subjects and disciplines provides the best guarantee that we have that the knowledge acquired by students at school does not rely solely on the authority of the individual teacher but on the teacher as a member of a specialist subject community (p. 114).

Unlike secondary teachers who usually specialise in several subjects (often within the same broader discipline) or tertiary educators who are experts having specialised in a certain discipline, primary school teachers are generalists who teach a range of subjects and are therefore less likely to hold specialist disciplinary knowledge of the subjects they teach. Primary initial teacher education covers some content and pedagogy; often teachers' content knowledge develops through experience, ongoing professional development and by using teaching resources created by disciplinary or subject experts. Therefore students may not encounter disciplinary knowledge and the concept of disciplinary thinking - as outlined in Chapter 2 - at primary school. However, I propose that the frameworks for thinking that students were inducted into through $\mathrm{P} 4 \mathrm{C}$ in this study constitute an early form of disciplinary thinking. When the discipline of philosophy is reconstructed as a school subject, the curriculum needs to have two focuses: students need to learn to distinguish what makes a question philosophical developing a substantive, propositional knowledge of philosophy - and to develop procedural, skills-based philosophical knowledge - developing the dispositions of a budding questioning, evaluating, collaborative, critical philosopher. Cam (2018) describes this procedural knowledge as:

The tools and procedures of conceptual exploration and reasoning, such as making distinctions, defining terms, uncovering and applying conceptual criteria, constructing 
thought-experiments, searching for counterexamples and engaging in and evaluating both deductive and inductive inference and argumentation (p. 63).

Philosophy is considered to be the discipline of thinking. Lipman (2003) holds that "the entire discipline of philosophy bears a unique relationship to the other disciplines, in that philosophy prepares students to think in those other disciplines" (p. 70). Philosophy is a model for other disciplines in its processes of reflection and critique of its own methodology and because philosophy requires the explicit teaching of logic and reasoning (Cam, 2018; Lipman, 1991). This makes philosophy a great introduction to disciplinary knowledge and thinking. Through their induction into philosophical language structures and thinking routines, the students in this study developed an understanding of what it means to think like a philosopher, an understanding which they could later apply to disciplinary thinking in other areas. Thus, this is an example of powerful knowledge in practice in the primary school context.

P4C also teaches students about the provisional nature of knowledge. The theory of powerful knowledge is based on a realist ontology with an interpretivist epistemology. This position holds that while there is truth and a reality out there which we can strive to understand, our understandings are only as strong as our shared interpretations can be. Ongoing research and new insights can always improve our understanding of truth and reality. A key finding that emerged in all of the post-intervention focus group interviews was that the students understood that one's ideas, and the group's understanding of a concept, could always be refined further. They valued, and saw as essential to 'being philosophical', the process of changing one's mind if presented with stronger reasoning for an alternative understanding of an idea. The intellectual humility that was both demonstrated and respected by students in the study, in relation to being open to shifting one's position, is a key disposition for scholarship within a discipline and interaction with an academic field. Students who can see the worth of this at primary school are well positioned to learn and develop throughout their education and beyond. The focus group students also recognised that not all positions are equal; there are shared co-constructed standards that can guide our judgements about the strength - or otherwise - of claims and arguments. 
I propose that the intersubjective process that occurred through the CoIs of argument, evaluation, negotiation and possibility thinking, which students came to value, occurred at the site of Bernstein's (2000) potential discursive gap. The experience of this intersubjectivity gave students an introductory taste of the kind of knowledge creation that happens in the disciplines. This can be conceived of as powerful knowledge in practice. Because of the ways that P4C builds students' understandings of disciplinary knowledge, provisional knowledge, and a realist ontology with an interpretivist epistemology, I contend that P4C offers students powerful knowledge. Concomitantly, P4C offers epistemic access for all learners, including diverse learners, to powerful knowledge. The democratic dialogic processes of the CoI can create the conditions for a community of thinkers who can evaluate and critique each other's ideas constructively. This is an example of what powerful knowledge can look like at primary school.

\section{Contribution to theory: enhancing knowledge}

My third research question asked, "How can P4C enlarge our conception of theories of powerful knowledge?" I have drawn on social realism as my key theoretical resource in interpreting the data in this study. While there is a strong literature arguing how and why epistemic access to powerful knowledge can offer social mobility and improve educational outcomes, very little scholarship has considered what constitutes powerful knowledge at primary school. This has been a key focus of this research.

My findings about enhancing capabilities, language, and social justice have indicated that P4C can not only contribute to powerful knowledge, but that it does so in a way that can open up powerful knowledge to all, including diverse, learners. In this section I propose a new conception of knowledge. This new form of knowledge that P4C allows for builds on, and extends beyond, powerful knowledge. This conception is necessary because Young's account of powerful knowledge is either silent about, or not conceptually framed in terms of, some important areas of social justice and inclusion, namely, the importance of indigenous knowledge and the value of learners' prior knowledge and experiences. By contrast, P4C highlights a stronger, more inclusive notion of powerful knowledge that I term 'enhancing knowledge'. 
Essentially, I argue that while the concept of powerful knowledge is a strong and emancipatory theory that helps educators to conceptualise how to ensure that all students have epistemic access to knowledge that will improve their educational and life prospects, the word powerful is complex and has many connotations. I propose that the term 'enhancing knowledge' conveys the essential meaning of the phrase 'powerful knowledge' without the negative connotations that some meanings of powerful can provoke. In addition, the language of enhancement can emphasise the fact that 'everyday knowledge', the knowledge that comes from experience, is valuable and useful in its own right and in conjunction with enhancing knowledge. Bernstein (1999) saw different knowledge forms as complementary rather than "oppositional” (p. 157) and cautioned against valuing one form over another. My conception of enhancing knowledge highlights the complementarity of different knowledge forms and therefore enhances recognition social justice for learners from a range of cultural backgrounds, and also for diverse learners with other prior knowledges. Instead of equating academic knowledge with powerful knowledge, I argue that critical thinking allows students to evaluate all forms of knowledge (for example, cultural, social, academic) in building enhancing knowledge in ways that allow them to understand and explain the world and to achieve their potential. I believe this alternative conception is consistent with Young and Muller's theory of powerful knowledge while distinguishing it from interpretations of powerful knowledge that erode recognition social justice. The conception of enhancing knowledge enables increased social justice for all students - especially diverse learners - by removing the problem of the negative connotations of the word powerful, by valuing indigenous knowledge, and by emphasising the value of critical thinking in connecting contextual and conceptual knowledge. Next I describe each of these gaps - or at the very least, features that can be misconstrued - in powerful knowledge, in turn.

\section{The problem with the word 'powerful'}

Building on Bernstein's notion of enhancement, Young (2008b) differentiates between knowledge of the powerful and powerful knowledge. Social realists concentrate on the power of knowledge, rather than the power of the knowers (Moore, 2013; Rata, 2012a). This understanding is grounded in the integration of a realist ontology and interpretive 
epistemology that is the basis of social realist understandings. Unfortunately, the word powerful is problematic in that it has so many different meanings and connotations, many of them negative, imbued with a feeling of domination. Language can often be a problematic tool because of its many layers, interpretations, and connotations. Young and Muller (2013) are careful to point this out too: "the two words 'power' and 'knowledge' are too general, too evocative, and open to too many diverse meanings for them not to have been used together in other ways and at other times" (p. 230). In Greek, there are two words for power: potentia and potestas; similarly in French: puissance and pouvoir. These two words differentiate between the different meanings of power as a capacity or a potential, and power as domination (Spinoza, 1958/1677). In distinguishing between powerful knowledge (PK) and knowledge of the powerful (KOTP), Muller and Young (2019) emphasise that:

Only one of them is a kind of knowledge, namely PK. KOTP is a way of referring to its use or origins, and the interests of those originators or users ... The point about PK is to affirm that social interests do not exhaust what is educationally significant about knowledge ... the 'power' in KOTP is not the same as the 'power' of PK ... In PK, by contrast [to KOTP], the power is potentially available to all who acquire it; it is a nonzero-sum property, a non-rivalrous good. Potentially, everyone can have this power, it is infinitely transferable, hence the fundamental democracy of PK and its conceptual link to social justice (pp. 2-3).

When Young and Muller describe academic, school knowledge and frameworks for thinking as powerful, they are focusing on the empowering potential of knowledge that has explanatory power and allows learners to better understand the world they live in. Of course they are not suggesting that this knowledge should be used to dominate others; however this will always be an unintended possible interpretation of any use of the word 'powerful'.

\section{The challenge - and value - of indigenous knowledge}

A potential difficulty that can arise when New Zealanders engage with the concept of powerful knowledge is the possible implicit suggestion that indigenous knowledge, which Young would categorise as everyday experiential knowledge, is not powerful. As I discussed in Chapter 2, Rata (2005, 2007, 2012a, 2012b) has interpreted the theory of powerful knowledge in this way, describing it in opposition to cultural knowledge. 
These dismissals of the value of indigenous knowledge have been described by Pihama (2019) as "colonising discourses" (p. 14) which "reinforce the position of 'white privilege'” (p. 13). Young's account of powerful knowledge does not address its implications for indigenous knowledge. Prima facie, there is nothing in Young's account that makes it incompatible with indigenous knowledge. Enhancing knowledge is a conception of knowledge that is explicitly intended to be compatible with, and inclusive of, indigenous knowledge. Indigenous knowledge is hugely powerful in building cultural understandings of the world for not just indigenous learners but for all learners, and in valuing and learning from the diverse cultural capital(s) of all learners in any learning environment. Young and Muller (2013) emphasise that their "argument is not that specialised knowledge has a higher cultural value than non-specialised knowledge" (p. 231). While this statement seems to argue for the value of cultural knowledge, it also seems to imply that indigenous knowledge is non-specialised. However, elders and kaumatua hold huge stores of specialised cultural knowledge. Indeed, the fact that many forms of indigenous culture and knowledge are taught at both undergraduate and postgraduate level is evidence of the specialised and powerful nature of cultural knowledge. The success of Young and Muller's position depends crucially on their definition of powerful knowledge and on the meaning of powerful as they use it. It is essential to clarify the definition, when using the theory of powerful knowledge, or any theory, for that matter. My reading of Young and Muller's definition is that powerful, disciplinary knowledge that students develop at school can connect to and enhance students' prior knowledge and understandings of the world, for example, indigenous knowledges and experiential knowledge, to allow students to expand their understandings. Muller's (2009) description of learning as starting from students' contexts and connecting to the conceptual understanding that explains the contexts, is consistent with this reading. My definition of enhancing knowledge emphasises this reading in order to distinguish it from (mis)interpretations of powerful knowledge (Rata, 2005, 2007, 2012a, 2012b) that claim that indigenous knowledge is not powerful knowledge. 


\section{Entitlement to enhancing knowledge}

One of the key motivators of Young's theory of powerful knowledge is a drive to redress the inequity caused by the British class system. Young draws on a strong history of thinkers - Bernstein, Durkheim, Bourdieu - who have sought equity of access for all learners to the knowledge, understandings and opportunities that will allow them to achieve educational success. The motivation to achieve equity of opportunity and access to educational success is just as strong in New Zealand; however, the understandings of the barriers and issues and the approaches needed here are different. While social class plays a part in influencing educational outcomes for learners, the evidence would suggest that so too does ethnicity. In New Zealand, a country that has a colonial history, a recognition of the importance and value of indigenous knowledges is essential in order to promote social justice (Carey \& Prince, 2015; McGregor, 2017; Nakata, 2007). Because of this, I have argued that enhancing knowledge can include, or is compatible with, indigenous knowledge. In my view, enhancing knowledge differs from powerful knowledge because it enhances recognition social justice by acknowledging the complementarity of knowledges.

Now that I have offered some reasons for distinguishing powerful knowledge from enhancing knowledge, I will outline where the similarities and differences in these concepts lie. I have already mentioned how enhancing knowledge is powerful in the ways that Young and Muller define powerful knowledge: it comprises modes, frameworks for understanding the world that have explanatory power, that enhance and potentially transform prior knowledge and understandings. It is disciplinary and differentiated. Enhancing knowledge is always provisional and defeasible: it is the best understanding we have so far, which may be added to and developed as new knowledge and understandings are grown by knowledge creators, refined through the systems of understanding and critique within their discipline[s]. However, enhancing knowledge has some importantly different connotations which I will describe next.

\section{Distinguishing enhancing knowledge from powerful knowledge}

Conceptualising powerful knowledge as enhancing knowledge explores the power of combining powerful knowledge with learners' prior knowledges, such as indigenous 
knowledge. The term enhancing explicitly aligns this conception with Bernstein's (2000) concept of the democratic right to enhancement. Put simply, powerful knowledge combined with everyday, prior knowledge results in a deeper, enhanced understanding of the world.

One common interpretation of the social realist argument is that powerful knowledge is the same as academic knowledge (McPhail \& Rata, 2016; Rata, 2016). However, I argue that while academic knowledge can constitute powerful knowledge, enhancing knowledge also has a much broader scope that can incorporate a range of forms of knowledge. Muller (2009) describes the need for students to develop both conceptual and contextual knowledge in building their understanding of the world. What makes the knowledge powerful in this case is the student's ability to see the deeper concept embodied in contextualised knowledge and then to be able to transfer understandings from one specific context to another. For example, within the logic of science, a student is developing powerful knowledge when they observe land erosion in their local community, develop their understanding of the concept that "naturally occurring processes contribute to changes in planet Earth's systems" (Ministry of Education, 1999), and can then apply this concept to understanding how glaciers change shape in Antarctica. Rather than privileging only academic knowledge, I propose that enhancing knowledge involves a critical intersubjectivity (Fay, 1996) that draws together and evaluates various forms of knowledge. It is by incorporating disciplinary and academic knowledge with one's prior knowledge and experiences, through critical thinking, that learners' understandings of the world are enhanced.

This is an important distinction from some understandings of powerful knowledge. Students' backgrounds, knowledge and experience are valued together with disciplinary knowledge. Enhancing knowledge connects with learners' prior knowledge. Whatever the learner's background might be, she brings knowledge with her to the classroom to which she connects her new learning. Enhancing knowledge, in combination with other knowledges such as cultural, indigenous, family, social, and environmental knowledge, will afford learners critical understandings and new possibilities and allow them to contribute new knowledge to the world; it is to this that we should aspire. 
Children's other knowledges are also windows or doors into enhancing knowledge. Different children's experience will allow them to access enhancing knowledge in different ways; for example, Olivia observed that some students' emphasis on ethics during P4C CoIs in her class was likely drawn from their cultural or religious knowledge. This was their window into philosophical thinking. The teacher's job was to use that context as a starting point for developing the other aspects of enhancing knowledge, in this case: philosophical thinking. Young (2012) argues that the teacher's role, "in Vygotsky's terms, ... involves enabling students to move through the 'zone of proximal development' from what they already know to engaging with, coming to share (and even sometimes going beyond) the subject knowledge of their teachers" (para. 30). As these students' enhancing knowledge grows and deepens, they may need to redefine their understanding of their window concept so that they can recognise its possibilities and restrictions in the context of philosophical thinking. This may also influence their understanding of that concept in relation to other knowledges, for example, cultural or religious ethics. Or they may be able to hold the different interpretations of the same concept in different knowledge spheres, knowing which contexts call for the different knowledge forms.

Linking contextual and conceptual understanding is a key part of the learning process for students as they develop enhancing knowledge; this is something that Young (2012) himself notes:

The opportunity provided by schools for pupils to move between their everyday concepts and the theoretical concepts that are located in school subjects lies at the heart of the purpose of schools and aims of any curriculum. The crucial difference between the two types of concept is that a pupil's 'everyday concepts' limit them to their experience, whereas the theoretical concepts to which subject teaching gives students access enable them to reflect on and move beyond the particulars of their experience (para. 19). Through P4C, the development of enhancing knowledge involved learners building understandings through communities of thinkers, interacting with knowledge (through, for example, texts, teachers, the curriculum), applying new knowledge in relevant contexts, challenging each other's interpretations and understandings with logic and intellectual humility, and developing language for thinking. 
I propose that critical thinking is a form of enhancing knowledge because it enables the transformation of different forms of knowledge and different ways of experiencing the world (for example, students' cultural capital, cultural knowledges, family knowledge, academic knowledge) into a viable, enhanced frame for understanding the world. Critical thinking incorporates epistemic frames, disciplinary frameworks, modes of understanding, skills, dispositions, and understandings and the relativist epistemological concept of fallibility or provisionality. In this study, as students developed critical thinking and critical intersubjectivity (Daniel et al., 2005; Fay, 1996) through P4C, they were inducted into powerful modes of analysing, evaluating, and critiquing new and alternative forms of knowledge. They were also able to become knowledge-producers in their own right, applying the same degree of critique to their own new ideas and knowledge. These benefits of enhancing knowledge were experienced by all, including diverse learners. As a result, enhancing knowledge is also a matter of social justice because, by enhancing diverse learners' understanding and capabilities, it can improve equity in education.

\section{$\mathrm{P}_{4} \mathrm{C}$ builds enhancing knowledge for all learners}

The results of this study indicate that Philosophy for Children is a programme with great potential to support the learning of a range of diverse learners in primary schools and to build enhancing knowledge for all learners.

One of the strengths of P4C is that every student has personal experience that they can draw on when discussing philosophical ideas. The topics that philosophy examines are core, common and contestable (Kennedy, 2004; Kennedy \& Kennedy, 2011), questions and subjects that children - who are natural philosophers (Wartenberg, 2009) - already wonder about, for example, friendship, bravery, and identity. These areas, which children discussed by drawing on their own everyday knowledge and experience, became a context from which conceptual knowledge and understanding could be constructed. In Chapter 7 I proposed that the intersubjectivity that developed through the CoIs, occurred in the site of Bernstein's (2000) potential discursive gap. The experience of evaluating and critiquing each other's ideas, and coming to new understandings together, gave students an introductory taste of disciplinary knowledge 
creation: enhancing knowledge in practice, at primary school. In addition, the philosophical thinking and language that students developed formed a foundational understanding of disciplinary thinking that students could apply to other disciplines. Furthermore, as is aptly articulated by 9 -year-old Freddy in the quote at the beginning of this chapter, students gained an appreciation for the ongoing process of refining knowledge understandings, the provisional nature of knowledge. This understanding is a key element of enhancing knowledge.

Although many New Zealand primary schools who teach P4C see it as an extension programme for gifted and talented students, the data indicate that there are compelling reasons to offer P4C to all students. P4C helped to develop students' critical thinking and language therefore, as a matter of social justice, this is the kind of powerful learning and powerful, enhancing knowledge to which all learners deserve to have epistemic access, not just those who have already demonstrated some proficiency in critical thinking. The argument could be made that students who need support to achieve at school are those who most deserve and need access to programmes that help them to develop their capacity to think. Furthermore, analysis of student voice at the end of the project indicated that one of the elements that children most valued about the philosophical CoI was the opportunity to hear other perspectives and to think together in order to come to a new shared understanding of a concept. The more diverse the group, the broader the range of perspectives students are exposed to, which strengthens intersubjectivity. An epistemically diverse group of thinkers that involves diversity, discussion, dissent, and dynamism (or feedback - a recognition of fallibilism) is not only more democratic but more effective (Anderson, 2006). This argument echoes Dewey's contention that true democracy requires interaction between diverse individuals in order to understand each other's needs and perspectives and to make decisions that serve mutually interpenetrating interests (Dewey, 1916).

The context and culture of a P4C CoI allowed students to participate without the potential barrier of written language. Students who may not have been able to convey their thinking in other ways got the opportunity to talk about their thinking and to muse, philosophise, and wonder. Every teacher in the study described how their 
potentially limiting preconceptions of diverse learners in their class were shattered by the quality of the dialogue they heard between students in the CoI. This study offers insights into how teaching philosophy can help teachers develop greater understanding about students' thinking abilities and improve teachers' expectations of their students. Teachers were able to identify and then to dismantle their own unconsciously held stereotypes, implicit biases, and deficit thinking in order to consciously hold high expectations for all of their learners. This shift can build epistemic justice for diverse learners as teachers recognise their responsibility to teach explicit knowledge, skills and dispositions that build academic capital and accelerate diverse learners' achievement.

For these reasons I propose that P4C has the potential to help diverse learners, indeed all students, to develop enhancing knowledge at primary school.

\section{Future directions for research}

While this study explored differences between schools in different socio-economic areas and drew some conclusions from these contrasts, my data is inconclusive in relation to ethnicity and biculturalism, so I cannot make any claims about the impact of P4C on the learning of students of different ethnicities. Further research is needed to better understand how P4C might best be tailored to meet the needs of learners of different cultural and ethnic groups to provide insights into improving the educational outcomes of diverse learners of different ethnicities and cultural backgrounds.

A key theme arising from this research is the power of language to shape thought. In addition, the findings of this study suggest that further research exploring what powerful, enhancing knowledge looks like at primary school is warranted. This might involve larger scale longitudinal research examining the impact of the language structures, thinking routines, and argument moves that students develop in $\mathrm{P} 4 \mathrm{C}$, on language and thinking in other school subjects and disciplines. This kind of research would deepen our understanding of the power and value of the language and thinking structures that students learn through P4C. 
While many students contributed frequently to whole class dialogue, which enabled me to make observations and form some understanding of the language and thinking development that occurred for them through the research project, the degree of student involvement varied, as I discussed in Chapter 6. This meant that, for the quieter students, the kinds of inferences that can be drawn about their motivations and thinking development are limited. Because critical thinking is an internal process, demonstrated through language, it can be challenging to identify the impact of $\mathrm{P} 4 \mathrm{C}$ on students who are quieter or silent during whole class communities of inquiry. Further research exploring the thinking of students who remain quiet in the CoI would help to further our understanding of the impact of P4C on diverse learners. It appeared that some of the quieter students in this study were still absorbing the language structures and argument schemas required to articulate their thinking in the context of a classroom dialogue. Longer research studies of over a year or more, and even more long-term longitudinal research and research methods using learning stories and thinking journals, as well as recordings of dialogue in small groups or pairs and interviews with quieter participants, could help to illuminate our understanding of the long-term trajectory of thinking and language development and involvement of quieter, diverse learners and the impact of $\mathrm{P} 4 \mathrm{C}$ on a wider range of students' thinking.

As Freddy articulated in the quote at the start of this chapter, ideas or knowledge are never finished, they are in a constant state of improvement. Achieving social justice in education is a complex, shifting, ongoing aim. The ideas this research proposes offer one small contribution to an ongoing conversation and praxis, with and between scholars, policy makers, teachers, and children. In an educational system that currently privileges those who are already privileged, Philosophy for Children offers teachers and students an alternative: a way to form a democratic CoI that can offer all learners the opportunities for enhancement, inclusion and participation. 



\section{References}

Adey, P., \& Shayer, M. (1993). An exploration of long-term far-transfer effects following an extended intervention program in the high school science curriculum.

Cognition and Instruction, 11(1), 1-29.

Albert, S. P. (2018). Putting philosophy to the service of schools to give children's voices real value. Childhood \& Philosophy, 14(30), 453-470.

Alexander, R. (2005). Towards dialogic teaching: Rethinking classroom talk. Cambridge: Dialogos.

Anderson, E. (2006). The epistemology of democracy. Episteme, 3(1-2), 8-22.

Anderson, M. L. (2006). Cognitive science and epistemic openness. Phenomenology and the Cognitive Sciences, 5, 125-154.

Anderson, R. C., Nguyen-Jahiel, K., McNurlen, B., Archodidou, A., Kim, S.-Y., Reznitskaya, A., \& Gilbert, L. (2001). The snowball phenomenon: Spread of ways of talking and ways of thinking across groups of children. Children, Cognition and Instruction, 19(1), 1-46.

Archer, M., Bhaskar, R., Collier, A., Lawson, T., \& Norrie, A. (2013). Critical realism: Essential readings. London: Routledge.

Arnot, M., \& Reay, D. (2007). A sociology of pedagogic voice: Power, inequality and pupil consultation. Discourse: Studies in the Cultural Politics of Education, 28(3), 311325.

Barker, J., \& Smith, F. (2001). Power, positionality and practicality: Carrying out fieldwork with children. Ethics, Place \& Environment, 4(2), 142-147.

Barnes, D. (1992). The role of talk in learning. In K. Norman (Ed.), Thinking voices: The work of the National Oracy Project. London: Hodder \& Stoughton.

Barnes, D. (2008). Exploratory talk for learning. In N. Mercer \& S. Hodgkinson (Eds.), Exploring talk in school (pp. 1-16). London: Sage.

Barron, B. (2003). When smart groups fail. The Journal of the Learning Sciences, 12, 307359.

Barrow, W. (2010). Dialogic, participation and the potential for Philosophy for Children. Thinking Skills and Creativity, 5(2), 61-69. doi:http://dx.doi.org/10.1016/j.tsc.2010.01.002

Barrow, W. (2015). 'I think she's learnt how to sort of let the class speak': Children's perspectives on Philosophy for Children as participatory pedagogy. Thinking Skills and Creativity, 17, 76-87.

Beck, J. (2013). Powerful knowledge, esoteric knowledge, curriculum knowledge. Cambridge Journal of Education, 43(2), 177-193.

Beeby, C. (1938). Annual report to Parliament. Wellington: Ministry of Education.

Bell, L. A. (1997). Theoretical foundations for social justice education. In M. Adams, L. A. Bell, \& P. Griffin (Eds.), Teaching for diversity and social justice: A sourcebook (pp. 3-15). New York: Routledge.

Benade, L. (2011). Philosophy for Children (P4C): A New Zealand school-based action research case study. New Zealand Journal of Teachers' Work, 8(2), 141-155.

Bernstein, B. (1962). Linguistic codes, hesitation phenomena and intelligence. Language and Speech, 5(1), 31-48.

Bernstein, B. (1971a). Class, codes and control. London: Routledge \& Kegan Paul. 
Bernstein, B. (1971b). Class, codes and control (Vol. 1. Theoretical studies towards a sociology of language). London: Routledge \& Kegan Paul.

Bernstein, B. (1972). On the classification and framing of educational knowledge. In M. Young (Ed.), Knowledge and control. London: Collier-Macmillan.

Bernstein, B. (1975). Class and pedagogies: Visible and invisible. Educational Studies, 1(1), 23-41.

Bernstein, B. (1996). Pedagogy, symbolic control and identity: Theory, research, critique. London: Taylor \& Francis.

Bernstein, B. (1999). Vertical and horizontal discourse: An essay. British Journal of Sociology of Education, 20(2), 157-173.

Bernstein, B. (2000). Pedagogy, symbolic control and identity: Theory, research, critique (Revised ed.). London: Rowman \& Littlefield.

Betts, B., \& McMaster, L. (2011). Disrupting gifted teenagers' mathematical identity with epistemological messiness. The Montana Mathematics Enthusiast, 8(1\&2), 329354.

Bhaskar, R. (1979). The possibility of naturalism. Hemel Hempstead: Harvester Press Ltd.

Bhaskar, R. (1998a). Philosophy and scientific realism. In M. Archer, R. Bhaskar, A. Collier, T. Lawson, \& A. Norrie (Eds.), Critical realism: Essential readings. London: Routledge.

Bhaskar, R. (1998b). The possibility of naturalism: A philosophical critique of the contemporary human sciences. London: Routledge.

Biesta, G. (1998). Mead, intersubjectivity, and education: The early writings. An International Journal, 17(2), 73-99. doi:10.1023/A:1005029131211

Biesta, G. (1999). Radical intersubjectivity: Reflections on the 'different' foundation of education. Studies in Philosophy and Education, 18(4), 203-220.

Biesta, G. (2011a). Learning democracy in school and society: Education, lifelong learning, and the politics of citizenship. Rotterdam: Sense Publishers.

Biesta, G. (2011b). Philosophy, exposure, and children - how to resist the instrumentalisation of philosophy in education. Journal of Philosophy of Education, 45(2), 305-319.

Biesta, G. (2012). Philosophy of education for the public good: Five challenges and an agenda. Educational Philosophy and Theory, 44(6), 581-593. doi:10.1111/j.14695812.2011.00783.x

Biesta, G. (2014). Pragmatising the curriculum: bringing knowledge back into the curriculum conversation, but via pragmatism. The Curriculum Journal, 25(1), 2949. doi:10.1080/09585176.2013.874954

Biesta, G. (2015). What is education for? On good education, teacher judgement, and eduational professionalism. European Journal of Education, 50(1), 75-87.

Biglan, A. (1973a). The characteristics of subject matter in different academic areas. Journal of Applied Psychology, 53(3), 195-203.

Biglan, A. (1973b). Relationships between subject matter characteristics and the structure and output of university departments. Journal of Applied Psychology, 53(3), 204-213.

Bleazby, J. B. (2011). Overcoming relativism and absolutism: Dewey's ideals of truth and meaning in philosophy for children. Educational Philosophy and Theory, 43(5), 453-466. doi:10.1111/j.1469-5812.2009.00567.x 
Bloor, M. (2001). Techniques of validation in qualitative research: A critical commentary. In R. M. Emerson (Ed.), Contemporary field research (pp. 383-396). Prospect Heights, IL: Waveland Press.

Boud, D. (2000). Sustainable assessment: Rethinking assessment for the learning society. Studies in Continuing Education, 22(2), 151-167. doi:10.1080/713695728

Bourdieu, P. (1984). Distinction: A social critique of the judgement of taste. Cambridge, MA: Harvard University Press.

Bourne, J. (2004). Framing talk: Towards a radical visible pedagogy. In B. Davies, A. Morais, \& J. Muller (Eds.), Reading Bernstein, researching Bernstein (pp. 61-74). London: RoutledgeFalmer.

Boyatzis, R. E. (1998). Transforming qualitative information: Thematic analysis and code development. London: Sage.

Braun, V., \& Clarke, V. (2006). Using thematic analysis in psychology. Qualitative Research in Psychology, 3(2), 77-101.

Braun, V., \& Clarke, V. (2012). Thematic analysis. In H. Cooper, P. Camic, D. Long, A. Panter, D. Rindskopf, \& K. Sher (Eds.), APA handbook of research methods in psychology, Vol. 2. Research designs: Quantitative, qualitative, neuropsychological, and biological. (Vol 2, pp. 37-71). https://doi.org/10.1037/13620-000

Braun, V., \& Clarke, V. (2019). Thematic analysis | a reflexive approach. Retrieved from https://www.psych.auckland.ac.nz/en/about/our-research/researchgroups/thematic-analysis.html

Bridgeman, S. (2012). The trouble with decile ratings. New Zealand Herald.

Brighouse, H. (2004). Justice. Malden, MA: Polity.

Brookfield, S. D. (2017). Becoming a critically reflective teacher (2nd ed.). San Francisco, CA: Jossey-Bass.

Broudy, H. S. (1977). Types of knowledge and purposes of education. In R. C. Anderson, R. J. Spiro, \& W. E. Montague (Eds.), Schooling and the acquisition of knowledge (pp. 1-17). Hillsdale, NJ: Lawrence Erlbaum.

Brown, J. S., Collins, A., \& Duguid, P. (1989). Situated cognition and the culture of learning. Educational Researcher, 18(1), 32-42.

Brown, M., \& White, J. (2012). An unstable framework - Critical perspectives on the framework for the National Curriculum. Retrieved from https://www.newvisionsforeducation.org.uk/about-thegroup/home/2012/04/05/an-unstable-framework/

Burgh, G. (2018). The need for philosophy in promoting democracy: A case for philosophy in the curriculum. Journal of Philosophy in Schools, 4(2), 38-58.

Burgh, G., \& Davey, S. (2004). Learning for democracy: Caring, dialogue and deliberative communities. Paper presented at the Schooling and Lifelong Learning for Democracy and Community Building, University of Technology, Sydney.

Burgh, G., Field, T., \& Freakley, M. (2006). Ethics and the community of inquiry: education for deliberative democracy. Southbank, Vic: Thomson Social Sciences Press.

Burgh, G., \& Yorshansky, M. (2011). Communities of inquiry: politics, power and group dynamics. Educational Philosophy and Theory, 43(5), 436-452. doi:http://dx.doi.org/10.1111/j.1469-5812.2007.00389.x

Burr, V. (2015). Social constructivism. (3rd ed.). Hove: Routledge.

Burroughs, M. D., \& Tollefsen, D. (2016). Learning to listen: Epistemic injustice and the child. Episteme, 13(3), 359-377. 
Butler, J. (1996). Professional development: Practice as text, reflection as process, and self as locus. Australian Journal of Education, 40, 265-283.

Butnor, A. (2012). Critical communities: Intellectual safety and the power of disagreement. Educational Perspectives, 44, 29-31.

Cam, P. (1995). Thinking together: Philosophical inquiry for the classroom. Sydney: Primary English Teaching Association and Hale \& Iremonger.

Cam, P. (2003). The question quadrant. Critical and Creative Thinking, 11(2), 61-64.

Cam, P. (2006a). 20 thinking tools: Collaborative inquiry for the classroom. Victoria: ACER Press.

Cam, P. (2006b). Philosophy and the school curriculum: Some general remarks. Critical and Creative Thinking: The Australasian Journal of Philosophy in Education, 14(1), 31-51.

Cam, P. (2008). Dewey, Lipman, and the tradition of reflective education. In M. Taylor, H. Schreier, \& P. Ghiraldelli (Eds.), Pragmatism, Education, and Children: International philosophical perspectives, (pp. 163-181). New York, NY: Rodopi.

Cam, P. (2009). Educating for democracy. Diogenes, 56, 37-48. Retrieved from http://go.galegroup.com/ps/i.do?id=GALE\%7CA238068230\&v=2.1\&u=vuw\&it= $\underline{\mathrm{r} \& \mathrm{p}=I T O F \& s w=w \& a s i d=e e c b f 386851 \mathrm{a} 5910 \mathrm{c0ee} 24 \mathrm{bf9ffb} 1 \mathrm{e} 02}$

Cam, P. (2014a). Commentary on Ann Margaret Sharp's 'The other dimension of caring thinking'. Journal of Philosophy in Schools, 1(1), 15.

Cam, P. (2014b). Democratic pedagogy. Journal of Philosophy in Schools, 1(1), 22-44.

Cam, P. (2018). The generic argument for teaching philosophy. Journal of Philosophy in Schools, 4, 59-75.

Canuto, A. T. (2018). Developing children's reasoning and inquiry, concept analysis, and meaning-making skills through the community of inquiry. Childhood \& Philosophy, 14(30), 427-452.

Capoccia, G. (2016). Critical junctures and institutional change. In J. Mahoney \& K. Thelen (Eds.), Advances in comparative historical analysis in the social sciences (pp. 1-41). Cambridge: Cambridge University Press.

Carey, M., \& Prince, M. (2015). Designing an Australian indigenous studies curriculum for the twenty-first century: Nakata's 'cultural interface', standpoints and working beyond binaries. Higher Education Research \& Development, 34(2), 270283. doi:10.1080/07294360.2014.956691

Carr, M. (2001). Assessment in early childhood settings: Learning stories. London: Paul Chapman.

Carr, M. (2006). Dimensions of strength for key competencies. Retrieved from https://nzcurriculum.tki.org.nz/Archives/Curriculum-projectarchives/Developing-the-draft/Key-competencies/Background-reading

Carr, M. (2008). Zooming in and zooming out: Challenges and choices in discussions about making progress (pp. 3-18). Making progress, measuring progress: Conference proceedings. Wellington: NZCER.

Cherednichenko, B., Harvey, G., \& Roberts, J. (2003). Philosophy in schools as a literacy pedagogy. Paper presented at the ACSA Conference, Adelaide, Australia.

Chzhen, Y., Gromada, A., Rees, G., Cuesta, J., \& Bruckauf, Z. (2018). An unfair start: Inequality in children's education in rich countries, Innocenti Report Card no. 15. Retrieved from https://www.unicef-irc.org/publications/995-an-unfair-starteducation-inequality-children.html 
Claxton, G. (2007). Expanding young people's capacity to learn. British Journal of Educational Studies, 55(2), 115-134.

Cohen, E. G. (1984). Talking and working together: Status, interaction, and learning. In P. Peterson, C. Wilkerson, \& M. Hallinan (Eds.), The social context of instruction: Group organization and group processes (pp. 171-187). New York: Academic Press.

Cohen, E. G., \& Lotan, R. A. (Eds.). (1997). Working for equity in heterogeneous classrooms: Sociological theory in practice. New York: Teachers College Press.

Cohen, E. G., Lotan, R. A., \& Leechor, C. (1989). Can classrooms learn? Sociology of Education, 75-94.

Cohen, E. G., Lotan, R. A., Scarloss, B. A., \& Arellano, A. R. (1999). Complex instruction: Equity in cooperative learning classrooms. Theory Into Practice, 38(2), 80-86.

Collins, A., Seely Brown, J., \& Holum, A. (1991). Cognitive apprenticeship: Making thinking visible. American Educator(Winter), 1-18.

Collins, R. (1998). The sociology of philosophies: A global theory of intellectual change. Cambridge, MA: Harvard University Press.

Colom, R., Garcia Moriyon, F., Magro, C., \& Morilla, E. (2014). The long-term impact of Philosophy for Children: A longitudinal study. Analytic Teaching and Philsophical Praxis, 35(1), 50-56.

Costa, A., \& Kallick, B. (2000a). Discovering and exploring habits of mind (Vol. 1.). Alexandria, VA: Association for Supervision and Curriculum Development.

Costa, A. \& Kallick, B. (2000b). Activating \& engaging habits of mind (Vol. 2). Alexandria, VA: Association for Supervision and Curriculum Development.

Costa, A. \& Kallick, B. (2000c). Assessing \& reporting on habits of mind (Vol. 3). Alexandria, VA: Association for Supervision and Curriculum Development.

Counsell, C. (2011). Disciplinary knowledge for all, the secondary history curriculum and history teachers' achievement. Curriculum Journal, 22(2), 201-225.

Creswell, J. W. (2003). Research design: Qualitative, quantitative, and mixed methods approaches (2nd ed.). Thousand Oaks, CA: Sage Publications, Inc.

Creswell, J. W. (2014). Educational research: Planning, conducting and evaluating quantitative and qualitative research. Harlow, Essex: Pearson.

Cummins, J. (1979). Cognitive/academic language proficiency, linguistic interdependence, the optimum age question and some other matters. Working Papers on Bilingualism, 19, 121-129.

Cummins, J. (1981a). Empirical and theoretical underpinnings of bilingual education. The Journal of Education, 163(1), 16-29. Retrieved from http://www.jstor.org/stable/42772934

Cummins, J. (1981b). The role of primary language development in promoting educational success for language minority students. In California State Department of Education (Ed.), Schooling and language minority students: A theoretical framework. Los Angeles: Evaluation, Dissemination and Assessment Center, California State University.

Cummins, J. (1984). Bilingualism and special education: Issues in assessment and pedagogy. Clevedon, Avon: Multilingual Matters.

Cummins, J. (2008). BICS and CALP: Empirical and theoretical status of the distinction. In B. Street \& N. H. Hornberger (Eds.), Encyclopedia of language and education (2nd ed., Vol. 2, pp. 71-83). Boston: Springer. 
Daniel, M. F., \& Auriac, E. (2011). Philosophy, critical thinking and Philosophy for Children. Educational Philosophy and Theory, 43(5), 415-435. doi:10.1111/j.1469-5812.2008.00483.x

Daniel, M. F., \& Gagnon, M. (2011). Developmental process of dialogical critical thinking in groups of pupils aged 4 to 12 years. Creative Education, 2(5), 418-428.

Daniel, M. F., Lafortune, L., Mongeau, P., Slade, C., Splitter, L., \& De la Garza, T. (2003). The development of dialogical critical thinking in children. Inquiry: Critical Thinking Across the Disciplines, 22(4), 43-55.

Daniel, M. F., Lafortune, L., Pallascio, R., Splitter, L., Slade, C., \& de la Garza, T. (2005). Modeling the development process of dialogical critical thinking in pupils aged 10 to 12 years. Communication Education, 54(4), 334-354. doi:10.1080/03634520500442194

Daniel, M. F., Pettier, J.-C., \& Auriac-Slusarczyk, E. (2011). The incidence of philosophy on discursive and language competence in four-year-old pupils. Creative Education, 2(3), 296-304.

Daniel, M. F., Splitter, L., Slade, C., Lafortune, L., Pallascio, R., \& Mongeau, P. (2002). Are the philosophical exchanges of pupils aged 10 to 12 relativistic or intersubjective? Critical \& Creative Thinking, 10(2), 1-19.

Daniel, M. F., Splitter, L., Slade, C., Lafortune, L., Pallascio, R., \& Mongeau, P. (2004). Dialogical critical thinking: Elements of definitions emerging in the analysis of transcripts from pupils aged 10 to 12 years. Australian Journal of Education, 48(3), 295-313.

Daniels, H. (2001). Vygotsky and pedagogy. London: RoutledgeFalmer.

Davis, B. (2004). Inventions of teaching: A genealogy. Mahwah, NJ: Lawrence Erlbaum Associates, Inc.

De La Garza, T. (2006). Education for justice. Thinking: The Journal of Philosophy for Children, 18(2), 13-18.

Delors, J., Al Mufti, I. a., Amagi, I., Carneiro, R., Chung, F., Geremek, B., Nanzhao, Z. (1996). Learning: The treasure within. Retrieved from https://unesdoc.unesco.org/ark:/48223/pf0000109590

Denzin, N. K., \& Lincoln, Y. S. (2003). The discipline and practice of qualitative research. In N. K. Denzin \& Y. S. Lincoln (Eds.), Strategies of qualitative inquiry (2nd ed., pp. 1-45). Thousand Oaks: Sage.

Denzin, N. K., \& Lincoln, Y. S. (2009). The elephant in the living room: Or extending the conversation about the politics of evidence. Qualitative Research, 9(139), 139160.

Dewey, J. (1910). How we think. Boston: DC Heath.

Dewey, J. (1916). Democracy and education. New York: Macmillan.

Dewey, J. (1925). Experience and nature. In J. A. Boydston (Ed.), The later works (19251953) (Vol. 1). Carbondale and Edwardsville: Southern Illinois University Press.

Dewey, J. (1929). Experience and nature (2nd ed.). La Salle, Illinois: Open Court.

Dewey, J. (1944). Democracy and education. Toronto: Macmillan Company.

Durkheim, E. (1977). The evolution of educational thought: Lectures on the formation and development of secondary education in France. London: Routledge.

Dwyer, C., \& Limb, M. (2001). Introduction: Doing qualitative research in geography. In M. Limb \& C. Dwyer (Eds.), Qualitative methodologies for geographers: Issues and debates. London/NY: Arnold/Oxford University Press. 
Echeverria, E., \& Hannam, P. (2013). Philosophical inquiry and the advancement of democratic praxis. Journal of Pedagogy, 4(1), 111-125.

Echeverria, E., \& Hannam, P. (2017). The community of philosophical inquiry (P4C): A pedagogical proposal for advancing democracy. In M. R. Gregory, J. Haynes, \& K. Murris (Eds.), The Routledge international handbook of Philosophy for Children (pp. 3-10). Abingdon: Routledge.

Elder, L., \& Paul, R. (2013). Critical thinking: Intellectual standards essential to reasoning well within every domain of thought. Journal of Developmental Education, 36(3), 34-35.

Elder-Vass, D. (2012). Towards a realist social constructionism. Sociologia, Problemas e Praticas, 10, 9-24.

Ely, M., Vinz, R., Downing, M., \& Anzul, M. (1997). On writing qualitative research: Living by words. London: RoutledgeFalmer.

Emanuel, A. (2013). So, what school did you go to? In M. Rashbrooke (Ed.), Inequality: A New Zealand crisis (pp. 145-147). Wellington: Bridget Williams Books.

Ennis, R. H. (1987). A taxonomy of critical thinking dispositions and abilities. In J. Baron \& R. Sternberg (Eds.), Teaching thinking skills: Theory and practice (pp. 9-26). New York: W. H. Freeman.

Ennis, R. H. (2013, May, 2013). Commentary on: Ilan Goldberg, Justine Kingsbury and Tracy Bowell's "Measuring critical thinking about deeply held beliefs". Paper presented at the OSSA, University of Windsor.

Education Review Office. (2012). Priority learners in New Zealand schools. Retrieved from https://www.ero.govt.nz/publications/evaluation-at-a-glancepriority-learners-in-new-zealand-schools/

Education Review Office. (2013). Accelerating the progress of priority learners in primary schools - summary. Retrieved from http://www.ero.govt.nz/NationalReports/Accelerating-the-Progress-of-Priority-Learners-in-Primary-SchoolsMay-2013

Education Review Office. (2016). School evaluation indicators: Effective practice for improvement and learner success. Wellington: Education Review Office: Te Tari Arotake Mātauranga.

Facione, P. A. (1990). Critical thinking: A statement of expert consensus for purposes of educational assessment and instruction. Research findings and recommendations. Newark, Del.: American Philsophical Association.

Facione, P. A. (2015). Critical thinking: what it is and why it counts. Insight Assessment, 2007(1), 1-23.

Fair, F., Haas, L. E., Gardosik, C., Johnson, D. D., Price, D. P., \& Leipnik, O. (2015). Socrates in the schools from Scotland to Texas: Replicating a study on the effects of a Philosophy for Children program. Journal of Philosophy in Schools, 2(1), 18-37.

Fay, B. (1996). Contemporary philosophy of social science : A multicultural approach. Oxford: Blackwell.

Feuerstein, R. (1980). Instrumental enrichment: An intervention program for cognition modifiability. Baltimore: University Park Press.

Field, T., \& Burgh, G. (1994). Philosophising with children. History Teacher, 32(1), 45-47.

Fisher, R. (2003). Teaching thinking. London: Continuum.

Fisher, R. (2005). Teaching children to think (2nd ed.). Cheltenham: Nelson Thornes Ltd. 
Fisher, R. (2007). Dialogic teaching: developing thinking and metacognition through philosophical discussion. Early Child Development and Care, 177(6), 615-631. doi:10.1080/03004430701378985

Fitch, E. F., \& Hulgin, K. (2008). Achieving inclusion through CLAD: Collaborative Learning Assessment through Dialogue. International Journal of Inclusive Education, 12(4), 423-439. doi:10.1080/13603110601121453

Francis, B., Mills, M., \& Lupton, R. (2017). Towards social justice in education: Contradictions and dilemmas. Journal of Education Policy, 32, 414-431. doi:10.1080/02680939.2016.1276218

Freire, P. (1972). Pedagogy of the oppressed. Harmondsworth: Penguin Education.

Freire, P. (2004). Pedagogy of indignation. Boulder, CO: Paradigm Publishers.

Fricker, M. (2007). Epistemic injustice: Power and the ethics of knowing. Oxford: Oxford University Press.

Gallagher, C., Hipkins, R., \& Zohar, A. (2012). Positioning thinking within national curriculum and assessment systems: Perspectives from Israel, New Zealand and Northern Ireland. Thinking Skills and Creativity, 7(2), 134-143.

Gallagher, M. (2009). 'Power is not evil': Rethinking power in participatory methods. Children's Geographies, 6(2), 137-150.

Gandin, L., \& Apple, M. (2002). Challenging neo-liberalism, building democracy: Creating the Citizen School in Porto Allegre, Brazil. Journal of Education Policy, 17(2), 259280.

Garcia-Moriyon, F., Rebollo, I., \& Colom, R. (2004). Evaluating Philosophy for Children: A meta-analysis. Thinking: The Journal of Philosophy for Children, 17(4), 14-22.

Gardner, H. (1999). The disciplined mind. New York, NY: Simon \& Schuster.

Gardner, H. (2006). Five minds for the future. Boston, MA: Harvard Business School Press.

Gardner, H., \& Dyson, V. (1994). Teaching for understanding in the disciplines - and beyond. Teachers College Record, 96(2), 198-218.

Gardner, S. (1995). Inquiry is no mere conversation (or discussion or dialogue). Facilitation of inquiry is hard work! Analytic Teaching, 16(2), 102-111.

Gardner, S. (1998). Philosophy for Children really works! Participation in a community of inquiry nourishes participants' perspective-taking capacity. Critical \& Creative Thinking: The Australasian Journal of Philosophy for Children, 6(1), 1-13.

Gardner, S. (2015). Inquiry is no mere conversation (or discussion or dialogue): Facilitation of inquiry is hard work! Journal of Philosophy in Schools, 2(1), 75-91.

Geertz, C. (1973). The interpretation of cultures: selected essays. London: Fontana.

Gewirtz, S., \& Cribb, A. (2002). Plural conceptions of social justice: Implications for policy sociology. Journal of Educaction Policy, 17(5), 499-509. doi:10.1080/02680930210158285

Gibbons, P. (1998). Classroom talk and the learning of new registers in a second language. Language and Education, 12, 99-118.

Gibbons, P. (2002). Scaffolding language, scaffolding learning: Teaching second language learners in the mainstream classroom. Portsmouth, NH: Heinemann.

Gilbert, J. (2005). Catching the knowledge wave. Wellington: NZCER.

Godinho, S., \& Shrimpton, B. (2003). Boys' and girls' use of linguistic space in smallgroup discussions: Whose talk dominates? Australian Journal of Language and Literacy, 26(3), 28-43. 
Goering, S., Shudak, N. J., \& Wartenberg, T. E. (Eds.). (2013). Philosophy in schools : An introduction for philosophers and teachers. New York, NY: Routledge.

Goldberg, I. Y. (2011). Reasoning and religion: The relevance of the academic study of religion to critical thinking pedagogy. (PhD). University of Waikato, Hamilton.

Goldberg, I. Y., Kingsbury, J., \& Bowell, T. (2013). Measuring critical thinking about deeply held beliefs. Paper presented at the OSSA, University of Windsor.

Golding, C. (2009). "That's a better idea!" Philosophical progress and Philosophy for Children. Childhood \& Philosophy, 5(10), 223-269.

Golding, C. (2010). “That's a better idea!” Philosophical progress in Philosophy for Children. University of Melbourne, Melbourne.

Golding, C. (2011a). Educating for critical thinking: Thought-encouraging questions in a community of inquiry. Higher Education Research \& Development, 30, 357-370.

Golding, C. (2011b). The many faces of constructivist discussion. Educational Philosophy and Theory, 43(5), 467-483.

Golding, C. (2014). A handy account of philosophy in schools. Journal of Philosophy in Schools, 1(1), 68-88.

Golding, C. (2017). Getting better ideas: A framework for understanding epistemic philosophical progress in Philosophy for Children. In M. R. Gregory, J. Haynes, \& K. Murris (Eds.), The Routledge international handbook of Philosophy for Children. Abingdon: Routledge.

Gorard, S., Siddiqui, N., \& Huat See, B. (2015). Philosophy for Children: Evaluation report and executive summary. Durham: Education Endowment Foundation.

Gregory, M. R. (2002). Constructivism, standards, and the classroom community of inquiry. Educational Theory 52(4), 397-408.

Gregory, M. R. (2011). Philosophy for Children and its critics: A Mendham dialogue. Journal of Philosophy of Education, 45(2), 199-219.

Gregory, M. R., Haynes, J., \& Murris, K. (Eds.). (2017). The Routledge international handbook of Philospohy for Children. Abingdon: Routledge.

Griffin, C. (1990). The researcher talks back. In W. Shaffir \& R. Stebbins (Eds.), Experiencing fieldwork. Newbury Park, CA: Sage.

Guba, E. G., \& Lincoln, Y. S. (1994). Competing paradigms in qualitative research. Handbook of Qualitative Research, 2, 163-194.

Guest, G., MacQueen, K. M., \& Namey, E. E. (2011). An introduction to applied thematic analysis. In Applied thematic analysis (pp. 3-20). Thousand Oaks, CA: Sage.

Halliday, M. A. K. (1993). Towards a language-based theory of learning. Linguistics and Education, 5, 93-116.

Halpern, D. F. (2013). Thought and knowledge: An introduction to critical thinking (5th ed.). London: Taylor \& Francis Group.

Hand, M. \& Winstanley, C. (2009). Philosophy in schools. London: Continuum.

Harpaz, Y. (2005a). Approaches to teaching thinking: Towards a conceptual mapping of the field. Teachers College Record, 109(8), 1845-1874.

Harpaz, Y. (2005b). Teaching and learning in a community of thinking. Journal of Curriculum and Supervision, 20(2), 136-157.

Harpaz, Y. (2014). Teaching and learning in a community of thinking: The third model. Dordrecht: Springer.

Hattie, J., \& Anderman, E. M. (Eds.). (2012). International guide to student achievement. New York: Routledge. 
Haynes, F. (2014). Teaching children to think for themselves: From questioning to dialogue. Journal of Philosophy in Schools, 1, 131-146.

Hennessy, S., Mercer, N., \& Warwick, P. (2011). A dialogic inquiry approach to working with teachers in developing classroom dialogue. Teachers College Record, 113(9), 1906-1959.

Hennessy, S., \& Rojas-Drummond, S. (2015). A tool for analysing dialogic interactions in classrooms. Retrieved from

http://www.educ.cam.ac.uk/research/projects/analysingdialogue/

Hennessy, S., Rojas-Drummond, S., Higham, R. J. E., Marquez, A. M., Maine, F., Rios, R. M., Barrera, M. J. (2016a). Developing a coding scheme for analysing classroom dialogue across educational contexts. In press, under review. Cambridge: University of Cambridge.

Hennessy, S., Rojas-Drummond, S., Higham, R. J. E., Marquez, A. M., Maine, F., Rios, R. M., Barrera, M. J. (2016b). Developing a coding scheme for analysing classroom dialogue across educational contexts. Learning, Culture and Social Interaction, 9, 16-44. doi:http://dx.doi.org/10.1016/j.lcsi.2015.12.001

Hernandez, D. J., \& Napierala, J. S. (2014). Mother's education and children's outcomes: How dual-generation programs offer increased opportunities for America's families. New York, NY: Foundation for Child Development.

Hipkins, R. (2009). Determining meaning for key competencies via assessment practices. Assessment Matters, 1, 4-20.

Hipkins, R. (2013). The 'everywhere and nowhere' nature of thinking as a subjectspecific competency. Thinking Skills and Creativity, 10, 221-232. doi:https://doi.org/10.1016/j.tsc.2013.05.006

Hipkins, R. (2017). Weaving a coherent curriculum: How the idea of 'capabilities' can help. Wellington: NZCER Press.

Hipkins, R., Bolstad, R., Boyd, S., \& McDowall, S. (2014). Key competencies for the future. Wellington: NZCER Press.

Hipkins, R., \& Boyd, S. (2011). The recursive elaboration of key competencies as agents of curriculum change. Curriculum Matters, 7, 70-86.

Hipkins, R., Reid, A., \& Bull, A. (2010). Some reflections on the philosophical and pedagogical challenges of transforming education. The Curriculum Journal, 21(1), 109-118.

Ho, L., Calma, T., Baldry, E., Briskman, L., \& Disney, J. (2011). What is social justice? Sydney: National Pro Bono Resource Centre.

Holstein, J., \& Gubrium, J. (1995). The active interview. Thousand Oaks, CA: Sage.

Holstein, J., \& Gubrium, J. (2000). The self that we live by: Narrative identity in the postmodern world. New York, NY: Oxford University Press.

Holt, L. (2008). Embodied social capital and geographic perspectives: Performing the habitus. Progress in Human Geography, 32(2), 227-246.

Howe, C., \& Abedin, M. (2013). Classroom dialogue: A systematic review across four decades of research. Cambridge Journal of Education, 43(3), 325-356.

Hutchins, E. (1996). Cognition in the wild. Cambridge, MA: MIT Press.

Jackson, L. (2008). Dialogic pedagogy for social justice: A critical examination. Studies in Philosophy and Education, 27(2-3), 137-148.

James, M., Oates, T., Pollard, A., \& Wiliam, D., Department for Education (DFE), corp creator. (2011). The framework for the National Curriculum: A report by the 
Expert Panel for the National Curriculum review. Retrieved from https://dera.ioe.ac.uk//13207/

Kennedy, D. (2004). The philosopher as teacher: The role of a facilitator in a community of philosophical inquiry. Metaphilosophy, 35(5), 744-765.

Kennedy, M., Fisher, M. B., \& Ennis, R. H. (1990). Critical thinking: Literature review and needed research. In L. Idol \& B. Fly Jones (Eds.), Educational values and cognitive instruction: Implications for reform (pp. 11-40). New Jersey: Lawrence Erlbaum Associates, Inc., Publishers.

Kennedy, N., \& Kennedy, D. (2011). Community of philosophical inquiry as a discursive structure, and its role in school curriculum design. Journal of Philosophy of Education, 45(2), 265-283.

Kennedy, N., \& Kennedy, D. (2013). Philosophical dialogue across the school curriculum: The case of mathematics. In M. B. Glina (Ed.), Philosophy for, with, and of children. Newcastle upon Tyne: Cambridge Scholars Publishing.

Kincheloe, J. L., McLaren, P., Steinberg, S. R., \& Monzó, L. D. (2018). Critical pedagogy and qualitative research: Advancing the bricolage. In N. K. Denzin \& Y. S. Lincoln (Eds.), The Sage handbook of qualitative research (5th ed., pp. 235-260). Thousand Oaks, CA: Sage.

Kitchener, R. F. (1990). Do children think philsophically? Metaphilosophy, 21(4), 416431.

Kitson, A. (2015). Bernstein on knowledge and pedagogy. London: Institute of Education.

Kohan, W. O. (2014). Philosophy and childhood. New York, NY: Palgrave Macmillan.

Kotzee, B. (2017). Education and epistemic injustice. In I. J. Kidd, J. Medina, \& J.

Pohlhaus, Gaile (Eds.), The Routledge handbook of epistemic injustice (1st ed.). New York, NY: Routledge.

Kovach, V. (2014). Philosophy for Children: training materials. Auckland: Philosophy for Children New Zealand.

Kovach, V. (2015a, 12 May 2015). [Email communication from Vanya Kovach, Philosophy for Children New Zealand].

Kovach, V. (2015b). Philosophy for Children New Zealand. Retrieved from http://www.p4c.org.nz/

Kuhn, D. (1991). The skills of argument. Cambridge, UK: Cambridge University Press.

Kuhn, D. (1992). Thinking as argument. Harvard Educational Review, 62(2), 155-179.

Kuhn, D. (2005). Education for thinking. Cambridge, MA: Harvard University Press.

Lam, C.-M. (2013). An empirical study of the effectiveness of Lipman's Philosophy for Children programme on promoting children's critical thinking in Hong Kong, China. In Childhood, Philosophy and Open Society (Vol. 22, pp. 67-120). Dordrecht: Springer.

Landahl, J. B., \& Gordon, G. (1972). The structure of scientific fields and the functioning of university graduate departments. American Sociological Review, 37, 57-72.

Lee, W., \& Carr, M. (2012). Learning stories: Constructing learner identities in early education. London: Sage.

Legg, C., \& Hookaway, C. (2019). Pragmatism. In E. N. Zalta (Ed.), The Stanford encyclopedia of philosophy (Spring 2019 ed.). Stanford, CA: Stanford University.

Levi-Strauss, C. (1966). The savage mind. Chicago, IL: University of Chicago Press.

Lincoln, Y. S., \& Guba, E. G. (1985). Naturalistic inquiry. Beverly Hills, CA: Sage.

Lincoln, Y. S., Lynham, S. A., \& Guba, E. G. (2018). Paradigmatic controversies, contradictions, and emerging confluences, revisited. In N. K. Denzin \& Y. S. 
Lincoln (Eds.), The Sage handbook of qualitative research (5th ed., pp. 108-150).

Thousand Oaks, CA: Sage.

Lipman, M. (1984). The cultivation of reasoning through philosophy. Educational Leadership, 42(1), 51-56.

Lipman, M. (1988). Critical thinking - what can it be? Educational Leadership, 46(1), 512.

Lipman, M. (1991). Thinking in education (1st ed.). New York, NY: Cambridge University Press.

Lipman, M. (1995). Good thinking. Inquiry: Critical Thinking Across the Disciplines, 15(2), 37-41.

Lipman, M. (1998a). The contributions of philosophy to deliberative democracy. In D. Owens \& I. Kucuradi (Eds.), Teaching philosophy on the eve of the twenty-first century (pp. 6-29). Ankara: International Federation of Philosophical Societies.

Lipman, M. (1998b). Teaching students to think reasonably - some findings of the Philosophy for Children program. The Clearing House, 71(5), 277-280.

Lipman, M. (2003). Thinking in education (2nd ed.). New York, NY: Cambridge University Press.

Lipman, M. (2004). Philosophy for Children's debt to Dewey. Critical and Creative Thinking, 12(1), 1-8.

Lipman, M. (2008). A life teaching thinking. New Jersey: Institute for the Advancement of Philosophy for Children (IAPC).

Lipman, M., \& Sharp, A. M. (1986). Social inquiry: Instructional manual to accompany Mark. Montclair, NJ: Montclair State College, Institute for the Advancement of Philosophy for Children (IAPC).

Lipman, M., Sharp, A. M., \& Oscanyan, F. S. (1980). Philosophy in the classroom (2nd ed.). Philadelphia: Temple University Press.

Littlejohn, S. W. (2002). Theories of human communication. Belmont, CA: Wadsworth/Thomson Learning.

Lynch, K., \& Baker, J. (2005). Equality in education: An equality of condition perspective. Theory and Research in Education, 3(2), 131-164.

Maharey, S. (2003). The Beeby vision today. Retrieved from https://www.beehive.govt.nz/speech/beeby-vision-today

Mahn, H. (1999). Vygotsky's methodological contribution to sociocultural theory. Remedial and Special Education, 20(6), 341-350.

Marope, M., Griffin, P., \& Gallagher, C. (2017). Future competences and the future of curriculum. Geneva: UNESCO International Bureau of Education.

Marples, J. (2015). SAPERE: Philosophy for Children, colleges, communities. Retrieved from http://www.sapere.org.uk/

Marsal, E., Dobashi, T., \& Weber, B. (Eds.). (2009). Children philosophize worldwide: Theoretical and practical concepts. Frankfurt am Main: Peter Lang GmbH.

Marsh, D., O'Toole, T., \& Jones, S. (2007). Young people and politics in the UK: Apathy or alienation? Basingstoke: Palgrave MacMillan.

Martens, E. (1990). Philosophy for Children and continental philosophy. Thinking: The Journal of Philosophy for Children, 9(1), 2-7.

Maton, K. (2004). The wrong kind of knower: Education, expansion and the epistemic device. In J. Muller, B. Davies, \& A. Morais (Eds.), Reading Bernstein, researching Bernstein (pp. 218-231). London: Routledge. 
Maton, K., \& Moore, R. (Eds.). (2010). Social realism, knowledge and the sociology of education. London: Continuum.

Matthews, G. B. (1994). The philosophy of childhood. Cambridge, MA: Harvard University Press.

McGregor, H. E. (2017). One classroom, two teachers? Historical thinking and indigenous education in Canada. Critical Education, 8(45), 1-18.

McLeod, J., \& Yates, L. (2006). Making modern lives: Subjectivity, schooling and social change. Albany, NY: State University of New York Press.

McPeck, J. E. (1990). Critical thinking and subject specificity: A reply to Ennis. Educational Researcher, 19(4), 10-12.

McPeck, J. E. (1991). What is learned in informal logic courses? Teaching Philosophy, 14(1), 25-34.

McPeck, J. E. (1994). Critical thinking and the 'trivial pursuit' theory of knowledge. In K. Walters (Ed.), Re-thinking reason: New perspectives in critical thinking (pp. 101117). New York, NY: State University of New York Press.

McPhail, G. (2012). Knowledge and the curriculum: Music as a case study in educational futures. New Zealand Journal Education Studies, 47(1), 33-46.

McPhail, G. (2016). The faultlines of recontextualisation: The limits of constructivism in education. British Educational Research Journal, 42(2), 294-313. doi:10.1002/berj.3199

McPhail, G., \& Rata, E. (2016). Comparing curriculum types: 'Powerful knowledge' and '21st century learning'. New Zealand Journal Education Studies, 51, 53-68. doi:10.1007/s40841-015-0025-9

Meadows, E. (2013). Learning to listen to differences: Democracy, Dewey and interpretive discussion. Journal of Curriculum Studies, 45(4), 441-461.

Mercer, N. (2000). Words and minds: How we use language to think together. London: Routledge.

Mercer, N. (2004). Sociocultural discourse analysis: Analysing classroom talk as a social mode of thinking. Journal of Applied Linguistics, 1(2), 137-168. doi:10.1558/japl.v1i2.137

Mercer, N. (2008). The seeds of time: Why classroom dialogue needs a temporal analysis. Journal of the Learning Sciences, 17(1), 33-59.

Mercer, N. (2010). The analysis of classroom talk: Methods and methodologies. British Journal of Educational Psychology, 80(1), 1-14.

Mercer, N., \& Hodgkinson, S. (Eds.). (2008). Exploring talk in school. London: Sage.

Mercer, N., \& Howe, C. (2012). Explaining the dialogic processes of teaching and learning: The value and potential of sociocultural theory. Learning, Culture and Social Interaction, 1(1), 12-21.

Mercer, N., \& Littleton, K. (2007). Dialogue and the development of children's thinking. London: Routledge.

Mercer, N., \& Littleton, K. (2013). Interthinking: Putting talk to work. Abingdon: Routledge.

Mercer, N., Warwick, P., Dawes, L., Sams, C., Wegerif, R., Littleton, K., Ahmed, A. (2015). Thinking together. Retrieved from https://thinkingtogether.educ.cam.ac.uk/

Mhlanga, D., \& Shepherd, N. (2014). Philosophy for Children: A model for Unhu/Ubuntu philosophy. International Journal of Scientific and Research Publications, 4(2), 665-669. 
Michaels, S., \& O'Connor, C. (2015). Conceptualizing talk moves as tools: Professional development approaches for academically productive discussion. In L. B. Resnick, C. Asterhan, \& S. Clarke (Eds.), Socializing intelligence through academic talk and dialogue (pp. 347-362). Washington, DC: American Educational Research Association.

Miles, M. B., \& Huberman, A. M. (1994). Qualitative data analysis (2nd. ed.). Thousand Oaks, CA: Sage.

Miles, M. B., Huberman, A. M., \& Saldana, J. (2014). Qualitative data analysis: A methods sourcebook (3rd ed.). Thousand Oaks, CA: Sage.

Millett, S., \& Flanagan, S. (2007). Philosophy in the talented Year 8 classroom: Improving thinking (and a lot more) through philosophical inquiry. TalentEd, 25(1), 1-10.

Millett, S., \& Tapper, A. (2012). Benefits of collaborative philosophical inquiry in schools. Educational Philosophy and Theory, 44(5), 546-567. doi:10.1111/j.14695812.2010.00727.x

Ministry of Education. (1999). The land changes: Keeping earth's systems in balance to sustain life. Wellington: Learning Media.

Ministry of Education. (2007). The New Zealand curriculum. Wellington: Learning Media.

Ministry of Education. (2012). The New Zealand curriculum update. Wellington: Learning Media.

Ministry of Education. (1993). The New Zealand curriculum framework - Te anga matauranga o Aotearoa. Wellington: Learning Media.

Ministry of Education. (2007a). From the New Zealand curriculum to school curriculum. Wellington: Learning Media.

Ministry of Education. (2007b). The New Zealand curriculum. Wellington: Learning Media.

Ministry of Education. (2016). Inclusive education. Retrieved from https://www.inclusive.tki.org.nz/

Ministry of Education. (2019a). Ministry of Education website. Retrieved from www.education.govt.nz

Ministry of Education. (2019b). School deciles. Retrieved from https://www.education.govt.nz/school/funding-andfinancials/resourcing/operational-funding/school-decile-ratings/

Mohr Lone, J., \& Wartenberg, T. E. (2009). PLATO: Philosophy Learning and Teaching Organization. Retrieved from http://plato-philosophy.org/

Moir, J. (2014, November 17). School meeting 'unwanted' standards. Stuff. Retrieved from http://www.stuff.co.nz/national/10731985/School-meeting-unwantedstandards

Moore, R. (2013). Social realism and the problem of the problem of knowledge in the sociology of education. British Journal of Sociology of Education, 34(3), 333-353. doi:10.1080/01425692.2012.714251

Moore, R., \& Muller, J. (1999). The discourse of 'voice' and the problem of knowledge and identity in the sociology of education. British Journal of Sociology of Education, 20(2), 189-206.

Moore, R., \& Young, M. (2001). Knowledge and the curriculum in the sociology of education: Towards a reconceptualisation. British Journal of Sociology of Education, 22(4), 445-461. doi:10.1080/01425690120094421 
Morse, J. (2018). Reframing rigor in qualitative inquiry. In N. K. Denzin \& Y. S. Lincoln (Eds.), The Sage handbook of qualitative research (5th ed., pp. 968). Thousand Oaks, CA: Sage.

Muller, J. (2004). The possibilities of Basil Bernstein. In J. Muller, B. Davies, \& A. Morais (Eds.), Reading Bernstein, researching Bernstein (pp. 1-12). London: Routledge.

Muller, J. (2009). Forms of knowledge and curriculum coherence. Journal of Education and Work, 22(3), 205-206.

Muller, J., \& Young, M. (2019). Knowledge, power and powerful knowledge re-visited. The Curriculum Journal. doi:10.1080/09585176.2019.1570292

Murdoch, K. (2015). The power of inquiry: Teaching and learning with curiosity, creativity and purpose in the contemporary classroom. Melbourne: Seastar Education.

Murris, K. (2000). Can children do philosophy? Journal of Philosophy of Education, 34(2), 261-279.

Murris, K. (2013). The epistemic challenge of hearing children's voice. Studies in Philosophy and Education, 32(3), 245-259.

Nash, R. (2007). Challenging ethnic explanations for educational failure. In E. Muller, R. Openshaw, \& J. Friedman (Eds.), Public policy and ethnicity. London: Palgrave Macmillan.

Naji, S., \& Rosnani, H. (Eds.). (2017). History, theory and practice of philosophy for children: International perspectives. London: Routledge, Taylor \& Francis Group.

Nakata, M. (2007). The cultural interface. The Australian Journal of Indigenous Higher Education, 36(Suppl.), 7-14.

Ndofirepi, A. P., Wadesango, N., Machingambi, S., Maphosa, C., \& Mutekwe, E. (2013). Can a philosophy for children programme empower the 21st century child in Africa? Studies of Tribes and Tribals, 11(2), 179-194.

Nichols, K., Burgh, G. and Fynes-Clinton, L. (2016). Reconstruction of Thinking Across the Curriculum through the Community of Inquiry. In M. R. Gregory, J. Haynes, \& K. Murris (Eds.), The Routledge international handbook of Philosophy for Children (pp. 245-252). Abingdon: Routledge.

Noddings, N. (2006). Critical lessons: What our schools should teach. Cambridge: Cambridge University Press.

North, C. E. (2006). More than words? Delving into the substantive meaning(s) of 'social justice' in education. Review of Educational Research, 76(4), 507-535.

Norton, Q. (2014). Education's McGuffin: Temporary autonomous zones. Paper presented at the ULearn conference, Rotorua.

O'Connor, C., \& Michaels, S. (2017). Supporting teachers in taking up productive talk moves: The long road to professional learning at scale. International Journal of Educational Research, 1-10. doi:https://doi.org/10.1016/j.ijer.2017.11.003

O'Riordan, N. J. (2016). Swimming against the tide: Philosophy for children as countercultural practice. Education 3-13: International Journal of Primary, Elementary and Early Years Education, 44(6), 648-660.

Organisation for Economic Cooperation and Development. (2005). The definition and selection of key competencies. Paris: Organisation for Economic Cooperation and Development.

Organisation for Economic Cooperation and Development. (2018a). Disparities in performance related to socio-economic status. PISA: Equity in education - 
breaking down barriers to social mobility. Paris: Organisation for Economic Cooperation and Development.

Organisation for Economic Cooperation and Development. (2018b). Educational disadvantage starts from age 10. Retrieved from

http://www.oecd.org/newsroom/educational-disadvantage-starts-from-age10.htm

Organisation for Economic Cooperation and Development. (2018c). The future of education and skills: Education 2030 The future we want. Paris: Organisation for Economic Cooperation and Development.

Oxford University Press. (2018). Oxford living dictionaries. Retrieved from https://en.oxforddictionaries.com/

Pairman, A. (2018). Living in this space: Case studies of children's lived experiences in four spatially diverse early childhood centres. Victoria University of Wellington, Wellington.

Pantaleo, S. (2007). Interthinking: Young children using language to think collectively during interactive read-alouds. Early Childhood Education Journal, 34(6), 439447.

Paul, R. W. (1984). Teaching critical thinking in the 'strong' sense: A focus on selfdeception, world views, and a dialectical mode of analysis. Informal Logic, 4(2), 2-7.

Paul, R. W. (1990). Critical and reflective thinking: A philosophical perspective. In B. F. Jones \& L. Idol (Eds.), Dimensions of Thinking and Cognitive Instruction. (pp. 445494). Hillsdale, NJ: Erlbaum.

Paul, R. W. (1992). Critical thinking: What, why, and how. New Directions for Community Colleges, 1992(77), 3-24.

Paul, R. W., \& Elder, L. (2008). The miniature guide to critical thinking: Concepts and tools. Dillon Beach, CA: Foundation for Critical Thinking Press.

Peirce, C.S. (1887). The fixation of belief. Popular Science Monthly 12: 1-15.

Peirce, C.S. (1899/1998). First rule of logic. In The Peirce Edition Project (ed.) The

Essential Peirce: Selected Philosophical Writings (Vol. 2, pp. 42-56). Bloomington, IN:

Indiana University Press.

Peirce, C.S. (1931). Principles of philosophy. In C. Hartshorne \& P. Weiss (Eds.) Collected papers of Charles Sanders Peirce, 1931-1958. Cambridge, MA: Harvard University Press.

Perkins, D. (1998). What is understanding. In M. S. Wiske (Ed.), Teaching for understanding (pp. 39-57). San Francisco, CA: Jossey-Bass.

Perkins, D., Tishman, S., Ritchhart, R., Donis, K., \& Andrade, A. (2000). Intelligence in the wild: A dispositional view of intellectual traits. Educational Psychology Review, 12(3), 269-293.

Perkins, D. N. (1995). Outsmarting IQ: The emerging science of learnable intelligence. New York, NY: Free Press.

Perkins, D. N., \& Grotzer, T. A. (1997). Teaching intelligence. American Psychologist, 52(10), 1125.

Peterson, C. (1996). Looking forward through the lifespan: Developmental psychology (3rd ed.). Maryborough, VIC: Prentice Hall.

Piaget, J. (1968). The construction of reality in the child. London: Routledge. 
Pihama, L. (2019). Colonisation, neoliberalism and Māori education: Herbison invited lecture, NZARE Annual Conference 2017. New Zealand Journal of Education Studies, 54, 5-19.

Plato. (1961). Theatetus. In E. Hamilton \& H. Cairns (Eds.), The collected dialogues of Plato. Princeton, NJ: Princeton University Press.

Power, S., \& Gewirtz, S. (2001). Reading education action zones. Journal of Education Policy, 16(1), 39-51.

Punch, K. (2014). Introduction to social research: Quantitative \& qualitative approaches. Los Angeles, CA: Sage.

Rashbrooke, M. (2014). The inequality debate: An introduction. Wellington: Bridget Williams Books.

Rashbrooke, M. (Ed.) (2013). Inequality: A New Zealand crisis. Wellington: Bridget Williams Books.

Rata, E. (2005). Rethinking biculturalism. Anthropological Theory, 5(3), 267-284. doi:10.1177/1463499605055960

Rata, E. (2007). Ethnic fundamentalism in New Zealand. Retrieved from https://skeptics.nz/journal/issues/84/ethnic-fundamentalism-in-new-zealand

Rata, E. (2012a). The politics of knowledge in education. British Educational Research Journal, 38(1), 103-124. doi:10.1080/01411926.2011.615388

Rata, E. (2012b). The politics of knowledge in education. New York, NY: Routledge.

Rata, E. (2013, September 7). Let's bring knowledge back into schools. New Zealand Herald. Retrieved from http://www.nzherald.co.nz/nz/news/article.cfm?c id=1\&objectid=11120838

Rata, E. (2016). A pedagogy of conceptual progression and the case for academic knowledge. British Educational Research Journal, 42(1), 168-184. doi:10.1002/berj.3195

Rawls, J. (1999). A theory of justice (Rev. ed.). Oxford: Oxford University Press.

Reich, R. (2002). Bridging liberalism and multiculturalism in American education. Chicago, IL: University of Chicago Press.

Resnick, L. B. (1991). Shared cognition: Thinking as social practice. In L. B. Resnick, J. M. Levine, \& S. D. Teasley (Eds.), Perspectives on socially shared cognition (pp. 1-20). Washington DC, WA: American Psychological Association.

Reznitskaya, A. (2008). Philosophical discussions in elementary school classrooms: Theory, pedagogy, research. Paper presented at the IAIE-IASCE Conference, Turin, Italy.

Reznitskaya, A., \& Anderson, R. C. (2002). The argument schema and learning to reason. In C. C. Block \& M. Pressley (Eds.), Comprehension instruction. New York, NY: Guilford Press.

Reznitskaya, A., Anderson, R. C., Dong, T., Li, Y., Kim, I.-H., \& Kim, S.-Y. (2008). Learning to think well: Application of argument schema theory to literacy instruction. In C. Collins Block \& S. R. Parris (Eds.), Comprehension instruction: Research-based best practices (2nd ed.). New York, NY: Guilford Press.

Reznitskaya, A., \& Gregory, M. (2013). Student thought and classroom language: Examining the mechanisms of change in dialogic teaching. Educational Psychologist, 48(2), 114-133.

Ritchhart, R., Church, M., \& Morrison, K. (2011). Making thinking visible: How to promote engagement, understanding, and independence for all learners. San Francisco, CA: Jossey-Bass. 
Roche, M. (2011). Creating a dialogical and critical classroom: Reflection and action to improve practice. Educational Action Research, 19(3), 327-343. doi:10.1080/09650792.2011.600607

Rogoff, B. (1990). Apprenticeship in thinking: Cognitive development in social context. New York, NY: Oxford University Press.

Rogoff, B., Baker-Sennett, J., Lacasa, P., \& Goldsmith, D. (1995). Development through participation in sociocultural activity. In J. J. Goodnow, P. J. Miller, \& F. Kessel (Eds.), Cultural practices as contexts for development. San Francisco, CA: JosseyBass.

Rubin, H. J., \& Rubin, I. S. (1995). Qualitative interviewing: The art of hearing data. London: Sage.

Rudolph, S., Sriprakash, A., \& Gerrard, J. (2018). Knowledge and racial violence: The shine and shadow of 'powerful knowledge'. Ethics and Education 13(1), 22-38. doi: 10.1080/17449642.2018.1428719

Rush, P. (2014). Valuing assessment. Set: Research information for teachers (Online)(2), 48-50.

Rutherford, J. (2005). Key competencies in the New Zealand curriculum: Development through consultation. Curriculum Matters, 1(1), 210-227.

Rychen, D. S. (2003). Investing in competencies - but which competencies and for what? A contribution to the ANCLI. Paper presented at the AEA Conference on Assessment Challenges for Democratic Society, Lyon.

Rychen, D. S., \& Salganik, L. H. (Eds.). (2003). Key competencies for a successful life and a well-functioning society. Gottingen: Hogrefe and Huber.

Ryle, G. (1962). The concept of mind. London: Hutchinson.

Sahlberg, P. (2012). A model lesson: Finland shows us what equal opportunity looks like. American Educator, 36(1), 20-40.

Säljö, R. (2009). Learning, theories of learning, and units of analysis in research. Educational Psychologist, 44(3), 202-208.

Salomon, G., \& Perkins, D. N. (1996). Learning in wonderland: What do computers really offer education? In K. Stephen (Ed.), Technology and the future of schooling: Ninety-fifth yearbook of the National Society for the Study of Education (Vol. II, pp. 111-130). Chicago, IL: Chicago University Press.

Salomon, G., \& Perkins, D. N. (1998). Individual and social aspects of learning. Review of Research in Education, 23, 1-24.

Sayer, R. A. (1992). Method in social science: A realist approach. London: Routledge.

Sayer, R. A. (2004). Why critical realism? In S. Fleetwood \& S. Ackroyd (Eds.), Critical realist approaches in organisation and management studies (pp. 6-20). London: Routledge.

Scholl, R. (2005). Student questions: Developing critical and creative thinkers. Thinking: The Journal of Philosophy for Children, 17(4), 34-47.

Scholl, R. (2012). Transforming pedagogy through philosophical inquiry. University of Queensland, Brisbane. Retrieved from http://espace.library.uq.edu.au/view/UQ:294963

Scholl, R. (2014). 'Inside-out pedagogy': Theorising pedagogical transformation through teaching philosophy. Australian Journal of Teacher Education, 39(6), 7.

Seixas, P. (1993). The Community of Inquiry as a Basis for Knowledge and Learning: The Case of History. American Educational Research Journal 30(2), 305-324. 
Seixas, P., Morton, T., Colyer, J., \& Fornazzari, S. (2013). The big six: Historical thinking concepts. Toronto: Nelson Education.

Sensoy, Ö., \& DiAngelo, R. (2014). Respect differences? Challenging the common guidelines in social justice education. Democracy \& Education, 22(2), 1-10.

Sewell, K. (2007). Foreword. In Ministry of Education (Ed.), New Zealand curriculum. Wellington: Learning Media.

Shaffer, D. W. (2006). Epistemic frames for epistemic games. Computers \& Education, 46(3), 223-234.

Shandomo, H. M. (2010). The role of critical reflection in teacher education. SchoolUniversity Partnerships, 4(1), 101-113.

Sharp, A. M. (1991). The community of inquiry: Education for democracy. Thinking: The Journal of Philosophy for Children, 9(2), 31-37.

Sharp, A. M. (2004). The other dimension of caring thinking. Critical \& Creative Thinking, 12(1), 9-15.

Siegel, H. (2008). Cultivating reason. In R. Curren (Ed.), A companion to the philosophy of education (pp. 305-319). Malden, MA: Blackwell Publishing Ltd.

Sigurthorsdottir, I. (2000). Philosophy for Children in action: Iceland. Thinking: The Journal of Philosophy for Children, 15(4), 16-19.

Silverman, D. (2013). Doing qualitative research (4th ed.). London: Sage.

Singer, P. (1995). Coping with global change: The need for new values. Critical \& Creative Thinking, 3(2), 1-12.

Spalding, N. J., \& Phillips, T. (2007). Exploring the use of vignettes: From validity to trustworthiness. Qualitative Health Research, 17(7), 954-962.

Spinoza, B. D. (1958/1677). Tractatus politicus (A. G. Wernham, Trans.). In B. D. Spinoza (Ed.), The political works. Oxford: Clarendon Press.

Splitter, L., \& Sharp, A. M. (1995). Teaching for better thinking: The classroom community of inquiry. Melbourne: Australian Council for Educational Research.

Sprod, T. (1998). "I can change your opinion on that": Social constructivist whole class discussions and their effect on scientific reasoning. Research in Science Education, 28(4), 463-480.

Stengel, B. S. (1997). 'Academic discipline' and 'school subject': Contestable curricular concepts. Journal of Curriculum Studies, 29, 585-602.

Sternberg, R. J. (1986). Critical thinking: Its nature, measurement, and improvement. New Haven, CT: Yale University.

Taylor, G. W., \& Ussher, J. M. (2001). Making sense of S\&M: A discourse analytic account. Sexualities, 4(3), 293-314.

Te Huia, V. (2015). Raising Māori student achievement in the New Zealand primary sector: Principals' perceptions and strategies for effective leadership. (Unpublished Masters thesis). Victoria University of Wellington, Wellington.

Teasley, S. D. (1995). The role of talk in children's peer collaborations. Developmental Psychology, 31(2), 207. doi:10.1037/0012-1649.31.2.207

Tishman, S., \& Perkins, D. (1997). The language of thinking. The Phi Delta Kappan, 78(5), 368-374. Retrieved from http://www.jstor.org/stable/20405798

Tishman, S., Perkins, D. N., \& Jay, E. (1996). The thinking classroom: Learning and teaching in a culture of thinking. Needham Heights, MA: Allyn and Bacon.

Topping, K. J., \& Trickey, S. (2007a). Collaborative philosophical enquiry for school children: Cognitive effects at 10-12 years. British Journal of Educational Psychology, 77(4), 271-288. 
Topping, K. J., \& Trickey, S. (2007b). Collaborative philosophical inquiry for schoolchildren: Cognitive gains at 2-year follow-up. British Journal of Educational Psychology, 77, 787-796. doi:10.1348/000709907X193032

Topping, K. J., \& Trickey, S. (2007c). Impact of philosophical enquiry on school students' interactive behaviour. Thinking Skills and Creativity, 2(2), 73-84.

Topping, K. J., \& Trickey, S. (2014). The role of dialog in philosophy for children. International Journal of Educational Research, 63(0), 69-78. doi:http://dx.doi.org/10.1016/j.ijer.2013.01.002

Tracy, S. J. (2010). Qualitative quality: Eight 'big-tent' criteria for excellent qualitative research. Qualitative Inquiry, 16, 837-851.

Tretter, T., Ardasheva, Y., \& Bookstrom, E. (2014). A brick and mortar approach: Scaffolding use of specific science language structures for first-year English language learners. The Science Teacher, 81(4), 39-44.

Trickey, S., \& Topping, K. J. (2006). Collaborative philosophical enquiry for school children: Socio-emotional effects at 11 to 12 years. School Psychology International, 27(5), 599-614. doi:10.1177/0143034306073417

Trickey, S., \& Topping, K. J. (2013). Assessing the outcomes of philosophical thinking with children. In S. Goering, N. J. Shudak, \& T. E. Wartenberg (Eds.), Philosophy in schools: An introduction for philosophers and teachers (pp. 288-298). New York, NY: Routledge.

UNESCO (Ed.) (2007). Philosophy: A school of freedom. Paris: UNESCO Publishing.

Vansieleghem, N., \& Kennedy, D. (Eds.). (2012). Philosophy for children in transition: Problems and prospects. Chichester: Wiley-Blackwell.

Vygotsky, L. S. (1962). Thought and language (A. Kozulin, Trans.). Cambridge, MA: MIT Press.

Vygotsky, L. S. (1978). Mind and society: The development of higher mental processes. Cambridge, MA: Harvard University Press.

Vygotsky, L. S. (1981). The genesis of higher-order mental functions. In J. V. Wertsch (Ed.), The concept of activity in Soviet psychology (pp. 144-188). Armonk, NY: Sharpe.

Vygotsky, L. S. (1997). The collected works of L. S. Vygotsky: The history of the development of higher mental functions (Vol. 4). New York, NY: Plenum.

Wartenberg, T. E. (2009). Big ideas for little kids: Teaching philosophy through children's literature. Lanham, MD: Rowman \& Littlefield Education.

Wartenberg, T. E. (2013). Elementary school philosophy. In S. Goering, N. J. Shudak, \& T. E. Wartenberg (Eds.), Philosophy in schools (pp. 34-41). New York, NY: Routledge.

Webb, N. (2009). The teacher's role in promoting collaborative dialogue in the classroom. British Journal of Educational Psychology, 79, 1-28.

Weber, B. (2008). Hope instead of cognition? The community of inquiry as a culture for human rights based on Richard Rorty's understanding of philosophy. Thinking: The Journal of Philosophy for Children, 18(4), 23.

Wegerif, R. (2011). Towards a dialogic theory of how children learn to think. Thinking Skills and Creativity, 6, 179-190.

Wegerif, R., \& Mercer, N. (1997). A dialogical framework for researching peer talk. In R. Wegerif \& P. Scrimshaw (Eds.), Computers and talk in the primary classroom (pp. 49-65). Clevedon: Multilingual Matters.

Wegerif, R., Mercer, N., Littleton, K., Rowe, D., \& Dawes, L. (2004). Talking for success: Widening access to educational opportunities through teaching children how to 
reason together: Final report to the Esmée Fairbairn Foundation (RG01-1222).

Retrieved from

https://thinkingtogether.educ.cam.ac.uk/publications/journals/Esmee KS1 Fin al Report1.pdf

Wells, G. (1999). Dialogic inquiry: Toward a sociological practice and theory of education. Cambridge: Cambridge University Press.

Wells, G., \& Claxton, G. (2002). Learning for life in the 21st century (G. Wells \& G. Claxton Eds.). Oxford: Blackwell.

Wertsch, J. V. (1985). Vygotsky and the social formation of mind. Cambridge, MA: Harvard University Press.

Wheelahan, L. (2007). How competency-based training locks the working class out of powerful knowledge: A modified Bernsteinian analysis. British Journal of Sociology of Education, 28(5), 637-651. doi:10.1080/01425690701505540

Wheelahan, L. (2009). Do educational pathways contribute to equity in tertiary education in Australia? Critical Studies in Education, 50(3), 261-275.

Wheelahan, L. (2010a). The role of the disciplines in curriculum: A critical realist analysis. In Why knowledge matters in curriculum: A social realist argument (pp. 70-86). New York, NY: Routledge.

Wheelahan, L. (2010b). Why knowledge matters in curriculum. Abingdon: Routledge.

Wheelahan, L. (2014). Babies and bathwater: Revaluing the role of the academy in knowledge. In P. Gibbs \& R. Barnett (Eds.), Thinking about higher education (pp. 125-137). London: Springer.

White, J. (2012). Philosophy in primary schools? Journal of Philosophy of Education, 46(3), 449-460.

Whitty, G. (2018). Taking subject knowledge out and putting it back in again? A journey in the company of Michael Young. In D. Guile, D. Lambert, \& M. J. Reiss (Eds.), Sociology, curriculum studies and professional knowledge: New perspectives on the work of Michael Young (pp. 17-30). Abingdon: Routledge.

Wiggins, G. P., \& McTighe, J. (2005). Understanding by design. Danvers, MA: Association for Supervision and Curriculum Development.

Wilkinson, I. A. G., Reznitskaya, A., Bourdage, K., Oyler, J., Glina, M. B., Drewry, R., Nelson, K. (2017). Toward a more dialogic pedagogy: Changing teachers' beliefs and practices through professional development in language arts classrooms. Language and Education, 31(1), 65-82.

Williams, S. (1993). Evaluating the effects of philosophical enquiry in a secondary school. Retrieved from https://www.thinkingscripts.co.uk/pdf/villagep4c.pdf

Wilson, J. (1992). Philosophy for Children: A note of warning. Thinking: The Journal of Philosophy for Children, 10(1), 17-18.

Wilson, J., \& While, A. E. (1998). Methodological issues surrounding the use of vignettes in qualitative research. Journal of Interprofessional Care, 12(1), 79-86. doi:10.3109/13561829809014090

Winstanley, C. (2018). Deep thinking and high ceilings: Using philosophy to challenge 'more able' pupils. Journal of Philosophy in Schools, 4(2), 111-133.

Wiske, M. S. (Ed.) (1998). Teaching for understanding: Linking research with practice. San Francisco, CA: Jossey-Bass Publishers.

Wiske, M. S., Sick, M., \& Wirsig, S. (2001). New technologies to support teaching for understanding. International Journal of Educational Research, 35, 483-501. 
Wood, B. (2011). Citizenship in our place: Exploring New Zealand young people's everyday, place-based perspectives on participation in society. (Doctor of Philosophy). Victoria University of Wellington, Wellington.

Wylie, C. (2013). Schools and inequality. In M. Rashbrooke (Ed.), Inequality: A New Zealand crisis (pp. 134-144). Wellington: Bridget Williams Books.

Yandell, J. (2014). Curriculum, pedagogy and assessment: Of rigour and unfinished revolutions. In M. Allen \& P. Ainley (Eds.), Education beyond the coalition: Reclaiming the agenda (pp. 5-23). London: Radicaled.

Yazan, B. (2015). Three approaches to case study methods in education: Yin, Merriam, and Stake. The Qualitative Report, 20(2), 134-152. Retrieved from http://nsuworks.nova.edu/tqr/vol20/iss2/12

Yeazell, M. (1981). What happens to teachers who teach philosophy for children? Thinking: The Journal of Philosophy for Children, 2, 86-88.

Young, I. M. (1990). Justice and the politics of difference. Princeton, NJ: Princeton University Press.

Young, M. (2000). Rescuing the sociology of educational knowledge from the extremes of voice discourse: Towards a new theoretical basis for the sociology of the curriculum. British Journal of Sociology of Education, 21(4), 523-536.

Young, M. (2008a). Bringing knowledge back in: From social constructivism to social realism in the sociology of education. Abingdon: Routledge.

Young, M. (2008b). From constructivism to realism in the sociology of the curriculum. Review of Research in Education, 32(1), 1-28. doi:10.3102/0091732x07308969

Young, M. (2010). Why educators must differentiate knowledge from experience. The Journal of the Pacific Circle Consortium for Education, 22(1), 9-20.

Young, M. (2012). The curriculum - 'An entitlement to powerful knowledge': A response to John White. Retrieved from

https://www.newvisionsforeducation.org.uk/2012/05/03/the-curriculum\%E2\%80\%98an-entitlement-to-powerful-knowledge $\% \mathrm{E} 2 \% 80 \% 99$-a-responseto-john-white/

Young, M. (2013). Overcoming the crisis in curriculum theory: A knowledge-based approach. Journal of Curriculum Studies, 45, 101-118. doi:10.1080/00220272.2013.764505

Young, M., Lambert, D., Roberts, C., \& Roberts, M. (2014). Knowledge and the future school: Curriculum and social justice. London: Bloomsbury.

Young, M., \& Muller, J. (2010). Three educational scenarios for the future: Lessons from the sociology of knowledge. European Journal of Education, 45(1), 11-27.

Young, M., \& Muller, J. (2013). On the powers of powerful knowledge. Review of Education, 1(3), 229-250. doi:10.1002/rev3.3017 


\section{Appendix A}

Development of the Dialogical Critical Thinking Process-Content and Form

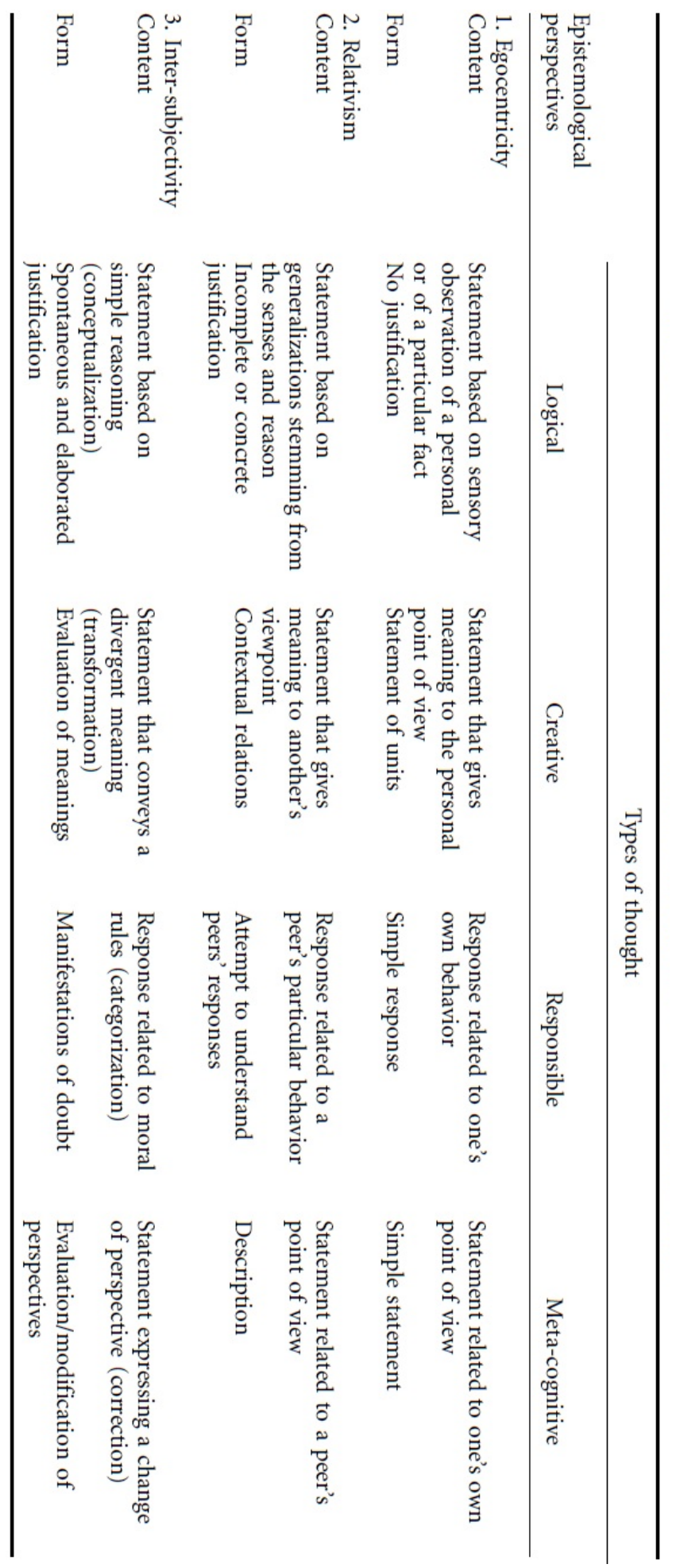

(Daniel et al., 2005, p. 344) 


\section{Appendix B}

\section{Scheme for Educational Dialogue Analysis (SEDA)}

\section{Invite elaboration or reasoning}

\begin{tabular}{|l|l|}
\hline I1 & Ask for explanation or justification of another's contribution \\
\hline I2 & Invite building on / elaboration / (dis)agreement / evaluation of another's contribution or view \\
\hline I3 & Invite possibility thinking based on another's contribution \\
\hline I4 & Ask for explanation or justification \\
\hline I5 & Invite possibility thinking or prediction \\
\hline I6 & Ask for elaboration or clarification \\
\hline
\end{tabular}

\section{Express or invite ideas}

\begin{tabular}{|l|l|}
\hline E1 & Invite opinions / beliefs/ideas \\
\hline E2 & Make other relevant contribution \\
\hline
\end{tabular}

Make reasoning explicit

\begin{tabular}{|l|l|}
\hline R1 & Explain or justify another's contribution \\
\hline R2 & Explain or justify own contribution \\
\hline R3 & Speculate or predict on the basis of another's contribution \\
\hline R4 & Speculate or predict \\
\hline
\end{tabular}

\section{Build on ideas}

\begin{tabular}{|l|l}
\hline B1 & Build on / explain / clarify others' contributions
\end{tabular}

B2 Clarify/ elaborate own contribution

Positioning and Coordinating

\begin{tabular}{|l|l} 
P1 & Synthesise ideas
\end{tabular} 


\begin{tabular}{|l|l|}
\hline P2 & Compare/ Evaluate alternative views \\
\hline P3 & Propose resolution \\
\hline P4 & Acknowledge shift in position \\
\hline P5 & Challenge viewpoint \\
\hline P6 & State (dis)agreement/ position \\
\hline
\end{tabular}

\section{Connect}

\begin{tabular}{|l|l|}
\hline C1 & Refer back \\
\hline C2 & Make learning trajectory explicit \\
\hline C3 & Link learning to wider contexts \\
\hline C4 & Invite inquiry beyond the lesson \\
\hline
\end{tabular}

\section{Reflect on dialogue or activity}

\begin{tabular}{|l|l|}
\hline RD1 & Talk about talk \\
\hline RD2 & Reflect on learning process/purpose/value \\
\hline RD3 & Invite reflection about process/purpose/value of learning \\
\hline
\end{tabular}

\section{Guide direction of dialogue or activity}

\begin{tabular}{|l|l|}
\hline G1 & Encourage student- student dialogue \\
\hline G2 & Propose action or inquiry activity \\
\hline G3 & Introduce authoritative perspective \\
\hline G4 & Provide informative feedback \\
\hline G5 & Focusing \\
\hline G6 & Allow thinking time \\
\hline
\end{tabular}

(Hennessy et al., 2016, pp. 1-23) 


\section{Appendix C}

\section{$\mathrm{P}_{4} \mathrm{C}$ for all information letter and consent form - Principals/BOTs}

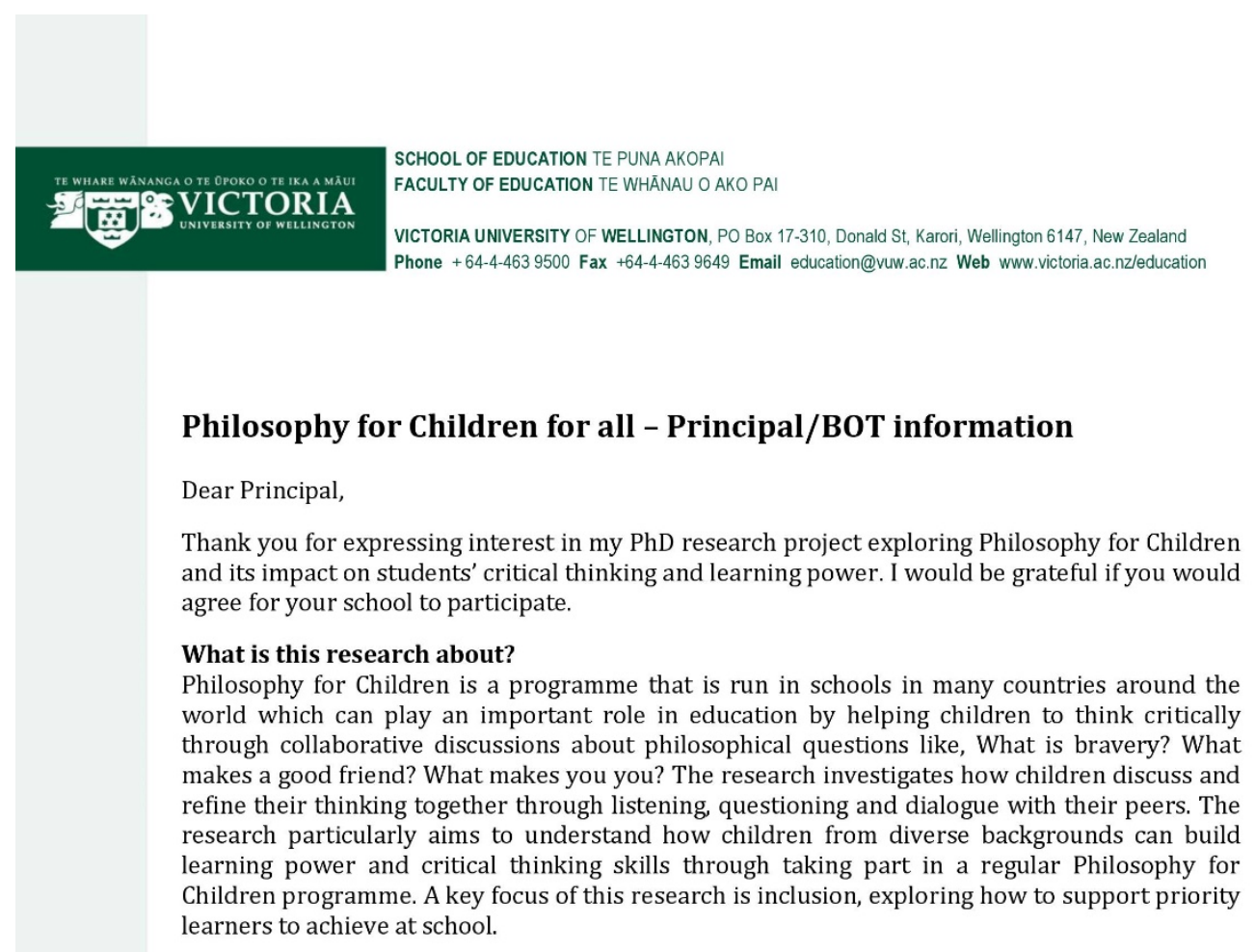

\section{What would it involve for your school?}

I know how busy and hardworking teachers are so I want to be very clear about what is involved in this research project. I will do everything I can to support the teacher throughout the research.

For the teacher, the research would involve:

- 2 days' professional development training during the school holidays in teaching Philosophy for Children (P4C) with P4CNZ's principal trainer, Vanya Kovach (at no cost this is covered by my research funding)

- Running an hour-long P4C lesson with his/her class each week during Term 3 and 4

- Taking part in an hour-long recorded interview at the beginning and end of the research

- Meeting with the three other participant teachers once a month to collaboratively plan the next month's lessons (in order to standardise the programme being offered across the schools and to minimise teacher workload by planning collaboratively)

- Allowing me to record a focus group interview with five sample students at the beginning of the project, during term three and the end of term four

- Allowing me to record a classroom P4C discussion at the beginning, middle, and end of the project, which will be transcribed for analysis

- Providing me with gender and ethnicity data for the class and their reading comprehension levels

- Gathering consent forms from the parents and students in line with Victoria University's ethics policy (I would help to administer this)

Individual consent will also be sought from the teacher. Parents/caregivers will be given an information sheet about the project and will be asked for their consent. They will have the opportunity to withdraw their child from the research. Separate consent will be sought from 
parents/caregivers if their child is invited to take part in the focus group interview and to keep an ongoing thinking journal.

To thank you for your school's involvement in this research, your school will receive a $\$ 100$ stationery voucher on the completion of the programme.

\section{Where will the information go? How can I find out about the findings?}

All material collected will be kept confidential. Pseudonyms will be used, and the teacher, class, and your school will not be identified. A research assistant employed to transcribe the interviews and discussions and conduct the data entry will sign a confidentiality contract. No one apart from my supervisors, Mark Sheehan, Sondra Bacharach, and Andrea Milligan, the research assistant, and I will have access to the data which will be kept secure in a locked cabinet or password protected file at Victoria University, and will be destroyed five years after the conclusion of the research. The thesis will be submitted for marking to the School of Education and deposited in the University Library. It is intended that one or more articles will be submitted for publication in scholarly journals. You are most welcome to a summary of the findings produced by the researcher and a copy of any publication stemming from this research.

\section{What else do I need to know?}

This research is part of a PhD project involving research across four Wellington primary schools; it has been approved by Victoria University Human Ethics Committee, approval number 22057. If you have any ethical concerns about this research you should contact Associate Professor Susan Corbett, Convenor of the Victoria University Human Ethics Committee: susan.corbett@vuw.ac.nz, (04) 4635480.

You have the right to withdraw your school at any point up until $31 / 8 / 15$, with no questions asked. The privacy and confidentiality of the information reported will be protected. Pseudonyms will be used, and your school, classes, teachers and students will not be identified. A research assistant employed to conduct the data entry will sign a confidentiality contract. No one apart from the research assistant and I will have access to the data which will be kept secure in a locked cabinet or password protected file at Victoria University, and will be destroyed five years after the conclusion of the research. Depending on funding, some follow-up research could be possible, but I would contact you about that separately and you do not have to agree to follow-up research at this point.

\section{What next?}

Should you agree to your school's participation in this project, please sign the attached consent form. If you have any questions or would like to receive further information about the project, please do not hesitate to contact me by phone, 463 9524, or email amy.m.austin@vuw.ac.nz,or my supervisor Mark Sheehan, at the School of Education at Victoria University by phone, 463 9687, or email mark.sheehan@vuw.ac.nz.

Your school's involvement in this research would be greatly valued.

Thank you,

Amy Austin

PhD Student

Faculty of Education, PA306B

Victoria University of Wellington

Donald St, Karori, Wellington 6012

PO Box 17-310, Karori, Wellington 6147 


\section{Philosophy for Children for all - Principal/BOT consent}

Principal Investigator: Amy Austin, Victoria University of Wellington Faculty of Education

- I give my consent for the project to be conducted in this school and understand that individual consent from teachers and students to participate will be sought.

- The research project has been explained to me, I understand what it involves, as detailed in the bullet points on the information sheet, and I have had the opportunity to ask questions and have them answered to my satisfaction.

- I understand that the research is confidential. Pseudonyms will be used and individual schools, classes, teachers or students will not be identified.

- I understand that the data collected will only be used for the research project and publication as described in the information sheet.

- I understand that all data will be stored securely in a locked cabinet or password protected files, and will be destroyed five years after the conclusion of the research.

- I understand that I may withdraw the school from this research project at any time up until 31/8/15 without giving a reason.

I agree to the statements above: Yes / No

$\square$ I would like to be offered a copy of publications stemming from this research project and a school-friendly newsletter.

Name:

School:

Email address:

\section{Signature:}

Date: 


\section{Appendix D}

\section{$\mathrm{P}_{4} \mathrm{C}$ for all information letter and consent form - Teachers}

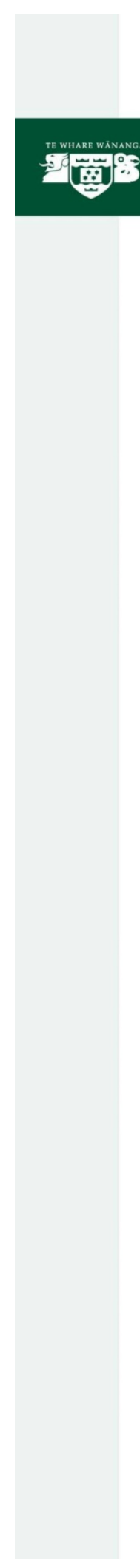

SCHOOL OF EDUCATION TE PUNA AKOPAI

FACULTY OF EDUCATION TE WHĀNAU O AKO PAI

VICTORIA UNIVERSITY OF WELLINGTON, PO Box 17-310, Donald St, Karori, Wellington 6147, New Zealand Phone +64-4-4639500 Fax +64-4-4639649 Email education@vuw.ac.nz Web www.victoria.ac.nzleducation

\section{Philosophy for Children for all}

Dear Teacher,

Thank you for expressing interest in my research project exploring Philosophy for Children and its impact on students' critical thinking and learning power. I would be grateful if you would agree to participate.

\section{What is this research about?}

Philosophy for Children is a programme that is run in schools in many countries around the world which can play an important role in education by helping children to think critically through collaborative discussions about philosophical questions like, What is bravery? What makes a good friend? What makes you you? The research investigates how children discuss and refine their thinking together through listening, questioning and dialogue with their peers. The research particularly aims to understand how children from diverse backgrounds can build learning power and critical thinking skills through taking part in a regular Philosophy for Children programme. A key focus of this research is inclusion, exploring how to support priority learners to achieve at school.

\section{What would it involve for your school?}

I know how busy and hardworking teachers are so I want to be very clear about what is involved in this research project. I will do everything I can to support you throughout the research.

The research would involve:

- 2 days' professional development training in teaching Philosophy for Children (P4C) with P4CNZ's principal trainer, Vanya Kovach (at no cost - this is covered by my research funding)

- Running an hour-long P4C lesson with your class each week during Term 3 and 4

- Taking part in a 45 minute-long recorded interview at the beginning and end of the research, which will be transcribed. You will have an opportunity to check the transcript before its contents are used in the thesis.

- Meeting with the three other participant teachers (from other local Wellington schools) once a month to collaboratively plan the next month's lessons (in order to standardise the programme being offered across the schools and to minimise teacher workload by planning collaboratively)

- Using the online NZCER Listening comprehension PAT to measure student comprehension (I would help to administer this)

- Allowing me to record a focus group interview with five sample students at the beginning of term three and the end of term four. These students will be invited to keep ongoing thinking journals as another data source for the research.

- Allowing me to record a classroom P4C discussion at the beginning, middle, and end of the project, which will be transcribed for analysis 
- Providing me with gender and ethnicity data for the class

- Gathering consent forms from the parents and students in a confidential way in line with Victoria University's ethics policy (I would help to administer this)

Parents/caregivers will be given an information sheet about the project and will be asked for their consent for their child to participate. They will have the opportunity to withdraw their child from the research if they wish. Separate consent will be sought from parents/caregivers to interview their child if they are invited to take part in the focus group interview and to keep an ongoing thinking journal.

\section{Where will the information go? How can I find out about the findings?}

All material collected will be kept confidential. Pseudonyms will be used, and you, your class, and your school will not be identified. A research assistant employed to transcribe the interviews and discussions and conduct the data entry will sign a confidentiality contract. No one apart from my supervisors, Mark Sheehan, Sondra Bacharach, and Andrea Milligan, the research assistant, and I will have access to the data which will be kept secure in a locked cabinet or password protected file at Victoria University, and will be destroyed five years after the conclusion of the research.

The thesis will be submitted for marking to the School of Education and deposited in the University Library. It is intended that one or more articles will be submitted for publication in scholarly journals. You are most welcome to a summary of the findings produced by the researcher and a copy of any publication stemming from this research.

\section{What else do I need to know?}

You have the right to withdraw at any point up until 3/8/15, with no questions asked. This research is part of a $\mathrm{PhD}$ project involving research across four Wellington primary schools; it has been approved by Victoria University Faculty of Education Ethics Committee, approval number 22057. If you have any ethical concerns about this research you should contact Dr Allison Kirkman, Chair of the Human Ethics Committee, Victoria University of Wellington: allison.kirkman@vuw.ac.nz, (04) 4635676.

\section{What next?}

If you are interested in participating in this project please sign the attached consent form. If you have any questions or would like to receive further information about the project, please do not hesitate to contact me by phone, 4639524 , or email amy.m.austin@vuw.ac.nz, or my supervisor Mark Sheehan, at the School of Education at Victoria University by phone, 463 9687, or email mark.sheehan@vuw.ac.nz.

Your involvement in this research would be greatly valued.

Thank you,

Amy Austin

PhD Student

Faculty of Education, PA306B

Victoria University of Wellington

Donald St, Karori, Wellington 6012

PO Box 17-310, Karori, Wellington 6147 


\section{Teacher Consent Form}

Research project: Philosophy for Children for all

Principal Investigator: Amy Austin, Victoria University of Wellington Faculty of Education

- I agree to participate in this research.

- The research project has been explained to me and I have had the opportunity to ask questions and have them answered to my satisfaction.

- I understand that the research is confidential. Pseudonyms will be used and individual schools, classes, teachers or students will not be identified.

- I understand that I will have an opportunity to check the transcripts of the interviews before publication.

- I understand that the data collected will only be used for the research project and publication as described in the information sheet.

- I understand that all data will be stored securely in a locked cabinet or password protected files, and will be destroyed five years after the conclusion of the research.

- I understand that I may withdraw from this research project at any time up until $3 / 8 / 15$, without giving a reason.

I agree to the statements above: Yes / No

$\square$ I would like to be offered a copy of publications stemming from this research project and a school-friendly newsletter.

Name:

School:

Email address (if you would like a copy of a summary of the findings and any other publications stemming from this research):

Signature:

Date: 


\section{Appendix E}

\section{$\mathrm{P}_{4} \mathrm{C}$ for all information letter and consent form - All parents/caregivers}

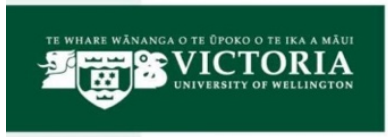

SCHOOL OF EDUCATION TE PUNA AKOPA

FACULTY OF EDUCATION TE WHANAU O AKO PAI

VICTORIA UNIVERSITY OF WELLINGTON, PO Box 17-310, Donald St, Karori, Wellington 6147, New Zealand Phone +64-4-4639500 Fax +64-4-4639649 Email education@vuw.ac.nz Web www.victoria.ac.nz/education

\section{Philosophy for Children for all: information for all parents/ caregivers}

Dear Parent/Caregiver,

I am a PhD student in Education at Victoria University of Wellington. As a part of this degree I am undertaking a research project leading to a thesis. The project is examining the educational impact of Philosophy for Children in New Zealand primary schools. The research project has received approval from the Victoria University Human Ethics Committee. Your child's class has been invited to be involved; I would be grateful if you would agree for your child to participate in this programme.

\section{What is this research about?}

Philosophy for Children is a programme that is run in schools in many countries around the world. It can play an important role in education by helping children to think critically and talk about questions that are important to them. The research investigates how children discuss and think together through listening, questioning and talking with their classmates. The research particularly aims to understand how children build critical thinking skills through taking part in a regular Philosophy for Children programme.

\section{What would it involve for your child?}

The Philosophy for Children programme will involve weekly hour-long classroom discussions led by the teacher on philosophical topics like: What is bravery? What makes a good friend? What makes you you? Children are encouraged to discuss their thoughts, to listen to each other's thinking, and to give reasons for their ideas.

The research would involve recording classroom discussions at the beginning, middle, and end of the Philosophy for Children programme (at the beginning of the research during Term 3, and at the beginning and the end of Term 4, 2015), which will be transcribed for the research. Students' comments will remain confidential. General demographic information on ethnicities of the whole class will be included in the data. It will not be possible for your child to be identified personally. Only grouped responses will be presented in the thesis.

Some children will be invited to participate in a focus group interview. I will send you a separate information sheet and consent form if your child is invited to participate in further research.

If you consent to your child's participation in this research, please let me know by returning the attached consent form. 
Where will the information go? How can I find out about the findings?

All material collected will be kept confidential. Pseudonyms will be used, and your child, their school, and class will not be identified. A research assistant employed to transcribe the discussions and conduct the data entry will sign a confidentiality contract. No one apart from my supervisors, Mark Sheehan, Sondra Bacharach, and Andrea Milligan, the research assistant, and I will have access to the data which will be kept secure in a locked cabinet or password protected file at Victoria University, and will be destroyed five years after the conclusion of the research.

The thesis will be submitted for marking to the School of Education and deposited in the University Library. It is intended that one or more articles will be submitted for publication in scholarly journals. You are most welcome to a summary of the findings produced by the researcher and a copy of any publication stemming from this research.

\section{What else do I need to know?}

This research is part of a $\mathrm{PhD}$ project involving research across four Wellington primary schools; it has been approved by Victoria University Human Ethics Committee, approval number 22057. If you have any ethical concerns about this research you should contact Associate Professor Susan Corbett, Convenor of the Victoria University Human Ethics Committee: susan.corbett@vuw.ac.nz, (04) 4635480.

You have the right to withdraw your child's contribution to the research up until $17 / 12 / 15$, with no questions asked. You do not have to agree to your child's participation in the research and your child can still take part in the Philosophy for Children discussions in class if you do not agree for them to take part in the research. I will be audio recording the class discussions; if you choose to withdraw your child's contribution I will ensure that what your child says will not be written down or used in the research. Declining your child's participation will not disadvantage their learning.

\section{What next?}

Please return the attached consent form to your child's teacher to indicate whether or not you consent to your child's participation in this research project. If you have any questions or would like to receive further information about the project, please do not hesitate to contact me by phone, 463 9524, or email amy.m.austin@vuw.ac.nz, or my supervisor Mark Sheehan, at the School of Education at Victoria University by phone, 463 9687, or email mark.sheehan@vuw.ac.nz.

Your child's involvement in this research would be greatly valued.

Ngā mihi,

Amy Austin

PhD Student

Faculty of Education, PA306B

Victoria University of Wellington

Donald St, Karori, Wellington 6012

PO Box 17-310, Karori, Wellington 6147 


\section{Philosophy for Children for all: consent for all parents/ caregivers}

Principal Investigator: Amy Austin, Victoria University of Wellington School of Education

- I agree for my child to participate in this research.

- The research project has been explained to me and I have had the opportunity to ask questions and have them answered to my satisfaction.

- I understand that the research is confidential. Pseudonyms will be used and individual schools, classes, teachers or students will not be identified.

- I understand that audio recordings will be made of classroom discussions that my child will be a part of.

- I understand that the data collected will only be used for the research project and publication as described in the information sheet.

- I understand that all data will be stored securely in a locked cabinet or password protected files, and will be destroyed five years after the conclusion of the research. This includes wiping the audio recording.

- I understand that I may withdraw my child from this research project at any time up until $17 / 12 / 15$, without giving a reason.

I agree to the statements above: Yes / No

$\square$ I would like to be offered a copy of publications stemming from this research project.

\section{Child's name:}

School:

Email address (if you would like a copy of a summary of the findings and any other publications stemming from this research):

\section{Parent/Caregiver signature:}

Date: 


\title{
Appendix $F$
}

\section{$\mathrm{P}_{4} \mathrm{C}$ for all information letter and consent form - Sample student}

\author{
parents/caregivers
}

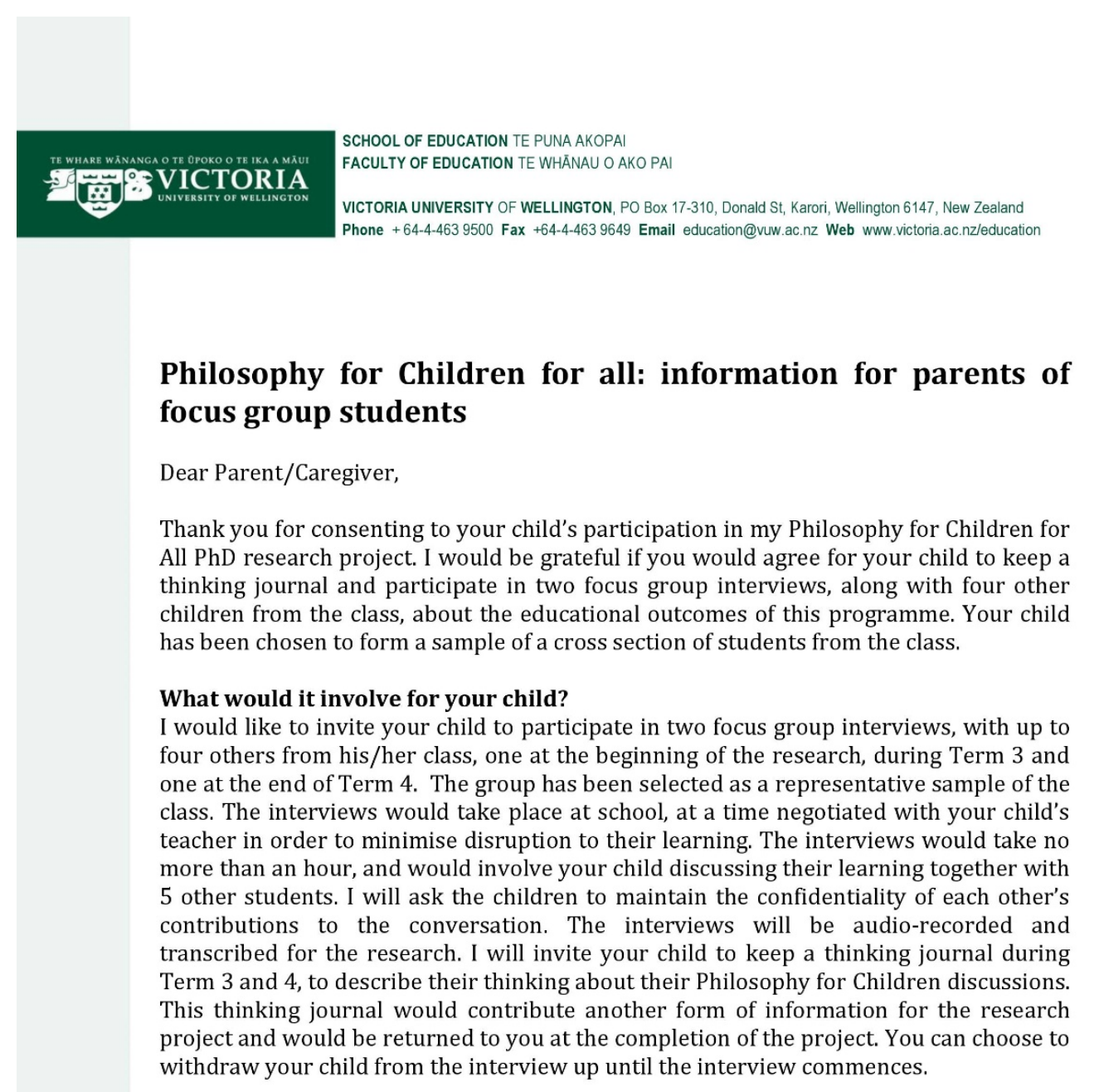

Where will the information go? How can I find out about the findings?

All material collected will be kept confidential. Pseudonyms will be used, and your child, their school, and class will not be identified. After each interview I will meet with your child at school and show them their written comments from the focus group so they can approve the statements that will be used in the thesis. Each child will only have access to their own comments.

A research assistant employed to transcribe the discussions and conduct the data entry will sign a confidentiality contract. No one apart from my supervisors, Mark Sheehan, Sondra Bacharach, and Andrea Milligan, the research assistant, and I will have access to the data which will be kept secure in a locked cabinet or password protected file at Victoria University, and will be destroyed five years after the conclusion of the research.

The thesis will be submitted for marking to the School of Education and deposited in the University Library. It is intended that one or more articles will be submitted for 
publication in scholarly journals. You are most welcome to a summary of the findings produced by the researcher and a copy of any publication stemming from this research.

\section{What else do I need to know?}

This research is part of a $\mathrm{PhD}$ project involving research across four Wellington primary schools; it has been approved by Victoria University Human Ethics Committee, approval number 22057. If you have any ethical concerns about this research you should contact Associate Professor Susan Corbett, Convenor of the Victoria University Human Ethics Committee: susan.corbett@vuw.ac.nz, (04) 4635480.

You have the right to withdraw your child's contribution to the research up until $17 / 12 / 15$, with no questions asked. You do not have to agree to your child's participation in the research and your child can still take part in the Philosophy for Children discussions in class if you do not agree for them to take part in the research. Declining your child's participation will not disadvantage their learning.

\section{What next?}

Please return the attached consent form to your child's teacher to indicate whether or not you consent to your child's participation in this research project. If you have any questions or would like to receive further information about the project, please do not hesitate to contact me by phone, 463 9524, or email amy.m.austin@vuw.ac.nz, or my supervisor Mark Sheehan, at the School of Education at Victoria University by phone, 463 9687, or email mark.sheehan@vuw.ac.nz.

Your child's involvement in this part of the research would be greatly valued.

Thank you,

Amy Austin

PhD Student

Faculty of Education, PA306B

Victoria University of Wellington

Donald St, Karori, Wellington 6012

PO Box 17-310, Karori, Wellington 6147 


\section{Philosophy for Children for all: consent for parents of focus group students}

Principal Investigator: Amy Austin, Victoria University of Wellington Faculty of Education

- I agree for my child to participate in this research.

- The research project has been explained to me and I have had the opportunity to ask questions and have them answered to my satisfaction.

- I understand that the research is confidential. Pseudonyms will be used and individual schools, classes, teachers or students will not be identified.

- I understand that the data collected will only be used for the research project and publication as described in the information sheet.

- I understand that I will have the opportunity to read and approve or make changes to the transcripts of my child's contributions before the thesis is published.

- I understand that all data will be stored securely in a locked cabinet or password protected files, and the learning journal will be returned to us at the completion of the project.

- I understand that all audio and transcript data will also be stored securely in a locked cabinet or password protected files, and will be destroyed five years after the conclusion of the research. This includes wiping the audio recording.

- I understand that I may withdraw my child from this research project at any time up until the morning of the interview, without giving a reason.

- I understand that there may be some follow-up research and that I will be contacted separately about this.

I agree to the statements above: Yes / No

$\square$ I would like to be offered a copy of publications stemming from this research project.

\section{Child's name:}

\section{School:}

\section{Email address:}

\section{(Continues over the page.)}


Postal address (for the return of the thinking journal and sending publications stemming from the research project):

\section{Parent/Caregiver signature:}

Date: 


\section{Appendix G}

\section{$\mathrm{P}_{4} \mathrm{C}$ for all information letter and assent form - All students}

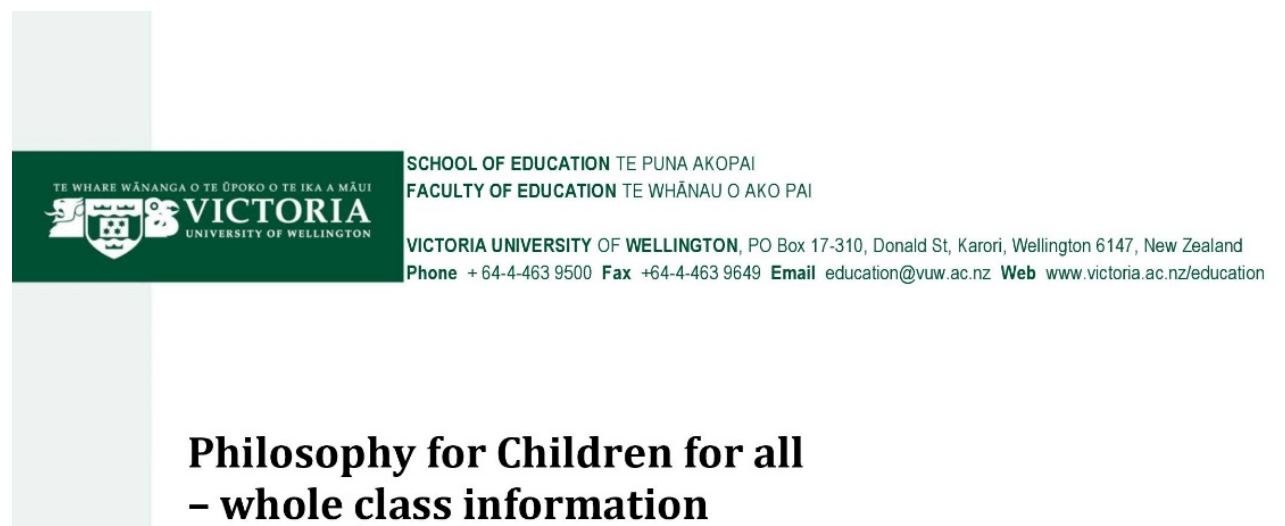

Dear Student,

I am a PhD student at Victoria University of Wellington. As a part of this degree I want to research how Philosophy for Children helps children to think. Your principal, teacher, and parents have agreed to this research, so now I would like to invite you to take part in this research project.

\section{What is this research about?}

Philosophy for Children is a programme that is run in schools in New Zealand and many countries around the world. It encourages children to talk about questions that are important to them. My research will investigate how children discuss and think together through listening, questioning and talking with their classmates.

\section{What would it involve for you?}

Your class will be having weekly hour-long classroom discussions led by the teacher on philosophical topics like: What is bravery? What makes a good friend? What makes you you?

I will record some of the classroom discussions at the beginning, middle, and end of the Philosophy for Children programme. Your conversation will be written down afterwards so that I can understand more about your talking and thinking. I will write about this in my thesis, which is a report on the research. I will keep your identity confidential so that anyone who reads the research won't know who you are or which class or school you are part of.

If you have any questions about the research, you can talk to your parents or your teacher or you can get in touch with me on amy.m.austin@vuw.ac.nz. Your teacher will be able to help you to email me.

Everyone in the class will join in with the Philosophy for Children discussions because they are a normal part of the classroom programme. However you 
do not have to agree to participate in the research. That means I wouldn't use any of your comments during Philosophy for Children discussions in my research. You can choose to withdraw your contributions from my research at any time up until 17/12/15.

If you are happy to take part in this research, please let me know by signing your name on the consent form, and giving it to your teacher.

Thank you!

Ngā mihi,

Amy Austin

PhD Student

Faculty of Education, PA306B

Victoria University of Wellington

Donald St, Karori, Wellington 6012

PO Box 17-310, Karori, Wellington 6147 


\section{Philosophy for Children for all - whole class consent form}

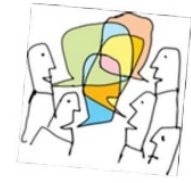

My teacher has explained the

Philosophy for

Children project to me,

I've discussed it with

my parent(s)/

caregiver(s) and I'm

happy to take part

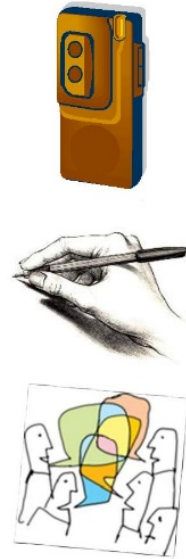

What I say can be recorded.

Some of my comments and ideas can be written down and included in the project.

I will show respect for other students' ideas by only discussing them in the group.

I understand that I can ask for my comments and ideas to be removed from the research at any time until the end of Term 4 this year.

\begin{tabular}{|l|}
\hline Yes $\sqrt{ }$ or No X \\
\hline \\
\hline \\
\hline
\end{tabular}




\title{
Appendix $\mathrm{H}$
}

\section{$\mathrm{P}_{4} \mathrm{C}$ for all information letter and assent form - Sample students}

\author{
SCHOOL OF EDUCATION TE PUNA AKOPAI
FACULTY OF EDUCATION TE WHĀNAU O AKO PAI
VICTORIA UNIVERSITY OF WELLINGTON, PO Box 17-310, Donald St, Karori, Wellington 6147, New Zealand
Phone + 64-4-463 9500 Fax +64-4-463 9649 Email education@vuw.ac.nz Web wWw.victoria.ac.nz/education \\ Philosophy for Children for all: information for focus group \\ students
}

Dear Student,

I am a PhD student at Victoria University of Wellington. As a part of this degree I want to research how Philosophy for Children helps children to think. Your principal, teacher, and parents have agreed to this research, so now I would like to invite you to take in this research project.

\section{What is this research about?}

Philosophy for Children is a programme that is run in schools in New Zealand and many countries around the world. It encourages children to talk about questions that are important to them. My research will investigate how children discuss and think together through listening, questioning and talking with their classmates.

\section{What would it involve for you?}

Your class will be having weekly hour-long classroom discussions led by the teacher on philosophical topics like: What is bravery? What makes a good friend? What makes you you?

I will record some of the classroom discussions at the beginning, middle, and end of the Philosophy for Children programme. Your conversation will be written down afterwards so that I can understand more about your talking and thinking. I will write about this in my thesis, which is a report on the research.

I would like to invite you to take part in a recorded group conversation at the beginning and end of the project. We will discuss your thoughts about learning and thinking and talking. Like the classroom discussions, this conversation will be written down afterwards so that I can understand more about your talking and thinking and I would write about this in my thesis. I will ask you and other students to respect others' ideas discussing them only in the group. After each interview I will meet with you at school and show you your written comments from the focus group so you can approve the statements that will be used in the thesis. You will only have access to their own comments.

I would also like to invite you to keep a thinking journal during the research project. We will set this up together and you can write or draw about your thoughts about Philosophy for Children and your learning and thinking. I would look at this to understand more about your thinking, and would write about this in my research.

I will keep your identity confidential so that anyone who reads the research won't know who you are or which class or school you are part of. 
If you have any questions about any part of the research, you can talk to your parents or your teacher or you can get in touch with me on amy.m.austin@vuw.ac.nz.Your teacher will be able to help you to email me.

You do not have to agree to participate in the research; just take part if you are comfortable with me asking you more questions about your learning and thinking. You can choose to withdraw from the group conversation any time before it takes place. If you want to, you can withdraw your contributions from my research at any time up until $17 / 12 / 15$.

If you are happy to take part in this research, please let me know by signing your name on the consent form, and giving it to your teacher.

\section{Thank you!}

Ngā mihi,

\section{Amy Austin}

\section{PhD Student}

Faculty of Education, PA306B

Victoria University of Wellington

Donald St, Karori, Wellington 6012

PO Box 17-310, Karori, Wellington 6147 


\section{Philosophy for Children for all - Consent for focus group students}

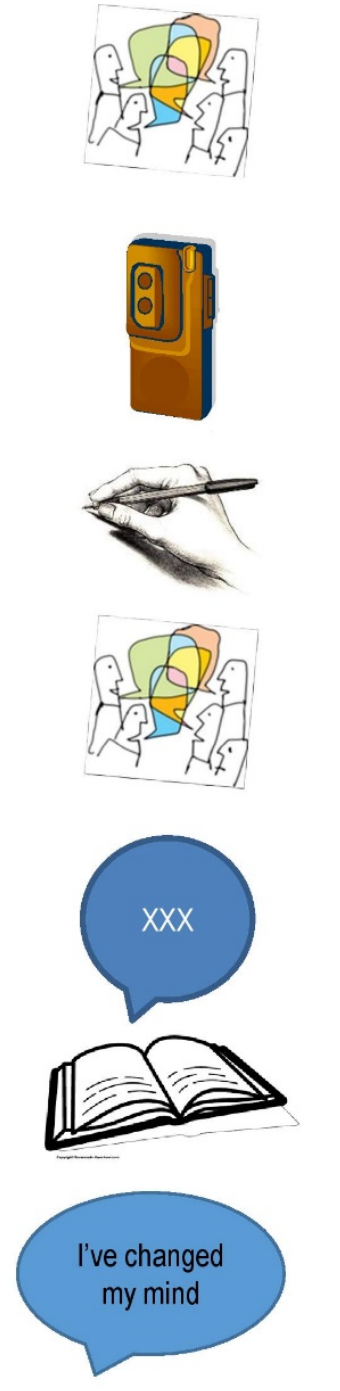
My teacher has explained the Philosophy for Children project to me, I've discussed it with my parent(s)/ caregiver(s) and I'm happy to take part.

What I say can be recorded.

Some of my comments and ideas can be written down and included in the project.

I will show respect for other students' ideas by only discussing them in the group.

I understand that I can ask for my comments and ideas to be removed from the research at any time until the end of Term 4 this year.

I am happy to keep a

Thinking Journal and let it be included in the project.

I understand that I can pull out of the group interview up until the morning of the group interview.

\begin{tabular}{|l|}
\hline Yes $\sqrt{\text { or No X }}$ \\
\hline \\
\hline \\
\hline
\end{tabular}




\section{Appendix I}

Temporal Analysis of Coded Student Utterances
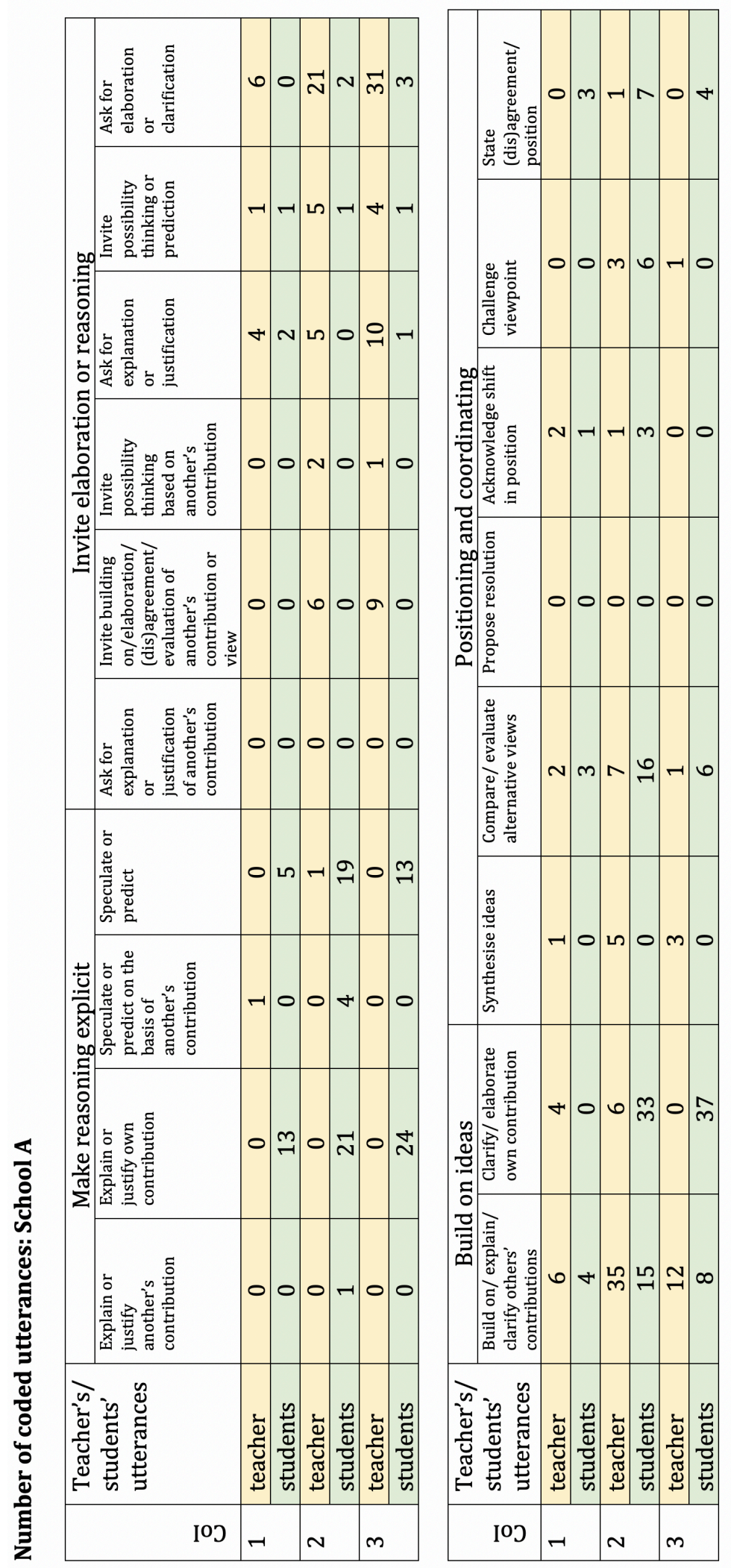

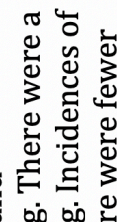

ช ข0

串跤

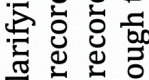

ป ป

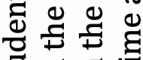

踏.

讪范苋

ฏ छ

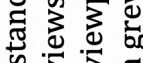

零

岁.

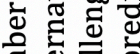

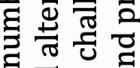

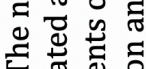

טำ

政娄

능

क्ष क्ष के

总苛

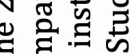

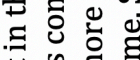

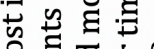

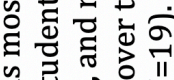

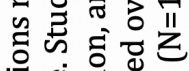

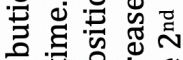

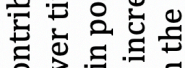

ชั워

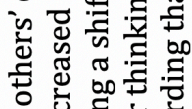

을

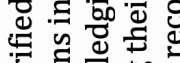

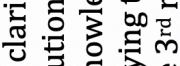

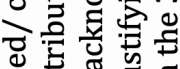

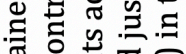

蛋

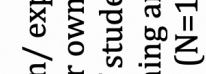

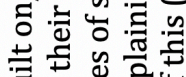

范节吉造

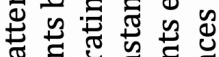

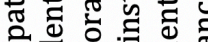

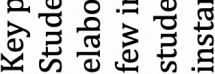



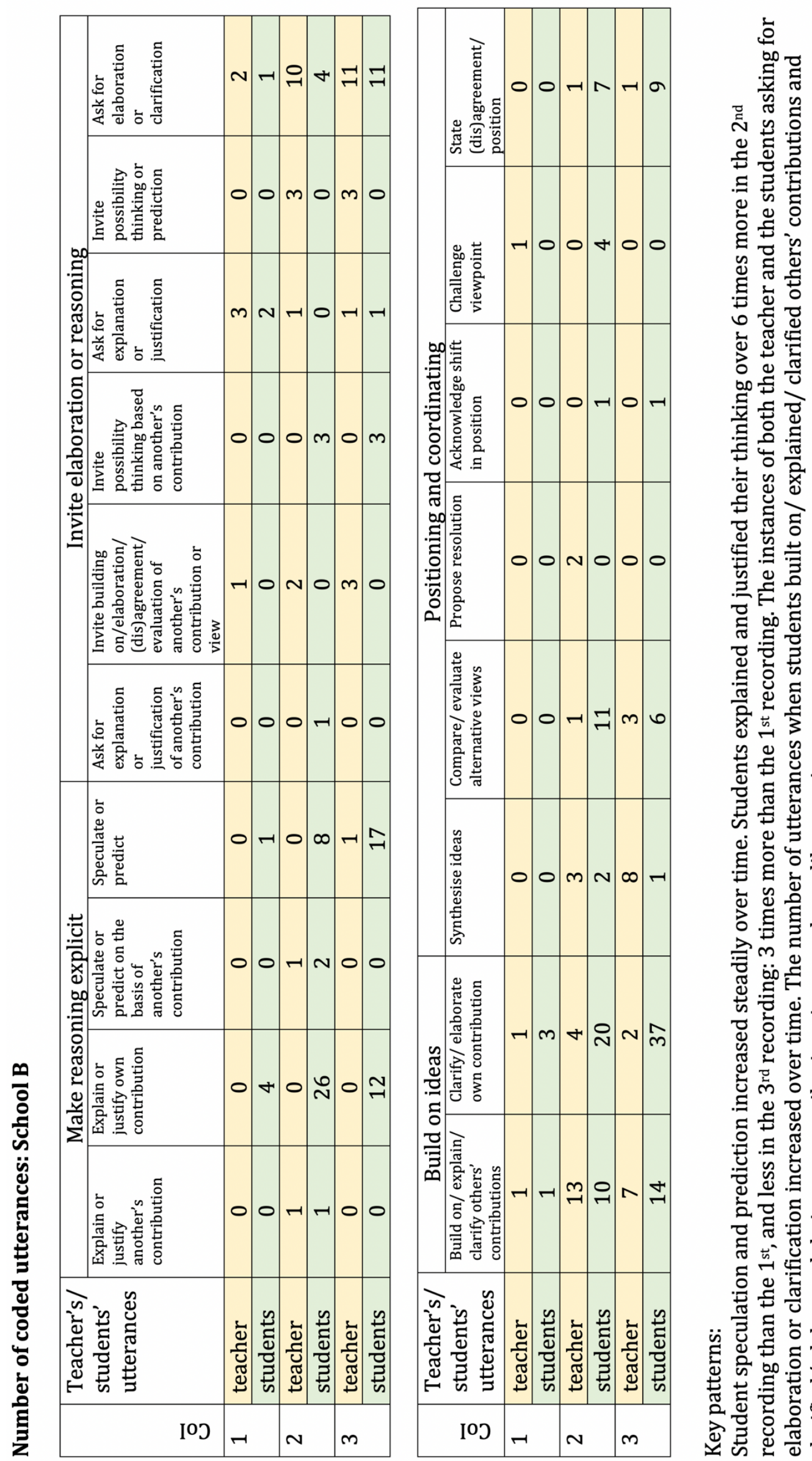

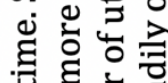

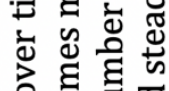

○吉导

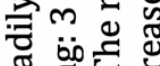

退它

के ఫ્ّ

원 히음

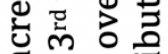

.

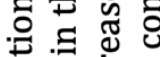

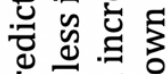

흘 율

సั

总豞恋

iั

के क्षे

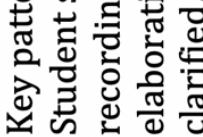



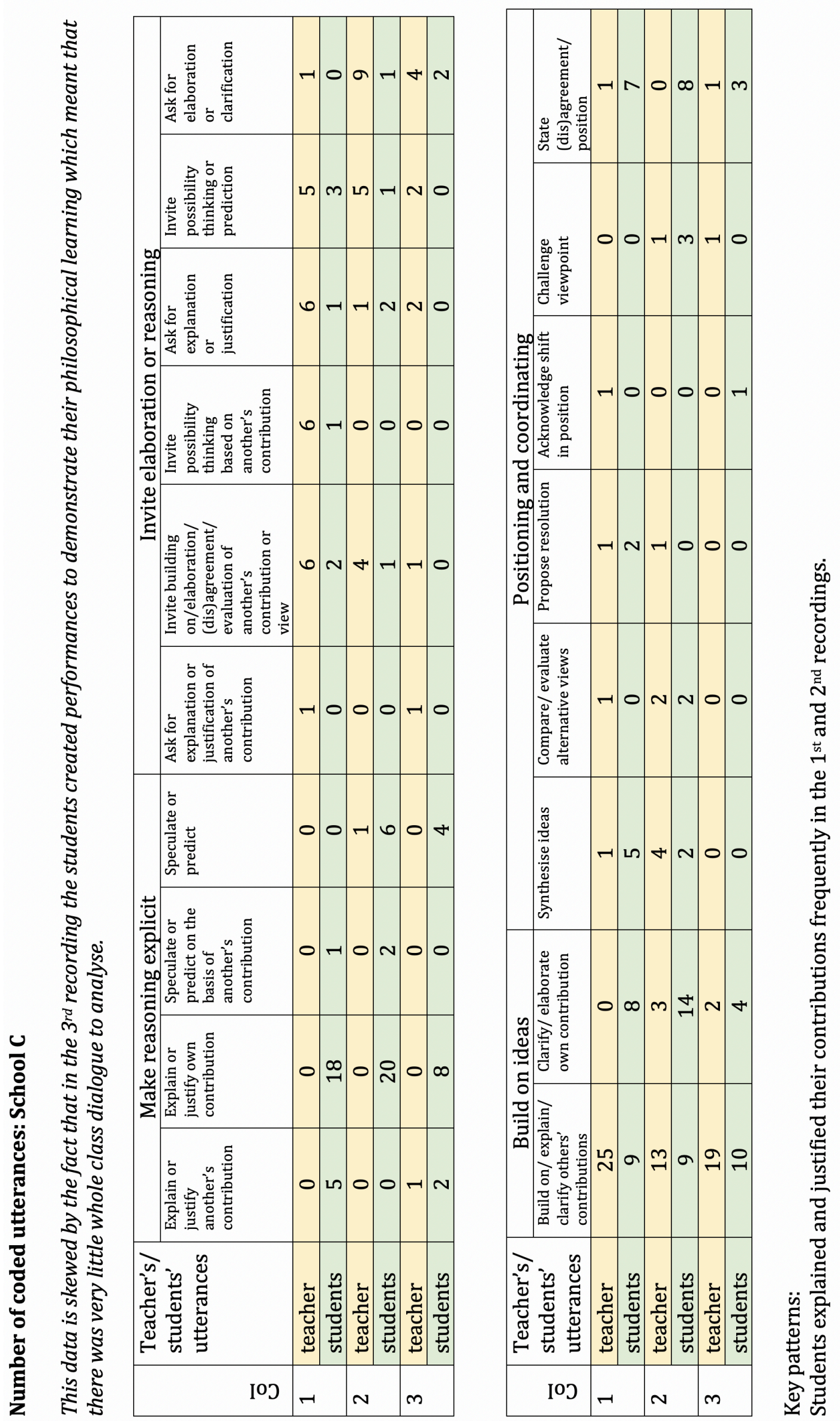

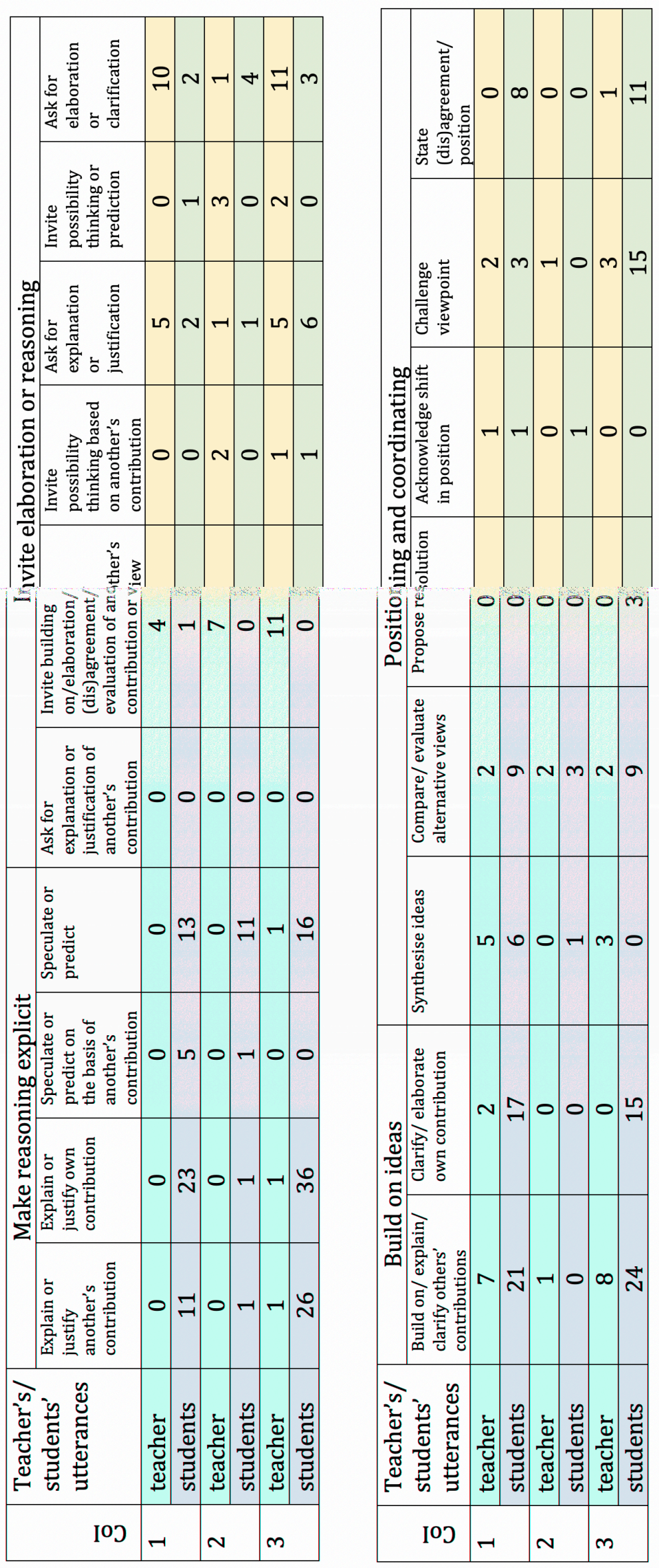

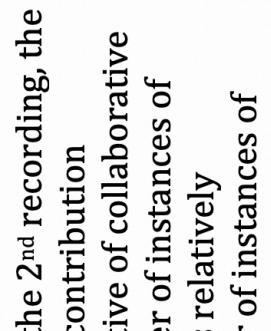

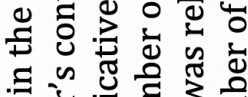

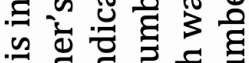

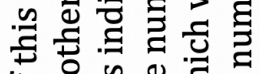

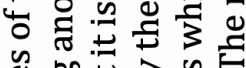

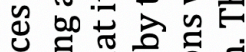

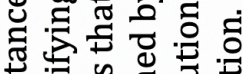
क्

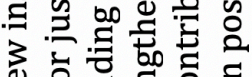
施实

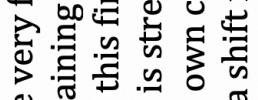

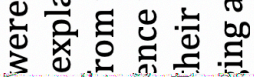

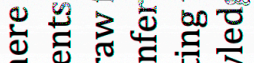

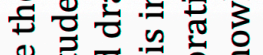

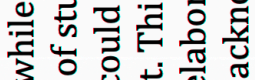
उ 월

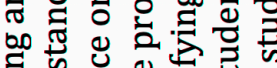

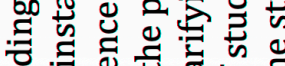

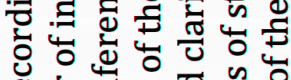

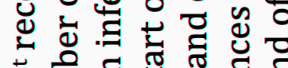

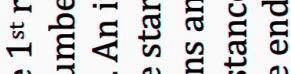

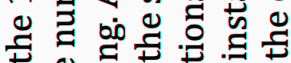

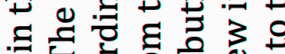

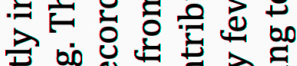

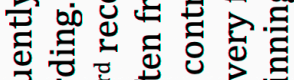

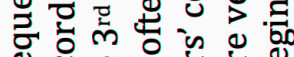
¿ ه

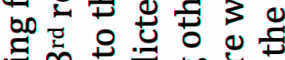

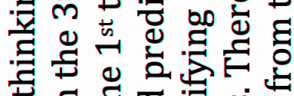

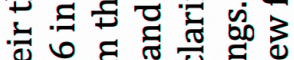

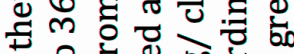

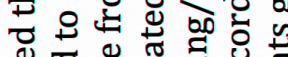
过要

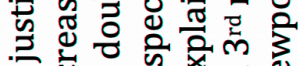

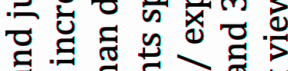

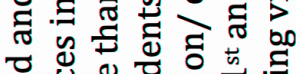

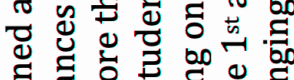

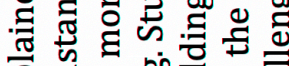

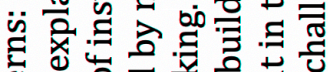

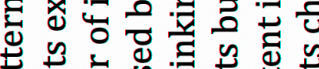

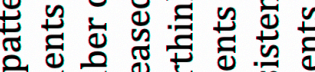

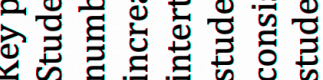

